\title{
Corrosion Effects on Bond Strength in Reinforced Concrete
}

by

\section{Kyle Stanish}

\begin{abstract}
A thesis submitted in conformity with the degree requirements for the degree of Master's of Applied Science

Graduate Department of Civil Engineering

University of Toronto
\end{abstract}

(C) Copyright by Kyle Stanish, 1997 
The author has granted a nonexclusive licence allowing the National Library of Canada to reproduce, loan, distribute or sell copies of this thesis in microform, paper or electronic formats.

The author retains ownership of the copyright in this thesis. Neither the thesis nor substantial extracts from it may be printed or otherwise reproduced without the author's permission.
L'auteur a accordé une licence non exclusive permettant à la Bibliothèque nationale du Canada de reproduire, prêter, distribuer ou vendre des copies de cette thèse sous la forme de microfiche/film, de reproduction sur papier ou sur format électronique.

L'auteur conserve la propriété du droit d'auteur qui protège cette thèse. $\mathrm{Ni}$ la thèse ni des extraits substantiels de celle-ci ne doivent être imprimés ou autrement reproduits sans son autorisation.

\section{Canadä}




\begin{abstract}
AUTHOR: Kyle Stanish

DEGREE: Master's of Applied Science

DEPARTMENT: Civil Engineering, University of Toronto

SUPERVISORS: Professors R.D. Hooton and S.J. Pantazopoulou

TITLE: Corrosion Effects on Bond Strength in Reinforced Concrete

COMPLETION DATE: September, 1997

Corrosion of the reinforcing steel in reinforced concrete will effect its structural performance. This is in two ways: loss of steel section and deterioration of steel-concrete bond. In this, bond effects are investigated using two methods for different influences. The first technique looks at the effect of spalling concrete. This would affect bond by lessening the confinement. This is simulated by debonding proportions of the perimeters of steel bars in a reinforced concrete member and testing in flexure. The second looks at the effect of corrosion products. This was accomplished by casting reinforced concrete slabs with the ends of the reinforcing bars anchored in the concrete for a known length; the centre portion unbonded. The ends were corroded to various corrosion levels and then tested in flexure. Also included is a test of the predictive power of this work.
\end{abstract}




\section{Acknowledgements}

My first thanks must go to my supervisors, Prof. R.D. Hooton and Prof. S.J. Pantazopoulou. Without their support, both in terms of advice and financially, this work would not have even been begun, never mind completed. I would also like to thank the lab technicians who were so helpful along the way, principally Urszula Nytko, Giovanni Buzzeo and John MacDonald. They created an atmosphere where it was possible to accomplish a great deal. I would also like to thank my fellow students who provided a pleasant atmosphere in the labs and made it a pleasure to come in to work.

I would like to thank NSERC for their scholarship support of me through my graduate work. I would like to thank St. Mary's Cement and Lafarge cement for providing some of the materials I needed.

Finally, I would like to thank my parents for allowing my curiosity to grow from a young age. They placed my feet on the path I have chosen and were always ready to give me support along the way. Without them I would not be the person I am today and words cannot express how grateful I am. Thank You. 


\section{Table of Contents}

$\begin{array}{lr}\text { Abstract } & \text { ii } \\ \text { Acknowledgements } & \text { iii } \\ \text { Table of Contents } & \text { iv } \\ \text { List } \text { of Tables } & \text { vi } \\ \text { List } \text { of Figures } & \text { vi }\end{array}$

1.0 Introduction $\quad 1$

References 3

2.0 Literature Review 4

2.1 Corrosion 4

2.2 Reinforcement-Concrete Bond 5

2.3 Effects of Corrosion on Structural Performance 8

2.4 Effects of Corrosion on Bond 9

References 12

3.0 Experimental Procedure $\quad 14$

3.1 The Materials Used 14

3.1.1 The Reinforcing Steel 14

3.1.2 The Concrete 14

3.2 Structural Testing 15

3.2.1 Structural Specimen $\quad 15$

3.2.2 Structural Tests $\quad 15$

$\begin{array}{ll}\text { 3.3 Material Tests } & 17\end{array}$

3.3.1 Strength Testing 17

$\begin{array}{ll}\text { 3.3.2 Sorptivity Testing } & 18\end{array}$

3.3.3 Chloride Ion Penetrability 18

3.4 The Experimental Series $\quad 19$

3.4.1 Series 1 - Effect of Spalling 20

3.4.2 Series 2 -The Effect of Corrosion Products 20

3.4.3 Series 3 - Combined Effects $\quad 21$

References 23

4.0 Experimental Results $\quad 24$

4.1 Material Results $\quad 24$

4.1.1 Fresh Concrete Properties $\quad 24$

4.1.2 Strength Testing 25

4.1.3 Sorptivity Testing 25 
4.1.4 Rapid Chloride Testing

4.1.5 Resistivity Measurements

4.2 Corrosion Activity Testing $\quad 27$

4.2.1 Corrosion Current

4.2.2 Corrosion Sample Results

4.2.3 Corrosion Levels

4.3 Structural Test Results

4.3.1 Series 1 - The Effect of Spalling

4.3.2 Series 2 - The Effect of Corrosion Products

4.3.2.1 Condition of Slabs Before Testing 33

4.3.2.2 Normal Mix Test Results $\quad 34$

4.3.2.3 Silica Fume Mix Test Results 36

4.3.2.4 General Discussion of Test Results

4.3.3 A Discussion of Bond $\quad 38$

References $\quad 40$

5.0 Series 3 Evaluation $\quad 41$

5.1 The Prediction 41

5.2 The Experimental Result $\quad 43$

5.2.1 Condition of Slab Prior to Testing 43

5.2.2 Structural Testing Results 43

5.3 Comparing the Prediction and the Response 45

References 48

6.0 Conclusions and Recommendations 49

6.1 Conclusions $\quad 49$

6.2 Recommendations $\quad 50$

$\begin{array}{ll}\text { Bibliography } & 52\end{array}$

Appendices

A

B

C

D

$\mathbf{E}$

$\mathbf{F}$

G

H

I
Steel Stress Strain Curve

Structural Design Calculations

Curvature-meter Measurement

Corrosion Current Evaluation Technique

Concrete Material Results

Corrosion Current Graphs

Steel Force Evaluation Program

Series 3 Prediction Calculations

Structural Results 


\section{List of Tables}

Table 3-1: Mix Designs $\quad 14$

Table 3-2: Material Testing Schedule $\quad 17$

Table 4-1: Fresh Concrete Properties $\quad 24$

Table 4-2: Strength Results $\quad 25$

Table 4-3: Sorptivity Values $\quad 25$

Table 4-4: Rapid Chloride Results 26

Table 4-5: Resistivity Data $\quad 26$

Table 4-6: Corrosion Results, Series 2

Table 4-7: Effective Corrosion Levels, Series 2

\section{List of Figures}

Figure 3-1: Specimen Diagram $\quad 15$

Figure 3-2: Testing Set-Up Schematic 16

Figure 3-3: Photograph of Testing Set-Up 16

Figure 3-4: Corrosion Set-Up 21

Figure 3-5: Alternate Wire Connections $\quad 21$

Figure 4-1: Conceptual Spalling Effects $\quad 30$

Figure 4-2: Series 1 Results $\quad 31$

Figure 4-3: Typical Crack Locations and Areas of Spalling 33

Figure 4-4: Series 2 - Normal Mix Results $\quad 35$

Figure 4-5: Series 2 - Silica Fume Mix Results

Figure 4-6: Bond Strength as a Function of Corrosion Level 38

Figure 5-1: Prediction $\quad 42$

Figure 5-2: Series 3 Experimental Results 44

Figure 5-3: Prediction Based on Rodriguez, et al. $\quad 47$

Figure 5-4: Presumed Actual Response $\quad 47$ 


\subsection{Introduction}

Corrosion damage of reinforced concrete is a serious problem that needs to be addressed. This damage is a large drain on the economy. For example, in 1986 the Ontario Ministry of Housing estimated there was a $\$ 1$ billion plus cost for repair in the approximately 3000 existing parking structures. ${ }^{1-1}$ Most of this damage is due to reinforcement corrosion. This is only one province and only refers to one type of structure, but shows the magnitude of the problem. Another example would be the West Asia Gulf region where repairs, maintenance and reconstruction programs run into the billions of dollars. ${ }^{1-2}$ Reinforced concrete corrosion is especially important as concrete is a widely used building material. By some estimates, approximately one ton of concrete is produced per person in the world per year. ${ }^{1-3}$

One reason for this large repair cost is that the role of chlorides in corrosion was ignored in standards until the 1970's. In the United Kingdom, there was no limit on the chloride content of concrete mix water until 1972, while the ACI code did not limit it until 1974. Limits on the chloride content of admixtures and of the concrete mix did not exist until the 1980's. ${ }^{1-4}$ Before this time there were a large number of buildings and parking garages erected, especially during the 1970's construction boom. This has led to an ageing infrastructure, with these buildings now running into difficulty. Thus, the repair bill is taking larger and larger proportions of the construction dollar. Twenty years ago, approximately $30 \%$ of construction expenditures were for repairs. This compares to the current level of $50 \%$, with indications that this will increase to the year 2000 and beyond. ${ }^{1-5}$ Given this large expenditure, any improvement in the efficiency of evaluation techniques has the potential for large savings. Thus more information regarding how different corrosion levels corrosion affect a structural member's capacity would be useful. It would help in evaluating corroded structures and determining the optimum time for repair when performing a life-cycle cost analysis.

Parking garages are a type of structure that often run in to problems with corrosion. They are normally unheated; so to prevent ice formation de-icing salts are employed. These de-icing salts contain chlorides that dissolve in the melt water. Also, water often is allowed to collect because of poor drainage conditions. This lack of drainage may be due to poor design - e.g. insufficient slope of the slabs, improper construction practices - e.g. misplaced drains, or lack of 
maintenance - e.g. not cleaning out the drains properly. Chlorides will then penetrate the concrete from the water and are able to attack the reinforcing steel. This causes corrosion. The common parking garage structure is a continuous flat slab. Thus, the only steel contained in the slab is the flexural reinforcement. Once the steel is attacked, the moment capacity of the slab will be affected. This is a condition regarding which more information is needed. Thus, an investigation on the effect of corrosion on the flexural capacity of reinforced concrete slabs was undertaken.

There are two mechanisms occurring. The first is the loss of the section properties. This refers to any weakening that may be occurring due to loss of steel at a cross-section and this influence on the sectional moment capacity. This influence has been studied, for example by J. Phillips as part of his doctoral work at the University of Toronto. ${ }^{1-6}$ The effect was found to be equivalent to a loss of steel area equal to the amount of steel corroded. A less studied influence is the effect of corrosion on the bond between the steel and the concrete. This work shall examine this issue.

To examine the effect of corrosion on bond, two influences on bond were studied. The first issue is the effect of spalling. Spalling will reduce bond by removing the concrete cover. This will lessen the confinement and thus reduce the bond. This influence was simulated for various proportions of the bars' perimeter along the entire length of the bar. The second effect is due to the creation of corrosion products. This has the effects of both changing the surface properties of the bar and exerting tensile stresses in the concrete, which leads to cracking. This influence was investigated for a variety of levels of corrosion and for two concrete mix designs. The mix designs chosen were typical of those used in properly designed parking garages.

Finally, a test of the predictive power of this work was performed. A normal slab was corroded and, after predicting the capacity based on the work done herein and by others, tested to failure. It was hoped to be able to predict both the load at ultimate capacity and the mode of failure. What follows are an investigation of the literature, the details of the experimental procedure undertaken, the results of this experimental program and a discussion of these results. 


\section{References}

${ }^{1-1}$ Report of the Advisory Committee on the Deterioration, Repair and Maintenance of Parking Garages Ministry of Housing, Ontario Buildings Branch, July 1988, pg. i

1-2 Corrosion Damage to Concrete Structures in Western Asia United Nations Centre for Human Settlements (Habitat), Nairobi, 1990, pg. i

${ }^{1-3}$ N.P. Mailvaganan Repair and Protection of Concrete Structures CRC Press c1992, pg. i (prologue)

${ }^{1-4}$ P. Pullar-Strecker, Corrosion Damaged Concrete: Assessment and Repair Anchor Brendon Ltd., Tiptree Essex, England c1987 pg. 91-6

1.5 N.P. Mailvaganan Repair and Protection of Concrete Structures CRC Press c1992, pg. i (prologue)

${ }^{1-6}$ J. Phillips, The Effect of Corrosion on the Structural Performance of New and Repaired OneWay Slabs, Ph.D. Thesis, University of Toronto, c1993 


\subsection{Literature Review}

When investigating the effects of corrosion on bond strength, there are a few subjects that must be examined before looking at the area as a whole. First, the process of corrosion must be understood. This includes why corrosion occurs and what affects it. Next, bond in normal, uncorroded specimens must be examined to see what is occurring in that situation. This allows us to focus on the potential differences between the two situations. Then, any structural effects of corrosion besides those on bond must be examined to determine what influence these could have. Finally, but most importantly, previous work on this subject must be examined for comparison. These subjects are all examined in this section.

\subsection{Corrosion}

Corrosion of the steel rebar in reinforced concrete occurs when the iron atoms combine with oxygen or chloride atoms to form a new compound. This is an electrochemical reaction that depends on the presence of water in the pores to act as an electrolyte.

Initially, the rusting of steel in a normal environment, without the presence of concrete, will be discussed. There are three distinct chemical reactions that occur:

$$
\begin{aligned}
& \mathrm{Fe} \rightarrow \mathrm{Fe}^{2+}+2 \mathrm{e}^{-} \\
& \mathrm{O}_{2}+4 \mathrm{e}^{-}+2 \mathrm{H}_{2} \mathrm{O} \rightarrow 4 \mathrm{OH}^{-} \\
& 2 \mathrm{Fe}^{2+}+1 / 2 \mathrm{O}_{2}+4 \mathrm{OH}^{-} \rightarrow 2 \mathrm{FeO} . \mathrm{OH}+\mathrm{H}_{2} \mathrm{O}
\end{aligned}
$$

Each of these reactions occurs at a different location in the chemical system. The iron disassociates at the anode (Reaction 2-1), and the oxygen and water react in the electrolyte (Reaction 2-2). These then react at the cathode to form corrosion products at the cathode. Reaction 2-3 is one typical cathodic reaction, but there are other possibilities. ${ }^{2-1}$ This is a normal course for corrosion reactions of any metal.

Once concrete is involved, there are some differences. The concrete initially prevents corrosion by creating a basic environment. This passivates the steel by changing the form of corrosion products. Instead of producing the loose product $\mathrm{FeO} . \mathrm{OH}$, the $\mathrm{FeO}_{2}$ and $\mathrm{FeO}_{3}$ are produced. These substances adhere more closely to the surface of the bar. The progress of 
corrosion is thus limited by restricting oxygen access. ${ }^{2-2}$ The protection of the alkalinity can be overcome through either carbonation, or chloride ingress. The steel then begins to rust. The reason for loss of protection with carbonation is loss of alkalinity. The corrosion products are then similar to those found in the bare steel situation. With loss of protection due to chloride ingress, the corrosion reactions are then slightly different, as the $\mathrm{pH}$ has not been reduced. Instead it is $\mathrm{FeCl}_{2}$ that is initially produced and this then forms $\mathrm{Fe}(\mathrm{OH})_{2}$, or other more complex oxides and chloride compounds

So what effect does this have on the mechanical properties of the steel? The first effect is that there is smaller area of steel. Some steel has become this weak corrosion product. Furthermore, the corrosion products have a larger volume than the original steel. This leads to stresses in the surrounding concrete and the potential for cracking. This obviously will have some effect on the performance of the reinforced concrete structure. It can also result in spalling of concrete cover.

Various factors affect the rate of corrosion in concrete. These include the concrete quality, the thickness of cover, any cracking that may exist, the water and oxygen content of the pore system and either the chloride concentration or the depth of carbonation; depending upon what is causing corrosion. The concrete quality affects corrosion rate by limiting the access of any deleterious substances as well as oxygen. The quality can be improved by both reducing the water-cement ratio and the inclusion of supplementary cementing materials. Increasing the concrete cover thickness has a similar effect of reducing the amount of aggressive substances that can enter. Cracks increase the amount of corrosion by providing pathways for deleterious chemicals and oxygen or water. The oxygen content and water content of the concrete are important as corrosion is an electrochemical process requiring the presence of both these substances to occur. If either of these substances are not present, then corrosion cannot occur.

\subsection{Reinforcement-Concrete Bond}

The bond between reinforcing steel and concrete is not fully understood, though a good working theory has been produced. Most of the main concepts are agreed upon, though some of the details are still being discussed. The reason for this is that the force transfer called bond is a complicated, multipart phenomenon. A useful method of describing the main forces is contained 
in Treece and Jirsa. ${ }^{2-3}$ They divide the main components into two main categories. The first is the bearing component on the lugs. This is what will cause splitting of the concrete. The second category is the friction component. This is both true friction and the effect of any secondary chemical bonding effects.

A good summary of the major influences on bond is contained in Nawy. ${ }^{2-4}$ The major factors are, according to Nawy:

1. Adhesion between the concrete and the reinforcing elements.

2. Gripping effect resulting from the drying shrinkage of the surrounding concrete

3. Frictional resistance to sliding and interlock on the reinforcing elements subjected to tensile stress.

4. Effect of concrete quality and strength in tension and compression.

5. Mechanical anchorage effects of the ends of the bars through the development length, splicing, hooks and crossbars.

6. Diameter, shape and spacing of reinforcement as they affect crack development.

It is suggested that factors 2,3 and 4 are most important. This list is not universally agreed upon, however, and current literature contains models for bond that focus more on the effects of bond rather than on absolute mechanisms. A typical model is presented by Cairns and Jones ${ }^{2-5,2-6}$ and Cairns and Bin Abdullah ${ }^{2-7}$. They view bond as containing both a splitting and a non-splitting component. The splitting component varies with the amount of confinement that the bar experiences, while the non-splitting component is fixed. They do not explain what causes the non-splitting component, only that it is possibly similar to the cohesive effect in soils.

An other variable that affects bond and has not been discussed so far is concrete confinement. Increasing the confinement around a bar increases its bond strength. ${ }^{2-8}$ This is true whether the confinement comes from transverse steel, e.g., stirrups, or from the stress field that exists in the concrete. This second situation can be explained best using an example. Where a beam intersects a column, the column load creates stresses that act perpendicular to the direction of the longitudinal beam steel. These stresses act to confine the steel and increase the bond strength. The influence of stress fields is not relied upon in design codes, ${ }^{2-9,2-10,2-11}$ though it is well accepted. This is because it is impossible to ensure that a stress field will always exist.

Before discussing specific bond strengths, it is important to understand how bond is tested in reinforced concrete. There are three main tests for determining bond strength, according to Nawy. ${ }^{2-12}$ These are: pull-out tests, embedded bar tests and beam tests. Each of these has its 
strengths and weaknesses, and will be further discussed. During this, however, it should be remembered what the purpose of the bond test is; to discover how well the steel transfers load to the concrete under service conditions. For most reinforced concrete applications, this is when the steel and the surrounding concrete are both in tension.

Pullout tests are relatively simple to perform. The steel is cast into a concrete sample to a known length. The steel is pulled upon while the concrete is restrained. This is continued until the steel either yields or is pulled out of the concrete. This test has the advantage of simplicity and ease of determination of the bond strength. It also allows the simultaneous measurement of slip between the concrete and the steel. Its disadvantage lies in the stress field that arises. The steel is in tension, but the concrete is in compression. This is important as it is known that concrete behaves differently in compression and tension. Concrete has little tensile strength and exhibits cracking at low tensile loads. These aspects are not represented in this type of test. A pull-out test has been standardized as ASTM C234-91a. ${ }^{2-13}$ This test, however, is strictly for evaluating different concrete types. It is not designed to be used for establishing bond values for structural design purposes or for determining the influence of different bar sizes or types. It does suggest however that this test could be adapted for research purposes if it is desired to study one of these influences.

An embedded bar test consists of a bar extended through a section of concrete. The bar is then pulled at both ends. The concrete will then crack and, based upon the crack spacing and widths, the bond stresses can be determined. This test does accurately model the stress field and is relatively simple to prepare. It is difficult to accurately monitor the crack spacing and widths, however. It is also difficult to interpret the data to give a direct stress. A basic understanding of what is occurring and how this relates to stress is difficult to achieve, as well.

The third test is the beam test. This test is set up in a variety of ways, the aim of which is to model a section of a beam with a known length of reinforcing steel embedded inside. This is then caused to bend so that the steel and the surrounding concrete are in tension. If done properly, this models service conditions well. It is also simple to understand and interpret. It can be difficult to do, however, due to the possibly unusual geometry involved. This has lead to a 
variety of set ups presented in the literature as compared to a standardized test which all researchers use.

Typical bond strengths for normal, ribbed bars thus can vary depending on the conditions that are encountered in service. The Eurocode does give values for use in design, with a built in factor of safety of 1.5. These values are dependent on the concrete strength and vary from 1.6 $\mathrm{MPa}$ for a concrete strength of $12 \mathrm{MPa}$ to $3.4 \mathrm{MPa}$ for a concrete strength of $35 \mathrm{MPa}$ to $4.3 \mathrm{MPa}$ for a concrete strength of $50 \mathrm{MPa}$. This is then modified to account for such issues as casting direction, bar diameter and actual stress in the bar. ${ }^{2-14}$ Some experimentally determined values reported by Cairns and Jones ${ }^{2-15,2-16}$ range from $3-5 \mathrm{MPa}$. This was for specimens with concrete strength near $30 \mathrm{MPa}$ and concrete specimen dimensions of either $320 \mathrm{~mm} \times 225 \mathrm{~mm}$ or $100 \mathrm{~mm}$ x $225 \mathrm{~mm}$. A formula has also been developed for bond strength, based on tests at the University of Texas. ${ }^{2-17}$ It proposes that bond stress is given by:

$$
\begin{gathered}
u=\frac{9.5 \sqrt{f_{c}^{\prime}}}{d_{b}} \leq 800 \mathrm{psi} \quad \text { (USCU) } \\
\text { or } u=\frac{20 \sqrt{f_{c}^{\prime}}}{d_{b}} \leq 5.52 \mathrm{MPa} \text { (metric). }
\end{gathered}
$$

Thus typical values would range from 1.5 $\mathrm{MPa}$, with weak concrete and a large diameter bar, to $5.5 \mathrm{MPa}$, with strong concrete and small bars.

\subsection{Effects of Corrosion on Structural Performance}

Corrosion of the reinforcing steel will affect the structural performance of a reinforced concrete section. In this section, we will discuss effects other than loss of bond. Bond effects are discussed in the next section.

The first effect is the corrosion influence on the steel properties. This influence is in two ways. First, there is a loss of steel section. The corrosion reactions convert the iron atoms into some other molecule, as described previously. These molecules form a brittle, weak substance that does not participate in load sharing. Thus in can be assumed that the load the steel can take reduces in proportion to the steel loss, as has been done in many typical analyses. ${ }^{2-18,} 2-19$ This 
assumption has been confirmed by the work of J. Phillips. ${ }^{2-20}$ This would have an obvious influence on the capacity of the member and consequent effects on safety.

The second effect corrosion has on structural performance is related to spalling. This is loss of the concrete around a bar due to its expansion. Spalling creates two difficulties. First, it can lead to a loss of bond. This will be discussed more extensively in the next section on bond. It also has the effect of loss of concrete section. This is more critical when the section that is spalling off is in the compression region. This can occur if the steel that is rusting is not the primary reinforcement but is included to control other effects, such as shrinkage and thermal movement. Unlike the concrete in the tension region, all the concrete in the compression region is used to resist load. Thus, if concrete is lost, this will have the effect of reducing the capacity of the member. This may not be critical at low levels of concrete loss due to the design factors of safety. If allowed to continue, however, then a significant weakening can occur. The beams will then also be failing in compression, which is a brittle failure. This is undesirable.

\subsection{Effects of Corrosion on Bond}

The effects of corrosion on bond have not been studied extensively. Some of the articles investigate the effect of using corroded steel as reinforcement. This is a very different situation from that of interest here and the results are not necessarily transferable. There have also been some studies on the effects of corrosion after steel inclusion.

If the steel is corroded before it is placed, then there is little or no decrease in the bond strength at low corrosion levels, up to about $1.0 \%$. $^{2-21}$ There may even be an increase in bond strength. It was felt that this is because the corrosion products at this level adhere to the bar. They would also increase the surface roughness.

If the steel corrodes in the concrete, there is a different situation. The expansion of the steel can cause cracking of the concrete. This will affect the bond strength. Al-Sulaimani, et al. ${ }^{2-}$ ${ }^{22}$ conducted a series of tests on pullout specimens in which they measured the slip versus load for different size bars corroded to different levels. The bars were corroded using impressed current techniques. They found that before the appearance of visible cracks, corrosion increased the bond strength. When visible cracks begin to appear on the surface, then the bond strength 
dropped down to slightly below the original level. Once extensive cracking occurred at about 7-8 $\%$ of mass loss then the bond strength decreased to about one third to one quarter of its original level. The slip at ultimate corrosion strength was found to be approximately the same, however. They attributed this trend to the effect of increased surface roughness at low corrosion levels and the deterioration of the rebar lugs at higher levels of corrosion.

Another series of tests was reported by Almusallam, et al. ${ }^{2-23}$ They electrochemically corroded a series of slab-shaped bending specimens to a variety of corrosion levels. They found that the mode of failure changed at different corrosion levels. At no or low corrosion, the slabs failed in flexure, as they were designed to do. At higher corrosion levels, from 10 to $25 \%$, the slabs, along with being weaker, failed in a combination of bond failure and shear cracking. This is of interest as these are brittle failure modes that are more dangerous.

There has been some work performed by Rodriguez, et al. ${ }^{2-24}$ They tested cubes with four bars at the corners to better simulate the actual conditions that exist during service. They tested cubes with and without stirrups. It was determined that the concrete quality and the cover to bar diameter ratio were not relevant if the cover was badly cracked. They also used these test results to establish relationships between residual bond strength and depth of attack penetration. The experimental values of attack penetration ranged between 0.04 and $0.5 \mathrm{~mm}$ of depth, but the authors felt that this could reasonably be extrapolated to a penetration of $1.0 \mathrm{~mm}$. The relationships developed were:

$$
\begin{aligned}
\mathrm{u} & =5.28-2.72 \mathrm{x} \quad \text { (with stirrups) } \\
\text { or } \quad \mathrm{u} & =3.00-4.76 \mathrm{x} \quad \text { (without stirrups) } \\
\text { where: } & \mathrm{u} \equiv \text { the bond strength in } \mathrm{MPa} \\
\mathrm{x} & \equiv \text { the attack penetration, in } \mathrm{mm}(0.05 \leq \mathrm{x} \leq 1.00)
\end{aligned}
$$

In this study, the stirrups were not corroded. An expression was also developed for the intermediate case when there were some stirrups, but were less than the minimum required in the anchorage length by the Eurocode.

The article by Rodriguez et al. ${ }^{2-25}$ also discussed the effect of confinement on the bond strength of corroded rebar. They found that increasing confinement increases the bond strength, just as determined for a uncorroded bar. 
Thus it can be seen that it is likely that corrosion will significantly affect bond. It is the aim of this work to study this influence and quantify it. Thus a few words on what the expected influence of certain factors is now appropriate.

The first effect is that of spalling. As bond develops due to both the bearing on the bar by the concrete and the friction between the concrete and the bar, how much does the loss of the concrete surrounding the bar affect this stress transfer? It is likely that the capacity will be reduced but by how much? Will the adhesion between the concrete and the steel be sufficient to provide some load transfer or will this effect be insufficient on its own to provide any significant load transfer?

The effect of the expansion of the bar due to the formation of the corrosion products must be considered. This will lead to cracking of the concrete in the neighbourhood of the bar. What influence will these cracks have on the forces that can be developed to share load between the steel and the concrete?

These questions form the crux of what is hoped to be accomplished in this experimental investigation. In the following section, the approach that was taken to explore these questions is outlined. 


\section{$\underline{\text { References }}$}

${ }^{2-1}$ P. Schiessl, ed. Corrosion of Steel in Concrete, Chapman and Hall, Ltd. c1988, pg. 8

${ }^{2-2}$ P. Schiessl, ed. Corrosion of Steel in Concrete, Chapman and Hall, Ltd. c1988, pg. 8

${ }^{2-3}$ R. A. Treece, and J. O. Jirsa, "Bond Strength of Epoxy Coated Reinforcing Bars", $A C I$ Materials Journal, v. 86 n. 2, March-April 1989, pg. 167-174

${ }^{2-4}$ Edward G. Nawy Reinforced Concrete: A Fundamental Approach 3rd Ed. Prentice-Hall Canada, Inc. Toronto c1996, pg. 414

${ }^{2-5} \mathrm{~J}$. Cairns and K. Jones, "An Evaluation of the Bond-Splitting Action of Ribbed Bars", $A C I$ Materials Journal v. 93 n.1, Jan.-Feb. 1996, pg. 10-19

${ }^{2-6} \mathrm{~J}$. Cairns and K. Jones, "The Splitting Forces Generated By Bond", Magazine of Concrete Research, v. 47 n. 171, 1995, pg. 153-65.

${ }^{2-7} \mathrm{~J}$. Cairns and R. Bin Abdullah, "Bond Strength of Black and Epoxy-Coated Reinforcement- A Theoretical Approach" ACI Materials Journal v. 93 n. 4, July-August 1996, pg. 362-9

${ }^{2-8} \mathrm{~K}$. Leet, Reinforced Concrete Design, $2^{\text {nd }}$ Ed. McGraw-Hill Inc, Toronto, 1996, pg. 239

${ }^{2.9}$ Canadian Standards Association Design of Concrete Structures for Buildings CAN/A23.3M84 Rexdale, Ont. 1984

2-10 "Suggested Development, Splice and Standard Hook Provisions for Deformed Bars in Tension"(ACI 408.1R-90) ACI Manual of Concrete Practice 1995, Part 3, ACI, Detroit

2-11 ENV 1992 - Eurocode $2 \mathrm{Cl} .9$

2-12 Edward G. Nawy Reinforced Concrete: A Fundamental Approach 3rd Ed. Prentice-Hall Canada, Inc. Toronto c1996, pg. 415

2-13 "Standard Test Method for Comparing Concretes on the Basis of Bond Developed with Reinforcing Steel" (ASTM C234-91a) 1994 Annual Book of ASTM Standards, V 04.02, ASTM, Philadelphia, pg.148-52

${ }^{2-14}$ ENV 1992 - Eurocode $2 \mathrm{Cl} .9$

2-15 J. Cairns and K. Jones, "An Evaluation of the Bond-Splitting Action of Ribbed Bars", $A C I$ Materials Journal v. 93 n.1, Jan.-Feb. 1996, pg. 10-19

2-16 J. Cairns and K. Jones, "The Splitting Forces Generated By Bond", Magazine of Concrete Research, v. 47 n. 171, 1995, pg. 153-65.

${ }^{2-17}$ K. Leet, Reinforced Concrete Design, $2^{\text {nd }}$ Ed. McGraw-Hill Inc, Toronto, 1996, pg. 241

${ }^{2-18} \mathrm{~S}$. Ting and A. Nowak, "Effect of Reinforcing Steel Area Loss on Flexural Behaviour of Reinforced Concrete Beams", ACI Structural Journal v. 88 n. 3, May-June 1991, pg. 30914

${ }^{2-19}$ Y. Yuan and M. Marosszeky, "Analysis of Corroded Reinforced Concrete Sections for Repair", Journal of Structural Engineering v. 117 n. 7, July 1991, pg. 2018-34 
2-20 J. Phillips, The Effect of Corrosion on the Structural Performance of New and Repaired OneWay Slabs, Ph.D. Thesis, University of Toronto, c1993, pg. 143

${ }^{2-21} \mathrm{M}$. Maslehuddin, et al. "Effect of Rusting of Reinforcing Steel on Its Mechanical Properties and Bond with Concrete", ACI Materials Journal, v. 87 n.5, Sept.- Oct. 1990, pg. 496502

${ }^{2-22}$ G.J. Al-Sulaimani, M. Kaleemullah, I. A. Basunbul, and Rasheeduzzafar, "Influence of Corrosion and Cracking on Bond Behaviour and Strength of Reinforced Concrete Members", ACI Structural Journal, v. 87 n. 2, Mar.-Apr. 1990, pg. 220-231

2-23 Abdullah A. Almusallam, Ahmad S. Al-Gahtani, Abdur Rauf Aziz, Fahd H. Dakhil and Rasheeduzzafar, "Effect of Reinforcement Corrosion on Flexural Behaviour of Concrete Slabs", Journal of Materials in Civil Engineering, v. 8 n. 3, August 1996, pg. 123 - 7

${ }^{2-24}$ J. Rodriguez, L. M. Ortega, J. Casal and J. M. Diez, "Assessing Structural Conditions of Concrete Structures with Corroded Reinforcement" Concrete in the Service of Mankind: Concrete Repair, Rehabilitation and Protection, First Ed. E \& FN Spon London, 1996, pg. $65-78$

${ }^{2-25}$ J. Rodriguez, L. M. Ortega, J. Casal and J. M. Diez, "Assessing Structural Conditions of Concrete Structures with Corroded Reinforcement" Concrete in the Service of Mankind: Concrete Repair, Rehabilitation and Protection, First Ed. E \& FN Spon London, 1996, pg. $65-78$ 


\subsection{Experimental Procedure}

There are two main ways in which corrosion can affect the bond between reinforcing bars and concrete. First, the corrosion products could cause spalling of the concrete cover. This will result in loss of confinement and presumably a reduction in bond strength. Second, there is the direct effect of the corrosion products. How will this change in state of matter affect the concrete - steel interface? A series of experiments was conducted to investigate each of these possible effects.

\subsection{The Materials Used}

\subsubsection{The Reinforcing Steel}

The reinforcing steel used was \#10M bars corresponding to CSA/G30.18-M92 for a nominal yield strength of $400 \mathrm{MPa}$. Its actual yield strength was $450 \mathrm{MPa}$ and it had a Young's Modulus of $180 \mathrm{GPa}$. A diagram of its stress-strain curve is included in Appendix A.

\subsubsection{The Concrete}

Two types of concrete were used. Both satisfy Class $\mathrm{C} 1$ concrete as defined by CAN/CSA A23.1-94. The first, referred to as the Normal Mix, contained Type 10 cement with $25 \%$ slag replacement by mass. The second, referred to as the Silica Fume Mix, contained Type 10SF cement with $25 \%$ slag replacement by mass. The admixtures used were ProAir air entrainer at $30 \mathrm{~mL} / 100 \mathrm{~kg}$ cementitious material, $25 \mathrm{XL}$ water reducer at $250 \mathrm{~mL} / 100 \mathrm{~kg}$ cementitious material, and RheoBuild 1000, a mid-range plasticizer, as required. The ranges of dosage of RheoBuild 1000 were $200-250 \mathrm{~mL} / 100 \mathrm{~kg}$ cementitious material for the Normal Mix and $250-300 \mathrm{~mL} / 100 \mathrm{~kg}$

\section{Table 3-1: Mix Designs}

\begin{tabular}{|c||c|c|}
\hline & Normal Mix & Silica Fume Mix \\
\hline w/cm: & 0.40 & 0.40 \\
\hline $20 \mathrm{~mm}$ Aggregate & $1130 \mathrm{~kg} / \mathrm{m}^{3}$ & $1130 \mathrm{~kg} / \mathrm{m}^{3}$ \\
\hline Sand & $670 \mathrm{~kg} / \mathrm{m}^{3}$ & $670 \mathrm{~kg} / \mathrm{m}^{3}$ \\
\hline Water & $155 \mathrm{~kg} / \mathrm{m}^{3}$ & $155 \mathrm{~kg} / \mathrm{m}^{3}$ \\
\hline Portland Cement & $293 \mathrm{~kg} / \mathrm{m}^{3}$ & $272.5 \mathrm{~kg} / \mathrm{m}^{3}$ \\
\hline Silica Fume & $0 \mathrm{~kg} / \mathrm{m}^{3}$ & $20.5 \mathrm{~kg} / \mathrm{m}^{3}$ \\
\hline Slag & $97 \mathrm{~kg} / \mathrm{m}^{3}$ & $97 \mathrm{~kg} / \mathrm{m}^{3}$ \\
\hline Air Content & $5-8 \%$ & $5-8 \%$ \\
\hline Slump & $175 \pm 25 \mathrm{~mm}$ & $175 \pm 25 \mathrm{~mm}$ \\
\hline
\end{tabular}


cementitious material for the Silica Fume Mix. These were selected to achieve the desired slump. These two concrete types were chosen to reflect typical concrete qualities used in parking structures. The mix design specifics are indicated in Table 3-1.

A standard curing regime was followed for all concrete specimens. They were moist cured for seven days and then were left in the lab air until they were tested. For the slabs that were corroded, this process was started at seven days of age.

\subsection{Structural Testing}

\subsubsection{Structural Specimen}

One standard structural specimen was used for all the structural tests. It was selected for minimum size such that it would fail in flexure. It was attempted to design a specimen that would resemble a section of a slab. The specimen used was $1300 \mathrm{~mm}$ long, $350 \mathrm{~mm}$ wide and $150 \mathrm{~mm}$ deep. It contained $3 \# 10 \mathrm{M}$ bars with a cover of $20 \mathrm{~mm}$. There is a centre-to-centre bar spacing of $125 \mathrm{~mm}$. A diagram of the specimen is provided as Fig. 3-1. The detailed calculations used to design the specimen are included in Appendix B.

Figure 3-1: Specimen Diagram



\subsubsection{Structural Tests}

The specimens were all tested identically. A four point loading test was used. A diagram of the testing set-up is included as Fig. 3-2, with a photograph included as Fig. 3-3. The load and the measurement of 3 LVDTs were continuously recorded as the test was undertaken. One LVDT was used to monitor the midpoint deflection of the slab while the other two were used to measure the curvature over the constant moment region on either side. This was done by hanging a bar from chains attached at the midheight of the slab below the load points. The difference between the deflections of the load points at midheight and of the centre-point at 
midheight was thus deternined. Further information on this curvature measurement is located in Appendix C.

Figure 3-2: Testing Set-Up Schematic

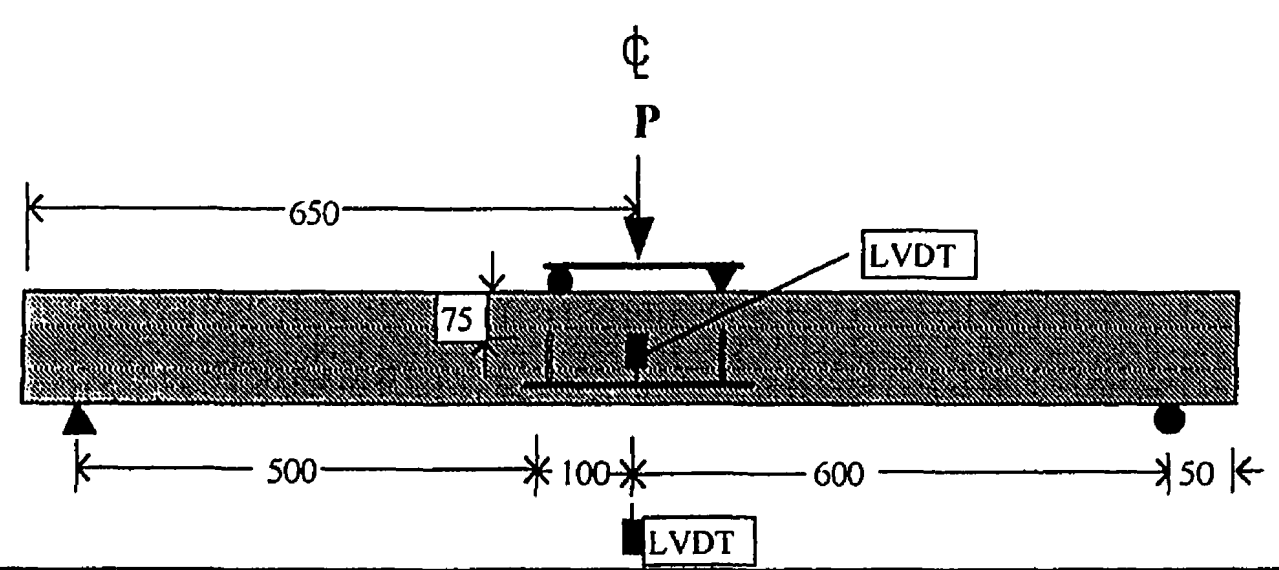

Figure 3-3: Photograph of Testing Set-Up

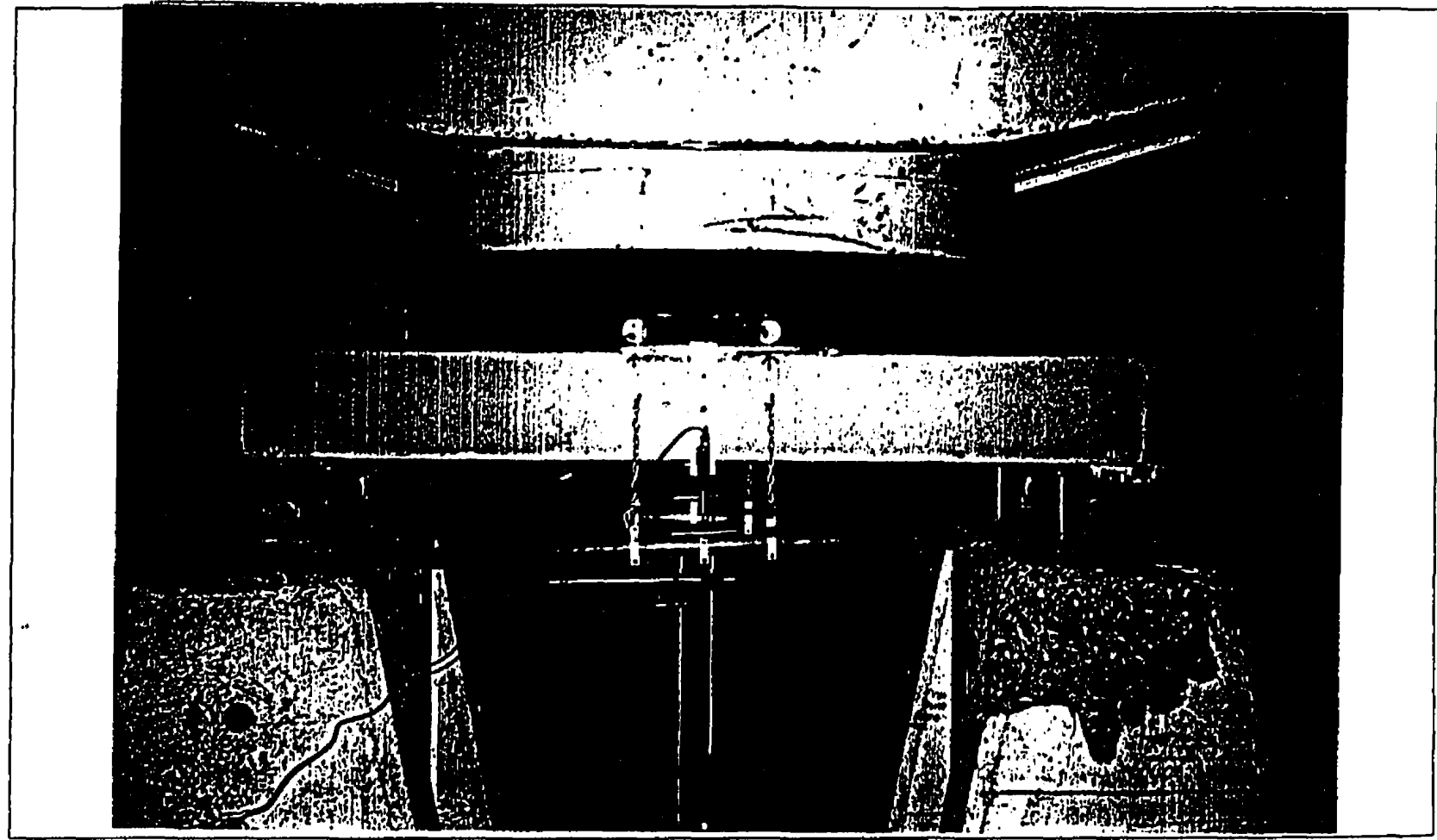




\subsection{Material Tests}

With each slab, three $100 \mathrm{~mm}$ diameter by $200 \mathrm{~mm}$ long cylinders were cast. These were used to test certain material properties that were felt to be important for the performance of the slabs under the test conditions. These tests were a compressive strength test, a sorptivity test and a rapid chloride ion penetration test (ASTM C1202). These tests were performed at seven and 28 days of age. Not all tests were performed on all slabs. A schedule was set up so that each series was tested for all properties. At least one cylinder was tested for strength for each slab. An outline of the test program is included as Table 3-2. A description of the material tests follows along with any variations that were used, with justifications.

Table 3-2: Material Testing Schedule

\begin{tabular}{|c|c||c|c|c|}
\hline Series & Condition & Strength Test & Rapid Chloride \& Resistivity & Sorptivity Test \\
\hline \hline 1, Normal & None & Yes & No & No \\
\hline & Quarter & Yes & No & No \\
\hline & Half & Yes & No & No \\
\hline 2, Normal & 0 & Yes & No & No \\
\hline & 2 & Yes & No & Yes \\
\hline & 5 & Yes & No & Yes \\
\hline & 8 & Yes & Yes & No \\
\hline & 10 & Yes & Yes & No \\
\hline 2, Silica & 0 & Yes & No & Yos \\
\hline Fume & 2 & Yes & No & Yes \\
\hline & 5 & Yes & No & No \\
\hline & 8 & Yes & Yes & No \\
\hline & 10 & Yes & Yes & Yes \\
\hline 3, Normal & 10 & Yes & Yes & \\
\hline
\end{tabular}

** Condition represents either portion of perimeter debonded or expected percentage of bar area corroded, whichever is relevant

\subsubsection{Strength Testing}

To determine concrete strength, $100 \mathrm{~mm}$ diameter cylinders were tested according to ASTM C39-93 $\mathrm{a}^{3-1}$ with one variation described below. For the slab mixes that only had their strength tested, this was done at seven and twenty-eight days. One cylinder was tested at seven days of age and two were tested at 28 days. For the other slab mixes that were tested for another 
property, in general only one cylinder was tested for strength at 28 days to confirm that they all had similar properties.

The one variation in testing was the moisture content at 28 days. The normal testing procedure is to ensure that the cylinders are saturated at the time of test. This was followed at seven days as they were just removed from the moist curing room. At 28 days of age, however, the cylinders had been left in lab air for three weeks and thus have dried to a certain extent. It was felt that it was appropriate to test in this moisture condition as the results would then better reflect the conditions at the time of the slabs are tested in four-point loading.

\subsubsection{Sorptivity Testing}

The sorptivity test measures the rate at which water is drawn into the pore structure of the dry concrete. To do this, disks $100 \mathrm{~mm}$ in diameter and $50 \mathrm{~mm}$ thick were dried at $50^{\circ} \mathrm{C}$ for seven days. They are then removed from the oven and allowed to cool in a sealed container until they reach ambient temperature. The sides are then sealed and one face is immersed in water. The mass of the disk is then taken at intervals for twenty-five minutes. This was done for three disks for each sample. The height of water rise was calculated by dividing the mass gained by the surface area of the disk and the density of water. These values, averaged for the three disks, were plotted versus the square root of time and the slope of the line of best fit is reported as the sorptivity of the sample.

\subsubsection{Chloride Ion Penetrability}

This test is performed in accordance with ASTM Standard C1202-94: Standard Test Method for Electrical Indication of Concrete's Ability to Resist Chloride Ion Penetration ${ }^{3-2}$ or AASHTO T259. This test subjects a $50 \mathrm{~mm}$ thick, $100 \mathrm{~mm}$ diameter concrete disk to a $60 \mathrm{~V}$ potential across the specimen. A sodium chloride reservoir is filled on one side of the disk, while a sodium hydroxide reservoir is filled on the other. This is maintained for 6 hours and the total charge passed is monitored. This charge is used to rate the quality of the concrete according to a scale included with the standard. The more charge passed, the greater the chloride ion penetrability. For further details, please refer to the relevant standard. 
This test was also used for an additional purpose. It was used to estimate the resistivity of the concrete. This was done by taking the current at 10 minutes and calculating the resistivity using the equation:

$$
\rho=\frac{V A}{I L}
$$

where: $\rho \equiv$ the resistivity, in $\Omega-\mathrm{cm}$

$\mathrm{V} \equiv$ the voltage, in $\mathrm{V}$

$A \equiv$ cross-sectional area, in $\mathrm{cm}^{2}$

$\mathrm{I} \equiv$ current, in $\mathrm{A}$

$\mathrm{L} \equiv$ the thickness of the specimen, in cm

The ten minute current was used to calculate the resistivity as this would allow sufficient time for the chloride and hydroxyl ions to have reached an equilibrium state in the pore solution. It would also minimize any effects of polarization that is commonly encountered when dealing with high resistivity materials. It also minimizes any potential thermal effects that may arise. This method of determination may not be as accurate as some other methods using techniques to minimize polarization, for example using alternating current or varying the voltage applied using direct current, but it does give an idea of the expected resistivity. Considering the simplicity of the test and the fact that this is principally being used to characterize to concrete and not for any predictive purposes, it was thought to be sufficient.

\subsection{The Experimental Series}

These tests were then used to evaluate the effect of corrosion. This was done by preparing three main series of tests, each of which was designed to look at a different effect. The first series examined the effect of spalling on structural performance. The second looked at how corrosion affected bond over a specific length. The third series looked at combined effects of area loss and bond loss and the predictive power of the work. These series consisted of a set of slabs with their accompanying cylinder specimens. The slabs were modified to examine the desired effect and the cylinders were used to establish the material properties of the concrete. As discussed in Section 3.3, not all material tests were performed on all slabs. A schedule was set up to ensure that each series contained at least one slab that was tested for each material property. 


\subsubsection{Series 1 - Effect of Spalling}

Spalling of concrete cover leads to loss of confinement and this could lead to a reduction of bond strength. This was modelled by debonding the bars along the bottom section with pipe insulation. Three standard specimens were tested, each with a different proportion of the bars' perimeter unbonded. One had none of the bar perimeter debonded, to serve as a control, one had one quarter of its bars' perimeters debonded while the final had one half of the bars' perimeters debonded. After casting, the slabs were moist cured for 7 days, then air cured for 21 days before testing.

\subsubsection{Series 2 - The Effect of Corrosion Products}

To determine the effect of corrosion products on bond strength, ten slabs were cast. Five were of the Normal Mix and five were made with the Silica Fume Mix. All Series 2 slabs had the centre section debonded with closed cell, foam pipe insulation while the ends were left as normal. The uncovered length was chosen so that at no corrosion, the full yield capacity of the rebar would just barely be developed. As the steel used had a definite strain hardening characteristic, it would then be noticeable if the corrosion either increased or decreased the slab capacity as any change in bond capacity would result in a change in possible steel stress and thus moment. The length used, as based upon ACI $408.1 \mathrm{R}-90,{ }^{3-3}$ was $250 \mathrm{~mm}$. The calculations are included in Appendix B.

All of the slabs were then corroded in the end sections by semi-immersing them in a $3 \%$ $\mathrm{NaCl}$ solution and applying a voltage across them. This caused the bars to become anodic. The section protected by the pipe insulation remained uncorroded. A schematic of this set-up is included as Fig. 3-4. One slab of each type was corroded to a different corrosion level as expressed by volumetric mass loss. They were corroded to approximately $2 \%, 5 \%, 8 \%$ and 10 $\%$ corrosion. One was left non-corroded to act as a control. The corrosion was monitored by recording the current that passed and applying Faraday's law to the integrated current. Details of this procedure are included as Appendix D. Corrosion was also confirmed by including a corrosion sample in the slab to be removed after testing. This sample was a pre-weighed length of rebar approximately $100 \mathrm{~mm}$ in length that was corroded, then cleaned according to ASTM $\mathrm{G} 1-90^{3-4}$ to remove the rust and finally weighed. The cleaning solution chosen was C.3.3: $200 \mathrm{~g}$ 
sodium hydroxide, $20 \mathrm{~g}$ zinc and reagent water to make $1000 \mathrm{~mL}$. For further information, refer to the standard.

\section{Figure 3-4: Corrosion Set-Up}

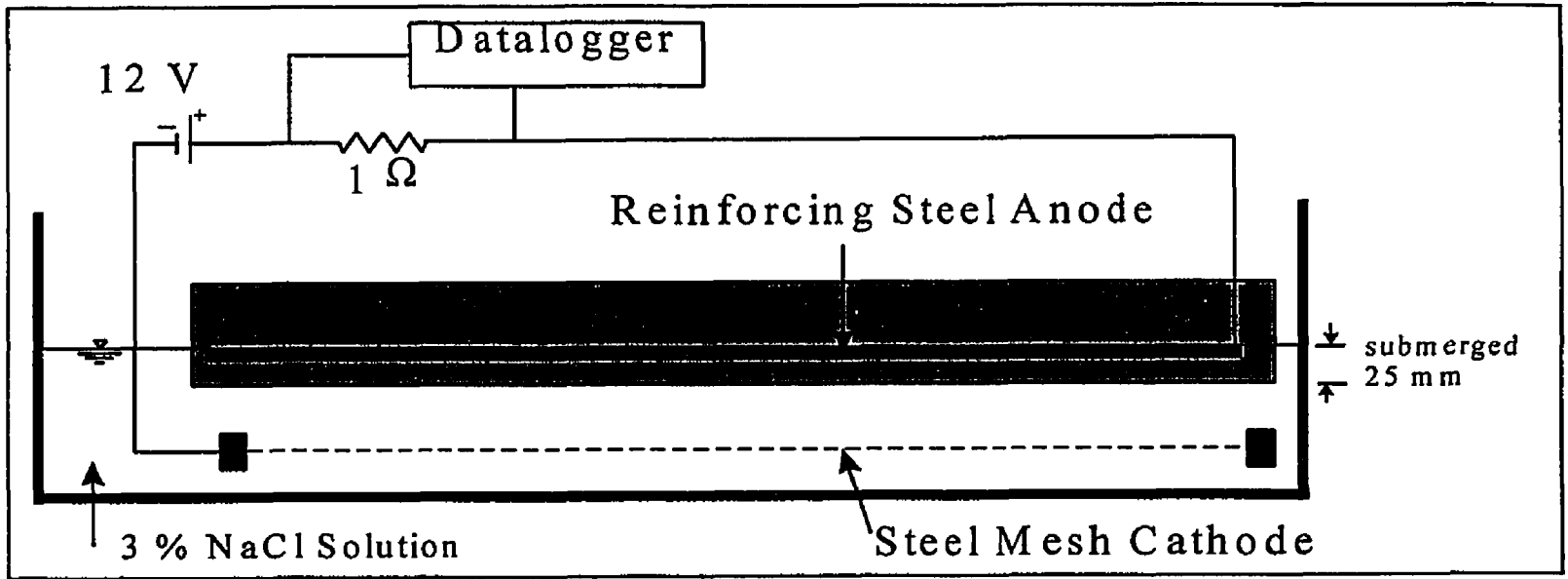

There were two methods used to connect the rebar to the power supply. Initially, the rebars were connected by running a wire from one rebar to the other, but the individual bars were still in parallel to each other. This technique is illustrated as Fig. 3-5(a). This proved to be unsatisfactory as this led to uneven corrosion. The bar where the wire connected to first corroded more, as determined by visual inspection, than the last bar. Thus the technique used to attach the bars was changed. Separate wires were attached to each bar and these were then connected to a common wire. This is Figure 3-5: Alternate Wire Connections

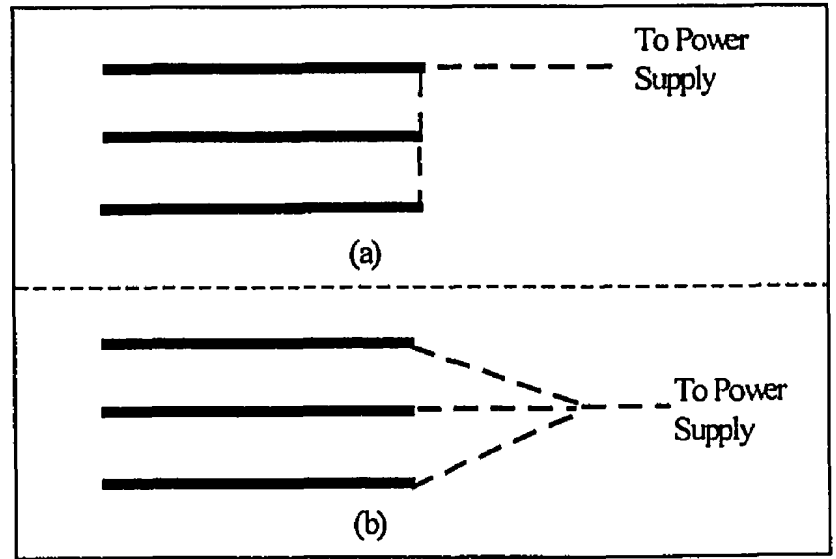
illustrated as Fig. 3-5(b). This proved to give more satisfactory results.

\subsubsection{Series 3- Combined Effects}

A final slab was then cast to investigate the total effects of corrosion. That is to determine the combined effects of steel section loss and the effect of corrosion products on bond. 
This was done by casting a normal slab that did not have any unbonded sections. It was then corroded to a corrosion level of $10 \%$ by applying a current. The ultimate strength was then predicted based upon previous work done in this thesis and that done by J. Phillips ${ }^{3-5}$. It was then tested in flexure in the standard manner.

Thus it was felt that the different effects of corrosion on reinforcing steel - concrete bond would be captured. The results of this experimental investigation are included in the next chapter. 


\section{References}

3-1 "Standard Test Method for Compressive Strength of Cylindrical Concrete Specimens" (ASTM C39-93a) 1994 Annual Book of ASTM Standards V 04.02, ASTM, Philadelphia, pg. $17-21$

3-2 "Standard Test Method for Electrical Indication of Chloride's Ability to Resist Chloride" (ASTM C1202-94) 1994 Annual Book of ASTM Standards V 04.02, ASTM, Philadelphia, pg. $620-5$

3.3 "Suggested Development, Splice, and Standard Hook Provisions of Deformed Bars in Tension" (ACI 408.1R-90) ACI Manual of Concrete Practice 1995, Part 3, ACI, Detroit

3-4 "Standard Practice for Preparing, Cleaning and Evaluating Corrosion Test Specimens" (ASTM G1-90) 1994 Annual Book of ASTM Standards V 03.02, Philadelphia, pg. 25-31

3-5 J. Phillips, The Effect of Corrosion on the Structural Performance of New and Repaired Oneway Slabs, Ph.D. Thesis, University of Toronto, c1993, pg. 143 


\subsection{Experimental Results}

The results of this experimental program can be divided into three main categories. The first deals with the testing of the material properties of the concrete. The second category relates to the corrosion activity of the slabs and its monitoring and evaluation. The third topic is the structural performance of the slabs. These broad categories will be used to discuss the results in this section.

The results of the structural testing of the third series will not be discussed here, as this is more of a test of the predictive power of the work done to that point. Both the prediction and the results are discussed separately in Chapter 5.

\subsection{Material Results}

The material results are divided into five main subsections of results. The first one discusses the properties of the fresh concrete tested. The remaining four correspond to the major tests performed: compressive strength, sorptivity, rapid chloride and resistivity. Each of these is discussed separately for the Normal Mix and the Silica Fume Mix. The results in their entirety for the individual slabs are included as Appendix $\mathrm{E}$.

\subsubsection{Fresh Concrete Properties}

The fresh concrete properties tested were slump, air content and plastic density. These were used to ensure consistency in concrete properties between the variety of mixes using the same mix design. A report of the various properties for each cast is included as Appendix $\mathrm{E}$, including admixture dosages. Table 4-1 is a summary of the results. The fresh concrete property test results varied little between mixes

\begin{tabular}{l}
\hline \multicolumn{1}{|c||}{ Table 4-1: Fresh Concrete Properties } \\
\begin{tabular}{|c|c|c|}
\hline & $\begin{array}{c}\text { Normal } \\
\text { Mix }\end{array}$ & $\begin{array}{c}\text { Silica } \\
\text { Fume Mix }\end{array}$ \\
\hline \hline Avg. Slump & $175 \mathrm{~mm}$ & $112 \mathrm{~mm}$ \\
\hline Slump COV & $21.8 \%$ & $53 \%$ \\
\hline $\begin{array}{c}\text { Avg. Air } \\
\text { Content }\end{array}$ & $6.9 \%$ & $6.7 \%$ \\
\hline $\begin{array}{c}\text { Air Content } \\
\text { COV }\end{array}$ & $17.4 \%$ & $14.0 \%$ \\
\hline $\begin{array}{c}\text { Avg. Plastic } \\
\text { Density }\end{array}$ & 2293 & 2312 \\
$\mathrm{~kg} / \mathrm{m}^{3}$ & $\mathrm{~kg} / \mathrm{m}^{3}$ \\
\hline $\begin{array}{c}\text { Plastic } \\
\text { Density COV }\end{array}$ & $1.7 \%$ & $2.2 \%$ \\
\hline
\end{tabular}
\end{tabular}

for the Normal Mix. The air content is within the target range and the plastic density has little 
variation. The coefficient of variation for the slump is slightly higher than for the other tests, but this is expected due to the nature of the test. Slight variations in workability, the actual factor of interest, can produce large changes in slump; at least at the relevant level of slump. ${ }^{4-1}$

The Silica Fume Mix properties are also summarized in Table 4-1. The results are generally consistent with small coefficients of variation between individual batch results. The exception to this, again, is the slump test. The five values for this test clustered around two points. The first three mixes chronologically had slumps around $150 \mathrm{~mm}$, while the last two had slumps of $50 \mathrm{~mm}$. The mixes had identical mix proportions and the other test results were similar so the mixes were used. This change in slump is attributed to a change in aggregate between these mixes. The aggregate was from the same source and the other physical and chemical properties were identical, but the grading of the aggregate may have slightly changed. The grading affects slump and workability, but other properties of the concrete remain unchanged. ${ }^{4-2}$ Extra care was taken with these mixes to ensure good compaction and placement, but no additional measures were required.

\subsubsection{Strength Testing}

The strength test summary is included as Table 4-2. As expected, the Silica Fume Mix is significantly stronger than the Normal Mix, by approximately 10 $\mathrm{MPa}$. Both the 7 day and 28 day strengths show this change.

\subsubsection{Sorptivity Testing}

The sorptivity values for the mixes were

Table 4-2: Strength Results

\begin{tabular}{|c||c|c|}
\hline & $\begin{array}{c}\text { Normal } \\
\text { Mix }\end{array}$ & $\begin{array}{c}\text { Silica } \\
\text { Fume Mix }\end{array}$ \\
\hline $\begin{array}{c}\text { 7 Day } \\
\text { Strength }\end{array}$ & $23.8 \mathrm{MPa}$ & $34.5 \mathrm{MPa}$ \\
\hline $\begin{array}{c}7 \text { Day } \\
\text { COV }\end{array}$ & $18.3 \%$ & $16.7 \%$ \\
\hline $\begin{array}{c}28 \text { Day } \\
\text { Strength }\end{array}$ & $36.4 \mathrm{MPa}$ & $42.6 \mathrm{MPa}$ \\
\hline $\begin{array}{c}28 \text { Day } \\
\text { COV }\end{array}$ & $14.4 \%$ & $13.5 \%$ \\
\hline
\end{tabular}
determined at seven and twenty-eight days. The average values within a mix type are reported in Table 4-3. For the Normal Mix, the values increased slightly between seven and Table 4-3: Sorptivity Values twenty-eight days; while for the Silica Fume Mix, the values decreased slightly. These changes are not considered

\begin{tabular}{|c||c|c|}
\hline & Normal Mix & Silica Fume Mix \\
\hline \hline $\begin{array}{c}7 \text { Day } \\
\text { Sorptivity }\end{array}$ & $0.111 \mathrm{~mm} / \mathrm{min}^{0.5}$ & $0.123 \mathrm{~mm} / \mathrm{min}^{0.5}$ \\
\hline $\begin{array}{c}28 \text { Day } \\
\text { Sorptivity }\end{array}$ & $0.104 \mathrm{~mm} / \mathrm{min}^{0.5}$ & $0.111 \mathrm{~mm} / \mathrm{min}^{0.5}$ \\
\hline
\end{tabular}


significant, however. The two mixes did have similar values at all ages. Thus, it is concluded that the difference in initial chloride penetration due to sorptivity effects would be negligible between the two different mix types.

\subsubsection{Rapid Chloride Testing}

According to the rapid chloride test, the chloride ion penetrability for the normal mix is moderate at seven days of age and moderate to low at twenty-eight days of age. This is typical of the quality of concrete used in parking structures. The

Table 4-4: Rapid Chloride Results

\begin{tabular}{|c||c|c|}
\hline & Normal Mix & $\begin{array}{c}\text { Silica Fume } \\
\text { Mix }\end{array}$ \\
\hline 7 Day & Moderate & Low \\
\hline 28 Day & $\begin{array}{c}\text { Moderate - } \\
\text { Low }\end{array}$ & Very Low \\
\hline
\end{tabular}

Silica Fume Mixes had a low chloride ion penetrability rating at seven days of age, dropping to very low at twenty-eight days of age. This is expected, as the addition of silica fume improves the chloride ion penetration resistance of concrete. The Silica Fume Concrete qualifies as LowPermeability Concrete as defined by CSA/S413-94 - Parking Structures Code, CI. 7.3.1.2. ${ }^{4-3}$ This requires, among other things, a 28 day coulomb rating of less than 1500 when tested according to ASTM C1202.

\subsubsection{Resistivity Measurements}

Table 4-5: Resistivity Data

The summary of the resistivity testing of the concrete is in Table 4-5. They follow the results of the rapid chloride testing rather closely. This is expected as they were developed using the rapid chloride testing apparatus. The reasoning

\begin{tabular}{|c||c|c|}
\hline & Normal Mix & Silica Fume Mix \\
\hline $\begin{array}{c}7 \text { Day } \\
\text { Resistivity }\end{array}$ & $6245 \Omega-\mathrm{cm}$ & $13366 \Omega$-cm \\
\hline $\begin{array}{c}\text { 28 Day } \\
\text { Resistivity }\end{array}$ & $12339 \Omega-\mathrm{cm}$ & $50806 \Omega$-cm \\
\hline
\end{tabular}
for the trends is identical to that previously discussed in Section 4.1.4.

Comparing the results between the two mixes is interesting. The Silica Fume Mix has obtained a similar resistivity at seven days as that obtained by the Normal Mix at twenty-eight days. At twenty-eight days, the resistivity of the Silica Fume Mix is about four times higher. This is a rating that would likely be unachievable for the Normal Mix, no matter its age. 


\subsection{Corrosion Activity Testing}

This section discusses the tests used to determine if corrosion is occurring and to monitor the rate and quantity of corrosion. Included in this section is a discussion of the monitoring of the corrosion current and the determination of corrosion levels using the included rebar test coupon. These aspects will each be discussed individually.

\subsubsection{Corrosion Current}

The current passing through the slabs was continuously recorded using a Campbell 10X datalogger. A reading was taken every minute. Every half-hour, one number was recorded which was the average of the minute by minute values. Graphs of the output are included as Appendix F. These values were integrated and Faraday's Law applied to determine the mass loss. This was converted to cross-sectional area loss based upon the density of steel. The values achieved are reported in Table 4-6, along with the values from the corrosion samples, discussed in the next section.

Table 4-6: Corrosion Results, Series 2

\begin{tabular}{|c||c|c|c|c|c|c|c|c|}
\hline & $\begin{array}{c}\text { Normal, } \\
2 \%\end{array}$ & $\begin{array}{c}\text { Normal, } \\
5 \%\end{array}$ & $\begin{array}{c}\text { Normal, } \\
8 \%\end{array}$ & $\begin{array}{c}\text { Normal, } \\
10 \%\end{array}$ & $\begin{array}{c}\text { Silica } \\
\text { Fume, } 2 \%\end{array}$ & $\begin{array}{c}\text { Silica } \\
\text { Fume, } 5 \%\end{array}$ & $\begin{array}{c}\text { Silica } \\
\text { Fume, } 8 \%\end{array}$ & $\begin{array}{c}\text { Silica } \\
\text { Fume, } 10 \%\end{array}$ \\
\hline \hline $\begin{array}{c}\text { Current } \\
\text { Estimate }\end{array}$ & $7.6 \%$ & $8.9 \%$ & $10.3 \%$ & $10.3 \%$ & $0.4 \%$ & $6.4 \%$ & $8.1 \%$ & $11.8 \%$ \\
\hline $\begin{array}{c}\text { Corrosion } \\
\text { Coupon }\end{array}$ & $3.1 \%$ & $0.3 \%$ & $0.2 \%$ & $18.4 \%$ & $1.5 \%$ & $5.4 \%$ & $17.7 \%$ & $29.6 \%$ \\
\hline $\begin{array}{c}\text { Connection } \\
\text { Method }\end{array}$ & (a) & (a) & (a) & (b) & (a) & (b) & (b) & (b) \\
\hline
\end{tabular}

For the Normal Slabs, the corrosion current fluctuated significantly at times, as can be seen from a superficial examination of the graphs. The average current was in the range of 100 $\mathrm{mA}$, but there were current spikes that at times approached at $1000 \mathrm{~mA}$. The current also occasionally decreased to almost zero, though rarely. It did, however, always return to the original value of approximately $100 \mathrm{~mA}$.

The corrosion currents monitored for the slabs made with the Silica Fume Mix were similar in pattern to that for the Normal Mix. Their average value was also about $100 \mathrm{~mA}$. 
There were also large variations in current levels, but these were not as high as for the Normal slabs. The maximum value was not more than around $700 \mathrm{~mA}$. The corrosion graph for the Silica Fume slab that was corroded to only $0.4 \%$ electrochemically is different from the others of this series. There is an initial high level of around $75 \mathrm{~mA}$, but this then decreases to a very low current of near $5 \mathrm{~mA}$, that then remains consistent for the duration of the corrosion period.

For two of these slabs, for a 15 day period the datalogger was not registering data as the datalogger's power supply was accidentally disconnected. To represent this time, it was assumed that the average current over this period was $100 \mathrm{~mA}$. This is represented in the graphs and was assumed for calculation of the corrosion loss by electrochemistry.

\subsubsection{Corrosion Sample Results}

The corrosion test coupons are small, preweighed $10 \mathrm{M}$ bars included in the slabs. These were corroded, cleaned and then weighed to determine the level of corrosion that took place in the slabs. The results from this are included in Table 4-6, along with the results from the corrosion current monitoring. Also included in this table is the method that was used to connect the rebar, (a) or (b). (See Section 3.4.2)

For the slabs connected using method (a), 3 out of the 4 resulted in very low levels of corrosion present, compared to that shown by electrochemistry. This may indicate that the connection was not sufficient to ensure that the voltage would be applied to all bars equally. The corrosion test coupons were connected last in order. Another explanation would be that the cover around one bar cracked before the other bars. The current then flowed principally through this bar, causing it to be greatly corroded while the other bars were not. It is unlikely that the crack would first occur over the corrosion sample, due to its small size, and thus the corrosion sample would report a lower level of corrosion than exists. One sample (Silica Fume Mix, $2 \%$ corrosion) had a higher level of corrosion than was predicted electrochemically, but the corrosion currents for this sample were unusual. The final sample of the four agreed rather well.

The slabs connected using method (b) show a different trend. In all of these cases, the corrosion levels by the sample are higher than that reported by corrosion current measurements. They are of the order of one and a half and two times greater. The reason for this may be the reaction that was assumed to occur. The assumed reaction is the one discussed in the Literature 
Review, with the iron atom from its 2 valence state reaction with oxygen and hydroxyl ions to form ferrous hydroxide. This may not be the reaction that is occurring. First, iron is a divalent element. There are also many possible reactions that could occur, for example binding with chlorides to produce ferrous chlorides and other, more complex molecules. ${ }^{4-4}$ These different reactions were not all considered when developing the original expression for corrosion current evaluation, but may be occurring. This could explain the discrepancy between the two values.

\subsubsection{Corrosion Levels}

Given the discrepancies between the two methods of determining the corrosion levels, what should be used as the final value for corrosion level? In this section, this dilemma is discussed.

A number was required to be assigned to each slab to represent the amount of steel that was corroded. To do this, the values for each slab from both the corrosion test coupon and the electrochemical current were examined. The method of connection was also considered and from this a number was estimated that would best represent, if not the exact level of actual corrosion, at least the relative level of damage.

For the slabs that were connected using connection type (a), it was felt that these two numbers represented an upper and lower bound of the corrosion damage. Thus the actual damage is reported as the average of these values. The exception is the normal slab that was targeted to be corroded to $2 \%$, as it was felt that the corrosion sample alone was more representative. This was based on visual examination. For the slabs connected using method (b), it was felt that the integrated current better reflected the level of damage. Thus this number is reported as the level of corrosion. A summary of these results is included as Table 4-7.

\section{Table 4-7: Effective Corrosion Levels, Series 2}

\begin{tabular}{|c||c|c|c|c|c|c|c|c|}
\hline $\begin{array}{c}\text { Original } \\
\text { Name }\end{array}$ & $\begin{array}{c}\text { Normal, } \\
2 \%\end{array}$ & $\begin{array}{c}\text { Normal, } \\
5 \%\end{array}$ & $\begin{array}{c}\text { Normal, } \\
8 \%\end{array}$ & $\begin{array}{c}\text { Normal, } \\
10 \%\end{array}$ & $\begin{array}{c}\text { Silica } \\
\text { Fume, } 2 \%\end{array}$ & $\begin{array}{c}\text { Silica } \\
\text { Fume, } 5 \%\end{array}$ & $\begin{array}{c}\text { Silica } \\
\text { Fume, } 8 \%\end{array}$ & $\begin{array}{c}\text { Silica } \\
\text { Fume, 10 } \%\end{array}$ \\
\hline $\begin{array}{c}\text { Corrosion } \\
\text { Level }\end{array}$ & $3.1 \%$ & $4.6 \%$ & $5.3 \%$ & $10.3 \%$ & $1.0 \%$ & $6.4 \%$ & $8.1 \%$ & $11.8 \%$ \\
\hline
\end{tabular}




\subsection{Structural Test Results}

This section will deal with a discussion of the three individual sets of slab results. Each set is discussed individually, examining their load response plots. The bond stresses that were developed are then determined and discussed.

\subsubsection{Series 1 - The Effect of Spalling}

This series contained three slabs, each of which had a different proportion of its bars' perimeters debonded using closed cell, foam, pipe insulation. The proportions were: none (control), one-quarter and one-half. The bottom portion of the bar towards the tensile surface of the slab was debonded to realistically reflect spalling activity. It might be considered that the one-quarter debonded slab would represent the effects of pop-out, while the half debonded slab would represent delamination. Figure 4-1 illustrates this.

\section{Figure 4-1: Conceptual Spalling Effects}



The moment-curvature plot obtained from the structural testing is included here as Fig. 42. An examination of this provides some important information. The control slab behaved quite predictably. It contained an initial, very stiff region until the concrete cracked $(\mathrm{O}-\mathrm{A})$. The steel then began to load elastically (A-B). While this response is less stiff than the uncracked section, significant stiffness still remains in the slab. Finally the steel begins to yield. This is represented 
by a significant loss of flexural stiffness (B-C), but as the steel has a substantial strain hardening effect, the slab still accepted more load.

The slab with a quarter of the bars' perimeters debonded had some substantial differences. Initially, it acted the same as the control slab (O-A). This is because the concrete provides most of the load resistance until cracking. After the slab cracks, the quarter-debonded slab was significantly more flexible than the control slab (A-B'). This may be interpreted as the slip required for the bar to achieve equal stress transfer in this situation is more than for the

\section{Figure 4-2: Series 1 Results}

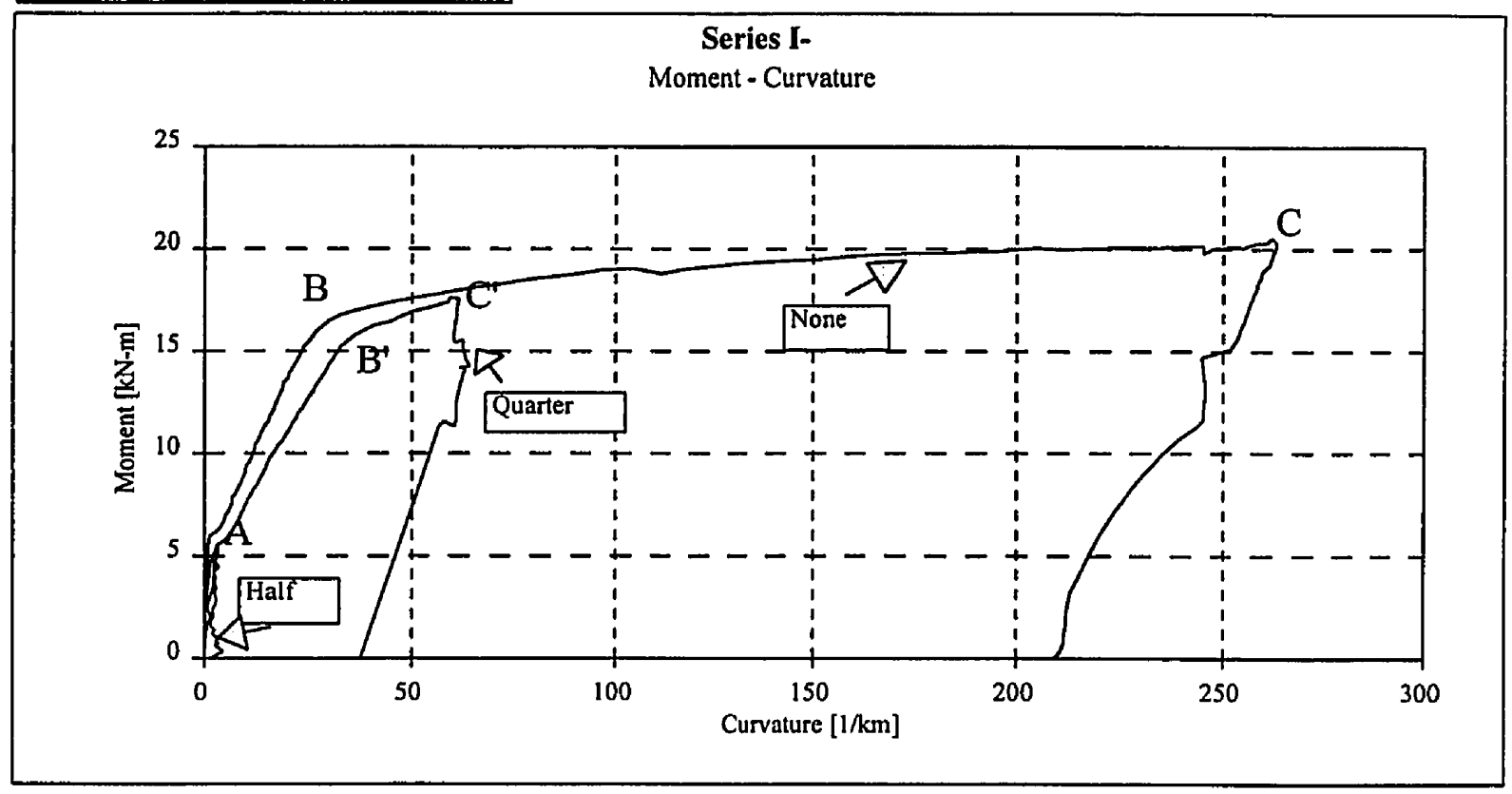

control. The slab does reach a point where the bar appears to begin to yield, however. Another possible explanation of this 'yield plateau' is that the slip has begun to reach a critical point, where increasing stress transfer requires ever increasing amounts of slip. The first explanation of bar yielding is favoured due to the high load at which this is occurring, similar to the yield load for the control slab. The most significant difference between the two load response curves occurs in the third region, after the bars have yielded ( $\left.B^{\prime}-C^{\prime}\right)$. For the control specimen, there was a large ductile response. The load was still able to be supported with ever increasing curvature until it was decided to unload the specimen as the curvature LVDTs reached the end of their range. For the one-quarter debonded specimen, this was not the case. There was a short time where the load was still maintained with increasing curvature, but this did not last long. A 


CORROSION EFFECTS ON BOND STRENGTH IN REINFORCED CONCRETE
Chapter 4
Experimental Results

point was reached where the load could no longer be supported and the slab began to unload itself. This can be clearly seen in the load response diagram. This is interpreted to mean that the bars have reached their ultimate slip and have now become debonded from the concrete. Since the concrete section is already cracked, this means that there is no residual capacity in the beam. It should be noted that this was a rather sudden event and that there was no warning of this failure point approaching, as compared to the normal yielding response.

The slab that contained one-half of its bars' perimeter debonded exhibited even more dramatic results. Until the beam cracked, the test went on as before. When the slab cracked, however, the steel did not begin participating in the resisting the load. The slab did not take any more load and would not support the load previously applied. This is the response that would have been achieved if the slab was unreinforced. The only difference is that the two halves of the slab did not fall but rested upon the steel that spanned between them. This leads to the conclusion that if one half or greater of the bars' perimeter is debonded along the entire slab then effectively no bond will occur between the steel and the concrete. The slabs will then act as if they were unreinforced.

This lack of bond if a bar has greater than half of its perimeter exposed is quite understandable. The bond developed is the component of the bearing stress of the lugs on the concrete that acts along the bar. Also developed, however, is a perpendicular component that in the normal situation is counteracted by the perpendicular component on the opposite side of the bar. This is developed due to the angled face of the lugs. If only a small portion of the perimeter is not confined, then it is possible for the perpendicular components to be equilibrated by the other sections of the perimeter. If the unconfined section reaches to high a proportion of the bars perimeter than the perpendicular components will not be equilibrated. In the case where half of the perimeter is unconfined, then there will be nothing to resist the perpendicular stress components of the bonded perimeter. This will result in the pushing out and sliding of the bar whenever it is loaded. This is due to the effect of the lugs. 


\subsubsection{Series 2 - The Effect of Corrosion Products}

Experimental Results

The condition of slabs before testing, the results of the Normal Mix test series, the Silica Fume Mix test series and some general conclusions of what can be inferred from the Moment Curvature graphs will be discussed.

\subsubsection{Condition of Slabs Before Testing}

All the slabs, except for the Silica Fume Mix slab that was corroded to $2 \%$, were cracked due to corrosion to some extent before they were tested. The extent of this damage varied, however, from small surface cracks to large sections spalling off the slab. As to be expected, the extent of damage increased with increasing corrosion levels.

The damage was originating from the ends of the bars that were corroded. The middle bar caused a vertical crack through the centre of the slab. It often reached the top face of the slab. The outside bars caused cracks that tended to run from the surface below the bars, through the bars and then they turned to reach the outside face of the concrete. If they extended through this entire section, they caused spalling of the concrete section. The extent of this cracking was only slightly longer than the length of bar that was corroded. There was a definite centre section that remained undamaged by the corrosion attack. A diagram of the typical crack patterns developed as well as common locations of spalling are included as Fig. 4-3.

\section{Figure 4-3: Typical Crack Locations and Areas of Spalling}



Along with the damage caused by cracking, there were also rust stains forming on the surfaces of the slabs. This staining was mostly concentrated at the area of the cracks. Often, rust 'stalactites' were formed on the bottom of the slab. These were quite easily damaged by the 
moving of the slabs in preparation for testing, but were seen to consist of a soft, flaky material that was gooey to the touch.

After testing, the condition of the bars in the centre portion covered by pipe insulation was determined. The steel bars were uncorroded as it was assumed indicating that the assumptions were justified.

\subsubsection{Normal Mix Test Results}

In this section, there were two sets of results. These were due to the two different concrete mixtures used for the slabs, the Normal Mix and Silica Fume Mix. These slabs contained steel that was anchored at the ends, but debonded in the middle. The end regions were then corroded to various degrees, while the centre, test region was uncorroded.

During testing, a structural crack developed. Unlike a normal, non-debonded slab where a diffuse crack pattern with a variety of flexural cracks would have developed, there was only one major crack. This is as the centre portion of the steel was unbonded and once the concrete cracks in one location it is then able to relax over the entire unbonded region and no tension is able to be developed in the concrete. The entire tensile strain developed in the steel is relieved at the crack location. The location of this crack was near the centre of the slab in the constant moment region as it is the location of maximum stress and thus first cracking.

The moment-curvature results of the Normal Series are contained here as Fig. 4-4. For all levels of corrosion, there was a very ductile response. The ultimate strengths of the slabs did change as they were corroded, however. It can be seen that the three lower levels of corrosion; 2 $\%, 5 \%$ and $8 \%$; were all weaker than the control specimen. Comparing the strengths between these samples, however, does not show any additional trend. They all had similar ultimate capacities. The moment-curvature graphs of the slabs corroded to five and eight percent have a point of interest. In these graphs, there can be seen definite indications of slip. That is, there are areas where, with little change in curvature, there are significant reductions in the moment capacity of the slab. This can be interpreted as where the stress transfer between the steel and the concrete is suddenly reduced so that the stress in the steel decreases. This leads to less moment being required to maintain the same level of curvature. In these cases some residual bond capacity available so that the slab was still able to accept load; the moment capacity did not 
decrease to zero. In the slab that was corroded to five percent, with increasing curvature, the moment taken reached higher levels than that which lead to the first slip.

\section{Figure 4-4: Series 2 - Normal Mix Results}

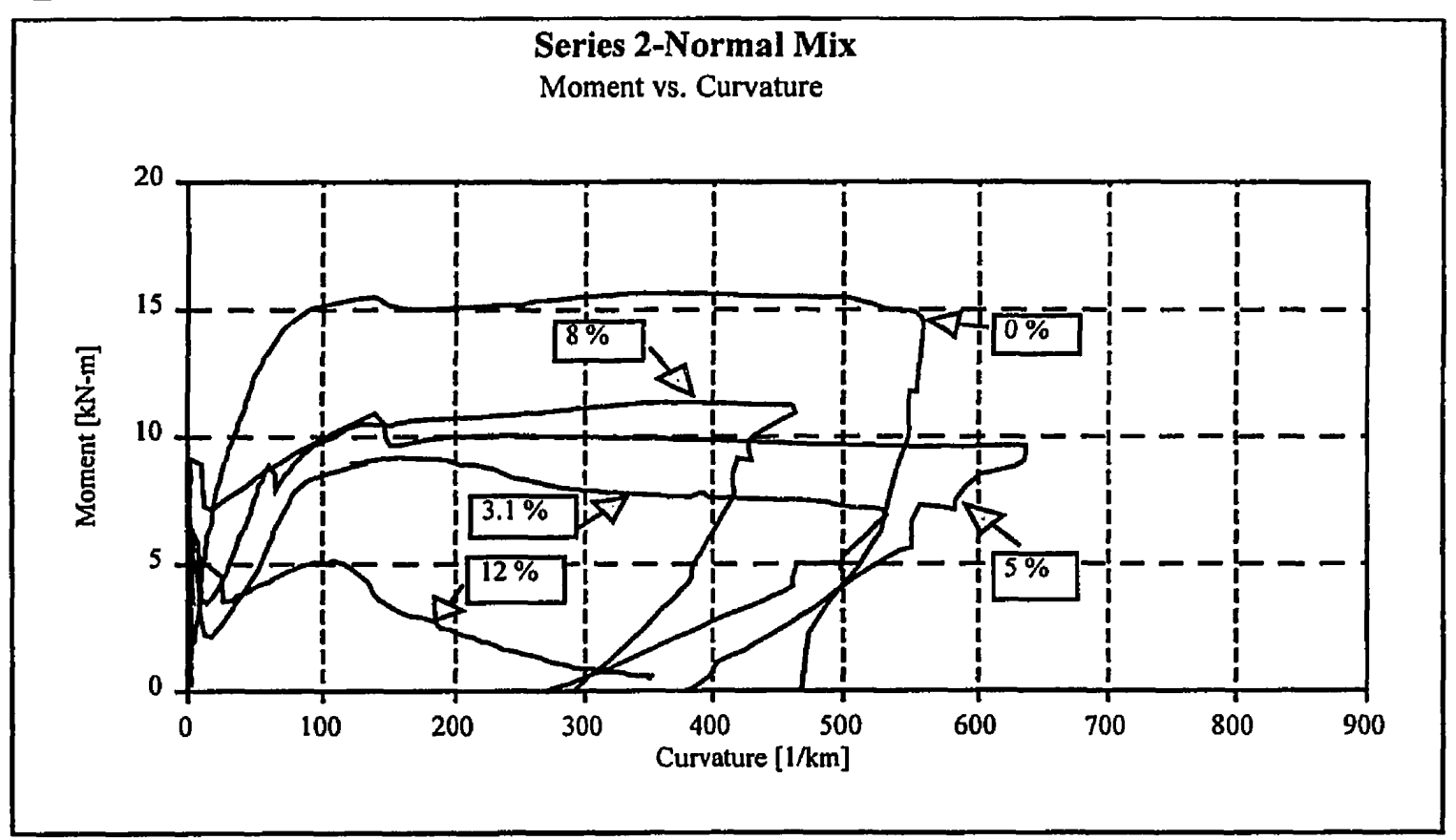

Figure 4-5: Series 2 - Silica Fume Mix Results

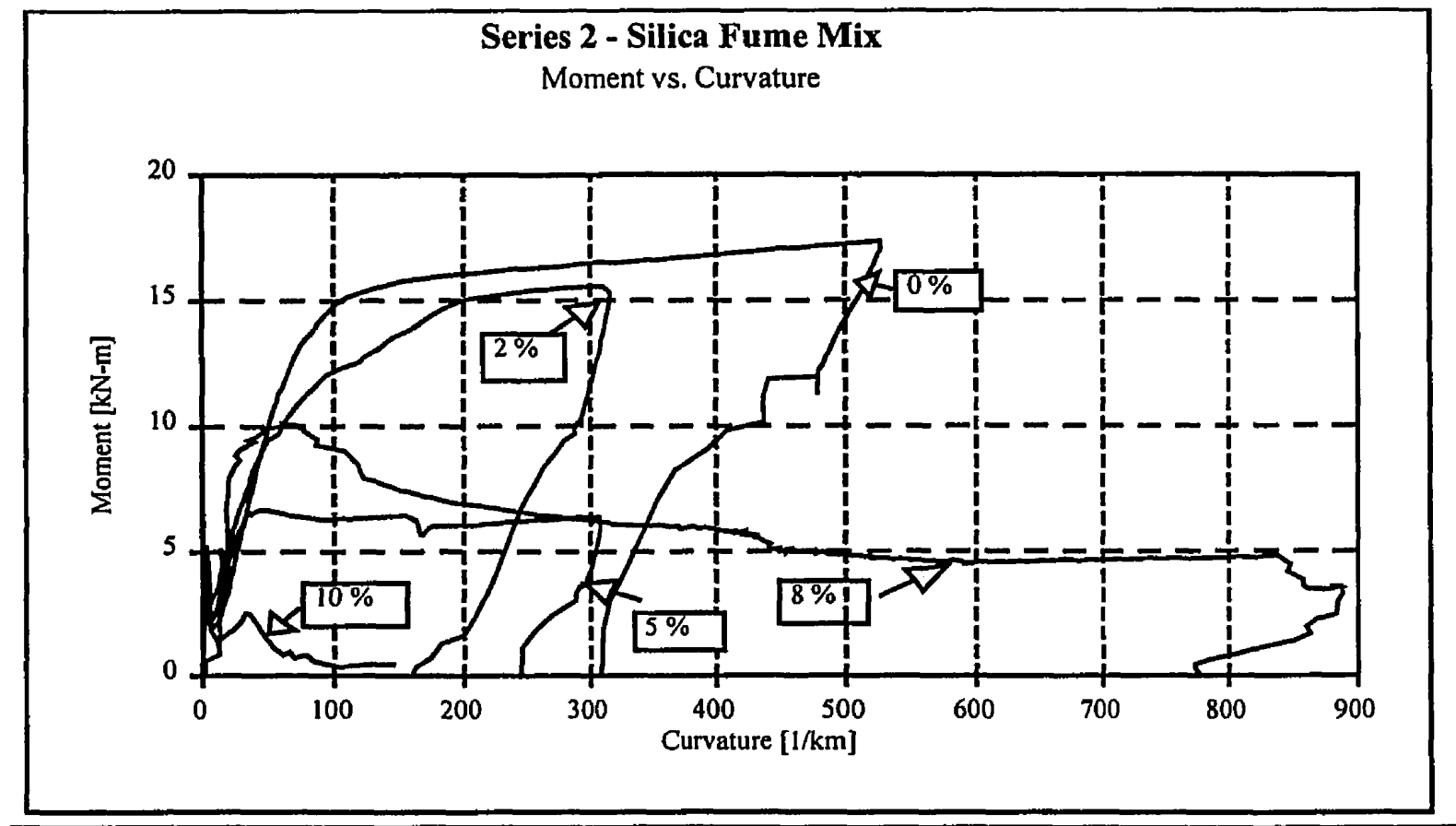


The slab that was corroded to the highest level, $12 \%$, behaved differently than the other, Normal Mix, corroded slabs. After the slab cracked, the moment capacity reduced dramatically. It showed a great increase in curvature before it accepted more load, that is, when the steel became active. This indicates the greater slip that must be required to activate bond forces. The moment resistance of the slab then increased for some increasing curvature. The moment capacity reached levels similar to that which was reached before the beam cracked, but no higher. It did exhibit a significantly more ductile response that an unreinforced slab that would have had similar capacity.

\subsubsection{Silica Fume Mix Test Results}

The results of the testing of the slabs made with the Silica Fume Mix are contained in Figure 4-5. These graphs plot measured moment-curvature relationships for the specimens. For this set of data, due to problems with the data acquisition, the curvature was not calculated the same way for all five slabs. For the slabs that were corroded to $0 \%, 2 \%$ and $8 \%$ steel section loss, there were no difficulties. Their curvatures were calculated using the curvature-meter as usual. For the slabs corroded to $5 \%$ and $10 \%$, the data from the LVDT's that are part of the curvature-meter were not recorded, so the curvature is based only upon the midpoint deflection. A single crack was developed due to structural testing, just as for the set of slabs cast with the Normal concrete mix.

The control specimen for this set of tests behaved quite predictably, just as for the normal series. It exhibited the same stiff, initial response until cracking, the loss of stiffness postcracking and the yield plateau. The difference between this and the control for the normal series is that it reached a higher load before yielding. This is because the Silica Fume concrete is stronger than the Normal concrete.

For the Silica Fume Mix slabs that were corroded to $2 \%$ and $5 \%$, a normal response is achieved in shape. There is a post-cracking increase in load and then a 'yield plateau' where there is a generally constant moment response for ever increasing curvature. These plateaus do not exhibit the gradually increasing load that the control specimen required and the start of this change in response is at a lower load level. Also of interest is a 'jog' in the $5 \%$ corroded 
specimen in the yield plateau that may indicate some slip in the bars and an adjustment in the response.

The slabs that are corroded to $8 \%$ and $10 \%$ have a different response. After cracking, there is an increase in strength, though for the $10 \%$ slab this does not reach the cracking load. After the load peaks, with increasing curvature there is a decrease in load required. This is exhibited as a negative slope of the post-peak region of the load - response curve. There are also numerous occasions of sudden decrease in moment with little change in curvature. This would indicate occasions of slip of the bars.

\subsubsection{General Discussion of Test Results}

From these, it is obvious that corrosion does have some influence on bond. Further details and evaluation of this influence is discussed in the Section 4.3.3. However, some general trends can be inferred from the moment - curvature diagrams. First, as has been pointed out, there is still a large ductile response. This is encouraging as one of the aims in design is to ensure ductility. The idea is to give adequate warning of impending failure to users of a structure.

Less encouraging is the relative magnitude of the cracking loads and the ultimate load, at least at the higher levels of corrosion achieved. For both sets of tests, the slabs that were corroded to the greatest amount, approximately 10 to $12 \%$, did not regain their cracking strength in the post-cracking region. Thus if these were structural members that had not cracked due to load but were corroded to this level, and then suddenly loaded past their cracking load, they would then suddenly fail. In these cases the level of corrosion when this dangerous response appeared was approximately $10 \%$, but this would be a function of the cracking strength of the concrete.

Thus it can be seen that at low levels of corrosion, while there is some possible loss of bond strength, the nature of the response will provide some warning of impending failure. However, at higher levels of corrosion this warning is lost and as such should be evaluated differently and more conservatively when considering structural integrity. 


\subsubsection{A Discussion of Bond}

Experimental Results

After testing, the moment and curvature information from Series 2 was taken and used to determine bond strengths. This was done for all the post-cracking points on each response curve using a program written for that purpose. The details of that program are contained in Appendix G. The maximum value of the bond at each corrosion level was then taken and is plotted for both the Normal Mix and Silica Fume Mix. This plot can be seen as Fig. 4-6.

For each set of tests, the linear regression of the bond strength [U,MPa] versus the percentage of steel area lost due to corrosion $[x, \%$ by mass] was determined. This gave the equations and $r^{2}$ values of:

$$
\begin{array}{lll}
\text { Normal Mix: } & \mathrm{U}=4.71-0.250 \mathrm{x}, & \mathrm{r}^{2}=0.6800 \\
\text { Silica Fume Mix: } & \mathrm{U}=5.27-0.361 \mathrm{x}, & \mathrm{r}^{2}=0.9112
\end{array}
$$

Figure 4-6: Bond Strength as a Function of Corrosion Level

\section{Bond Strength as a Function of Corrosion Level}

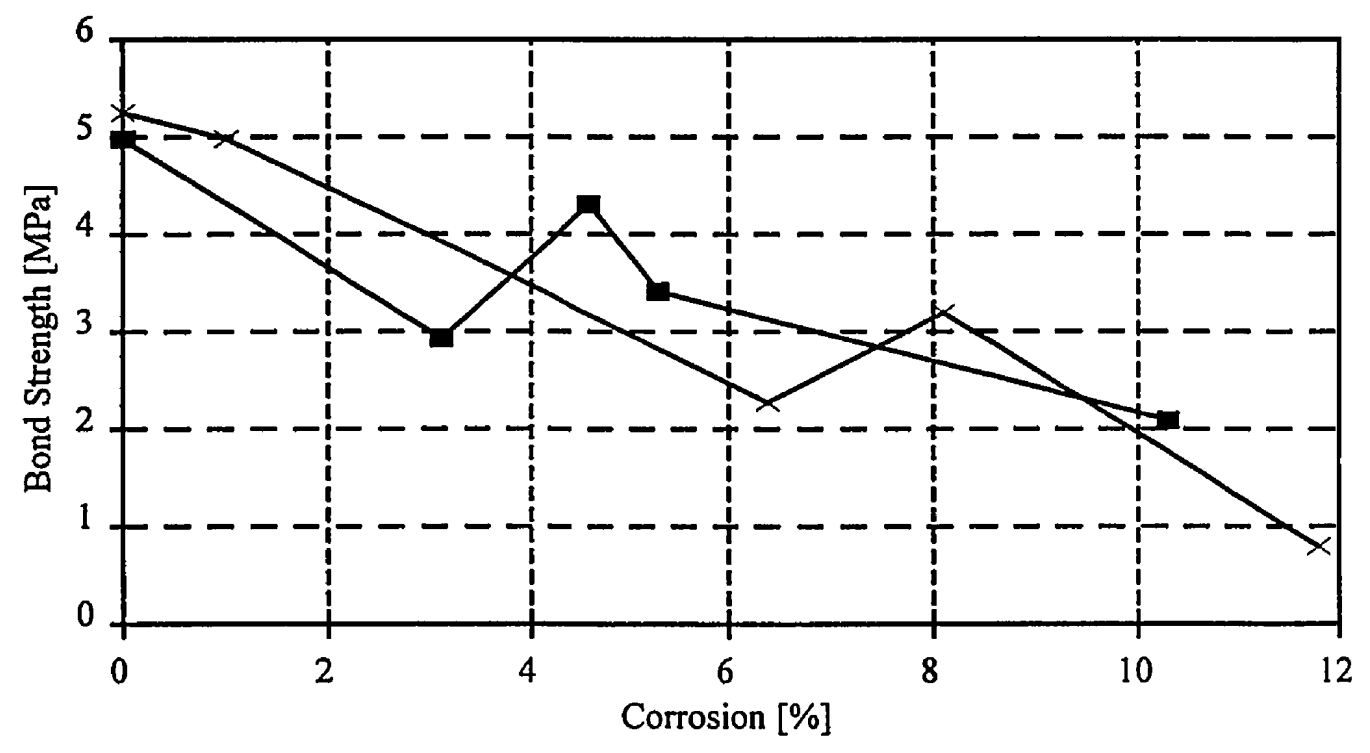

$\rightarrow$ Normal $\rightarrow$ Silica Fume

The Silica Fume Mix showed a well-correlated linear relationship, while the results for the Normal Mix were not as clear. The Normal Mix did have a general trend of decreasing bond 
strength with increasing corrosion levels. The explanation for this lack of clarity in the Normal Mix results may come from the techniques that were used to connect the rebar to the power supply. Out of the four corroded specimens for the Normal Mix results, three were corroded using connection type (a); while for the Silica Fume series three were connected using connection type (b). A discussed previously (Section 3.4.2), connection type (b) gave superior control over the corrosion process and made the corrosion more even between the bars. It was also easier to gauge the amount of corrosion that had occurred. This may explain the difference in correlation coefficients between the two sets of results.

However, it is seen that there is a relationship between the amount of corrosion and the bond strength that exists. It also appears to be linear with a decreasing slope. This agrees with what has been reported before in the literature, for example by Rodriguez, et al. ${ }^{4-5}$ As discussed in Chapter 2 - Literature Review, they have developed a linear equation relating bond strength and depth of corrosion penetration based upon a series of tests of bars embedded in cubes.

The loss of bond with increasing corrosion levels is as expected. The corrosion will first damage the concrete due to the expansive pressures it exerts. This will lead to cracking and it is easy to see how this may cause weakening of the anchorage of the reinforcing steel. In addition, the corrosion causes the surface properties of the reinforcing steel to change. It creates a weak layer of corrosion product that will break off under relatively low stress levels. The may lead to lubrication and the prevention of both the development of friction and concrete-steel interlock. At high levels of corrosion, which were probably not reached here, there is also the possibility that the effect of lugs on the reinforcing bars may be eliminated. This would occur if the entire lug was corroded and then would break off at relatively low stresses. 


\section{$\underline{\text { References }}$}

4-1 A.M. Neville, Properties of Concrete, $3^{\text {rd }}$ Ed., Longman Scientific and Technical England, 1981 , pg. 220

4-2 A.M. Neville, Properties of Concrete, $3^{\text {rd }}$ Ed., Longman Scientific and Technical England, 1981, pg. 210

4-3 Canadian Standards Association Parking Structures-Structural Design, CSA/S413-94, Rexdale, Ont., 1994, Cl. 7.3

${ }^{4-4}$ P. Schiessl, ed. Corrosion of Steel in Concrete, Chapman and Hall, Ltd. c1988, pg. 61

4-5 J. Rodriguez, L. M. Ortega, J. Casal and J. M. Diez, "Assessing Structural Conditions of Concrete Structures with Corroded Reinforcement" Concrete in the Service of Mankind: Concrete Repair, Rehabilitation and Protection, First Ed. E \& FN Spon London, 1996, pg. $65-78$ 


\subsection{Series 3 Evaluation}

This section discusses the slab designated as Series 3. The purpose of this slab was not primarily to determine any additional information, but to evaluate what has gone before. Thus, a standard slab was cast from the Normal Mix and corroded to a predetermined level. This level was selected as $10 \%$. This level was chosen to test the more critical values of the possibilities. Before testing, the information from previous parts of this experimental program was used to predict the capacity, in combination with the work done by J. Phillips. ${ }^{5-1}$ How this evaluation was performed and the results of the experimental test are discussed here.

\subsection{The Prediction}

Two elements were considered explicitly when predicting the failure load and the mode of failure for the slab. These were bond pullout effects and the effect of steel section loss. Shear failure was not considered explicitly as the specimen type used was identical to the ones previously used, where shear was not critical. Corrosion will not affect the shear capacity where there are no stirrups, thus shear capacity need not be checked at this stage.

The corrosion level was determined using the techniques used previously, namely by integrating the current that has passed and by using a corrosion coupon. The integrated current suggested a corrosion level of $18 \%$, while the corrosion coupon estimated the corrosion level at $11 \%$. These two values were average to give a representative corrosion level of $14.5 \%$. This value was used in the work that follows.

To evaluate the beam, a failure envelope was constructed along the length of the beam. This failure envelope consists of two portions. The first is if the beam fails due to steel section loss. This is a constant value along the length of the beam. The second portion is the limit that will cause an anchorage failure. This limit will vary along the length of the beam depending upon the available length for anchorage. The section property evaluation was done considering only the remaining, uncorroded steel, as indicated by J. Phillips. ${ }^{5-2}$ The development length calculation was based upon a bond strength of $1.09 \mathrm{MPa}$, using the formula developed in this report for the Normal Mix. More explicit calculations are included as Appendix $\mathrm{H}$. 
After the failure envelope was constructed, the moment diagram for various loads was determined until these two curves intersected. The lowest load at which this occurs is the failure load. Depending upon the location of this first intersection, the failure mode can be determined. If this intersection is in the part of the failure envelope where bond governs, then bond failure will be the failure mode. If it is in the section where steel section loss governs, then the slab will fail by yielding.

The failure envelope was constructed for a corrosion level of $14.5 \%$, the actual corrosion level determined for the slab tested. Trial and error determined that the lowest load that would cause the curves to intersect is $28.5 \mathrm{kN}$. This corresponds to a maximum moment of $7.13 \mathrm{kN}-\mathrm{m}$ in the centre region. The slab would fail due to a bond failure. A diagram of the failure envelope and the moment diagram at failure is contained herein as Fig. 5-1. It is noteworthy that the capacity envelope does not contain a horizontal portion. That is there is no portion where there is sufficient anchorage to allow the yield strength to be developed, even though it is reduced by the amount of the steel that has been corroded.

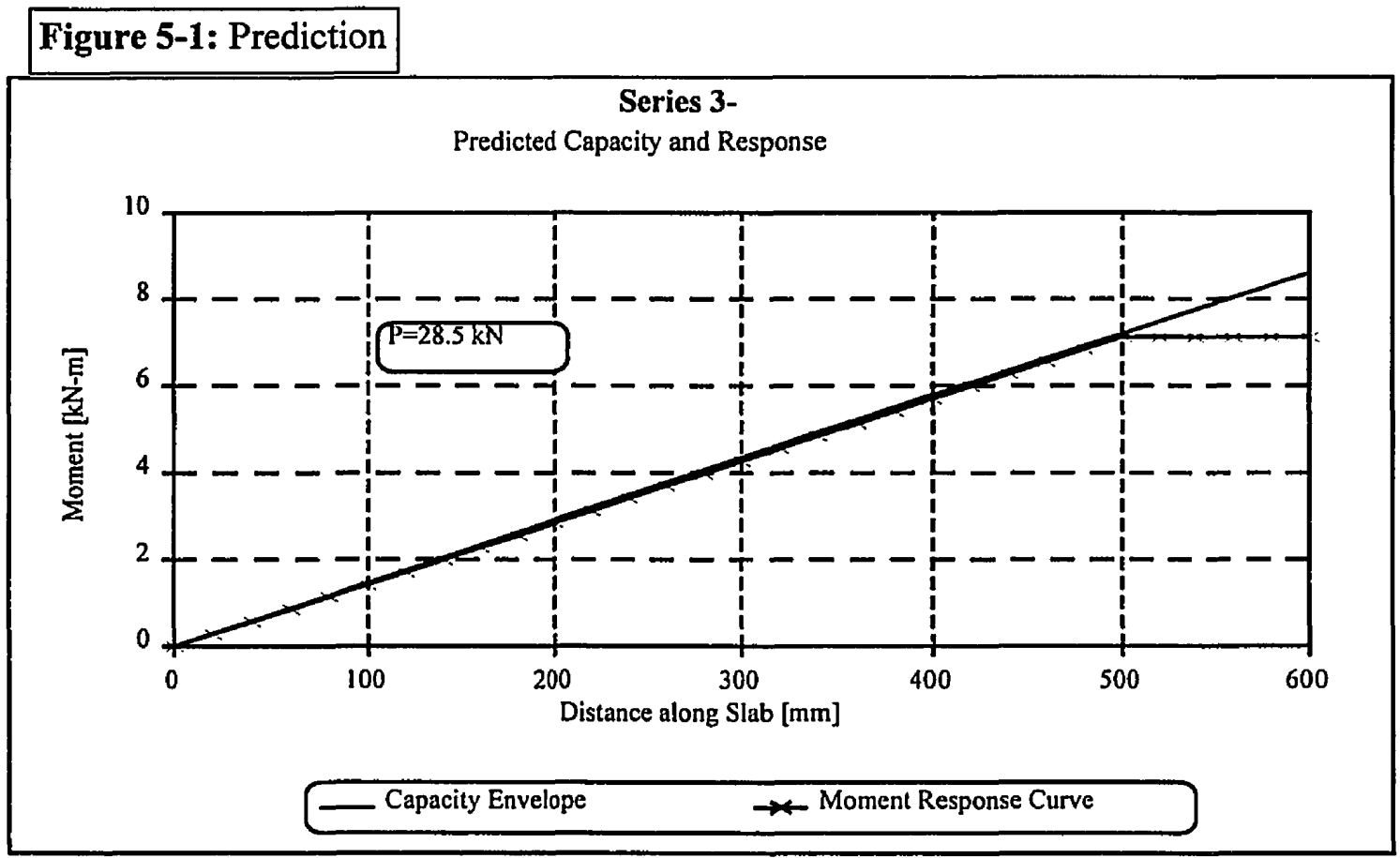




\subsection{The Experimental Result}

The results of the structural testing are discussed in this section along with the condition of the slab before testing. What is not discussed is the results of the material tests performed. This is as the same concrete mix design that was previously designated as the Normal mix was used. The material test results are a part of the same statistical family that the previous Normal mix results were and were discussed in Chapter 4 with them. The results of this specific set of tests are included in Appendix E.

\subsubsection{Condition of Slab Prior to Testing}

The test slab had cracking due to corrosion before it was tested. Unlike the slabs from Series 2 that had cracking along the ends and sides, with some reaching to the top face, the cracking in this slab was only visible along the bottom face of the slab. This cracking was primarily in the longitudinal direction and ran the entire length of the slab. There were some minor lateral cracks, however.

There was extensive rust staining along the bottom of the slab as well. This included the formation of the rust 'stalactites' and the deposition of salt ridges along the outside of slab. None of this was visible on the portions on the slab that were not immersed in the salt solution, or were farther from the steel bars.

\subsubsection{Structural Testing Results}

This specimen was tested in flexure as the other slabs. The moment - curvature response is shown in Figure 5-2. Also shown is the moment - curvature response of the Control specimen for Series 1 . It is identical to the slab tested here except it was uncorroded.

The initial portions of both curves are similar (O-A) as for both slabs this is before cracking and as such the condition of the steel does not effect the response. In the control slab, there is a pre-steel yielding portion of the curve that is more flexible (A-B) and this is initially mirrored by the corroded specimen (A-D). The effect of corrosion then begins to be demonstrated. At $D$, there is evidence of slip occurring and the response is then less stiff than the control (D-E). The load is still increasing, but a greater increase in curvature is required to develop the same increase in supported moment than for the control. At $E$, the corroded slab exhibits a sudden loss in moment with no change in curvature. This is another point of slip of 
the bars. In this case, the moment is then regained with little change in curvature and the load continues to increase until point $F$. The rate of this increase in load is similar to that which was experienced before the slip at point $\mathrm{E}$. After $\mathrm{F}$, their is a dramatic change in the shape of the response curve. The load decreases with increasing curvature. (F-G) The load decreases to a point where it is approximately half of the peak load and then remains steady with increasing curvature. The load remained constant until the slab was unloaded at point $\mathrm{G}$.

Figure 5-2: Series 3 Experimental Results

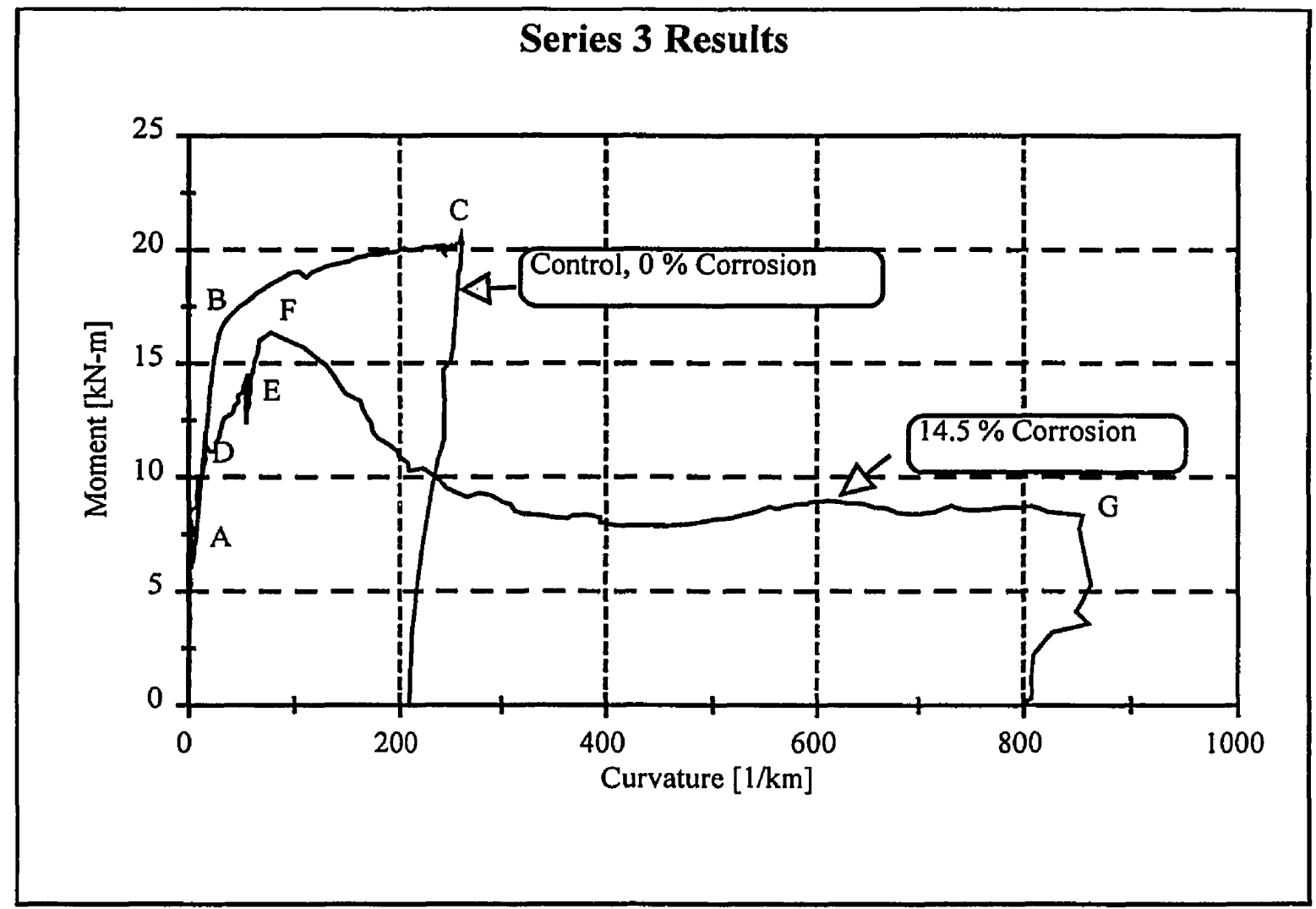

The corroded specimen still exhibited a large ductile response. In Figure 5-2, it appears that the ductility of the corroded response is greater than that of the control specimen. This is not the case. Between these two tests, the range of the curvature-meter LVDT's was changed. The slabs were more flexible than was expected before testing, so a greater range was required for the data. The control test was ended when the curvature-meter reached the end of its range and this gives the appearance of less ductility. The control specimen would still be capable of exhibiting 
greater ductility than that showed here, at least as much as that demonstrated by the corroded specimen.

The ductile response is unstable for the corroded specimen. It exhibits a negative postpeak modulus and if this situation occurred in practice then rapid failure would have occurred. In a real structure, if the load reached the point $F$, then the load would not be reduced so the additional response would not be exhibited. The moment at any point on the curve is the maximum capacity at that curvature but this would be insufficient to support the load from the previous point. This would lead to increasing curvature with an inability to support the load until failure is reached. This is much less preferable than the uncorroded response of increasing capacity with increasing curvature.

\subsection{Comparing the Prediction and the Response}

There were two elements to the prediction; the load at failure and the mode of failure. The predicted load at failure was $28.5 \mathrm{kN}$ and it was predicted to fail in bond. The slab failed at a moment of $16.35 \mathrm{kN}-\mathrm{m}$, which is equivalent to a load of $65.4 \mathrm{kN}$. It did fail in bond. This can be seen due to the shape of the moment - curvature response curve as discussed in the previous section.

The is a large difference between the predicted failure load and the actual failure load. As the mode of failure was as predicted, the inaccuracies lie in the predicted bond strength. Using the formula developed previously, the predicted bond strength was $1.09 \mathrm{MPa}$. As the actual failure load was much higher than that predicted, the actual maximum bond strength must be higher. The reason for this is that the corrosion level at which the bond strength was to be predicted was higher than the maximum value used to determine the formula. The maximum experimental value used to develop the relationship was $10.5 \%$. Thus, to apply this relationship to the level of $14.5 \%$ is an extrapolation. The other, more important, reason is the quality of the relationship developed. While for the Silica Fume mix the relationship had a good correlation coefficient of 0.911 , for the Normal mix used in this technique the correlation was only 0.680 . Thus it is to be expected that the values predicted would be less accurate.

As a further test, the capacity based upon the results reported by Rodriguez, et al..$^{5-3}$ was calculated. This was done by determining the depth of penetration based upon uniform corrosion 
as the authors did in their paper. The depth of penetration was calculated as $0.416 \mathrm{~mm}$ and this resulted in a bond strength of $1.267 \mathrm{MPa}$. This value was then used in the identical technique to calculate the capacity of the slab. This predicts a capacity of $33.5 \mathrm{kN}$. A diagram of the moment capacity envelope and bending moment diagram predicted at failure is included as Figure 5-3. While this is a slightly better prediction that that which came from the work done here, it is still much lower than the actual, experimental value.

Finally, the experimentally determined capacity was used to calculate the bond strength truly developed, Fig. 5-4. This was done by using the reverse procedure used to predict the capacity. That is, the bending moment diagram at failure was plotted and the moment capacity envelope was plotted for a number of bond strengths until the two curves intersected, giving failure. This resulted in a bond strength of $2.55 \mathrm{MPa}$. For this calculation, however, the maximum capacity based upon steel section loss had to be ignored. This was as the capacity based on that prediction was only $13.82 \mathrm{kN}-\mathrm{m}$, which was exceeded experimentally even though the slab failed in bond. This value for the bond strength determined experimentally is much higher than that predicted from the relationships developed earlier, as much as two and a half times.

The bond strengths as predicted by this equation were conservative for this situation and the factor of error was such that it would be considered an appropriate level for the factor of safety. This same degree of error cannot be assumed to always occur, however, and these equations should not be used assuming that this will be the case. A more appropriate technique would be to develop an expression that would predict the true mean value of the bond strength and apply a ration analysis to determine appropriate levels of safety. 
Figure 5-3: Prediction Based on Rodriguez, et al.

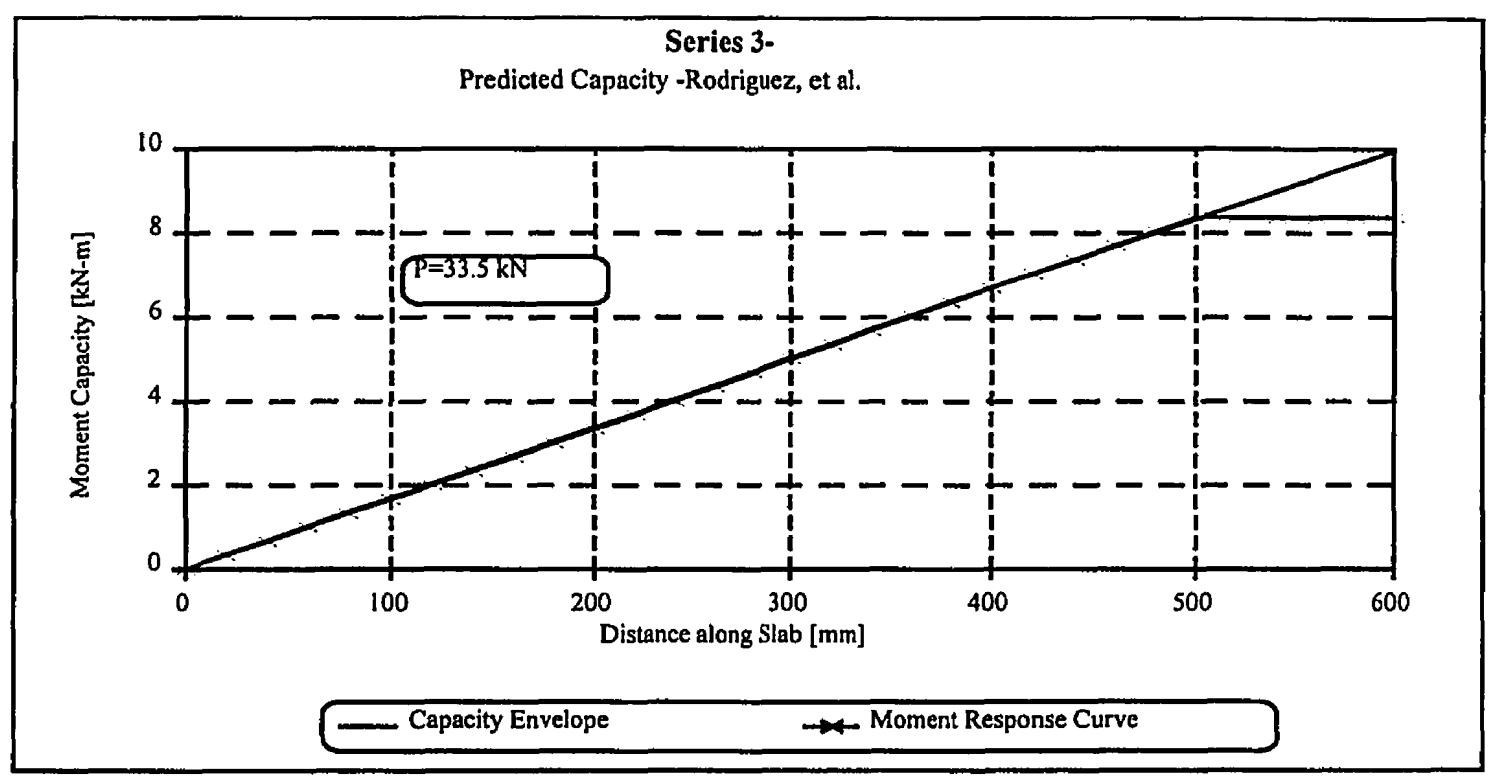

Figure 5-4: Presumed Actual Response

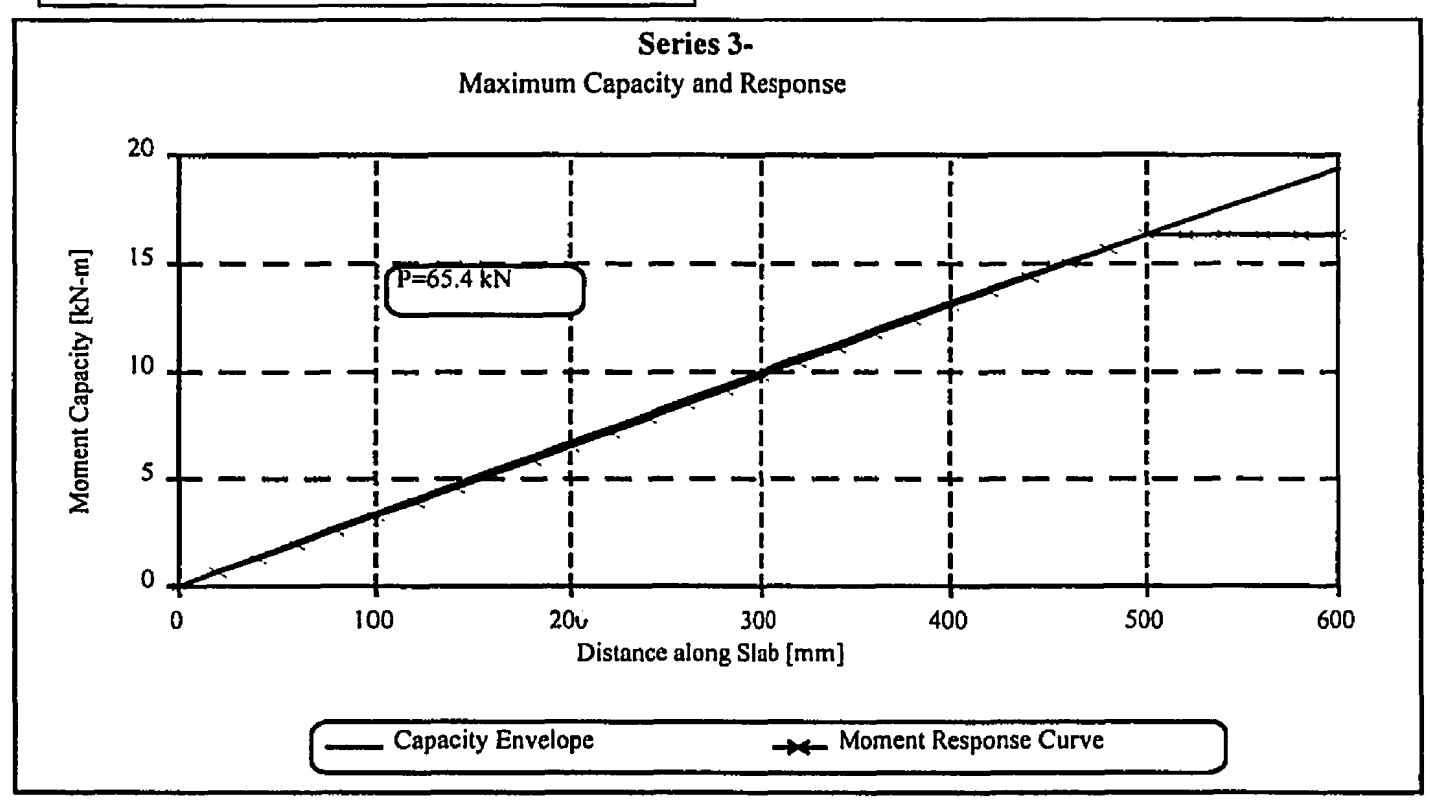




\section{References}

${ }^{5-1}$ J. Phillips, The Effect of Corrosion on the Structural Performance of New and Repaired OneWay Slabs, Ph.D. Thesis, University of Toronto, c1993, pg. 143

${ }^{5-2}$ J. Phillips, The Effect of Corrosion on the Structural Performance of New and Repaired OneWay Slabs, Ph.D. Thesis, University of Toronto, c1993, pg. 143

5-3J. Rodriguez, L. M. Ortega, J. Casal and J. M. Diez, "Assessing Structural Conditions of Concrete Structures with Corroded Reinforcement" Concrete in the Service of Mankind: Concrete Repair, Rehabilitation and Protection, First Ed. E \& FN Spon London, 1996, pg. 65-78 


\subsection{Conclusions and Recommendations}

First, the conclusions that can be drawn for this series of experiments are presented. Then recommendations for further work are discussed.

\subsection{Conclusions}

1. The apparent corrosion level for the specimens varied depending upon the technique used to measure it; using corrosion coupons or by integrating the corrosion current and applying Faraday's Law. This made it difficult to determine an actual corrosion level for the specimens that would represent the situation produced.

2. The corrosion pattern varied depending upon the technique used to connect the rebar to the power supply. One technique caused different corrosion amounts to occur in the different bars, as determined by visual inspection. The other technique caused more uniform corrosion between the bars.

3. The corrosion current was highly variable both between specimens and at different times in one slab even though the applied voltage remained constant.

4. A bar with approximately one quarter of its perimeter debonded from the concrete over its entire length has the bond strength to develop similar capacity as a standard bar, but will not be as ductile. If half of the bar's perimeter is debonded, though, it will have zero bond strength. The specimen will then act as if it were unreinforced.

5. Cracking and spalling of the concrete in the end regions was exhibited at minimal corrosion levels, e.g. 2-3\%, for the centre debonded and uncorroded specimens.

6. Corrosion damage does not appear to reduce the ductility of reinforced concrete members.

7. Bond strength reduces linearly with increasing corrosion levels, and equations defining this relationship with a variety of success were developed for the concrete tested herein.

8. The relationships developed in this thesis for bond and the method proposed by J. Phillips to deal with section capacity were unable to successfully predict the capacity of a trial slab 
corroded to $14.5 \%$ section loss. For this slab, the ultimate capacity was greater than that predicted by the work of J. Phillips considering section loss, though the slab appeared to fail in bond. The predicted capacity based upon bond considerations was less than that predicted by considering section effects. The problem was thought to lie either in the poor fit of the bond prediction expression for the concrete used or due to the difficulty in determining the representative corrosion level. Difficulty may have also arisen as the development length was longer for the Series 3 slab, creating the potential for a different distribution of bond stresses possibly altering the maximum average stress that can be developed. The cracking pattern was also different which may change the behaviour and relationships of corrosion and bond.

\subsection{Recommendations}

1. In Series 1 , where the effect of concrete spalling was simulated, there was a large change in the response between the level of one quarter of the bars' perimeter debonded and one half. More information should be gathered on this changing influence by examining different portions of bars perimeter debonding, for example $30 \%, 35 \%, 40 \%, 45 \%$. This would require the use of a larger bar so that it is reasonably possible use smaller increments of the proportion of the bar debonded.

2. One of the main difficulties in this work was controlling the amount of corrosion that was developed and characterizing it. This difficulty was partially overcome by change the technique used to connect the rebar to the power supply. This was not a complete remedy, however, and better results may have been obtained if, instead of using three bars, a single bar was used. This would reduce the problems of differential corrosion.

3. The specimens in this study were corroded using an applied voltage. This voltage created a current that was larger than any that would be encountered in the real world. While it is necessary to speed up the corrosion process to study it experimentally, it is suspected that this large current may have effects on the structure of the corrosion products. Instead of being deposited on or near the rebar, the corrosion products may be transported into the body of the concrete or into the salt solution. This would then obviously change the expansive pressures that are exerted as well as the surface characteristics of the reinforcing steel. This may not be 
as important when considering section properties, as done by J. Phillips, but would be more important when considering bond influences. It is recommended that a series of tests be performed that would reduce the acceleration of the corrosion process and mimic better the natural situation to evaluate the possibility of this influence. This could possibly be achieved by wet/dry cycling the specimens to cause corrosion without an applied current. 


\section{Bibliography}

"Suggested Development, Splice and Standard Hook Provisions for Deformed Bars in Tension"(ACI 408.1R-90) ACI Manual of Concrete Practice 1995, Part 3, ACI, Detroit

Abdullah A. Almusallam, Ahmad S. Al-Gahtani, Abdur Rauf Aziz, Fahd H. Dakhil and Rasheeduzzafar, "Effect of Reinforcement Corrosion on Flexural Behaviour of Concrete Slabs", Journal of Materials in Civil Engineering, v. 8 n. 3, August 1996, pg. 123-7

G.J. Al-Sulaimani, M. Kaleemullah, I. A. Basunbul, and Rasheeduzzafar, "Influence of Corrosion and Cracking on Bond Behaviour and Strength of Reinforced Concrete Members", ACI Structural Journal, v. 87 n. 2, Mar.-Apr. 1990, pg. 220-31

"Standard Test Method for Compressive Strength of Cylindrical Concrete Specimens" (ASTM C39-93a) 1994 Annual Book of ASTM Standards V 04.02, ASTM, Philadelphia, pg. 1721

"Standard Test Method for Comparing Concretes on the Basis of Bond Developed with Reinforcing Steel" (ASTM C234-91a) 1994 Annual Book of ASTM Standards, V 04.02, ASTM, Philadelphia, pg.148-52

"Standard Test Method for Half-Cell Potentials of Uncoated Reinforcing Steel in Concrete" (ASTM C876-91) 1994 Annual Book of ASTM Standards V 04.02, ASTM, Philadelphia, pg. $432-7$

"Standard Test Method for Electrical Indication of Chloride's Ability to Resist Chloride" (ASTM C1202-94) 1994 Annual Book of ASTM Standards V 04.02, ASTM, Philadelphia, pg. $620-5$

"Standard Practice for Preparing, Cleaning and Evaluating Corrosion Test Specimens" (ASTM G1-90) 1994 Annual Book of ASTM Standards V 03.02, Philadelphia, pg. 25-31

J. Cairns and K. Jones, "An Evaluation of the Bond-Splitting Action of Ribbed Bars", $A C I$ Materials Journal, v. 93 n.1, Jan.-Feb. 1996, pg. 10-19

J. Cairns and K. Jones, "The Splitting Forces Generated By Bond", Magazine of Concrete Research, v. 47 n. 171, 1995, pg. 153-65

J. Cairns and R. Bin Abdullah, "Bond Strength of Black and Epoxy-Coated Reinforcement- A Theoretical Approach", ACI Materials Journal, v. 93 n 4, July-August 1996, pg. $362-9$

Canadian Standards Association Design of Concrete Structures for Buildings CAN/A23.3-M84 Rexdale, Ont., 1984 
Canadian Standards Association Parking Structures-Structural Design, CSA/S413-94, Rexdale, Ont., 1994

Corrosion Damage to Concrete Structures in Western Asia, United Nations Centre for Human Settlements (Habitat), Nairobi, 1990

ENV 1992 - Eurocode 2

K. Leet, Reinforced Concrete Design, $2^{\text {nd }}$ Ed. McGraw-Hill Inc., Toronto, 1996

N.P. Mailvaganan, Repair and Protection of Concrete Structures, CRC Press c1992

M. Maslehuddin, et al. "Effect of Rusting of Reinforcing Steel on Its Mechanical Properties and Bond with Concrete", ACI Materials Journal, v. 87 n.5, Sept.- Oct. 1990, pg. 496-502

Edward G. Nawy Reinforced Concrete: A Fundamental Approach, 3rd Ed. Prentice-Hall Canada, Inc. Toronto, c1996

A.M. Neville, Properties of Concrete, $3^{\text {rd }}$ Ed., Longman Scientific and Technical England, c1981

P. Pullar-Strecker, Corrosion Damaged Concrete: Assessment and Repair, Anchor Brendon Ltd., Tiptree Essex, England, c1987

J. Phillips, The Effect of Corrosion on the Structural Performance of New and Repaired OneWay Slabs, Ph.D. Thesis, University of Toronto, c1993

Report of the Advisory Committee on the Deterioration, Repair and Maintenance of Parking Garages, Ministry of Housing, Ontario Buildings Branch, July 1988

J. Rodriguez, L. M. Ortega, J. Casal and J. M. Diez, "Assessing Structural Conditions of Concrete Structures with Corroded Reinforcement" Concrete in the Service of Mankind: Concrete Repair, Rehabilitation and Protection, First Ed. E \& FN Spon London, 1996

P. Schiessl, ed. Corrosion of Steel in Concrete, Chapman and Hall, Ltd. c1988

A. Smith, E. Hinton and R. Lewis, Civil Engineering Systems: Analysis and Design $1^{\text {st }}$ ed., John Wiley and Sons, Toronto, c1983

S. Ting and A. Nowak, "Effect of Reinforcing Steel Area Loss on Flexural Behaviour of Reinforced Concrete Beams", ACI Structural Journal, v. 88 n. 3, May-June 1991, pg. 309-14

R. A. Treece, and J. O. Jirsa, "Bond Strength of Epoxy Coated Reinforcing Bars", ACI Materials Journal, v86 n2 March-April 1989 p. 167-174 
Y. Yuan and M. Marosszeky, "Analysis of Corroded Reinforced Concrete Sections for Repair", Journal of Structural Engineering, v. 117 n. 7, July 1991, pg. 2018-34 


\section{Steel Stress-Strain Curves}

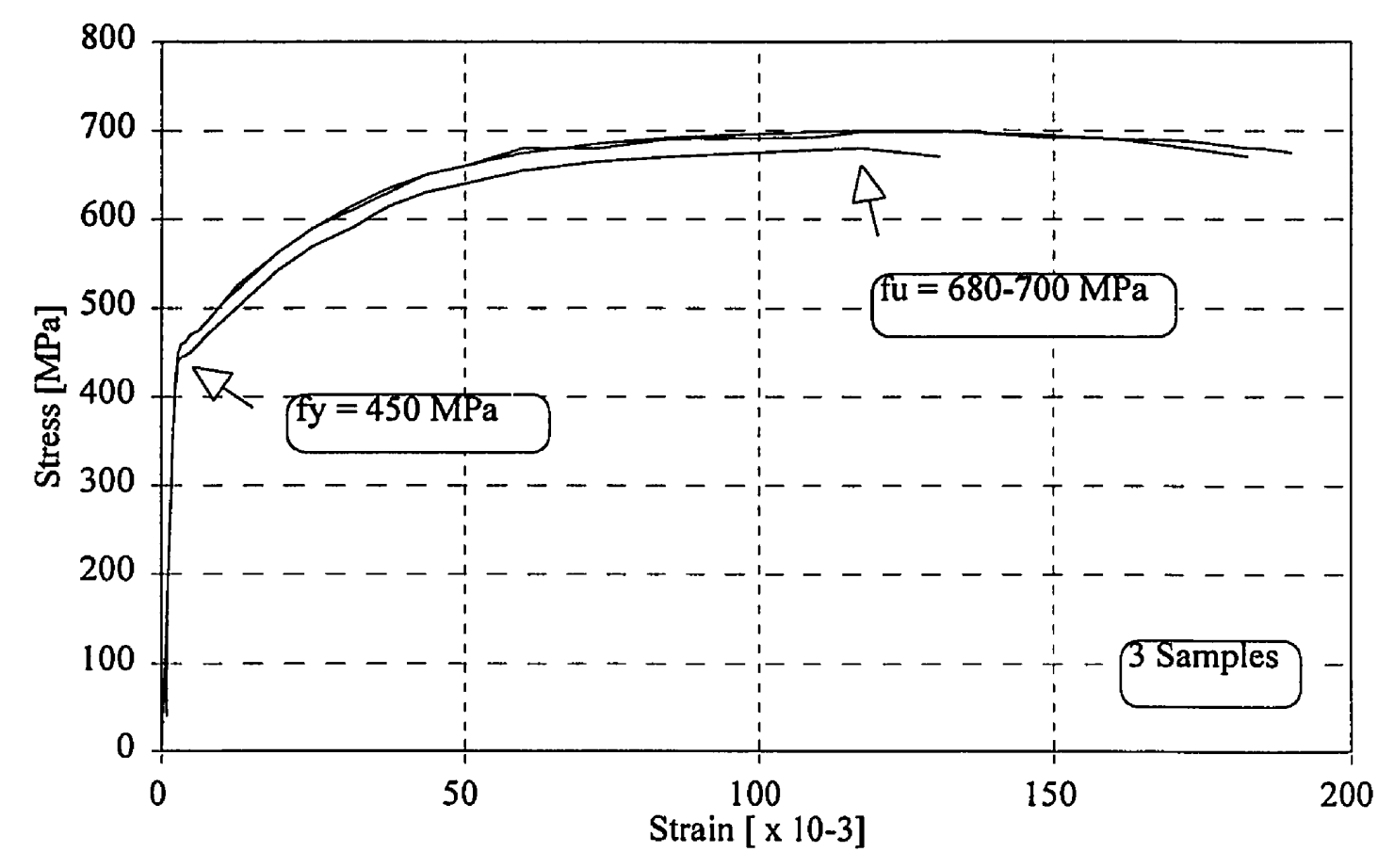




\section{Structural Design Calculations}

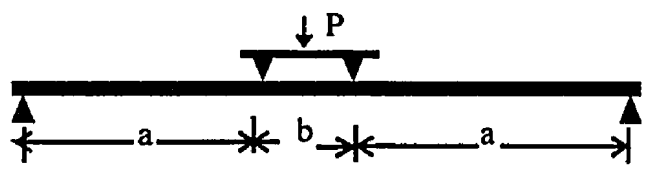

Aims: 1. Failure mode in moment rather than shear.

2. Resembles a section of a slab. (wider than it is deep, no stirrups)

3. Minimize size.

4. At least three bars to provide some internal averaging of effects.

For initial designs, use a concrete strength of $35 \mathrm{MPa}$ and a steel yield point of $450 \mathrm{MPa}$.

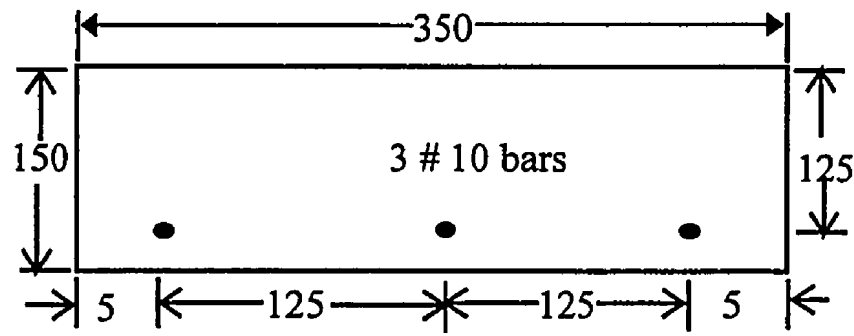

This is a diagram of the final crosssection arrived at.

Follows is a calculation of its shear and moment capacities.

Moment Capacity

$$
\begin{aligned}
& \mathrm{T}=\mathrm{C} \\
& \mathrm{A}_{\mathrm{s}} \mathrm{f}_{\mathrm{y}}=0.85 \mathrm{f}_{\mathrm{c}} \mathrm{b} \mathrm{a} \\
& \left(300 \mathrm{~mm}^{2}\right)(450 \mathrm{MPa})=0.85(35 \mathrm{MPa})(350 \mathrm{~mm}) \mathrm{a} \\
& \mathrm{a}=13 \mathrm{~mm} \\
& \begin{aligned}
\mathrm{M} & =\mathrm{T}(\mathrm{d}-\mathrm{a} / 2) \\
& =\left(300 \mathrm{~mm}^{2}\right)(450 \mathrm{MPa})(125 \mathrm{~mm}-(13 \mathrm{~mm}) / 2) \\
& =16.0 \mathrm{kN}-\mathrm{m}
\end{aligned}
\end{aligned}
$$

\section{Shear Capacity}

$$
\begin{aligned}
V_{c} & =0.2\left(\sqrt{f^{\prime}}\right) b_{w} d \\
& =0.2(\sqrt{3} 5 \mathrm{MPa})(350 \mathrm{~mm})(125 \mathrm{~mm}) \\
& =51.8 \mathrm{kN}
\end{aligned}
$$

A length had to be chosen so that the beam would fail in moment long before it failed in shear. 
It was decided that the limiting factor would be that it would reach no more than $65 \%$ of its shear capacity when it fails in moment.

The testing set-up would be simply supported with a constant moment region.

$$
\begin{aligned}
& \mathrm{M}_{\max }=(\mathrm{P} / 2)^{*} \mathrm{a} \\
& \mathrm{V}_{\text {max }}=\mathrm{P} / 2
\end{aligned}
$$

Therefore, $\quad M_{\max } / V_{\max }=a$

$$
\text { Also, } \mathrm{M}_{\max }=16.0 \mathrm{kN}-\mathrm{m} \text { and } \mathrm{V}_{\max }=0.65(51.8 \mathrm{kN})=33.7 \mathrm{kN}
$$

Thus, $\mathrm{a}=0.475 \mathrm{~m}$

Thus the distance from the support to the loading point shall be $500 \mathrm{~mm}$.

The distance $b$ was selected as the minimum that would be reasonably sure to provide a sufficient constant moment region.

In this case, it was felt that $200 \mathrm{~mm}$ would be sufficient.

To provide for cover on the ends, $50 \mathrm{~mm}$ were added on either side.

This gives a total specimen length of $1300 \mathrm{~mm}$.

Thus, the dimensions of the test specimen were $1300 \mathrm{~mm} \times 350 \mathrm{~mm} \times 150 \mathrm{~mm}$. Three \#10M rebars were used with a bottom cover of $25 \mathrm{~mm}$ to the centre of the bars (or $20 \mathrm{~mm}$ clear cover). Fifty millimetres cover was provided at the ends and at either side. 


\section{Development Length Calculations (As per ACI 408.1R-90)}
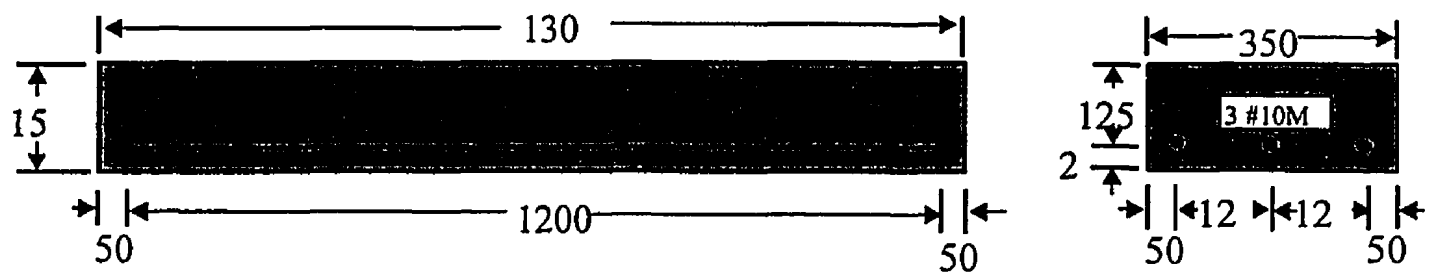

$$
\begin{array}{ll}
\mathrm{A}_{\mathrm{b}}=100 \mathrm{~mm}^{2}=0.155 \mathrm{in}^{2} & \text { (Area of a single bar) } \\
\mathrm{d}_{\mathrm{b}}=10 \mathrm{~mm}=0.787 \mathrm{in} & \text { (bar diameter) } \\
\mathrm{f}_{\mathrm{y}}=450 \mathrm{MPa}=65220 \mathrm{psi} & \text { (yield stress of steel) } \\
\mathrm{f}_{\mathrm{c}}=35 \mathrm{MPa}=5070 \mathrm{psi} & \text { (concrete compressive strength) } \\
\Phi=1.0 & \text { (factor of safety) } \\
\mathrm{C}_{\mathrm{c}}=25 \mathrm{~mm}=1.0 \mathrm{in} & \text { (concrete cover) } \\
\mathrm{K}=0.5 \mathrm{~d}_{\mathrm{b}}+\mathrm{C}_{\mathrm{c}}=1.197 & \text { (confinement factor) } \\
\mathrm{l}_{\mathrm{db}}=5500 \mathrm{~A}_{\mathrm{b}} /\left(\Phi \mathrm{K}_{\mathrm{f}}^{\prime} \text { ) }=10.01 \mathrm{in}=250 \mathrm{~mm}\right. &
\end{array}
$$

Therefore the development length chosen was $250 \mathrm{~mm}$.

(Note that $\mathrm{ACI}$ is in pound-inch units and thus a conversion was required from metric and back again.) 


\section{Curvature-meter Evaluation}

The curvature-meter is the technique used to evaluate the deformation tendencies of the various slabs. It consists of a bar hung from two points on the neutral axis at either end of the constant moment region of the beam. As the neutral axis changes during the test for reinforced concrete, the mid height was used. Then, using a LVDT, the deflection between the midpoint of the span at the neutral axis and the bar is measured. This information can then be used to calculate the curvature. This calculation assumes an elastic response, which is not the case for concrete after it has cracked. It was still useful, however, as it allowed a comparison between slabs of their relative deformation. The development of the relevant formulas is described in the following.

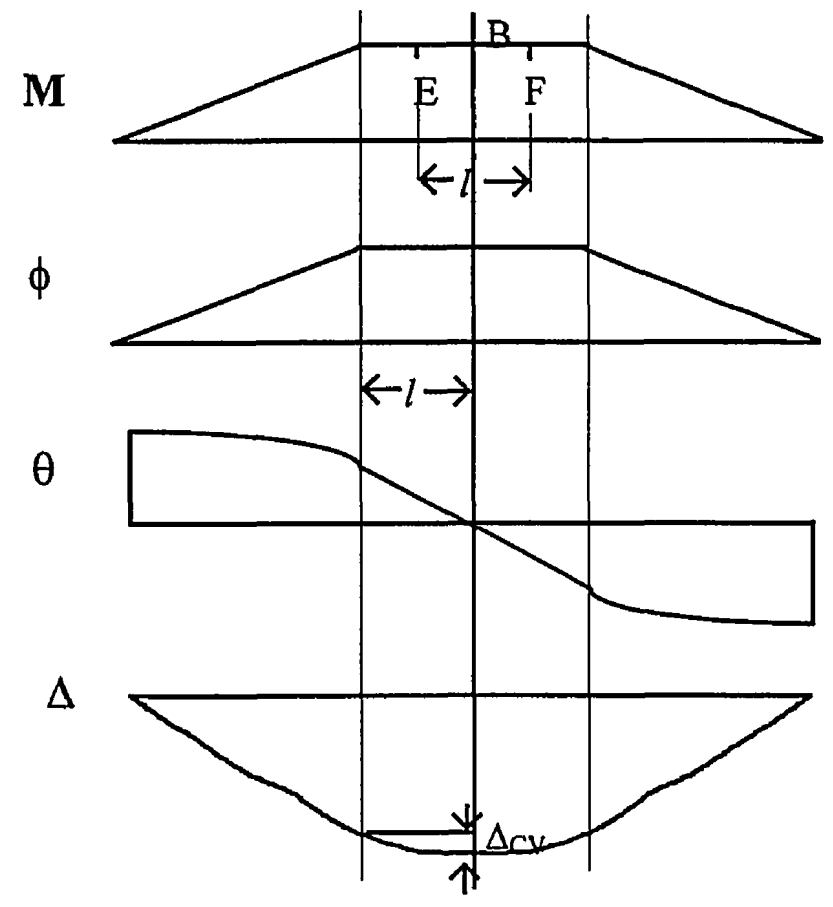

Consider the diagrams to the left. These are typical moment, curvature, slope and deflection diagrams for a member loaded in four point bending, assuming that the beam behaves elastically. Using these, we will first compute the average slope between $\mathrm{A}$ and $\mathrm{B}$. It is :

$$
\theta_{\mathrm{AV}, \mathrm{AB}}=\frac{-\Delta_{\mathrm{CV}}}{l}
$$

Note that the negative of this is the average slope of section $\mathrm{BC}$. Also note that the average slope in these sections corresponds to the slope at the midpoints of these sections as the slope varies linearly for this

region. The midpoints have been designated $\mathrm{E}$ and $\mathrm{F}$. Note that the distance between $\mathrm{E}$ and $\mathrm{F}$ is also $l$. Now it is necessary to calculate the curvature in the constant moment region. This will correspond exactly to the average curvature between $\mathrm{E}$ and $\mathrm{F}$ as the curvature is constant. Thus: $\phi_{\mathrm{CMR}}=\phi_{\mathrm{EF}, \mathrm{AV}}=\frac{\frac{\Delta}{l}-\left(-\frac{\Delta}{l}\right)}{l}=2 \frac{\Delta}{l^{2}}$

This formula has been used to determine the curvature of the slabs. 


\section{Corrosion Current Calculations}

The current was continually recorded as described in the Experimental Procedures. This value was then converted into percent lost based upon the following procedure.

By Faraday's Law, $n=\frac{C}{F}$

where: $\mathbf{n}$ is the number of equivalents reacting,

$C$ is the charge passed and

$\mathrm{F}$ is Faraday's constant, 96487 C/equiv.

Now, C = It

where: $I$ is the current passing and

$t$ is the length of time.

Also, $\mathrm{n}=\mathrm{mz}$

where: $m$ is the number of mols,

$\mathrm{n}$ is the number of equivalents and

$z$ is the charge on an ion.

Thus, $\mathrm{m}=\frac{\mathrm{It}}{\mathrm{Fz}}$.

Now, we desire mass loss.

But, $w=m A^{t m}$

where: $w$ is the mass loss, and

$\mathrm{A}^{\mathrm{tm}}$ is the atomic mass.

Thus, $w=\frac{\mathrm{ItA}^{\mathrm{tn}}}{\mathrm{Fz}}$

To convert this to volumetric percent loss, first the volume loss needs to be determined.

$\mathrm{V}_{\text {loss }}=\frac{\mathrm{w}}{\mathrm{r}}$

where: $\rho$ is the density of the steel.

The original volume of the corroded steel is $A_{s} * l_{\text {corr }}$

where: $A_{s}$ is the area of steel and

$l_{\text {corr }}$ is the total length of steel that is to be corroded.

Thus, $\%$ lost $=\frac{\mathrm{w}}{\rho \mathrm{A}_{\mathrm{s}} \mathrm{l}_{\text {corr }}} \times 100 \%$ or $\frac{\mathrm{ItA}^{\mathrm{tm}}}{\mathrm{FzA}_{\mathrm{s}} \mathrm{l}_{\text {corr }} \rho} \times 100 \%$ 
Now it is possible to convert this for the situations that will be encountered in this experimental program. There will be two slightly different situations. For series 2 , the corroded length will be just the ends of the rebars, while for series 3 , the corroded length will be the entire bar.

\section{Series 2}

$$
\begin{aligned}
& A^{\mathrm{tm}}=55.85 \mathrm{~g} / \mathrm{mol} \text { (as mostly iron) } \\
& \mathrm{F}=96487 \mathrm{C} / \text { equiv. } \\
& \mathrm{z}=2 \text { equiv } / \mathrm{mol} \\
& A_{\mathrm{s}}=100 \mathrm{~mm}^{2} \\
& \mathrm{l}_{\text {corr }}=6 * 250 \mathrm{~mm}+100 \mathrm{~mm}=1600 \mathrm{~mm} \\
& \rho=7850 \mathrm{~kg} / \mathrm{m}^{3}=7850 \times 10^{-6} \mathrm{~g} / \mathrm{mm}^{3}
\end{aligned}
$$

Thus \%lost $=23.04 \times 10^{-6} \mathrm{It}$

where: $I$ is in Amperes and

$t$ is in seconds.

\section{Series 3}

$$
\begin{aligned}
& A^{\mathrm{tm}}=55.85 \mathrm{~g} / \mathrm{mol} \text { (as mostly iron) } \\
& F=96487 \text { C/equiv } \\
& z=2 \text { equiv } / \mathrm{mol} \\
& A_{s}=100 \mathrm{~mm}^{2} \\
& l_{\text {corr }}=3 * 1200 \mathrm{~mm}+100 \mathrm{~mm}=3700 \mathrm{~mm} \\
& \rho=7850 \mathrm{~kg} / \mathrm{m}^{3}=7850 \times 10^{-6} \mathrm{~g} / \mathrm{mm}^{3}
\end{aligned}
$$

Thus, $\%$ lost $=9.964 \times 10^{-6} \mathrm{It}$

where: $I$ is in Amperes and

$t$ is in seconds. 


\section{Fresh Concrete Properties of Mixes}

Series 1 - Control Slab:

Slump: $180 \mathrm{~mm}$

Air Content: $9 \%$

Plastic Density: $2305 \mathrm{~kg} / \mathrm{m}^{3}$

Admixture Dosages:

ProAir: $45 \mathrm{~mL} / 100 \mathrm{~kg}$ cementitious $25 \mathrm{XL}: 250 \mathrm{~mL} / 100 \mathrm{~kg}$ cementitious RheoBuild 1000: $500 \mathrm{~mL} / 100 \mathrm{~kg}$ cementitious

Series 1 - Half Covered:

Slump: $180 \mathrm{~mm}$

Air Content: $8 \%$

Plastic Density: $2246 \mathrm{~kg} / \mathrm{m}^{3}$

Admixture Dosages:

ProAir: $35 \mathrm{~mL} / 100 \mathrm{~kg}$ cementitious

$25 \mathrm{XL}: 260 \mathrm{~mL} / 100 \mathrm{~kg}$ cementitious

RheoBuild 1000: $310 \mathrm{~mL} / 100 \mathrm{~kg}$ cementitious

\section{Series 1 - Quarter Covered:}

Slump: $200 \mathrm{~mm}$

Air Content: $5 \%$

Plastic Density: $2260 \mathrm{~kg} / \mathrm{m}^{3}$

Admixture Dosages:

ProAir: $30 \mathrm{~mL} / 100 \mathrm{~kg}$ cementitious

$25 \mathrm{XL}: 250 \mathrm{~mL} / 100 \mathrm{~kg}$ cementitious

RheoBuild1000: $300 \mathrm{~mL} / 100 \mathrm{~kg}$ cementitious

Series 2 - Normal, Control:

Slump: $110 \mathrm{~mm}$

Air Content: $6.5 \%$

Plastic Density: $2336 \mathrm{~kg} / \mathrm{m}^{3}$

Admixture Dosages:

ProAir: $30 \mathrm{~mL} / 100 \mathrm{~kg}$ cementitious

$25 \mathrm{XL}: 250 \mathrm{~mL} / 100 \mathrm{~kg}$ cementitious

RheoBuild 1000: $300 \mathrm{~mL} / 100 \mathrm{~kg}$ cementitious
Series 2 - Normal, 2 \% Corrosion:

Slump: $210 \mathrm{~mm}$

Air Content: $6 \%$

Plastic Density: $2274 \mathrm{~kg} / \mathrm{m}^{3}$

Admixture Dosages:

ProAir: $30 \mathrm{~mL} / 100 \mathrm{~kg}$ cementitious

$25 \mathrm{XL}: 250 \mathrm{~mL} / 100 \mathrm{~kg}$ cementitious

RheoBuild 1000: $275 \mathrm{~mL} / 100 \mathrm{~kg}$ cementitious

Series 2 - Normal, 5 \% Corrosion:

Slump: $210 \mathrm{~mm}$

Air Content: $6.5 \%$

Plastic Density: $2336 \mathrm{~kg} / \mathrm{m}^{3}$

Admixture Dosages:

ProAir: $30 \mathrm{~mL} / 100 \mathrm{~kg}$ cementitious

$25 \mathrm{XL}: 250 \mathrm{~mL} / 100 \mathrm{~kg}$ cementitious

RheoBuild 1000: $250 \mathrm{~mL} / 100 \mathrm{~kg}$ cementitious

Series 2 - Normal, $8 \%$ Corrosion:

Slump: $210 \mathrm{~mm}$

Air Content: $8 \%$

Plastic Density: $2246 \mathrm{~kg} / \mathrm{m}^{3}$

Admixture Dosages:

ProAir: $30 \mathrm{~mL} / 100 \mathrm{~kg}$ cementitious

$25 \mathrm{XL}: 250 \mathrm{~mL} / 100 \mathrm{~kg}$ cementitious

RheoBuild1000: $225 \mathrm{~mL} / 100 \mathrm{~kg}$ cementitious

Series 2 - Normal, $10 \%$ Corrosion:

Slump: $160 \mathrm{~mm}$

Air Content: $7 \%$

Plastic Density: $2306 \mathrm{~kg} / \mathrm{m}^{3}$

Admixture Dosages:

ProAir: $30 \mathrm{~mL} / 100 \mathrm{~kg}$ cementitious

$25 \mathrm{XL}: 250 \mathrm{~mL} / 100 \mathrm{~kg}$ cementitious

RheoBuild 1000: $200 \mathrm{~mL} / 100 \mathrm{~kg}$ cementitious 
Series 2 - Silica, Control:

Slump: $125 \mathrm{~mm}$

Air Content: $7 \%$

Plastic Density: $2316 \mathrm{~kg} / \mathrm{m}^{3}$

Admixture Dosages:

ProAir: $30 \mathrm{~mL} / 100 \mathrm{~kg}$ cementitious

$25 \mathrm{XL}: 250 \mathrm{~mL} / 100 \mathrm{~kg}$ cementitious

RheoBuild1000: $350 \mathrm{~mL} / 100 \mathrm{~kg}$ cementitious

Series 2 - Silica, $2 \%$ Corrosion:

Slump: $160 \mathrm{~mm}$

Air Content: $8 \%$

Plastic Density: $2246 \mathrm{~kg} / \mathrm{m}^{3}$

Admixture Dosages:

ProAir: $30 \mathrm{~mL} / 100 \mathrm{~kg}$ cementitious

$25 \mathrm{XL}: 250 \mathrm{~mL} / 100 \mathrm{~kg}$ cementitious

RheoBuild1000: $350 \mathrm{~mL} / 100 \mathrm{~kg}$ cementitious

Series 2 - Silica, 5 \% Corrosion:

Slump: $50 \mathrm{~mm}$

Air Content: $5.5 \%$

Plastic Density: $2359 \mathrm{~kg} / \mathrm{m}^{3}$

Admixture Dosages:

ProAir: $30 \mathrm{~mL} / 100 \mathrm{~kg}$ cementitious

$25 \mathrm{XL}: 250 \mathrm{~mL} / 100 \mathrm{~kg}$ cementitious

RheoBuild 1000: $300 \mathrm{~mL} / 100 \mathrm{~kg}$ cementitious

Series 2 - Silica, $8 \%$ Corrosion:

Slump: $175 \mathrm{~mm}$

Air Content: $7 \%$

Plastic Density: $2274 \mathrm{~kg} / \mathrm{m}^{3}$

Admixture Dosages:

ProAir: $30 \mathrm{~mL} / 100 \mathrm{~kg}$ cementitious

$25 \mathrm{XL}: 250 \mathrm{~mL} / 100 \mathrm{~kg}$ cementitious

RheoBuild1000: $300 \mathrm{~mL} / 100 \mathrm{~kg}$ cementitious
Series 2 - Silica, $10 \%$ Corrosion:

Slump: $50 \mathrm{~mm}$

Air Content: $6 \%$

Plastic Density: $2362 \mathrm{~kg} / \mathrm{m}^{3}$

Admixture Dosages:

ProAir: $30 \mathrm{~mL} / 100 \mathrm{~kg}$ cementitious

$25 \mathrm{XL}: 250 \mathrm{~mL} / 100 \mathrm{~kg}$ cementitious

RheoBuild1000: $300 \mathrm{~mL} / 100 \mathrm{~kg}$ cementitious

Series 3 - $10 \%$ Corrosion:

Slump: $130 \mathrm{~mm}$

Air Content: $6.5 \%$

Plastic Density: $2359 \mathrm{~kg} / \mathrm{m}^{3}$

Admixture Dosages:

ProAir: $30 \mathrm{~mL} / 100 \mathrm{~kg}$ cementitious

$25 \mathrm{XL}: 250 \mathrm{~mL} / 100 \mathrm{~kg}$ cementitious

RheoBuild1000:200 mL/100 kg cementitious 
CORROSION EFFECTS ON BOND STRENGTH IN REINFORCED CONCRETE

Appendix E

Concrete Material Results

\section{Material Results Summary}

\begin{tabular}{|c|c|c|c|c|c|c|c|c|}
\hline \multirow[t]{2}{*}{ Specimen } & \multicolumn{2}{|c|}{ Strength [MPa] } & \multicolumn{2}{|c|}{ Rapid Chloride } & \multicolumn{2}{|c|}{ Resistivity $[\Omega-\mathrm{cm}]$} & \multicolumn{2}{|c|}{ Sorptivity $[\mathrm{mm} / \mathrm{min} 0.5]$} \\
\hline & 7 Day & 28 Day & 7 Day & 28 Day & 7 Day & 28 Day & 7 Day & 28 Day \\
\hline $1-\mathrm{N}-0$ & 25.7 & 38.6 & - & - & - & - & - & - \\
\hline $1-\mathrm{N}-1 / 4$ & 21.6 & 31.5 & - & - & - & - & $\overline{-}$ & - \\
\hline $1-\mathrm{N}-1 / 2$ & 19.4 & 31.9 & - & - & - & - & - & - \\
\hline $2-\mathrm{N}-0$ & 30.5 & 42.9 & - & - & - & - & - & - \\
\hline $2-\mathrm{N}-2$ & - & 32.2 & - & - & - & - & 0.0814 & 0.1189 \\
\hline $2-\mathrm{N}-5$ & - & 38.6 & - & - & - & - & 0.0974 & 0.1202 \\
\hline $2-N-8$ & - & 30.4 & Mod. & Mod. & 6894 & 11578 & - & - \\
\hline $2-\mathrm{N}-10$ & - & 32.1 & Mod. & Low & 7466 & 15736 & - & - \\
\hline $2-S-0$ & 26.9 & 47.9 & - & - & - & - & - & - \\
\hline $2-S-2$ & - & 40.9 & - & - & - & - & 0.1178 & 0.1119 \\
\hline $2-S-5$ & 39.0 & 37.1 & Low & V. Low & 14279 & 49162 & - & - \\
\hline $2-S-8$ & - & 41.2 & - & - & - & - & 0.1283 & 0.1102 \\
\hline $2-S-10$ & 33.1 & 49.6 & Low & V. Low & 12453 & 52450 & - & - \\
\hline $3-\mathrm{N}-10$ & 22.0 & 37.0 & High & Mod. & 4374 & 9704 & 0.1550 & 0.0728 \\
\hline
\end{tabular}




\section{CORROSION EFFECTS ON BOND STRENGTH IN REINFORCED CONCRETE

\begin{tabular}{ll} 
Appendix F & Corrosion Current Graphs \\
\hline
\end{tabular}

\section{Corrosion Current}

Normal Mix, 3 \% Corrosion



Corrosion Current

Normal Mix, $5 \%$ Corrosion

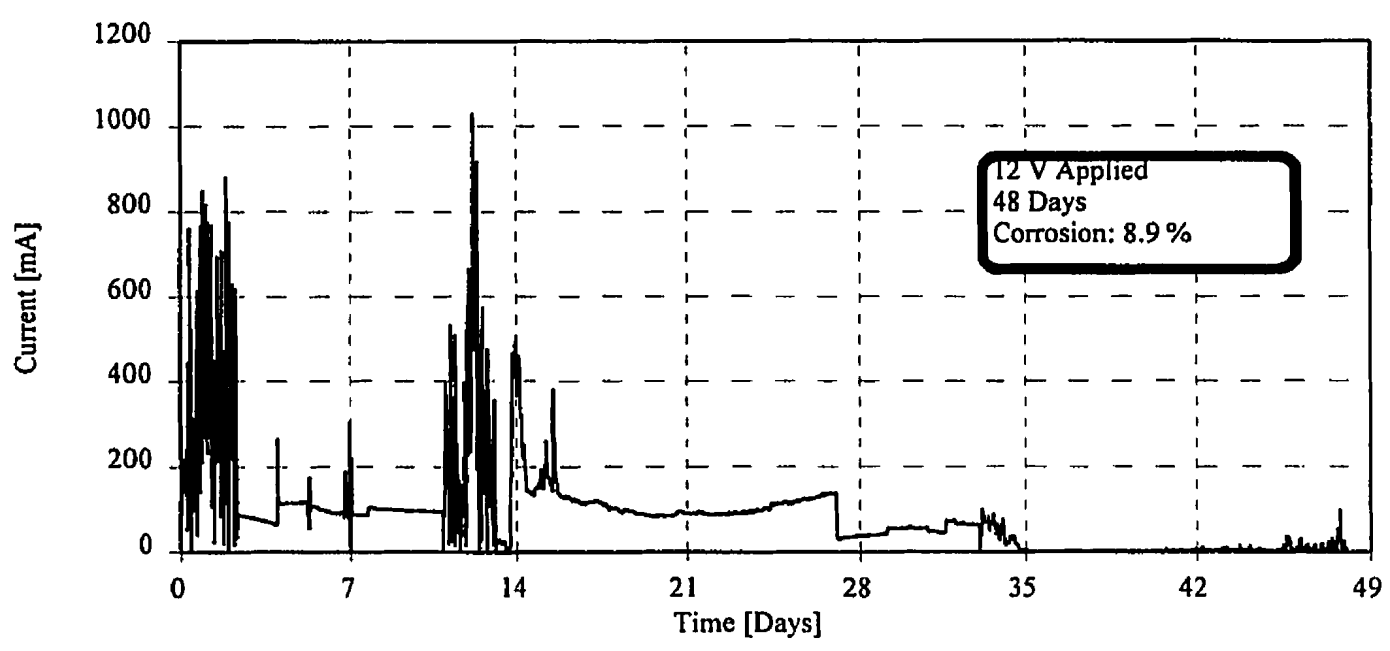




\begin{tabular}{cc} 
CORROSION EFFECTS ON BOND STRENGTH IN REINFORCED CONCRETE \\
Appendix F & Corrosion Curtent Graphs \\
\hline
\end{tabular}

\section{Corrosion Current}

Normal Mix, $8 \%$ Corrosion

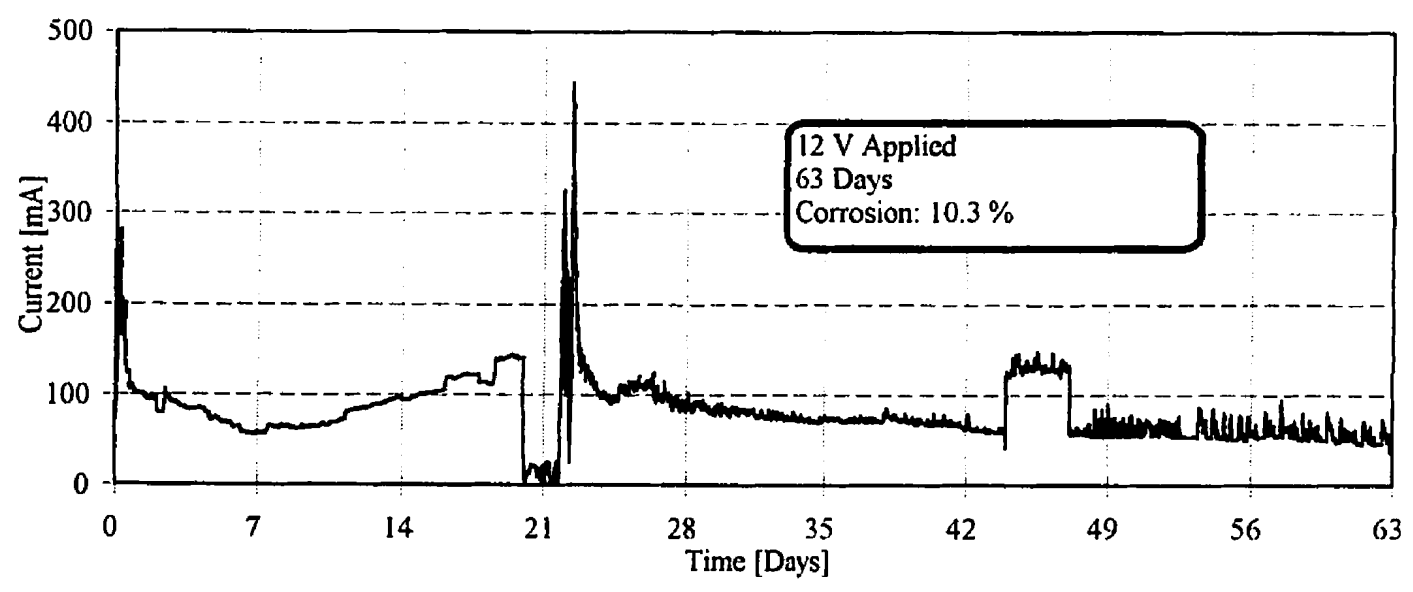

Corrosion Current

Normal Mix, $10 \%$ Corrosion

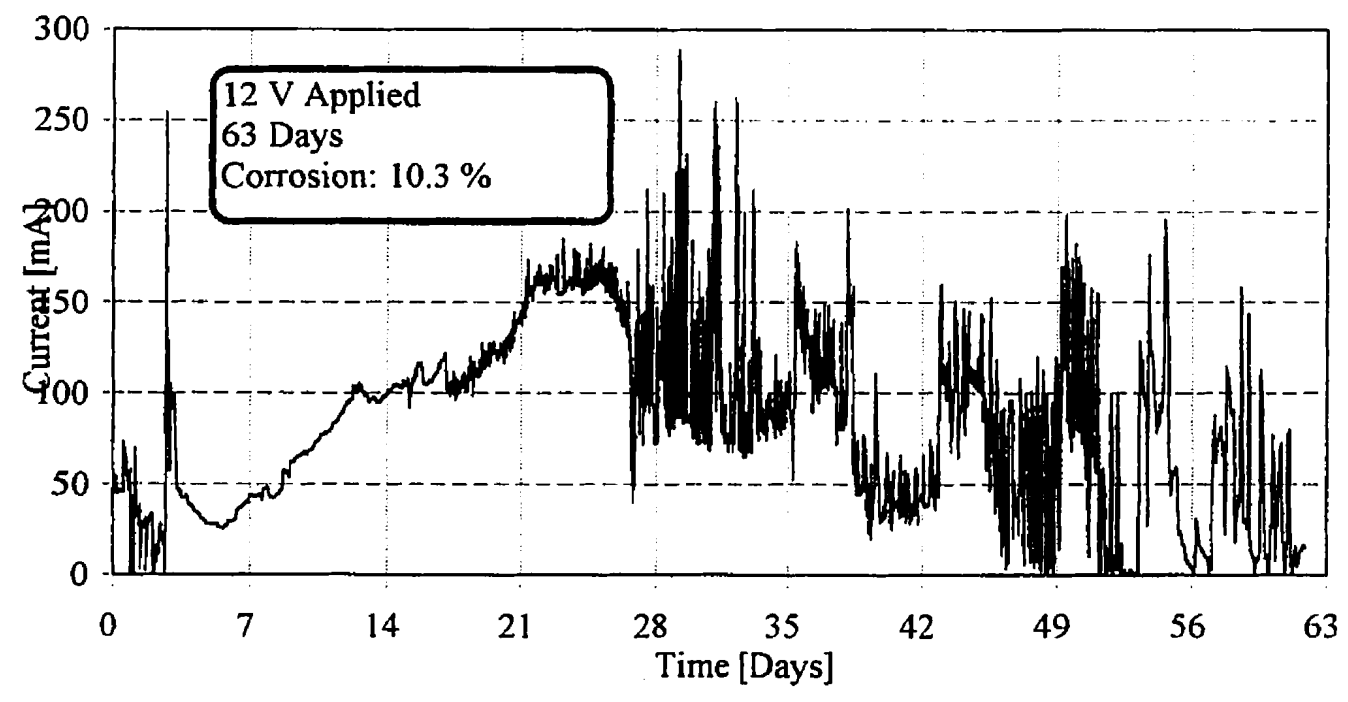




\section{\begin{tabular}{ll} 
Appendix F & Corrosion Current Graphs \\
\hline
\end{tabular}}

\section{Corrosion Current}

Silica Fume Mix, 2\% Corrosion

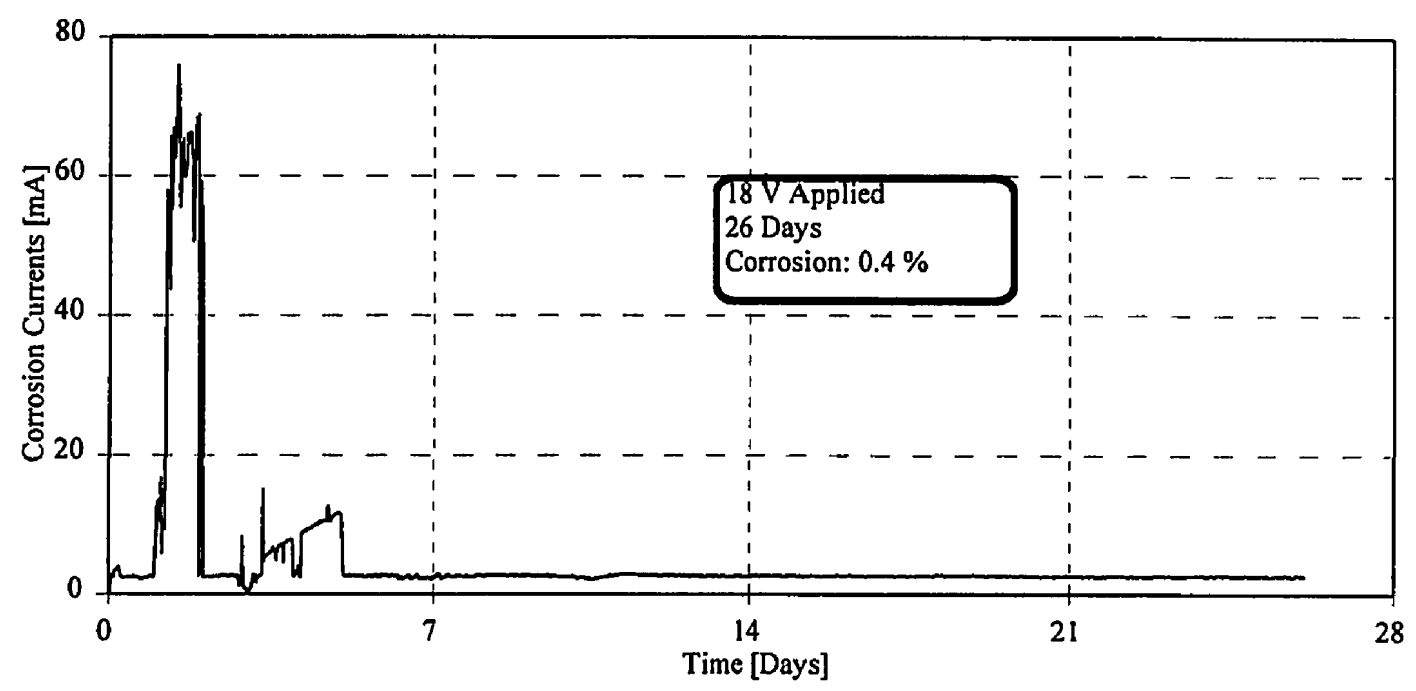

Corrosion Current

Silica Fume Mix, 5 \% Corrosion

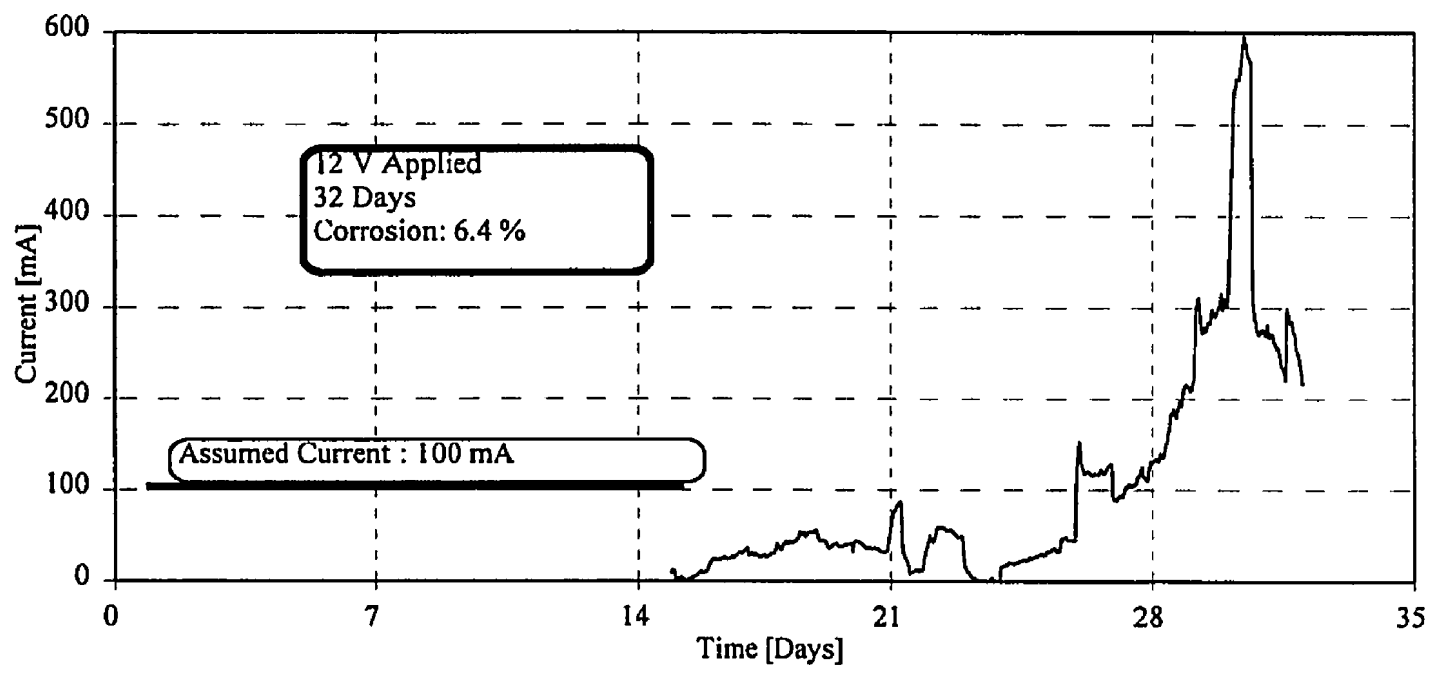




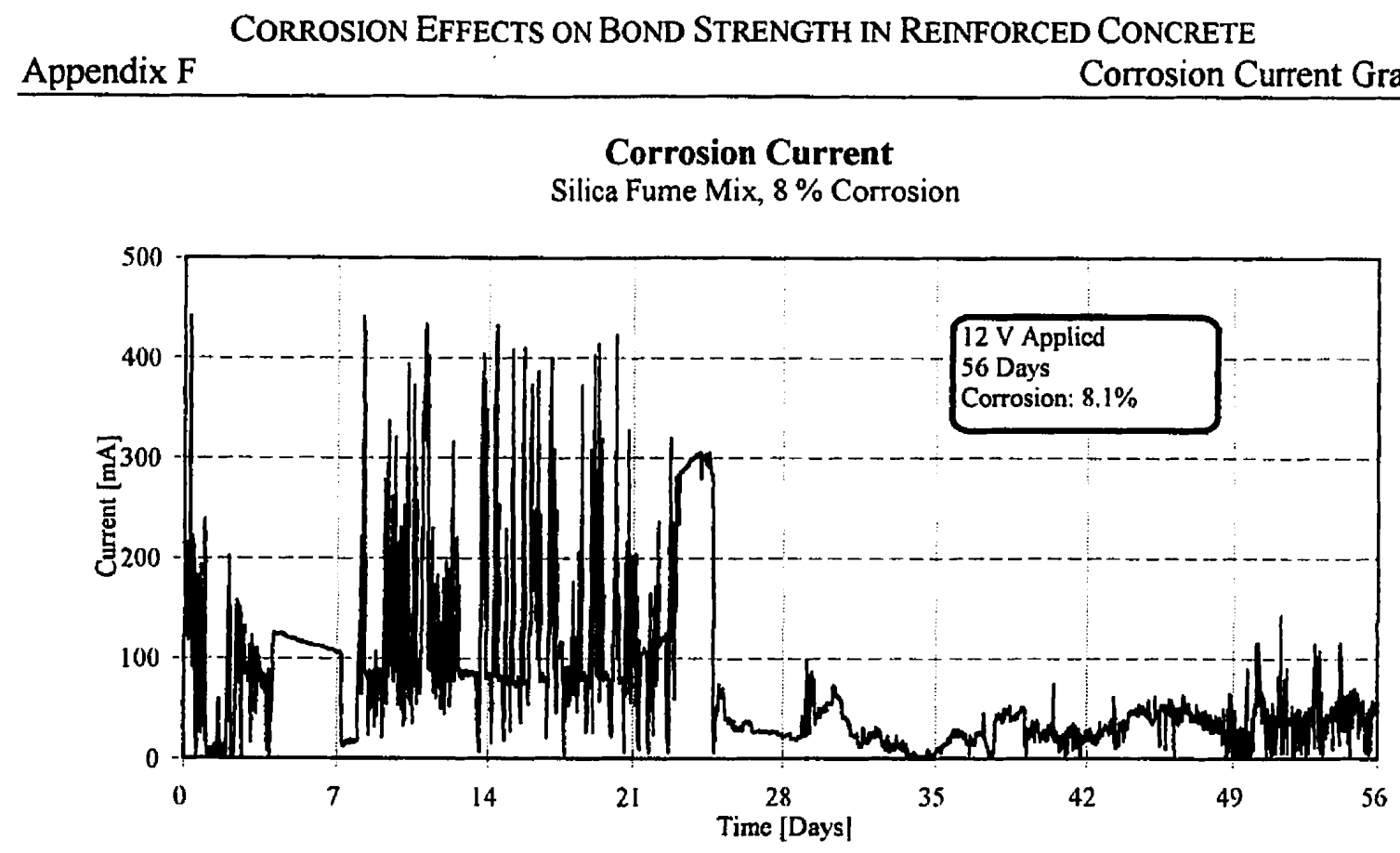

Corrosion Current

Silica Fume Mix, 10\% Corrosion

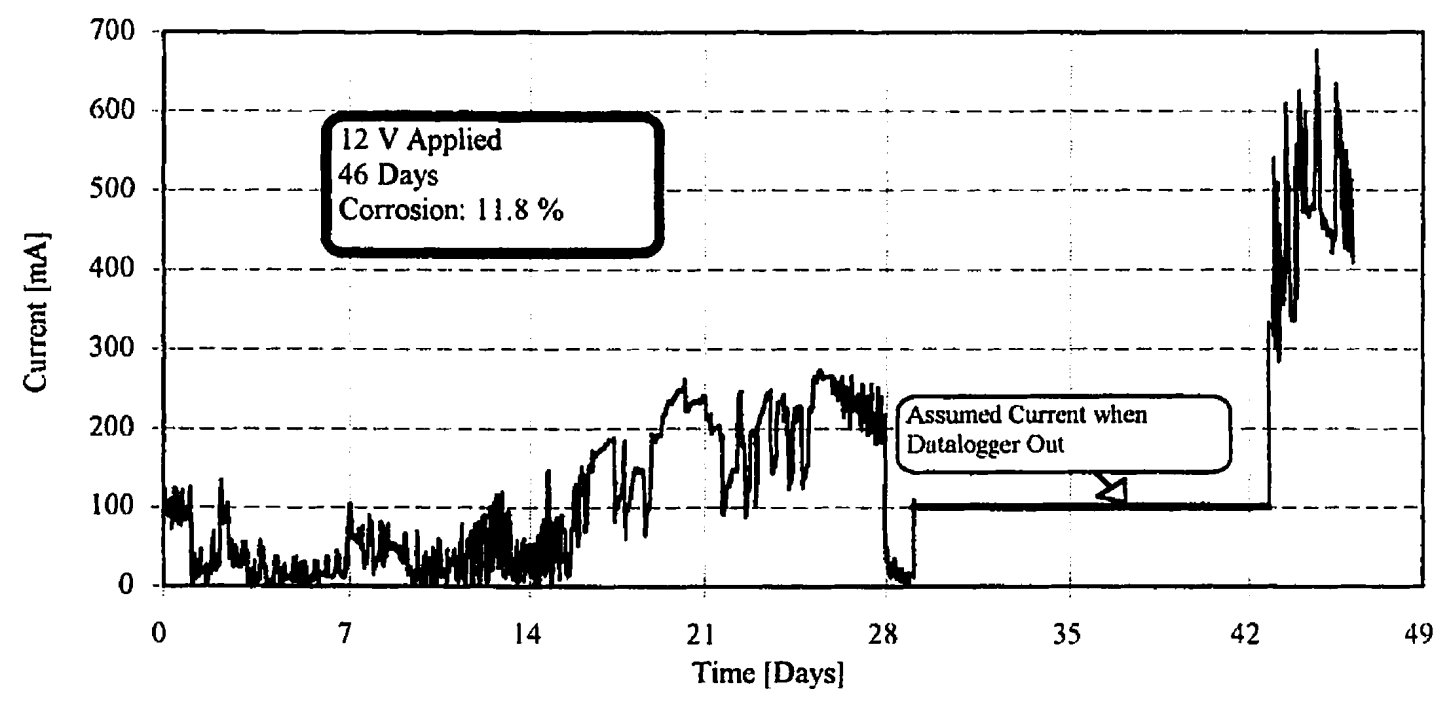




\section{Corrosion Current}

Series 3

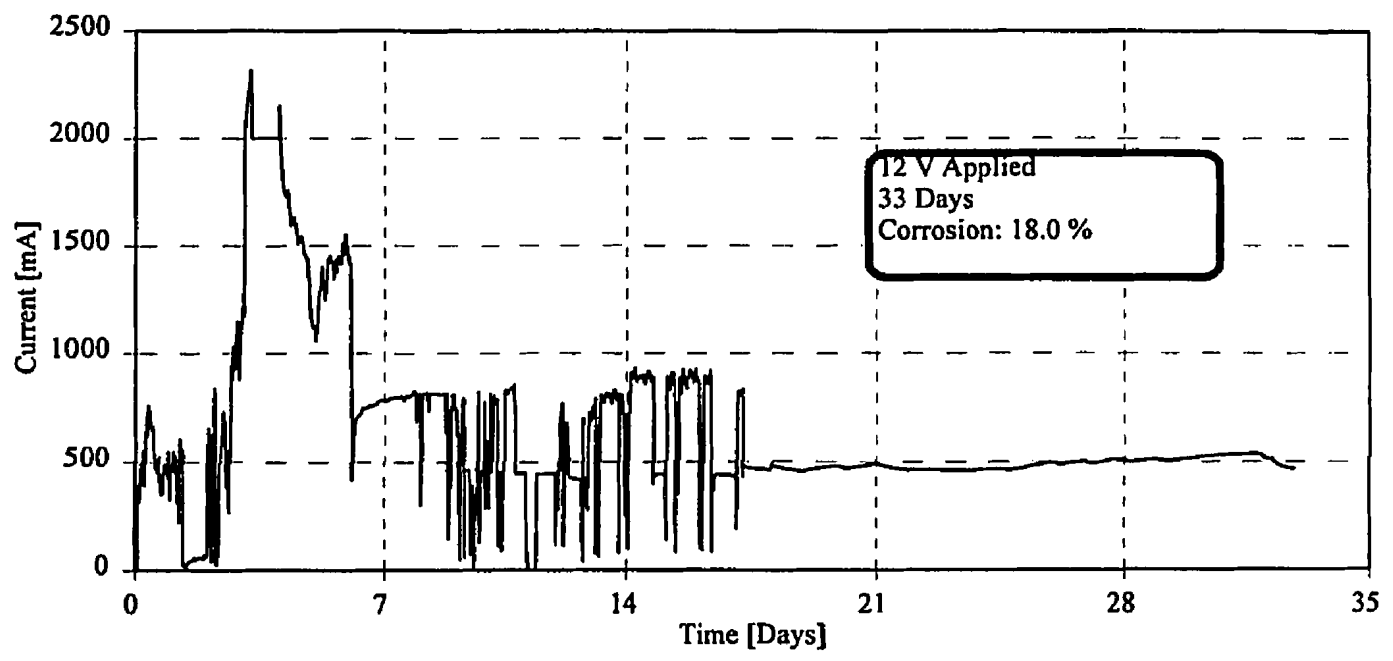




\section{Bond Evaluation}

To evaluate the strength of the bond in the Series 2 slabs, it was first necessary to determine the stress in the bars. This was using the measured moments and curvatures for all points in the moment curvature diagram after the slabs cracked using a computer program written in FORTRAN 77 for this purpose. A copy of this program is below. It contains a root-finding subroutine written by A. Smith, E. Hinton and R. Lewis, Civil Engineering Systems: Analysis \& Design, John Wiley \& Sons, Toronto, c1983

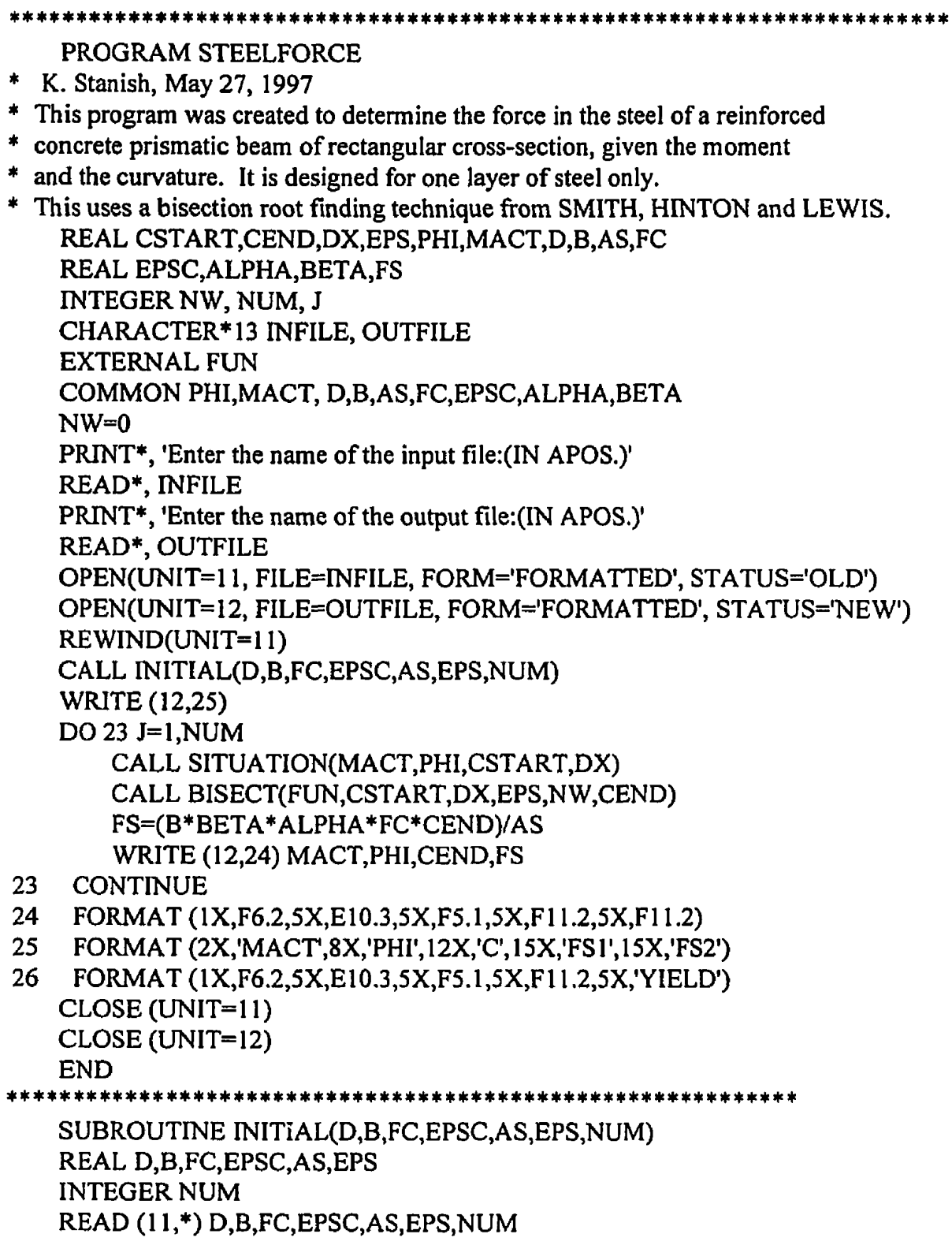




\section{RETURN}

END

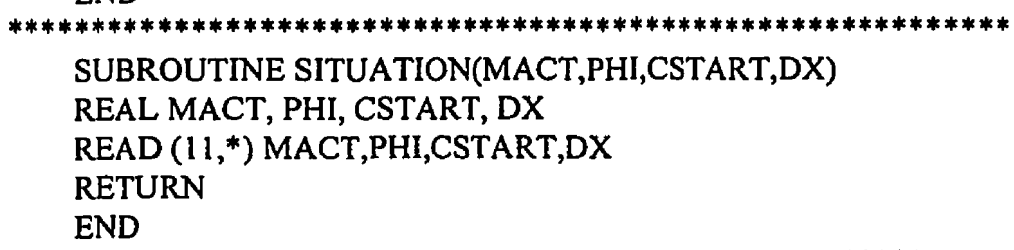

* The routine determines by the method of interval halving the root

* of an equation of a single variable.

* FUN = name of subroutine supplied by the user

* to define the equation.

* For example:

* $\quad$ SUBROUTINE EQUN(X,F)

* $\quad \mathrm{F}=\mathrm{X} * \mathrm{X}-6.0 * \mathrm{X}+4.0$

* RETURN

* END

* XSTART $=$ Start of coarse search range

* DX = Initial increment for coarse search

* EPS = Minimum acceptable interval of uncertainty

* for convergence

* NW = Output channel for intermediate printout.

* $\quad$ Set NW=0 to suppress all printout.

* XROOT $=$ Computed value of root

* A coarse search is carried out to find the initial interval of

* uncertainty. If no root is found within $10000^{*} \mathrm{DX}$ the search is

* abandoned.

* Note that two roots close to together may be missed by the coarse

* search.

* A distinction is made between roots and possible discontinuities

* and a warning is printed.

* The name of the actual subroutine corresponding to FUN must appear

* in an external statement in the driving program.




IF(NW.GT.0) WRITE(NW,50)XI,FI

$F A C=1.0$

5 CONTINUE

$\mathrm{X} 2=\mathrm{X} 1+\mathrm{DX} 1$

CALL FUN(X2,F2)

IF(NW.GT.0) WRITE(NW,50)X2,F2

C TEST FOR CHANGE OF SIGN INFUNCTION

IF(F1*F2.LT.0.0) GOTO 20

C NO CHANGE OF SIGN

$\mathrm{FAC}=2.0 * \mathrm{FAC}$

$\mathrm{DX} 1=\mathrm{FAC} * \mathrm{DX}$

$\mathrm{F} 1=\mathrm{F} 2$

$\mathrm{X} 1=\mathrm{X} 2$

C SET LIMIT ON EXTENT OF SEARCH

IF(FAC.LT.10000.0) GOTO 5

IF(NW.GT.0)WRITE(NW, 10)XSTART,X2

10 FORMAT(24H IN BISECT NO ROOT FOUND,

$+\quad$ 8H BETWEEN,F12.3,4H AND,F12.3) STOP

20 CONTINUE

C INTERVAL OF UNCERTAINTY DEFINED BY X1,X2

$C$ NOW FIND SLOPE OF FUNCTION IN THIS INTERVAL SIGN $=1.0$

IF(F2.LT.0.0) SIGN $=-1.0$

C SET VARIABLE TO TEST FOR DISCONTINUITY

$\mathrm{FM} 1=\mathrm{F} 1$

$\mathrm{FM}=\mathrm{F} 1$

C MAIN ITERATION LOOP STARTS HERE

30 CONTINUE

NDISC $=0$

$\mathrm{XM}=0.5 *(\mathrm{X} 1+\mathrm{X} 2)$

IF(SIGN*FM.LT.SIGN*FM1) NDISC $=1$

CALL FUN(XM,FM)

C OUTPUT ITERATION VALUES IF REQUIRED

IF(NW.GT.0) WRITE(NW,50)XM,FM

50 FORMAT(10H IN BISECT,2F 16.4)

IF(SIGN*FM.LT.0.0) GOTO 60

GOTO 70

60 CONTINUE

$\mathrm{X} 1=\mathrm{XM}$

GOTO 80

70 CONTINUE

$\mathrm{X} 2=\mathrm{XM}$

80 CONTINUE

C TEST FOR CONVERGENCE

IF(ABS(X2-X1).GT.EPS) GOTO 30

$\mathrm{XROOT}=\mathrm{XM}$

IF(NDISC.EQ.0) RETURN

IF(NW.GT.0) WRITE(NW,90)

90 FORMAT(39H IN BISECT POSSIBLE DISCONTINUITY FOUND)

RETURN

END 
After the stress in the steel was determined for all points in the post-cracking region of the moment-curvature response, the bond stress that had arisen were determined. This was done by dividing the force in a bar by the surface area of the bar that is in contact with the concrete at each end. The maximum value was then determined and that was reported as the bond capacity of the corroded bars. 


\section{Series 3 Predictions}

$$
\begin{aligned}
& \text { Material Properties: } f_{c}=37.0 \mathrm{MPa} \quad \mathrm{f}=450 \mathrm{MPa} \\
& b=350 \mathrm{~mm} \quad \mathrm{~d}=125 \mathrm{~mm} \\
& \mathrm{~A}_{\mathrm{s}}=300 \mathrm{~mm}^{2} \text { (before corrosion) } \\
& 14.5 \% \text { corrosion loss }
\end{aligned}
$$

\section{Section Calculations:}

This is calculated as if the steel was reduced by the percent that it was corroded by. Thus, consider as if the slab had a steel area of $0.855\left(300 \mathrm{~mm}^{2}\right)$ or $256.5 \mathrm{~mm}^{2}$.

$$
\begin{aligned}
& T=C \\
& A_{s} f_{y}=0.85 f_{c}^{\prime} b a \\
& \left(256.5 \mathrm{~mm}^{2}\right)(450 \mathrm{MPa})=0.85(37.0 \mathrm{MPa})(350 \mathrm{~mm}) \mathrm{a} \\
& \mathrm{a}=10.5 \mathrm{~mm} \\
& \begin{aligned}
\mathrm{M} & =\mathrm{T}(\mathrm{d}-\mathrm{a} / 2) \\
& =\left(246 \mathrm{~mm}^{2}\right)(450 \mathrm{MPa})(125 \mathrm{~mm}-(10.5 \mathrm{~mm}) / 2) \\
& =13.82 \mathrm{kN}-\mathrm{m}
\end{aligned}
\end{aligned}
$$

The shear properties of the section remain unchanged from the normal section and thus will not be a factor.

\section{Bond Effects:}

The bond strength will also possibly limit the design. The anchorage capacity of the bar will vary along the length of the slab, and is thus derived here as a function of the longitudinal position.

$$
\begin{aligned}
& u=4.71-0.250(14.5)=1.09 \mathrm{MPa} \text { (from previous work) } \\
& \text { Thus, } \mathrm{F}_{\mathrm{s}}=\mathrm{upl}(\mathrm{x}) \leq \mathrm{f}_{\mathrm{y}} \mathrm{A}_{\mathrm{s}}
\end{aligned}
$$

The limit is already calculated as the section property. This is concerned with the first situation. 
As before, $\mathrm{C}=\mathrm{T}$

$$
\begin{aligned}
0.85 \mathrm{f}_{\mathrm{c}} \mathrm{b} a & =F_{s} \\
\mathrm{a} & =\frac{\mathrm{F}_{\mathrm{s}}}{0.85 \mathrm{f}_{\mathrm{c}} \mathrm{b}}=\frac{u p l(\mathrm{x})}{0.85 \mathrm{f}_{\mathrm{c}} \mathrm{b}}
\end{aligned}
$$

Now, $M_{f}=F_{s}\left(d-\frac{a}{2}\right)=u p l(x)\left(d-\frac{u p l(x)}{1.7 f_{c}^{\prime} b}\right)$

Thus, we can plot the failure envelope, realizing that $l(x)=x$ if $x$ is the distance from the support, which is also the location the bars start.

\section{Moment Diagram:}

Also required is the moment diagram as a function of $x$. There are two sections to this moment diagram, when $\mathrm{x}<500 \mathrm{~mm}$ and when $500 \mathrm{~mm}<\mathrm{x}<600$ $\mathrm{mm}$. If we note symmetry, then it is simple to

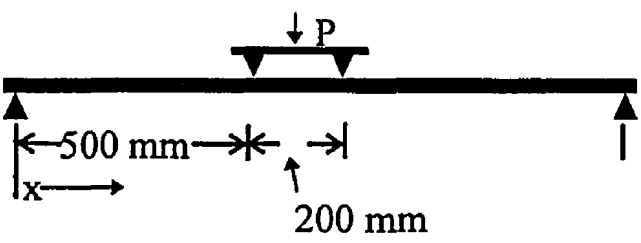
determine by inspection that:

$$
\begin{aligned}
\mathrm{M}(\mathrm{x}) & =\mathrm{P} / 2 \mathrm{x} ; \quad \mathrm{x} \leq 500 \mathrm{~mm} \\
& =\mathrm{P} / 4 ; \quad 500 \mathrm{~mm} \leq \mathrm{x} \leq 600 \mathrm{~mm} .
\end{aligned}
$$

This information was then plotted for different values of $\mathrm{P}$ until the two curves intersect. The lowest load at which this occurs is the failure load. Depending upon which mode governs at the point of intersection of the curves, the failure mode can be determined. For this situation, the intersection of the curves occurs when $\mathrm{P}=28.5 \mathrm{kN}$. The location of intersection is in the region where bond strength. 


\begin{tabular}{|c|c|c|c|c|c|c|}
\hline \multicolumn{6}{|c|}{ Appendix I } & Structural \\
\hline \multicolumn{7}{|l|}{$\begin{array}{l}\text { Series 1 } \\
\overline{\bar{C}} \\
\text { Control }\end{array}$} \\
\hline $\begin{array}{l}\text { Load } \\
(\mathrm{kN})\end{array}$ & $\begin{array}{l}\text { Moment } \\
(\mathrm{kN}-\mathrm{m})\end{array}$ & $\begin{array}{c}\begin{array}{c}\text { M.P. Displ. } \\
(\mathrm{mm})\end{array} \\
\end{array}$ & \begin{tabular}{|c} 
E. Curv. LVDT \\
$(\mathrm{mm})$
\end{tabular} & $\begin{array}{c}\begin{array}{c}\text { W. Curv. LVDT } \\
(\mathrm{mm})\end{array} \\
\end{array}$ & \begin{tabular}{|c}
$\begin{array}{c}\text { Curv. LVDT Avg. } \\
(\mathrm{mm})\end{array}$ \\
\end{tabular} & $\begin{array}{c}\text { Curvature } \\
(1 / \mathrm{km})\end{array}$ \\
\hline 1.71 & 0.43 & 0.007 & 0.001 & 0.002 & 0.002 & -0.30 \\
\hline 2.79 & 0.70 & 0.033 & 0.001 & 0.002 & 0.000 & $-0.0 \AA$ \\
\hline 3.83 & 0.96 & 0.048 & 0.001 & 0.002 & 0.002 & -0.37 \\
\hline 4.92 & 1.23 & 0.069 & 0.001 & 0.002 & 0.001 & -0.19 \\
\hline 6.04 & 1.51 & 0.083 & 0.000 & 0.001 & -0.001 & 0.25 \\
\hline 7.11 & 1.78 & 0.103 & -0.000 & 0.001 & 0.001 & -0.2 \\
\hline 8.1 d & 2.05 & 0.122 & -0.001 & 0.001 & -0.000 & 0.03 \\
\hline 9.19 & 2.30 & 0.139 & -0.000 & -0.001 & 0.001 & -0.15 \\
\hline 10.29 & 2.57 & 0.159 & -0.001 & 0.000 & -0.001 & 0.18 \\
\hline 11.32 & 2.83 & 0.177 & -0.002 & 0.001 & -0.001 & $0.2 \mathrm{G}$ \\
\hline 12.34 & 3.09 & 0.197 & -0.002 & -0.001 & -0.002 & 0.3 \\
\hline 13.45 & 3.36 & 0.219 & -0.003 & -0.001 & -0.002 & 0.39 \\
\hline 14.4 吗 & 3.61 & 0.254 & -0.003 & -0.001 & -0.002 & $\overrightarrow{0.4 \AA}$ \\
\hline 15.53 & 3.88 & 0.253 & -0.003 & -0.002 & -0.001 & 0.29 \\
\hline 16.61 & 4.15 & 0.279 & -0.003 & -0.001 & -0.003 & 0.61 \\
\hline 17.62 & 4.41 & 0.294 & -0.004 & -0.002 & -0.004 & 0.73 \\
\hline 18.67 & 4.67 & 0.318 & -0.004 & -0.002 & -0.004 & $0.7 \mathrm{q}$ \\
\hline 20.74 & 5.19 & 0.358 & -0.006 & -0.004 & -0.005 & 0.94 \\
\hline 21.86 & 5.46 & 0.383 & -0.006 & -0.003 & -0.004 & 0.81 \\
\hline 22.90 & 5.72 & 0.409 & -0.007 & -0.005 & -0.006 & 1.23 \\
\hline 23.89 & 5.97 & 0.433 & -0.008 & -0.006 & -0.006 & 1.19 \\
\hline 24.98 & 6.24 & 0.567 & -0.018 & -0.018 & -0.017 & 3.4 \\
\hline 25.89 & $6.4 \pi$ & 0.627 & -0.020 & -0.023 & -0.022 & 4.40 \\
\hline 26.87 & 6.72 & 0.688 & -0.023 & -0.027 & -0.025 & 4.98 \\
\hline 27.97 & 6.99 & 0.776 & -0.025 & -0.030 & -0.027 & 5.41 \\
\hline 29.06 & 7.27 & 0.957 & $-0.03 d$ & -0.032 & -0.032 & 6.30 \\
\hline 30.13 & 7.53 & 1.015 & -0.033 & -0.034 & -0.034 & 6.79 \\
\hline 31.14 & 7.79 & 1.089 & -0.037 & -0.036 & -0.034 & 6.84 \\
\hline 32.24 & 8.06 & 1.164 & -0.040 & -0.039 & -0.039 & 7.85 \\
\hline 33.28 & 8.32 & 1.232 & -0.043 & $\mid-0.041$ & -0.042 & 8.33 \\
\hline $34.3 \$$ & 8.59 & 1.299 & -0.046 & -0.044 & -0.045 & 9.06 \\
\hline 35.39 & 8.85 & 1.474 & -0.050 & -0.047 & -0.048 & 9.60 \\
\hline $36.3 \S$ & 9.09 & 1.516 & -0.052 & -0.048 & -0.051 & $10.1 f$ \\
\hline 37.47 & $9.3 \pi$ & 1.590 & -0.055 & -0.051 & -0.052 & 10.36 \\
\hline 38.51 & 9.63 & 1.668 & -0.058 & -0.053 & -0.056 & 71.21 \\
\hline 39.54 & 9.88 & 1.770 & -0.062 & -0.056 & -0.059 & 11.80 \\
\hline 40.5 & 10.14 & 1.856 & -0.065 & -0.058 & -0.062 & 12.35 \\
\hline 41.66 & 10.41 & 1.951 & -0.068 & -0.060 & -0.063 & 12.55 \\
\hline 42.70 & 10.68 & 2.037 & -0.072 & -0.063 & -0.06 & $13.4 \mathrm{~g}$ \\
\hline 43.80 & 10.95 & 2.117 & -0.075 & -0.065 & -0.070 & 14.09 \\
\hline 44.81 & 11.20 & 2.198 & -0.079 & -0.069 & -0.073 & 14.65 \\
\hline 45.82 & 11.46 & 2.283 & -0.082 & -0.070 & -0.077 & 15.31 \\
\hline 46.41 & 11.60 & 2.408 & -0.089 & -0.073 & -0.080 & 15.94 \\
\hline 47.42 & 11.86 & 2.445 & -0.089 & -0.074 & -0.081 & 16.29 \\
\hline
\end{tabular}




\section{CORROSION EFFECTS ON BOND STRENGTH IN REINFORCED CONCRETE}

\begin{tabular}{|c|c|c|c|c|c|c|}
\hline 48.41 & 12.12 & 2.503 & -0.092 & -0.076 & -0.085 & 16.99 \\
\hline $49.5 €$ & 12.39 & 2.571 & -0.095 & -0.078 & -0.087 & 17.32 \\
\hline 50.67 & 12.66 & 2.644 & -0.099 & -0.080 & -0.089 & 17.89 \\
\hline 51.64 & 12.91 & 2.705 & -0.101 & -0.079 & -0.092 & 18.44 \\
\hline 52.66 & 13.16 & 2.795 & -0.105 & -0.085 & -0.095 & 19.0 \\
\hline 53.70 & 13.42 & 2.888 & -0.109 & -0.086 & -0.096 & 19.1 \\
\hline 54.71 & 13.68 & 2.979 & -0.113 & -0.088 & -0.102 & 20.32 \\
\hline 55.7 \& & 13.94 & 3.076 & -0.117 & -0.092 & -0.103 & 20.59 \\
\hline 56.77 & 14.19 & $3.17 \mathrm{I}$ & -0.120 & -0.093 & -0.108 & 21.64 \\
\hline 57.86 & 14.46 & 3.297 & -0.127 & -0.096 & -0.111 & 22.24 \\
\hline 58.90 & 14.73 & 3.414 & -0.131 & -0.098 & -0.115 & 22.93 \\
\hline 59.91 & 14.98 & 3.524 & -0.137 & -0.101 & -0.119 & 23.79 \\
\hline 60.93 & 15.23 & 3.623 & -0.142 & -0.102 & -0.122 & 24.34 \\
\hline 61.94 & 15.48 & 3.740 & -0.146 & -0.106 & -0.127 & 25.37 \\
\hline 62.93 & 15.73 & 3.858 & -0.154 & -0.109 & -0.131 & 26.24 \\
\hline 63.92 & 15.98 & 4.004 & -0.162 & -0.114 & -0.136 & 27.11 \\
\hline 65.01 & 16.25 & 4.138 & -0.169 & -0.117 & -0.143 & 28.62 \\
\hline 66.03 & 16.51 & 4.342 & -0.182 & -0.123 & -0.152 & 30.44 \\
\hline 67.01 & 16.75 & 4.555 & -0.195 & -0.132 & -0.164 & 32.80 \\
\hline 68.03 & 17.01 & 4.923 & -0.221 & -0.146 & -0.184 & 36.73 \\
\hline 68.71 & 17.19 & 5.323 & -0.248 & -0.157 & -0.204 & 40.78 \\
\hline 69.42 & 17.35 & 5.725 & -0.273 & -0.167 & -0.221 & 44.24 \\
\hline 70.03 & 17.51 & 6.125 & -0.298 & -0.183 & -0.241 & $48.1 \mathrm{~g}$ \\
\hline 70.64 & 17.66 & 6.512 & -0.326 & -0.198 & -0.261 & 52.20 \\
\hline 71.20 & 17.80 & 6.913 & -0.353 & -0.210 & -0.284 & 56.78 \\
\hline 71.92 & 17.98 & 7.303 & -0.380 & -0.229 & -0.307 & 61.30 \\
\hline 72.51 & 18.13 & 7.702 & -0.413 & -0.245 & -0.328 & 65.53 \\
\hline 73.02 & 18.25 & 8.100 & -0.443 & -0.262 & -0.353 & 70.54 \\
\hline 73.66 & 18.41 & 8.500 & -0.474 & -0.281 & -0.377 & 75.42 \\
\hline 74.25 & 18.56 & 8.900 & -0.504 & -0.299 & -0.401 & 80.16 \\
\hline 74.73 & 18.68 & 9.280 & -0.538 & -0.317 & -0.426 & 85.1 \\
\hline 75.21 & 18.80 & 9.680 & -0.568 & -0.335 & -0.453 & 90.61 \\
\hline 75.81 & 18.97 & 10.080 & -0.603 & -0.356 & $-0.48 \mathrm{~d}$ & 96.0 \\
\hline 76.22 & 19.06 & 10.600 & -0.659 & -0.388 & -0.521 & 104.25 \\
\hline 75.21 & 18.80 & 10.880 & -0.698 & -0.415 & -0.556 & 111.25 \\
\hline 76.09 & 19.02 & 11.280 & -0.718 & -0.453 & -0.588 & 117.50 \\
\hline 76.51 & 19.14 & 11.680 & -0.750 & -0.484 & -0.617 & 123.37 \\
\hline $77.0 \mathrm{~S}$ & 19.26 & 12.080 & -0.788 & -0.513 & -0.651 & 130.13 \\
\hline 77.40 & 19.35 & 12.480 & -0.823 & -0.545 & -0.684 & $136.7 \mathrm{~s}$ \\
\hline 77.72 & 19.43 & 12.870 & -0.864 & -0.578 & -0.723 & 144.50 \\
\hline 78.04 & 19.51 & 13.270 & -0.907 & -0.611 & $-0.76 \mathrm{~d}$ & 152.00 \\
\hline 78.60 & 19.65 & 13.680 & -0.945 & -0.640 & -0.793 & 158.50 \\
\hline 78.84 & 19.70 & 14.080 & -0.975 & -0.665 & -0.820 & 164.00 \\
\hline 79.08 & 19.77 & 14.480 & -1.003 & -0.694 & -0.848 & 169.50 \\
\hline 79.18 & 19.80 & 14.870 & -1.035 & -0.713 & -0.875 & 175.00 \\
\hline 79.16 & 19.79 & 15.260 & -1.067 & -0.734 & -0.902 & 180.37 \\
\hline
\end{tabular}




\section{CORROSION EFFECTS ON BOND STRENGTH IN REINFORCED CONCRETE}

Appendix I

Structural Results

\begin{tabular}{|c|c|c|c|c|c|c|}
\hline 79.40 & 19.85 & 15.680 & -1.098 & -0.753 & -0.928 & 185.50 \\
\hline 79.5 & 19.88 & 16.080 & -1.130 & -0.773 & -0.952 & 190.37 \\
\hline $79.6 \notin$ & 19.92 & 16.500 & -1.170 & -0.793 & -0.983 & 196.62 \\
\hline 80.3 & 20.08 & 17.120 & -1.225 & -0.822 & -1.023 & 204.50 \\
\hline $79.9 d$ & 19.99 & 17.520 & -1.258 & -0.840 & -1.050 & 210.00 \\
\hline 80.04 & 20.01 & 17.920 & -1.288 & -0.858 & -1.073 & 214.63 \\
\hline 80.25 & 20.06 & 18.330 & -1.314 & -0.879 & -1.096 & 219.13 \\
\hline 80.38 & 20.10 & 18.720 & -1.336 & -0.898 & -1.118 & 223.50 \\
\hline 80.36 & 20.09 & 19.120 & -1.347 & -0.915 & -1.133 & 226.50 \\
\hline 80.36 & 20.09 & 19.520 & -1.362 & -0.932 & -1.148 & 229.50 \\
\hline 80.38 & 20.10 & 19.920 & -1.373 & -0.943 & -1.158 & 231.50 \\
\hline 80.28 & 20.07 & 20.320 & -1.383 & -0.953 & -1.170 & 234.00 \\
\hline 80.49 & 20.12 & 20.750 & -1.395 & -0.965 & -1.181 & 236.12 \\
\hline 80.54 & 20.14 & 21.160 & -1.413 & -0.975 & -1.194 & 239.00 \\
\hline 80.64 & 20.16 & 21.600 & -1.427 & -0.984 & -1.206 & 241.12 \\
\hline 80.68 & 20.17 & 21.990 & -1.439 & -0.993 & -1.217 & 243.37 \\
\hline 80.70 & 20.18 & 22.390 & -1.448 & -1.000 & $-1.22 \mathrm{~S}$ & 245.00 \\
\hline 79.59 & 19.90 & 22.640 & -1.450 & -0.998 & -1.226 & 245.12 \\
\hline 79.16 & 19.79 & 23.050 & -1.450 & -0.998 & -1.225 & 245.0 \\
\hline 79.26 & 19.82 & 23.460 & -1.451 & -0.998 & -1.225 & 245.00 \\
\hline 79.56 & 19.89 & 23.880 & -1.455 & -0.998 & -1.227 & 245.37 \\
\hline 79.45 & 19.86 & 24.280 & -1.461 & -0.995 & -1.230 & 246.00 \\
\hline 79.50 & 19.88 & 24.680 & -1.466 & -0.993 & -1.230 & $246.0 \mathrm{~g}$ \\
\hline 79.69 & 19.92 & 25.070 & -1.471 & -0.989 & -1.233 & 246.50 \\
\hline 79.71 & 19.94 & 25.260 & -1.475 & -0.990 & -1.233 & 246.50 \\
\hline 80.14 & 20.04 & 25.650 & -1.483 & -0.989 & -1.236 & 247.25 \\
\hline 80.30 & 20.08 & 26.060 & -1.490 & -0.990 & -1.242 & 248.3 \\
\hline $80.2 \$$ & 20.06 & 26.460 & -1.499 & -0.990 & -1.246 & 249.25 \\
\hline 80.37 & 20.08 & 26.870 & -1.508 & -0.992 & -1.250 & 250.00 \\
\hline 80.49 & 20.12 & 27.240 & -1.517 & -0.995 & -1.258 & 251.50 \\
\hline 80.38 & 20.10 & 27.640 & -1.524 & -0.995 & -1.259 & 251.87 \\
\hline $80.4 \emptyset$ & 20.12 & 28.050 & -1.533 & -0.998 & -1.267 & 253.37 \\
\hline 80.54 & 20.14 & 28.440 & -1.540 & -1.000 & -1.269 & 253.75 \\
\hline 80.33 & 20.08 & 28.860 & -1.545 & -1.000 & $-1,274$ & 254.8 \\
\hline 80.70 & 20.18 & 29.260 & -1.555 & -1.003 & -1.279 & 255.8 \\
\hline 80.97 & 20.24 & 29.650 & -1.564 & -1.008 & -1.287 & 257.3 \\
\hline 81.16 & 20.29 & 29.920 & -1.57 & -1.012 & -1.292 & 258.38 \\
\hline 81.18 & 20.30 & 30.040 & -1.573 & -1.013 & -1.294 & 258.8 \\
\hline 81.21 & 20.30 & 30.380 & -1.587 & -1.020 & -1.303 & 260.50 \\
\hline $82.2 q$ & 20.57 & 30.640 & -1.592 & -1.023 & -1.308 & 261.50 \\
\hline 81.16 & 20.29 & 30.910 & -1.601 & -1.027 & -1.314 & 262.88 \\
\hline 80.12 & 20.03 & 30.940 & -1.598 & -1.025 & -1.313 & 262.50 \\
\hline 79.02 & 19.76 & 30.960 & -1.596 & -1.023 & -1.309 & $261.8^{\circ}$ \\
\hline 77.99 & 19.50 & 30.930 & -1.594 & -1.020 & -1.308 & 261.50 \\
\hline 76.89 & 19.22 & 30.850 & -1.590 & -1.018 & -1.306 & 261.13 \\
\hline 75.71 & 18.93 & 30.720 & -1.582 & -1.013 & -1.298 & 259.50 \\
\hline
\end{tabular}


CORROSION EFFECTS ON BOND STRENGTH IN REINFORCED CONCRETE

Appendix I

Structural Results

\begin{tabular}{|c|c|c|c|c|c|c|}
\hline $74.3 \mathrm{~d}$ & 18.59 & 30.670 & -1.581 & -1.010 & -1.296 & 259.13 \\
\hline 73.3 & 18.33 & 30.600 & -1.578 & -1.008 & -1.293 & 258.50 \\
\hline 72.19 & 18.05 & 30.560 & -1.575 & -1.006 & -1.291 & 258.25 \\
\hline 71.10 & 17.77 & 30.520 & -1.571 & -1.003 & -1.288 & 257.62 \\
\hline 69.98 & 17.49 & 30.440 & -1.568 & -1.001 & -1.285 & 257.00 \\
\hline $68.9 q$ & 17.24 & 30.400 & -1.566 & -0.999 & -1.283 & 256.50 \\
\hline 67.84 & 16.96 & 30.320 & -1.562 & -0.998 & -1.280 & 256.00 \\
\hline 66.80 & 16.70 & 30.280 & -1.559 & -0.995 & -1.278 & 255.50 \\
\hline 65.73 & 16.43 & 30.240 & -1.557 & -0.993 & -1.276 & 255.12 \\
\hline 64.67 & 16.17 & 30.150 & -1.553 & -0.990 & -1.272 & 254.38 \\
\hline 63.54 & 15.89 & 30.120 & -1.548 & -0.988 & -1.270 & 254.00 \\
\hline 62.50 & 15.63 & 30.040 & -1.546 & -0.985 & -1.268 & 253.50 \\
\hline 61.49 & 15.37 & 30.000 & -1.543 & -0.983 & -1.264 & 252.7 \\
\hline 60.4 & 15.12 & 29.920 & -1.538 & -0.980 & -1.259 & 251.87 \\
\hline 58.84 & 14.71 & 29.140 & -1.488 & -0.959 & -1.224 & 244.75 \\
\hline 53.96 & 13.49 & 28.960 & -1.489 & -0.966 & -1.228 & 245.50 \\
\hline 50.81 & 12.72 & 28.960 & -1.486 & -0.965 & -1.227 & 245.37 \\
\hline 48.92 & 12.23 & 28.960 & -1.487 & -0.968 & -1.226 & 245.25 \\
\hline 47.74 & 11.94 & 28.960 & -1.488 & -0.965 & -1.226 & 245.12 \\
\hline 46.60 & 11.65 & 28.960 & -1.485 & -0.965 & -1.226 & 245.12 \\
\hline 45.21 & 11.30 & 28.680 & -1.481 & -0.953 & -1.217 & 243.37 \\
\hline 42.9 & 10.73 & 28.290 & -1.458 & -0.935 & -1.196 & 239.12 \\
\hline 39.47 & 9.87 & 27.900 & -1.424 & -0.925 & -1.173 & 234.62 \\
\hline 34.67 & 8.67 & 27.300 & -1.388 & -0.901 & -1.146 & 229.25 \\
\hline 28.77 & 7.19 & 26.680 & -1.353 & -0.889 & -1.118 & 223.50 \\
\hline $23.0 €$ & 5.76 & 26.090 & -1.320 & -0.875 & -1.096 & 219.13 \\
\hline 17.80 & 4.45 & 25.540 & -1.298 & -0.864 & -1.079 & 215.7 \\
\hline 12.89 & 3.22 & 24.920 & -1.279 & -0.853 & -1.064 & 212.88 \\
\hline 8.92 & 2.23 & 24.520 & -1.274 & -0.845 & -1.059 & 211.87 \\
\hline 6.10 & 1.52 & 24.440 & -1.275 & -0.841 & -1.058 & 211.62 \\
\hline 4.43 & 1.11 & 24.370 & -1.273 & -0.840 & -1.057 & 211.3 \\
\hline 3.13 & 0.78 & 24.300 & -1.273 & -0.840 & -1.056 & 211.25 \\
\hline 1.90 & 0.48 & 24.150 & -1.270 & -0.83 & -1.054 & 210.7 \\
\hline 0.7 . & 0.19 & 23.860 & -1.266 & -0.833 & -1.051 & 210.12 \\
\hline-0.26 & -0.07 & 23.480 & -1.263 & -0.821 & -1.043 & 208.50 \\
\hline-0.39 & -0.10 & 23.360 & -1.257 & -0.820 & -1.040 & 208.00 \\
\hline
\end{tabular}

Series 1 Quarter Debonded

\begin{tabular}{|r|r|r|r|r|r|r||}
\hline \hline $\begin{array}{c}\text { Load } \\
(\mathrm{kN})\end{array}$ & $\begin{array}{c}\text { Moment } \\
(\mathrm{kN}-\mathrm{m})\end{array}$ & $\begin{array}{c}\text { M.P. Displ. } \\
(\mathrm{mm})\end{array}$ & $\begin{array}{c}\text { E. Curv. LVDT } \\
(\mathrm{mm})\end{array}$ & $\begin{array}{c}\text { W. Curv. LVDT } \\
(\mathrm{mm})\end{array}$ & $\begin{array}{c}\text { Curv. LVDT Avg. } \\
(\mathrm{mm})\end{array}$ & $\begin{array}{c}\text { Curvature } \\
(\mathrm{l} / \mathrm{km})\end{array}$ \\
\hline \hline 0.13 & 0.03 & $0.00 \mathrm{~d}$ & -0.002 & 0.005 & 0.002 & -0.40 \\
\hline 1.23 & 0.31 & 0.070 & -0.004 & 0.004 & 0.001 & -0.1 \\
\hline 2.46 & 0.62 & 0.110 & -0.004 & 0.001 & -0.001 & 0.29 \\
\hline 3.65 & 0.91 & 0.110 & -0.003 & 0.003 & -0.000 & 0.03 \\
\hline 4.79 & 1.19 & 0.150 & -0.003 & 0.003 & -0.009 & 0.03 \\
\hline
\end{tabular}


CORRosion EFFECTS ON BOND STRENGTH IN REINFORCED CONCRETE

\begin{tabular}{|c|c|c|c|c|c|c|}
\hline Append & & & & & & Structural \\
\hline 5.94 & 1.48 & 0.160 & -0.005 & 0.003 & -0.001 & 0.16 \\
\hline 6.97 & 1.74 & 0.190 & -0.002 & 0.002 & -0.001 & 0.24 \\
\hline 8.04 & 2.01 & 0.220 & -0.006 & -0.001 & -0.002 & 0.30 \\
\hline 9.08 & 2.27 & 0.240 & -0.005 & 0.002 & 0.000 & -0.01 \\
\hline 10.24 & 2.56 & 0.270 & -0.005 & 0.001 & -0.003 & 0.50 \\
\hline 11.39 & 2.85 & 0.290 & -0.007 & 0.001 & -0.003 & 0.60 \\
\hline 12.44 & 3.10 & $0.32 d$ & -0.007 & 0.000 & -0.004 & 0.73 \\
\hline 13.53 & 3.38 & 0.350 & -0.008 & 0.002 & -0.004 & 0.89 \\
\hline 14.58 & 3.65 & 0.390 & -0.008 & -0.001 & -0.005 & 0.94 \\
\hline 15.67 & 3.92 & 0.420 & -0.009 & -0.002 & -0.006 & 1.11 \\
\hline $16.7 \AA$ & 4.19 & 0.430 & \begin{tabular}{|c|}
-0.011 \\
\end{tabular} & -0.003 & -0.006 & 1.24 \\
\hline 17.81 & 4.47 & 0.470 & -0.012 & -0.005 & -0.007 & 1.39 \\
\hline 18.89 & 4.72 & 0.510 & -0.009 & -0.006 & -0.008 & 1.65 \\
\hline 19.90 & 4.97 & 0.550 & -0.014 & -0.009 & -0.010 & 2.03 \\
\hline 21.01 & 5.25 & 0.630 & -0.011 & -0.010 & -0.013 & 2.59 \\
\hline 22.10 & 5.52 & 0.690 & -0.023 & -0.012 & -0.016 & 3.23 \\
\hline 23.19 & 5.80 & 0.870 & -0.025 & -0.029 & -0.027 & 5.44 \\
\hline 24.23 & 6.06 & 0.960 & -0.028 & -0.037 & -0.031 & 6.29 \\
\hline 25.27 & 6.32 & 1.040 & -0.031 & -0.043 & -0.037 & 7.32 \\
\hline 26.31 & 6.58 & 1.110 & -0.032 & -0.048 & -0.040 & 7.92 \\
\hline 27.46 & 6.87 & 1.190 & -0.035 & -0.052 & -0.043 & 8.64 \\
\hline 28.50 & 7.13 & 1.290 & -0.036 & -0.057 & -0.04 & 9.33 \\
\hline 29.60 & 7.40 & 1.360 & -0.038 & -0.062 & -0.050 & 9.99 \\
\hline 30.77 & 7.69 & 1.450 & -0.042 & -0.066 & -0.054 & 10.72 \\
\hline 31.94 & 7.99 & 1.550 & -0.045 & -0.070 & -0.057 & 11.43 \\
\hline 33.04 & 8.26 & 1.630 & -0.046 & -0.072 & -0.061 & 12.24 \\
\hline 34.13 & 8.53 & 1.710 & -0.052 & -0.077 & -0.067 & 13.33 \\
\hline 35.12 & 8.78 & 1.800 & -0.057 & -0.081 & -0.069 & 13.79 \\
\hline 36.22 & 9.05 & 1.910 & -0.059 & -0.083 & -0.072 & 14.49 \\
\hline 37.20 & 9.30 & 1.990 & -0.063 & -0.088 & -0.076 & 15.16 \\
\hline 38.22 & 9.55 & 2.070 & -0.066 & -0.091 & -0.079 & 15.72 \\
\hline 39.28 & 9.82 & 2.160 & -0.070 & -0.096 & -0.082 & 16.30 \\
\hline 40.34 & 10.09 & 2.270 & -0.073 & -0.099 & -0.085 & $\overline{17.06}$ \\
\hline 41.50 & 10.37 & 2.370 & -0.075 & -0.104 & -0.090 & 17.94 \\
\hline 42.57 & 10.64 & 2.500 & -0.081 & -0.110 & -0.095 & 19.00 \\
\hline 43.69 & 10.92 & 2.590 & -0.081 & -0.115 & -0.099 & 19.78 \\
\hline 44.73 & 11.18 & 2.680 & -0.086 & -0.121 & -0.103 & 20.65 \\
\hline 45.82 & 11.46 & 2.830 & -0.089 & -0.123 & -0.107 & 21.36 \\
\hline 46.81 & 11.70 & 2.980 & -0.094 & -0.128 & -0.111 & 22.25 \\
\hline 47.90 & 11.98 & 3.100 & -0.097 & -0.133 & -0.114 & 22.84 \\
\hline 48.9 & 12.24 & 3.190 & -0.101 & -0.137 & -0.120 & 23.99 \\
\hline 49.99 & 12.50 & 3.310 & -0.106 & -0.141 & -0.124 & 24.70 \\
\hline 51.03 & 12.76 & 3.430 & -0.107 & -0.145 & -0.127 & 25.47 \\
\hline 52.20 & 13.05 & 3.550 & -0.113 & -0.149 & -0.13 & 26.29 \\
\hline 53.24 & 13.31 & 3.670 & -0.117 & -0.152 & -0.135 & 26.9 \\
\hline 54.28 & 13.57 & 3.780 & -0.120 & -0.156 & -0.139 & 27.85 \\
\hline
\end{tabular}




\section{CORROSION EFFECTS ON BOND STRENGTH IN REINFORCED CONCRETE}

Appendix I

Structural Results

\begin{tabular}{|c|c|c|c|c|c|c|}
\hline 55.38 & 13.84 & 3.910 & -0.128 & -0.163 & -0.143 & 28.62 \\
\hline 56.37 & 14.09 & 4.020 & -0.131 & -0.163 & -0.147 & 29.3 \\
\hline $57.4 \mathrm{Q}$ & 14.36 & 4.150 & -0.135 & -0.166 & -0.151 & 30.2 \\
\hline 58.53 & 14.63 & 4.270 & -0.140 & $-0.17 d$ & -0.155 & 31.0 \\
\hline 59.73 & 14.93 & 4.420 & -0.146 & -0.174 & -0.160 & $32.0 \mathrm{~s}$ \\
\hline 60.90 & 15.23 & 4.590 & -0.153 & -0.178 & -0.166 & 33.12 \\
\hline 61.89 & 15.47 & 4.750 & -0.161 & -0.183 & -0.172 & 34.4 \\
\hline 62.96 & 15.74 & 4.950 & -0.168 & -0.192 & -0.180 & 36.0 \\
\hline 64.08 & 16.02 & 5.180 & -0.180 & -0.204 & -0.192 & 38.4 \\
\hline 65.09 & $16.2 \pi$ & 5.460 & -0.193 & -0.217 & -0.206 & 41.1 \\
\hline 65.79 & 16.44 & 5.860 & -0.213 & -0.239 & -0.225 & 45.0 \\
\hline $66.7 \$$ & 16.69 & 6.110 & -0.223 & -0.251 & -0.237 & 47.4 \\
\hline 67.8 & 16.95 & 6.480 & -0.243 & -0.263 & -0.253 & 50.5 \\
\hline 68.69 & 17.17 & 6.870 & -0.270 & -0.279 & -0.27 作 & 55.08 \\
\hline 69.60 & 17.40 & 7.270 & -0.296 & -0.293 & -0.296 & $\overline{59.1}$ \\
\hline 70.51 & 17.63 & 7.700 & -0.320 & -0.274 & -0.297 & 59.4 \\
\hline 70.16 & 17.54 & 8.100 & -0.332 & -0.284 & -0.308 & 61.6 \\
\hline 69.10 & 17.27 & $8.13 d$ & -0.330 & -0.282 & -0.306 & 61.27 \\
\hline 67.84 & 16.96 & 8.190 & -0.328 & -0.282 & -0.305 & 61.0 \\
\hline 66.59 & 16.65 & 8.250 & -0.327 & -0.282 & $-0.30 \mathrm{~s}$ & 61.0 \\
\hline 65.51 & 16.39 & 8.310 & -0.324 & -0.283 & -0.304 & 60.7 \\
\hline 64.48 & 16.12 & 8.390 & -0.322 & -0.284 & -0.304 & $\overline{60.70}$ \\
\hline 63.30 & 15.83 & 8.530 & -0.320 & -0.283 & -0.302 & 60.36 \\
\hline 62.21 & 15.55 & 8.670 & -0.317 & -0.285 & -0.302 & 60.3 \\
\hline 61.70 & 15.43 & 9.070 & -0.319 & -0.292 & -0.305 & 60.9 \\
\hline 62.10 & 15.53 & 9.500 & -0.316 & -0.303 & -0.311 & 62.1 \\
\hline 61.97 & 15.49 & 9.910 & -0.312 & -0.313 & -0.314 & 62.7 \\
\hline 60.77 & 15.19 & 10.030 & -0.297 & -0.327 & -0.313 & 62.5 \\
\hline 59.30 & 14.83 & 10.060 & -0.294 & -0.337 & $-0.31 d$ & 63.1 \\
\hline 58.18 & 14.54 & 10.110 & -0.294 & -0.342 & -0.318 & 63.5 \\
\hline 57.09 & $14.2 \pi$ & 10.190 & -0.292 & -0.354 & -0.323 & 64.5 \\
\hline 56.77 & 14.19 & 10.630 & -0.267 & -0.351 & -0.310 & 61.9 \\
\hline 56.63 & 14.16 & 11.030 & -0.233 & -0.399 & -0.317 & 63.3 \\
\hline 55.35 & 13.84 & 11.310 & -0.225 & -0.402 & -0.313 & 62.6 \\
\hline 52.55 & 13.14 & 11.630 & -0.216 & -0.401 & -0.309 & 61.7 \\
\hline 49.88 & 12.47 & 11.690 & -0.214 & -0.395 & -0.304 & 60.8 \\
\hline 47.99 & 11.99 & 11.750 & -0.213 & -0.395 & -0.305 & 60.96 \\
\hline 46.73 & 11.68 & 11.750 & -0.212 & -0.396 & $-0.30 \mathrm{~S}$ & 60.9 \\
\hline 45.50 & 11.38 & 11.810 & -0.211 & -0.396 & -0.304 & 60.7 \\
\hline 45.56 & 11.39 & 12.210 & -0.201 & -0.397 & -0.299 & 59.8 \\
\hline 46.28 & 11.57 & 12.620 & -0.182 & -0.399 & -0.291 & 58.2 \\
\hline 45.24 & 11.31 & 12.710 & -0.169 & -0.399 & -0.284 & 56.8 \\
\hline-0.11 & -0.03 & 7.990 & -0.078 & -0.298 & -0.188 & 37.58 \\
\hline
\end{tabular}


CORROSION EFFECTS ON BOND STRENGTH IN REINFORCED CONCRETE

Appendix I

Structural Results

Series 1 - Half

\begin{tabular}{|c|c|c|c|c|c|c|}
\hline $\begin{array}{l}\text { Load } \\
(\mathrm{kN})\end{array}$ & $\begin{array}{l}\text { Moment } \\
(\mathrm{kN}-\mathrm{m})\end{array}$ & $\begin{array}{c}\text { M.P. DispI. } \\
(\mathrm{mm})\end{array}$ & \begin{tabular}{|c|} 
E. Curv. LVDT \\
$(\mathrm{mm})$
\end{tabular} & $\begin{array}{l}\text { W. Curv. LVDT } \\
\text { (mm) }\end{array}$ & $\begin{array}{l}\text { Curv. LVDT Avg. } \\
\text { (mm) }\end{array}$ & $\begin{array}{c}\text { Curvature } \\
(1 / \mathrm{km})\end{array}$ \\
\hline 0.04 & 0.01 & $\overline{0.000}$ & -0.003 & -0.000 & 0.000 & 0.00 \\
\hline 1.14 & 0.28 & 0.030 & -0.001 & 0.001 & -0.000 & 0.05 \\
\hline 2.23 & 0.56 & 0.050 & -0.002 & -0.000 & -0.001 & 0.12 \\
\hline 3.33 & 0.83 & 0.080 & -0.003 & -0.002 & -0.002 & 0.30 \\
\hline 4.33 & 1.08 & 0.110 & -0.003 & -0.003 & -0.003 & 0.51 \\
\hline 5.42 & 1.36 & 0.120 & -0.004 & -0.003 & -0.003 & 0.59 \\
\hline 6.43 & 1.61 & 0.140 & -0.001 & -0.003 & -0.003 & $\overline{0.66}$ \\
\hline 7.44 & 1.86 & 0.160 & -0.006 & -0.003 & -0.007 & 1.31 \\
\hline $8.4 \mathrm{q}$ & 2.12 & 0.200 & -0.006 & -0.003 & -0.007 & 1.31 \\
\hline 9.47 & 2.37 & 0.240 & -0.008 & -0.004 & -0.005 & 0.91 \\
\hline 10.43 & 2.61 & 0.240 & -0.006 & -0.005 & -0.005 & 1.07 \\
\hline 11.45 & 2.86 & 0.280 & -0.007 & -0.007 & -0.006 & 1.14 \\
\hline 15.71 & 3.93 & 0.410 & -0.012 & -0.010 & -0.014 & 2.88 \\
\hline 16.71 & 4.19 & 0.480 & -0.015 & -0.008 & -0.012 & 2.36 \\
\hline 17.84 & 4.46 & 0.520 & -0.016 & -0.007 & -0.018 & 3.5 \\
\hline $18.8 \%$ & 4.72 & 0.600 & -0.017 & -0.013 & -0.014 & 2.70 \\
\hline 19.93 & 4.98 & 0.660 & -0.020 & -0.011 & -0.017 & 3.45 \\
\hline 20.96 & 5.24 & 0.720 & -0.022 & -0.010 & -0.016 & 3.16 \\
\hline 22.04 & 5.51 & 0.810 & -0.022 & -0.009 & -0.016 & 3.29 \\
\hline 20.92 & 5.23 & 1.000 & -0.024 & -0.006 & -0.017 & 3.41 \\
\hline 19.81 & 4.95 & 1.030 & -0.025 & -0.005 & -0.016 & 3.16 \\
\hline 18.70 & 4.68 & 1.080 & -0.022 & -0.005 & -0.012 & 2.37 \\
\hline 17.5 & 4.39 & 1.140 & -0.022 & -0.004 & -0.013 & 2.53 \\
\hline 16.31 & 4.08 & 1.160 & -0.022 & -0.004 & -0.013 & 2.55 \\
\hline 15.01 & 3.75 & 1.200 & -0.019 & -0.002 & -0.011 & 2.16 \\
\hline 13.85 & $3.4 \mathrm{~d}$ & 1.200 & -0.017 & -0.003 & -0.015 & 3.02 \\
\hline $12.6 \mathrm{~S}$ & 3.16 & 1.210 & -0.019 & -0.003 & -0.012 & 2.40 \\
\hline 11.54 & 2.89 & 1.240 & -0.018 & -0.002 & -0.015 & $\overline{2.94}$ \\
\hline 10.39 & 2.60 & 1.280 & -0.016 & -0.003 & -0.014 & 2.73 \\
\hline 9.35 & 2.34 & 1.520 & -0.016 & -0.002 & -0.009 & 1.86 \\
\hline 8.24 & 2.06 & 1.920 & -0.015 & -0.001 & -0.012 & $\overline{2.30}$ \\
\hline 7.11 & 1.78 & 2.390 & -0.015 & -0.000 & -0.008 & 1.54 \\
\hline 6.32 & 1.58 & 2.810 & -0.014 & -0.000 & -0.008 & 1.51 \\
\hline 5.50 & 1.37 & 3.270 & -0.018 & -0.000 & -0.013 & 2.59 \\
\hline 4.89 & 1.22 & 3.690 & -0.017 & -0.000 & -0.010 & 2.00 \\
\hline 4.41 & 1.10 & 4.120 & -0.014 & -0.008 & -0.012 & $\overline{2.48}$ \\
\hline 3.61 & 0.90 & 4.600 & -0.024 & -0.007 & -0.018 & 3.55 \\
\hline 3.59 & 0.89 & 5.060 & -0.024 & -0.007 & -0.015 & 3.06 \\
\hline 3.29 & 0.82 & 5.520 & -0.023 & -0.008 & -0.016 & 3.10 \\
\hline 3.01 & 0.77 & 5.940 & -0.025 & -0.007 & -0.014 & 2.88 \\
\hline 2.84 & 0.71 & 6.390 & -0.022 & -0.012 & -0.020 & 3.99 \\
\hline 2.87 & 0.72 & 6.850 & -0.018 & -0.012 & -0.016 & 3.11 \\
\hline 2.83 & 0.71 & 7.320 & -0.017 & -0.012 & -0.016 & 3.14 \\
\hline
\end{tabular}




\begin{tabular}{|c|c|c|c|c|c|c|}
\hline $0 b^{\prime} Z E$ & $291^{\circ} 0^{-}$ & OSE'0- & $\varepsilon \varepsilon 0^{\prime} 0$ & $\nabla L^{\prime} \varepsilon$ & $S L^{\prime} 6$ & $20.6 \varepsilon$ \\
\hline $86^{\circ} 62$ & $\mathrm{OSI}^{\circ} \mathrm{O}^{-}$ & 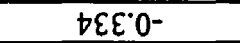 & $6 \varepsilon 0^{\circ} 0$ & $\nabla 9^{\circ} \varepsilon$ & 676 & $86^{\circ} L \varepsilon$ \\
\hline $50^{\circ} 62$ & sti.0- & OZE'0- & $2+0^{\circ} 0$ & $\angle S^{\prime} \varepsilon$ & $s Z^{\prime} 6$ & $66^{\circ} 9 \varepsilon$ \\
\hline$\varepsilon L \angle Z$ & $6 \varepsilon I^{\circ} 0^{-}$ & દIE.0- & $S+0^{\circ} 0$ & $87^{\circ} \varepsilon$ & 668 & $56^{\circ} \varsigma \varepsilon$ \\
\hline $16^{\circ} \mathrm{SZ}$ & OEI'0- & $662^{\circ} 0^{-}$ & $S \rightarrow 0^{\circ} 0$ & $6 \varepsilon^{\prime} \varepsilon$ & $\varepsilon L^{\prime} 8$ & $\varepsilon 6^{\circ} \circ \varepsilon$ \\
\hline$s 9^{\circ}+z$ & EZI'0- & $68 Z^{\circ} 0^{-}$ & $s+0^{\circ} 0$ & $6 \tau^{\circ} \varepsilon$ & 678 & $\angle 6^{\circ} \varepsilon \varepsilon$ \\
\hline $19^{\circ} \varepsilon \tau$ & $81^{\circ} 0^{-}$ & SLZ'0- & $S+0^{\circ} 0$ & $81^{\circ} \varepsilon$ & $\varepsilon Z^{\prime} 8$ & $\varepsilon 6^{\circ} Z \varepsilon$ \\
\hline$S L^{\prime} I Z$ & $601^{\circ} 0^{-}$ & $092^{\circ} 0^{-}$ & $\angle \Delta 0^{\circ} 0$ & $60^{\circ} \varepsilon$ & $\angle 6 . L$ & $68^{\circ} \backslash \varepsilon$ \\
\hline $29^{\circ} 02$ & EOI'0- & $\angle+Z^{\prime} 0^{-}$ & $2+0^{\circ} 0$ & $00^{\circ} \varepsilon$ & $O L L$ & $08^{\circ} 0 \mathcal{E}$ \\
\hline $6 \varepsilon^{\circ} 6 \mathrm{I}$ & $\angle 60^{\circ} 0^{-}$ & $\varepsilon \varepsilon Z^{\circ} 0^{-}$ & $0+0^{\circ} 0$ & $688^{\circ} \mathrm{Z}$ & $S D^{\circ} L$ & $8 L^{\circ} 62$ \\
\hline $6 t^{\circ} 81$ & $260^{\circ} 0^{-}$ & $12 Z^{\circ} 0^{-}$ & $\angle \varepsilon 0^{\circ} 0$ & $08^{\circ} \mathrm{Z}$ & $61 . \mathrm{L}$ & $\nabla L .82$ \\
\hline $0 S^{\circ} 81$ & $\varepsilon 60^{\circ} 0^{-}$ & ZIZ०0- & $9 \varepsilon 0^{\circ} 0$ & $I L^{\prime} Z$ & $\varepsilon 6.9$ & $0<\angle 2$ \\
\hline $0 L^{\prime} \angle I$ & $680^{\circ} 0^{-}$ & $66 \mathrm{I}^{\circ} \mathrm{O}^{-}$ & $\angle \varepsilon 0^{\circ} 0$ & $19^{\circ} \mathrm{Z}$ & $99^{\circ} 9$ & $\varepsilon 9^{\circ} 92$ \\
\hline$\$ 6^{\circ} \mathrm{SI}$ & $080^{\circ} 0^{-}$ & $\angle 8 I^{\circ} 0^{-}$ & $\tau \varepsilon 0^{\circ} 0$ & 052 & $6 \varepsilon^{\prime} 9$ & $\angle S^{\prime} S Z$ \\
\hline $9 L^{\circ} D I$ & $\forall \angle 0^{\circ} 0^{-}$ & $\angle L I^{\circ} 0^{-}$ & $1 \varepsilon 0^{\circ} 0$ & $1 \nabla^{2} 2$ & $21^{\circ} 9$ & $\angle t^{\circ} t z$ \\
\hline$s t^{\circ} \downarrow I$ & $Z \angle 0^{\circ} 0^{-}$ & $99 \mathrm{l}^{\circ} 0^{-}$ & $620^{\circ} 0$ & $I \varepsilon^{\prime} Z$ & $78^{\circ} \mathrm{S}$ & $S E^{\circ} \varepsilon Z$ \\
\hline $6 L^{\circ} \mathrm{ZI}$ & $790^{\circ} 0^{-}$ & SSI'0- & $\angle 20^{\circ} 0$ & $0 \tau^{2} z$ & $\angle S^{\circ} S$ & $82^{\prime} 22$ \\
\hline $6 Z^{\circ} \varepsilon I$ & $990^{\circ} 0^{-}$ & $t+1^{\circ} 0^{-}$ & $\nabla 20^{\circ} 0$ & $60^{\circ} \mathrm{Z}$ & $6 Z^{\circ} \mathrm{S}$ & $\angle I^{\circ} I Z$ \\
\hline $1 \tau^{\circ} \mathrm{II}$ & $9 S 0^{\circ} 0^{-}$ & $\nabla \varepsilon I^{\circ} 0^{-}$ & $220^{\circ} 0$ & $66 \mathrm{I}$ & $20^{\circ} \mathrm{s}$ & $\angle 0^{\circ} 02$ \\
\hline$\varepsilon t^{\circ} 0 \mathrm{l}$ & $2 S 0^{\circ} 0^{-}$ & $\varepsilon Z I^{\circ} 0^{-}$ & $810^{\circ} 0$ & $98 . \mathrm{I}$ & $\nabla L^{\prime} t$ & 56.81 \\
\hline$O L^{\circ} 0 \mathrm{I}$ & ${ }^{\circ} S 0^{\circ} 0^{-}$ & SII $0^{-}$ & $S 10^{\circ} 0$ & $\angle L^{\prime} I$ & $\angle D^{\circ} D$ & $68^{\circ} \angle \mathrm{I}$ \\
\hline $8 I^{\prime} 6$ & $9+0^{\circ} 0^{-}$ & $60 \mathrm{I}^{\circ} \mathrm{O}^{-}$ & $110^{\circ} 0$ & $\angle 9^{\circ} \mathrm{l}$ & $\varepsilon Z^{\prime} t$ & $\varepsilon 6.91$ \\
\hline$\angle 68$ & $\mathrm{StO}^{\circ} 0^{-}$ & $260^{\circ} 0^{-}$ & $110^{\circ} 0$ & $\angle S^{\circ} I$ & $\$ 6^{\circ} \varepsilon$ & $28^{\circ} \mathrm{Sl}$ \\
\hline$\varepsilon t^{\circ} 6$ & $\angle \forall 0^{\circ} 0^{-}$ & $760^{\circ} 0^{-}$ & $010^{\circ} 0$ & $9 S^{\prime} \mathrm{I}$ & $89^{\circ} \varepsilon$ & $\nabla L^{\circ} \not 1$ \\
\hline $9 \varepsilon^{\prime \prime} 6$ & $\angle D 0^{\circ} 0^{-}$ & $760^{\circ} 0^{-}$ & $010^{\circ} 0$ & $S S^{\prime} I$ & $8 \varepsilon^{\prime} \varepsilon$ & $\varepsilon S^{\prime} \varepsilon I$ \\
\hline $26^{\circ} \mathrm{L}$ & $0+0^{\circ} 0^{-}$ & $\angle 80^{\circ} 0^{-}$ & $800^{\circ} 0$ & $60^{\circ} \mathrm{I}$ & $90^{\circ} \varepsilon$ & $s Z^{\prime 2 I}$ \\
\hline$\$ 0 . \mathrm{L}$ & $S E 0^{\circ} 0^{-}$ & $\rightarrow \angle 0^{\circ} 0^{-}$ & $S 00^{\circ} 0$ & $z \varepsilon^{\prime} I$ & $69^{\prime} \mathrm{Z}$ & $9 L^{\circ} 0 \mathrm{I}$ \\
\hline $99^{\circ} \mathrm{S}$ & $820^{\circ} 0^{-}$ & $850^{\circ} 0^{-}$ & $200^{\circ} 0$ & $\varepsilon I^{\prime} I$ & $\varepsilon \varepsilon \tau$ & ZЕ' 6 \\
\hline$\angle E^{\prime} S$ & $\angle 2 O^{\circ} O^{-}$ & $160^{\circ} 0^{-}$ & $100^{\circ} 0$ & 26.0 & $\varepsilon 0^{2} \mathrm{Z}$ & 118 \\
\hline $25^{\circ} 1$ & $800^{\circ} 0^{-}$ & $\operatorname{si0} 0^{\circ} 0^{-}$ & $000^{\circ} 0$ & $\varepsilon \varsigma^{\circ} 0$ & $\nabla L I$ & 96.9 \\
\hline$S 0^{\circ} \varepsilon$ & $\mathrm{SIO}^{\circ} 0^{-}$ & $910^{\circ} 0^{-}$ & $000^{\circ} 0$ & $\varepsilon S^{\circ} 0$ & 66.1 & $S 6{ }^{\circ} \mathrm{L}$ \\
\hline 19.1 & $800^{\circ} 0^{-}$ & SI0'0- & $000^{\circ} 0^{-}$ & $\varepsilon S^{\circ} 0$ & $\angle Z Z$ & $\angle 0^{\circ} 6$ \\
\hline $25^{\circ} 1$ & $800^{\circ} 0^{-}$ & $\nabla 10^{\circ} 0^{-}$ & $100^{\circ} 0^{-}$ & 250 & $\operatorname{ss} Z$ & $2 \tau^{\prime} 01$ \\
\hline $8 t^{\prime} \mathrm{Z}$ & $210^{\circ} 0^{-}$ & $\varepsilon 10^{\circ} 0^{-}$ & $100^{\circ} 0^{-}$ & $05^{\circ} 0$ & $88^{\circ} \mathrm{Z}$ & ES.1I \\
\hline $6 L^{\prime} I$ & $600^{\circ} 0^{-}$ & $\angle 10^{\circ} 0^{-}$ & $100^{\circ} 0^{-}$ & $\angle \nabla^{\circ} 0$ & $\varepsilon Z^{\circ} \varepsilon$ & $26^{\circ} \mathrm{ZI}$ \\
\hline$L L I I$ & $600^{\circ} 0^{-}$ & $010^{\circ} 0^{-}$ & $100^{\circ} 0^{-}$ & $S t^{\circ} 0$ & $\angle S^{\prime} \varepsilon$ & $0 \varepsilon^{\circ} \not I$ \\
\hline$S \tau^{\circ} I$ & $900^{\circ} 0^{-}$ & $\angle 00^{\circ} 0^{-}$ & $500^{\circ} 0^{-}$ & $2 b^{\circ} 0$ & $06^{\circ} \varepsilon$ & I9.SI \\
\hline $62^{\circ} 0$ & $100^{\circ} 0^{-}$ & $200^{\circ} 0^{-}$ & $200^{\circ} 0^{-}$ & $8 \varepsilon^{\circ} 0$ & $\angle I^{\circ} \mathrm{D}$ & 69.91 \\
\hline $06^{\circ} 0$ & $500^{\circ} 0^{-}$ & $100^{\circ} 0^{-}$ & $100^{\circ} 0$ & SЕ० & $98^{\circ} \varepsilon$ & $\varepsilon t^{\circ} \varsigma l$ \\
\hline โЕ' & $\angle 00^{\circ} 0^{-}$ & $200^{\circ} 0^{-}$ & $100^{\circ} 0$ & $\angle E \cdot O$ & $\varsigma \varsigma^{\prime} \varepsilon$ & $0 z^{\prime} \neq 1$ \\
\hline $60^{\circ} 0^{-}$ & $000^{\circ} 0$ & $100^{\circ} 0^{-}$ & $200^{\circ} 0$ & $9 \varepsilon 0$ & $56{ }^{\circ} \mathrm{Z}$ & $6 L 11$ \\
\hline$I E 0^{-}$ & $200^{\circ} 0$ & $000^{\circ} 0$ & $\varepsilon 00^{\circ} 0$ & I $\varepsilon^{\circ} 0$ & $0 \mathrm{I}^{2} \mathrm{Z}$ & It8 \\
\hline $0 z^{\prime} 0^{-}$ & $100^{\circ} 0$ & $200^{\circ} 0$ & $500^{\circ} 0$ & $\varepsilon Z^{\circ} 0$ & $2 \varepsilon^{\prime} l$ & $0 \varepsilon^{\circ} S$ \\
\hline IS.0- & $\varepsilon 00^{\circ} 0$ & $100^{\circ} 0$ & $900^{\circ} 0$ & $\angle I^{\circ} 0$ & $9 L^{\circ} 0$ & $b 0^{\circ} \varepsilon$ \\
\hline $82^{\circ} 0^{-}$ & $100^{\circ} 0$ & $200^{\circ} 0$ & $\angle 00^{\circ} 0$ & $2 I^{\circ} 0$ & ZE. 0 & $0 \varepsilon^{\prime \prime} I$ \\
\hline $68^{\circ} 0^{-}$ & $700^{\circ} 0$ & $800^{\circ} 0$ & $600^{\circ} 0$ & $00^{\circ} 0$ & $70^{\circ} 0^{-}$ & $\nabla 0^{\circ} 0^{-}$ \\
\hline$(\mathrm{UrV} / \mathrm{l})$ & (uw) & (uw) & (um) & (uw) & $(\mathrm{U}-\mathrm{N} Y)$ & (NY) \\
\hline әมฺุEAnก & כ & 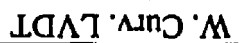 & I & Ids!a $\mathrm{d}^{\prime} w$ & \{uəurow & peoT \\
\hline
\end{tabular}

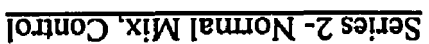


CORROSION EFFECTS ON BOND STRENGTH IN REINFORCED CONCRETE

Appendix I

Structural Results

\begin{tabular}{|c|c|c|c|c|c|c|}
\hline 40.01 & 10.00 & 3.85 & 0.029 & -0.360 & -0.171 & 34.20 \\
\hline 41.15 & 10.29 & 3.98 & 0.020 & -0.376 & -0.185 & 36.95 \\
\hline 42.11 & 10.53 & 4.13 & 0.013 & -0.390 & -0.188 & 37.67 \\
\hline 43.26 & 10.82 & 4.28 & 0.013 & -0.411 & -0.200 & 40.02 \\
\hline 44.36 & 11.09 & 4.45 & 0.016 & -0.431 & -0.213 & 42.53 \\
\hline 45.34 & 11.34 & 4.61 & 0.023 & -0.454 & -0.216 & 43.10 \\
\hline 46.28 & 11.57 & 4.77 & 0.033 & -0.473 & -0.226 & 45.10 \\
\hline 47.29 & 11.82 & 4.93 & 0.033 & -0.493 & -0.230 & 45.94 \\
\hline 48.31 & 12.08 & 5.01 & 0.029 & -0.500 & -0.238 & 47.58 \\
\hline 49.35 & 12.34 & 5.13 & 0.018 & -0.513 & -0.246 & 49.15 \\
\hline 50.41 & 12.60 & 5.25 & 0.009 & -0.528 & -0.262 & 52.48 \\
\hline 51.40 & 12.85 & 5.41 & 0.000 & -0.539 & -0.275 & 54.95 \\
\hline 52.52 & 13.13 & 5.57 & -0.010 & -0.558 & -0.285 & 57.01 \\
\hline 53.64 & 13.41 & 5.77 & -0.020 & -0.579 & -0.304 & 60.85 \\
\hline 54.66 & 13.66 & 5.96 & -0.031 & -0.598 & -0.319 & 63.89 \\
\hline 55.70 & 13.92 & 6.17 & -0.041 & -0.620 & -0.334 & 66.83 \\
\hline 56.77 & 14.19 & 6.38 & -0.054 & -0.644 & -0.352 & 70.43 \\
\hline 57.81 & 14.45 & 6.69 & -0.072 & .0 .680 & -0.380 & 75.98 \\
\hline 58.90 & 14.73 & 6.98 & -0.096 & -0.714 & -0.410 & 82.09 \\
\hline 59.97 & 14.99 & 7.41 & -0.132 & -0.756 & -0.450 & 89.95 \\
\hline 60.66 & 15.17 & 7.85 & -0.175 & -0.806 & -0.495 & 99.03 \\
\hline 60.98 & 15.25 & 8.29 & -0.223 & -0.852 & -0.538 & 107.50 \\
\hline 61.28 & 15.32 & 8.73 & -0.243 & -0.899 & -0.574 & 114.87 \\
\hline 61.68 & 15.42 & 9.16 & -0.290 & -0.939 & -0.617 & 123.37 \\
\hline 61.81 & 15.45 & 9.58 & -0.333 & -0.980 & -0.658 & 131.50 \\
\hline 61.97 & 15.49 & 10.01 & -0.368 & -1.015 & -0.693 & 138.50 \\
\hline 61.52 & 15.38 & 10.45 & -0.397 & -1.036 & -0.717 & 143.38 \\
\hline 60.82 & 15.21 & 10.89 & -0.430 & -1.055 & -0.743 & 148.63 \\
\hline 60.39 & 15.10 & 11.30 & -0.464 & -1.095 & -0.781 & 156.25 \\
\hline 60.21 & 15.05 & 11.73 & -0.505 & -1.125 & -0.817 & 163.37 \\
\hline 60.10 & 15.03 & 12.15 & -0.534 & -1.154 & -0.848 & 169.62 \\
\hline 60.05 & 15.01 & 12.59 & -0.574 & -1.191 & -0.883 & 176.50 \\
\hline 60.15 & 15.04 & 13.01 & -0.611 & -1.228 & -0.921 & 184.12 \\
\hline 60.18 & 15.05 & 13.45 & -0.650 & -1.263 & -0.958 & 191.50 \\
\hline 60.34 & 15.09 & 13.89 & -0.677 & -1.309 & -0.987 & 197.37 \\
\hline 60.37 & 15.09 & 14.29 & -0.712 & -1.353 & -1.033 & 206.50 \\
\hline 60.45 & 15.11 & 14.73 & -0.746 & -1.396 & -1.075 & 215.00 \\
\hline 60.61 & 15.15 & 15.13 & -0.787 & -1.439 & -1.113 & 222.62 \\
\hline 60.69 & 15.17 & 15.56 & -0.822 & -1.480 & -1.153 & 230.50 \\
\hline 60.77 & 15.19 & 15.97 & -0.875 & -1.503 & -1.191 & 238.25 \\
\hline 60.69 & 15.17 & 16.41 & -0.933 & -1.518 & -1.228 & 245.50 \\
\hline 60.72 & 15.18 & 16.86 & -0.980 & -1.530 & -1.258 & 251.50 \\
\hline 61.01 & 15.25 & 17.30 & -1.023 & -1.525 & -1.276 & 255.25 \\
\hline 61.17 & 15.29 & 17.73 & -1.060 & -1.512 & -1.289 & 257.75 \\
\hline 61.41 & 15.35 & 18.17 & -1.083 & -1.522 & -1.306 & 261.13 \\
\hline 61.46 & 15.37 & 18.61 & -1.118 & -1.535 & -1.328 & 265.50 \\
\hline 61.46 & 15.37 & 19.07 & -1.151 & -1.548 & -1.351 & 270.12 \\
\hline 61.52 & 15.38 & 19.50 & -1.178 & -1.561 & -1.373 & 274.50 \\
\hline 61.60 & 15.40 & 19.97 & -1.210 & -1.575 & -1.394 & 278.87 \\
\hline 61.70 & 15.43 & 20.41 & -1.240 & -1.588 & -1.415 & 283.00 \\
\hline
\end{tabular}




\section{CORROSION EFFECTS ON BOND STRENGTH IN REINFORCED CONCRETE}

Appendix I

Structural Results

\begin{tabular}{|c|c|c|c|c|c|c|}
\hline 61.78 & 15.45 & 20.85 & -1.268 & -1.598 & -1.435 & 287.00 \\
\hline 61.89 & 15.47 & 21.29 & -1.297 & -1.610 & -1.453 & 290.62 \\
\hline 62.00 & 15.50 & 21.76 & -1.328 & -1.623 & -1.477 & 295.37 \\
\hline 62.08 & 15.52 & 22.17 & -1.358 & -1.633 & -1.497 & 299.37 \\
\hline 62.08 & 15.52 & 22.62 & -1.390 & -1.644 & -1.519 & 303.75 \\
\hline 62.02 & 15.51 & 23.08 & -1.414 & -1.653 & -1.535 & 307.00 \\
\hline 62.18 & 15.55 & 23.49 & -1.445 & -1.661 & -1.555 & 311.00 \\
\hline 62.29 & 15.57 & 23.93 & -1.478 & -1.670 & -1.576 & 315.13 \\
\hline 62.26 & 15.57 & 24.37 & -1.510 & -1.681 & -1.598 & 319.50 \\
\hline 62.40 & 15.60 & 24.81 & -1.542 & -1.690 & -1.618 & 323.50 \\
\hline 62.48 & 15.62 & 25.21 & -1.575 & -1.700 & -1.640 & 328.00 \\
\hline 62.42 & 15.61 & 25.62 & -1.605 & -1.710 & -1.660 & 332.00 \\
\hline 62.64 & 15.66 & 2.6 .07 & -1.639 & -1.720 & -1.683 & 336.50 \\
\hline 62.53 & 15.63 & 26.49 & -1.672 & -1.730 & -1.704 & 340.75 \\
\hline 62.61 & 15.65 & 26.89 & -1.705 & -1.739 & -1.725 & 345.00 \\
\hline 62.58 & 15.65 & 27.29 & -1.746 & -1.748 & -1.749 & 349.75 \\
\hline 62.56 & 15.64 & 27.74 & -1.780 & -1.758 & -1.769 & 353.87 \\
\hline 62.56 & 15.64 & 28.19 & -1.815 & -1.768 & -1.793 & 358.50 \\
\hline 62.53 & 15.63 & 28.62 & -1.848 & -1.778 & -1.815 & 363.00 \\
\hline 62.56 & 15.64 & 29.05 & -1.880 & -1.791 & -1.836 & 367.25 \\
\hline 62.61 & 15.65 & 29.48 & -1.913 & -1.805 & -1.863 & 372.50 \\
\hline 62.53 & 15.63 & 29.93 & -1.945 & -1.819 & -1.883 & 376.62 \\
\hline 62.58 & 15.65 & 30.33 & -1.981 & -1.833 & -1.908 & 381.50 \\
\hline 62.50 & 15.63 & 30.77 & -2.011 & -1.845 & -1.930 & 386.00 \\
\hline 62.61 & 15.65 & 31.21 & -2.043 & -1.860 & -1.953 & 390.62 \\
\hline 62.42 & 15.61 & 31.61 & -2.071 & -1.874 & -1.975 & 395.00 \\
\hline 62.45 & 15.61 & 32.05 & -2.103 & -1.890 & -1.999 & 399.87 \\
\hline 62.02 & 15.51 & 36.98 & -2.428 & -2.075 & -2.254 & 450.87 \\
\hline 62.05 & 15.51 & 37.43 & -2.458 & -2.094 & -2.278 & 455.63 \\
\hline 62.08 & 15.52 & 37.87 & -2.490 & -2.113 & -2.304 & 460.87 \\
\hline 62.05 & 15.51 & 38.32 & -2.522 & -2.133 & -2.330 & 466.00 \\
\hline 62.00 & 15.50 & 38.76 & -2.555 & -2.150 & -2.355 & 471.00 \\
\hline 62.05 & 15.51 & 39.21 & -2.588 & -2.169 & -2.385 & 477.00 \\
\hline 61.92 & 15.48 & 39.66 & -2.631 & -2.190 & -2.413 & 482.50 \\
\hline 61.94 & 15.49 & 40.11 & -2.665 & -2.213 & -2.441 & 488.12 \\
\hline 61.97 & 15.49 & 40.57 & -2.701 & -2.234 & -2.470 & 494.00 \\
\hline 61.92 & 15.48 & 41.02 & -2.747 & -2.258 & -2.509 & 501.87 \\
\hline 60.82 & 15.21 & 41.47 & -2.959 & -2.242 & -2.605 & 521.00 \\
\hline 60.13 & 15.03 & 41.90 & -3.074 & -2.228 & -2.654 & 530.87 \\
\hline 59.91 & 14.98 & 42.36 & -3.181 & -2.206 & -2.698 & 539.50 \\
\hline 59.81 & 14.95 & 42.81 & -3.196 & -2.211 & -2.706 & 541.12 \\
\hline 59.83 & $14 . \overline{96}$ & 43.24 & -3.200 & -2.228 & -2.716 & 543.25 \\
\hline 59.89 & 14.97 & 43.70 & -3.200 & -2.255 & -2.730 & 546.00 \\
\hline 59.81 & 14.95 & 44.14 & -3.203 & -2.284 & -2.746 & 549.25 \\
\hline 59.46 & 14.87 & 44.57 & -3.201 & -2.330 & -2.768 & 553.62 \\
\hline 58.71 & 14.68 & 45.02 & -3.200 & -2.370 & -2.788 & 557.50 \\
\hline 57.62 & 14.40 & 45.10 & -3.201 & -2.378 & -2.793 & 558.50 \\
\hline 56.47 & 14.12 & 45.11 & -3.201 & -2.380 & -2.793 & 558.62 \\
\hline 55.24 & 13.81 & 44.97 & -3.201 & -2.375 & -2.790 & 558.00 \\
\hline
\end{tabular}




\section{CORROSION EFFECTS ON BOND STRENGTH IN REINFORCED CONCRETE}

Appendix I

Structural Results

\begin{tabular}{||l|l|l|l|l|l|l||}
\hline \hline 54.15 & 13.54 & 44.83 & -3.201 & -2.368 & -2.786 & 557.25 \\
\hline 52.98 & 13.24 & 44.71 & -3.201 & -2.361 & -2.783 & 556.63 \\
\hline 51.80 & 12.95 & 44.59 & -3.202 & -2.355 & -2.781 & 556.13 \\
\hline 50.60 & 12.65 & 44.46 & -3.201 & -2.348 & -2.778 & 555.50 \\
\hline 49.51 & 12.38 & 44.35 & -3.201 & -2.343 & -2.775 & 555.00 \\
\hline 48.39 & 12.10 & 44.25 & -3.198 & -2.336 & -2.770 & 554.00 \\
\hline 47.10 & 11.78 & 44.24 & -3.201 & -2.335 & -2.770 & 554.00 \\
\hline 47.16 & 11.79 & 43.11 & -3.201 & -2.273 & -2.739 & 547.87 \\
\hline 44.30 & 11.08 & 43.15 & -3.201 & -2.272 & -2.739 & 547.75 \\
\hline 42.57 & 10.64 & 43.14 & -3.201 & -2.272 & -2.739 & 547.75 \\
\hline 41.34 & 10.33 & 43.14 & -3.202 & -2.271 & -2.739 & 547.87 \\
\hline 40.27 & 10.07 & 43.14 & -3.200 & -2.272 & -2.739 & 547.75 \\
\hline 39.12 & 9.78 & 42.32 & -3.201 & -2.255 & -2.730 & 546.00 \\
\hline 35.92 & 8.98 & 40.93 & -3.201 & -2.195 & -2.699 & 539.87 \\
\hline 30.69 & 7.67 & 39.46 & -3.201 & -2.131 & -2.667 & 533.38 \\
\hline 25.35 & 6.34 & 38.09 & -3.197 & -2.074 & -2.636 & 527.13 \\
\hline 19.46 & 4.86 & 36.58 & -3.113 & -2.011 & -2.554 & 510.75 \\
\hline 14.01 & 3.50 & 35.09 & -2.956 & -1.950 & -2.444 & 488.87 \\
\hline 9.14 & 2.28 & 33.72 & -2.815 & -1.914 & -2.365 & 473.00 \\
\hline 5.61 & 1.40 & 33.55 & -2.792 & -1.918 & -2.355 & 471.00 \\
\hline 3.32 & 0.83 & 33.49 & -2.782 & -1.917 & -2.351 & 470.12 \\
\hline 2.00 & 0.50 & 33.44 & -2.777 & -1.915 & -2.348 & 469.50 \\
\hline 0.74 & 0.18 & 33.39 & -2.771 & -1.913 & -2.344 & 468.87 \\
\hline-0.37 & -0.09 & 33.21 & -2.750 & -1.905 & -2.330 & 466.00 \\
\hline
\end{tabular}

Series 2 - Normal Mix, $2 \%$ Corrosion

\begin{tabular}{||c|c|c|c|c|c|c||}
\hline $\begin{array}{c}\text { Load } \\
(\mathrm{kN})\end{array}$ & $\begin{array}{c}\text { Moment } \\
(\mathrm{kN}-\mathrm{m})\end{array}$ & $\begin{array}{c}\text { M.P. Displ. } \\
(\mathrm{mm})\end{array}$ & $\begin{array}{c}\text { E. Curv. LVDT } \\
(\mathrm{mm})\end{array}$ & $\begin{array}{c}\text { W. Curv. LVDT } \\
(\mathrm{mm})\end{array}$ & $\begin{array}{c}\text { Curv. LVDT Avg. } \\
(\mathrm{mm})\end{array}$ & $\begin{array}{c}\text { Curvature } \\
(1 / \mathrm{km})\end{array}$ \\
\hline \hline 0.10 & 0.03 & 0.00 & -0.001 & 0.002 & 0.000 & -0.03 \\
\hline 1.18 & 0.29 & 0.05 & -0.001 & 0.002 & 0.000 & -0.06 \\
\hline 2.24 & 0.56 & 0.10 & -0.002 & 0.002 & 0.000 & -0.05 \\
\hline 3.31 & 0.83 & 0.14 & -0.003 & 0.001 & 0.001 & -0.16 \\
\hline 2.08 & 0.52 & 0.28 & -0.009 & -0.000 & -0.006 & 1.12 \\
\hline 0.98 & 0.24 & 0.28 & -0.007 & 0.000 & -0.004 & 0.84 \\
\hline 2.11 & 0.53 & 0.31 & -0.007 & -0.001 & -0.004 & 0.78 \\
\hline 3.21 & 0.80 & 0.35 & -0.007 & -0.002 & -0.004 & 0.89 \\
\hline 4.28 & 1.07 & 0.38 & -0.008 & -0.002 & -0.005 & 1.04 \\
\hline 5.35 & 1.34 & 0.42 & -0.008 & -0.002 & -0.005 & 1.04 \\
\hline 6.43 & 1.61 & 0.43 & -0.009 & -0.002 & -0.007 & 1.43 \\
\hline 7.53 & 1.88 & 0.46 & -0.009 & -0.003 & -0.006 & 1.20 \\
\hline 8.61 & 2.15 & 0.49 & -0.009 & -0.004 & -0.007 & 1.31 \\
\hline 9.71 & 2.43 & 0.53 & -0.010 & -0.003 & -0.007 & 1.36 \\
\hline 10.80 & 2.70 & 0.55 & -0.010 & -0.004 & -0.007 & 1.36 \\
\hline 11.85 & 2.96 & 0.59 & -0.010 & -0.004 & -0.007 & 1.48 \\
\hline 12.94 & 3.24 & 0.63 & -0.010 & -0.005 & -0.009 & 1.70 \\
\hline 14.04 & 3.51 & 0.65 & -0.010 & -0.005 & -0.009 & 1.75 \\
\hline
\end{tabular}




\section{CORROSION EFFECTS ON BOND STRENGTH IN REINFORCED CONCRETE}

Appendix I

Structural Results

\begin{tabular}{|c|c|c|c|c|c|c|}
\hline 15.17 & 3.79 & 0.70 & -0.011 & -0.005 & -0.009 & 1.75 \\
\hline 16.27 & 4.07 & 0.71 & -0.011 & -0.006 & -0.009 & 1.73 \\
\hline 17.36 & 4.34 & 0.75 & -0.011 & -0.006 & -0.009 & 1.76 \\
\hline 18.47 & 4.62 & 0.77 & -0.012 & -0.007 & -0.010 & 1.99 \\
\hline 19.56 & 4.89 & 0.80 & -0.013 & -0.007 & -0.010 & 2.05 \\
\hline 20.66 & 5.16 & 0.82 & -0.014 & -0.008 & -0.011 & 2.18 \\
\hline 21.75 & 5.44 & 0.88 & -0.015 & -0.009 & -0.013 & 2.50 \\
\hline 20.02 & 5.00 & 1.00 & -0.030 & -0.028 & -0.031 & 6.14 \\
\hline 15.80 & 3.95 & 1.05 & -0.039 & -0.039 & -0.039 & 7.86 \\
\hline 13.05 & 3.26 & 1.08 & -0.044 & -0.046 & -0.045 & 9.01 \\
\hline 11.31 & 2.83 & 1.12 & -0.049 & -0.052 & -0.051 & 10.19 \\
\hline 10.04 & 2.51 & 1.16 & -0.054 & -0.059 & -0.056 & 11.24 \\
\hline 8.90 & 2.23 & 1.21 & -0.061 & -0.068 & -0.065 & 13.06 \\
\hline 8.67 & 2.17 & 1.42 & -0.082 & -0.095 & -0.089 & 17.75 \\
\hline 9.57 & 2.39 & 1.61 & -0.097 & -0.119 & -0.108 & 21.50 \\
\hline 10.64 & 2.66 & 1.80 & -0.117 & -0.138 & -0.128 & 25.61 \\
\hline 11.74 & 2.93 & 1.97 & -0.137 & -0.156 & -0.147 & 29.44 \\
\hline 12.82 & 3.21 & 2.13 & -0.151 & -0.176 & -0.164 & 32.84 \\
\hline 13.92 & 3.48 & 2.30 & -0.165 & -0.194 & -0.180 & 36.01 \\
\hline 15.03 & 3.76 & 2.47 & -0.181 & -0.214 & -0.198 & 39.59 \\
\hline 16.10 & 4.03 & 2.63 & -0.195 & -0.233 & -0.215 & 42.93 \\
\hline 17.20 & 4.30 & 2.81 & -0.209 & -0.252 & -0.231 & 46.18 \\
\hline 18.30 & 4.57 & 2.97 & -0.225 & -0.268 & -0.247 & 49.41 \\
\hline 19.38 & 4.85 & 3.13 & -0.238 & -0.286 & -0.263 & 52.58 \\
\hline 23.25 & 5.81 & 3.76 & -0.261 & -0.344 & -0.303 & 60.51 \\
\hline 24.37 & 6.09 & 3.93 & -0.267 & -0.365 & -0.316 & 63.21 \\
\hline 25.46 & 6.37 & 4.13 & -0.272 & -0.365 & -0.319 & 63.84 \\
\hline 26.47 & 6.62 & 4.33 & -0.278 & -0.388 & -0.333 & 66.58 \\
\hline 27.54 & 6.89 & 4.52 & -0.284 & -0.407 & -0.347 & 69.44 \\
\hline 28.56 & 7.14 & 4.71 & -0.291 & -0.428 & -0.360 & 72.06 \\
\hline 29.49 & 7.37 & 4.89 & -0.298 & -0.449 & -0.375 & 75.06 \\
\hline 30.26 & 7.57 & 5.09 & -0.307 & $-0 . \overline{453}$ & -0.381 & 76.10 \\
\hline 31.22 & 7.81 & 5.29 & -0.318 & -0.474 & -0.396 & 79.25 \\
\hline 31.92 & 7.98 & 5.50 & -0.326 & -0.494 & -0.411 & 82.19 \\
\hline 32.64 & 8.16 & 5.70 & -0.339 & -0.518 & -0.429 & 85.85 \\
\hline 33.15 & 8.29 & 5.89 & -0.353 & -0.541 & -0.447 & 89.44 \\
\hline 33.49 & 8.37 & 6.11 & -0.366 & -0.563 & -0.465 & 92.94 \\
\hline 33.73 & 8.43 & 6.31 & -0.383 & -0.583 & -0.484 & 96.84 \\
\hline 34.03 & 8.51 & 6.52 & -0.396 & -0.607 & -0.503 & 100.50 \\
\hline 34.32 & 8.58 & 6.73 & -0.411 & -0.634 & -0.523 & 104.50 \\
\hline 34.48 & 8.62 & 6.93 & -0.430 & -0.656 & -0.545 & 109.00 \\
\hline 34.75 & 8.69 & 7.14 & -0.453 & -0.675 & -0.565 & 113.00 \\
\hline 34.96 & 8.74 & 7.35 & -0.466 & -0.698 & -0.583 & 116.50 \\
\hline 35.23 & 8.81 & 7.57 & -0.481 & -0.718 & -0.601 & 120.25 \\
\hline 35.50 & 8.87 & 7.77 & -0.495 & -0.734 & -0.616 & 123.25 \\
\hline 35.60 & 8.90 & 7.97 & -0.513 & -0.753 & -0.632 & 126.37 \\
\hline 35.76 & 8.94 & 8.17 & -0.528 & -0.773 & -0.650 & 130.00 \\
\hline 35.90 & 8.97 & 8.38 & -0.477 & -0.793 & -0.635 & 127.00 \\
\hline 36.00 & 9.00 & 8.58 & -0.487 & -0.811 & -0.649 & 129.88 \\
\hline
\end{tabular}




\section{CORROSION EFFECTS ON BONd STRENGTH IN REINFORCED CONCRETE}

\begin{tabular}{|c|c|c|c|c|c|c|}
\hline 36.22 & 9.05 & 8.77 & -0.500 & -0.828 & -0.665 & 133.00 \\
\hline 36.32 & 9.08 & 8.97 & -0.518 & -0.848 & -0.683 & 136.50 \\
\hline 36.46 & 9.11 & 9.19 & -0.535 & -0.868 & -0.703 & 140.50 \\
\hline 36.62 & 9.15 & 9.40 & -0.568 & -0.890 & -0.729 & 145.75 \\
\hline 36.70 & 9.17 & 9.58 & -0.598 & -0.905 & -0.753 & 150.50 \\
\hline 36.83 & 9.21 & 9.80 & -0.628 & -0.932 & -0.780 & 156.00 \\
\hline 36.80 & 9.20 & 10.01 & -0.655 & -0.950 & -0.803 & 160.50 \\
\hline 36.75 & 9.19 & 10.21 & -0.675 & -0.968 & -0.823 & 164.50 \\
\hline 36.70 & 9.17 & 10.42 & -0.700 & -0.988 & -0.846 & 169.12 \\
\hline 36.64 & 9.16 & 10.63 & -0.738 & -1.013 & -0.878 & 175.50 \\
\hline 36.62 & 9.15 & 10.83 & -0.750 & -1.033 & -0.894 & 178.75 \\
\hline 36.54 & 9.13 & 11.05 & -0.779 & -1.055 & -0.918 & 183.50 \\
\hline 36.51 & 9.13 & 11.28 & -0.805 & -1.080 & -0.943 & 188.62 \\
\hline 36.35 & 9.09 & 11.48 & -0.830 & -1.108 & -0.970 & 194.00 \\
\hline 36.19 & 9.05 & 11.69 & -0.850 & -1.113 & -0.983 & 196.50 \\
\hline 35.66 & 8.91 & 11.90 & -0.855 & -1.178 & -1.018 & 203.50 \\
\hline 35.74 & 8.93 & 12.11 & -0.876 & -1.210 & -1.045 & 209.00 \\
\hline 35.66 & 8.91 & 12.31 & -0.910 & -1.236 & -1.075 & 215.00 \\
\hline 35.50 & 8.87 & 12.51 & -0.938 & -1.261 & -1.102 & 220.37 \\
\hline 35.12 & 8.78 & 12.73 & -0.970 & -1.283 & -1.128 & 225.50 \\
\hline 34.93 & 8.73 & 12.93 & -1.000 & -1.305 & -1.153 & 230.62 \\
\hline 34.27 & 8.57 & 13.15 & -1.035 & -1.336 & -1.188 & 237.50 \\
\hline 33.68 & 8.42 & 13.35 & -1.065 & -1.368 & -1.218 & 243.50 \\
\hline 33.44 & 8.36 & 13.57 & -1.100 & -1.400 & -1.253 & 250.50 \\
\hline 33.31 & 8.33 & 13.77 & -1.119 & -1.430 & -1.275 & 255.00 \\
\hline 33.12 & 8.28 & 13.97 & -1.141 & -1.451 & -1.298 & 259.50 \\
\hline 32.93 & 8.23 & 14.18 & -1.165 & -1.473 & -1.320 & 264.00 \\
\hline 32.67 & 8.17 & 14.37 & -1.188 & -1.493 & -1.343 & 268.50 \\
\hline 32.40 & 8.10 & 14.54 & -1.220 & -1.507 & -1.365 & 273.00 \\
\hline 32.35 & 8.09 & 14.75 & -1.235 & -1.515 & -1.378 & 275.50 \\
\hline 32.21 & 8.05 & 14.96 & -1.265 & -1.518 & -1.393 & 278.50 \\
\hline 32.13 & 8.03 & 15.18 & -1.295 & -1.502 & -1.400 & 280.00 \\
\hline 31.92 & 7.98 & 15.39 & -1.328 & -1.533 & -1.431 & 286.25 \\
\hline 31.84 & 7.96 & 15.59 & -1.353 & -1.553 & -1.455 & 291.00 \\
\hline 31.79 & 7.95 & 15.77 & -1.368 & -1.573 & -1.472 & 294.38 \\
\hline 31.65 & 7.91 & 15.98 & -1.378 & -1.598 & -1.489 & 297.87 \\
\hline 31.55 & 7.89 & 16.19 & -1.393 & -1.613 & -1.504 & 300.87 \\
\hline 31.55 & 7.89 & 16.44 & -1.428 & -1.635 & -1.533 & 306.50 \\
\hline 31.44 & 7.86 & 16.66 & -1.463 & -1.664 & -1.565 & 313.00 \\
\hline 31.33 & 7.83 & 16.88 & -1.486 & -1.688 & -1.590 & 318.00 \\
\hline 31.28 & 7.82 & 17.08 & -1.515 & -1.713 & -1.618 & 323.50 \\
\hline 31.17 & 7.79 & 17.30 & -1.558 & -1.741 & -1.650 & 330.00 \\
\hline 31.09 & 7.77 & 17.51 & -1.593 & -1.775 & -1.686 & 337.25 \\
\hline 31.04 & 7.76 & 17.72 & -1.620 & -1.792 & -1.708 & 341.50 \\
\hline 30.98 & 7.75 & 17.94 & -1.643 & -1.813 & -1.729 & 345.88 \\
\hline 30.88 & 7.72 & 18.16 & -1.670 & -1.845 & -1.760 & 352.00 \\
\hline 30.85 & 7.71 & 18.38 & -1.704 & -1.873 & -1.790 & 358.00 \\
\hline 30.80 & 7.70 & 18.57 & -1.728 & -1.888 & -1.810 & 362.00 \\
\hline 30.72 & 7.68 & 18.73 & -1.761 & -1.909 & -1.838 & 367.50 \\
\hline
\end{tabular}




\section{CORROSION EFFECTS ON BOND STRENGTH IN REINFORCED CONCRETE}

Appendix I

Structural Results

\begin{tabular}{|c|c|c|c|c|c|c|}
\hline 30.69 & $\bar{~} 7.67$ & $\begin{array}{l}18.94 \\
\end{array}$ & -1.789 & -1.930 & -1.862 & $\overline{372.37}$ \\
\hline 30.69 & 7.67 & 19.21 & -1.820 & -1.950 & -1.888 & 377.50 \\
\hline 30.61 & 7.65 & 19.48 & -1.843 & $-1.98 \mathrm{I}$ & -1.913 & 382.62 \\
\hline 31.14 & 7.79 & 19.69 & -1.876 & -2.015 & -1.948 & 389.50 \\
\hline 31.12 & 7.78 & 19.91 & -1.913 & -2.023 & -1.968 & 393.62 \\
\hline 30.56 & 7.64 & 20.13 & -1.923 & -2.048 & -1.986 & 397.25 \\
\hline 30.42 & 7.61 & 20.34 & -1.935 & -2.070 & -2.005 & 401.00 \\
\hline 30.40 & 7.60 & 20.56 & -1.951 & -2.105 & -2.030 & 406.00 \\
\hline 30.37 & 7.59 & 20.76 & -1.968 & -2.138 & -2.055 & 411.00 \\
\hline 30.45 & 7.61 & 20.97 & -1.993 & -2.170 & -2.084 & 416.87 \\
\hline 30.32 & 7.58 & 21.17 & -2.025 & -2.208 & -2.119 & 423.75 \\
\hline 30.29 & 7.57 & 21.37 & -2.045 & -2.243 & -2.148 & 429.50 \\
\hline 30.21 & 7.55 & 21.57 & -2.082 & -2.288 & -2.187 & 437.38 \\
\hline 30.16 & 7.54 & 21.77 & -2.111 & -2.333 & -2.225 & 445.00 \\
\hline 30.10 & 7.53 & 21.98 & -2.133 & -2.360 & -2.250 & 450.00 \\
\hline 30.10 & 7.53 & 22.18 & -2.163 & -2.402 & -2.283 & 456.62 \\
\hline 30.05 & 7.51 & 22.39 & -2.189 & -2.446 & -2.319 & 463.87 \\
\hline 30.00 & 7.50 & 22.60 & -2.208 & -2.480 & -2.348 & 469.50 \\
\hline 30.00 & 7.50 & 22.81 & -2.233 & -2.514 & -2.376 & 475.25 \\
\hline 29.89 & 7.47 & 23.03 & -2.262 & -2.549 & -2.408 & 481.50 \\
\hline 29.73 & 7.43 & 23.27 & -2.295 & -2.578 & -2.440 & 488.00 \\
\hline 29.41 & 7.35 & 23.49 & -2.328 & -2.595 & -2.463 & 492.50 \\
\hline 29.04 & 7.26 & 23.71 & -2.366 & -2.635 & -2.504 & 500.75 \\
\hline 28.85 & 7.21 & 23.92 & -2.397 & -2.675 & -2.538 & 507.50 \\
\hline 28.77 & 7.19 & 24.13 & -2.428 & -2.713 & -2.573 & 514.63 \\
\hline 28.72 & 7.18 & 24.36 & -2.458 & -2.752 & -2.607 & 521.38 \\
\hline 28.69 & 7.17 & 24.58 & -2.486 & -2.788 & -2.641 & 528.12 \\
\hline 27.65 & 6.91 & 24.69 & -2.493 & $-2,818$ & -2.656 & 531.25 \\
\hline 26.58 & 6.65 & 24.48 & -2.453 & -2.793 & -2.625 & 525.00 \\
\hline 25.49 & 6.37 & 24.32 & -2.433 & -2.773 & -2.605 & 521.00 \\
\hline 24.39 & 6.10 & 24.15 & -2.404 & -2.750 & -2.580 & 516.00 \\
\hline 23.27 & 5.82 & 23.95 & -2.378 & -2.725 & -2.554 & 510.87 \\
\hline 22.20 & 5.55 & 23.76 & -2.345 & -2.702 & -2.525 & 505.00 \\
\hline 21.08 & 5.27 & 23.56 & -2.317 & -2.679 & -2.500 & 500.00 \\
\hline 19.05 & 4.76 & 23.49 & -2.304 & -2.670 & -2.490 & 498.00 \\
\hline 20.22 & 5.05 & 23.48 & -2.304 & -2.669 & -2.489 & 497.75 \\
\hline 19.95 & 4.99 & 22.20 & -2.151 & -2.502 & -2.324 & 464.75 \\
\hline 17.62 & 4.40 & 22.00 & -2.128 & -2.480 & -2.306 & 461.25 \\
\hline 16.47 & 4.12 & 22.00 & -2.129 & -2.479 & -2.308 & 461.50 \\
\hline 15.62 & 3.91 & 21.76 & -2.096 & -2.448 & -2.270 & 454.00 \\
\hline 14.97 & 3.74 & 21.50 & -2.051 & -2.410 & -2.230 & 446.00 \\
\hline 14.24 & 3.56 & 21.19 & -2.023 & -2.368 & -2.194 & 438.75 \\
\hline 13.47 & 3.37 & 20.87 & -1.970 & -2.325 & -2.149 & 429.87 \\
\hline 12.65 & 3.16 & 20.55 & -1.925 & -2.283 & -2.103 & 420.50 \\
\hline 11.82 & 2.96 & 20.21 & -1.870 & -2.234 & -2.053 & 410.50 \\
\hline 10.97 & 2.74 & 19.85 & -1.819 & -2.191 & -2.004 & 400.75 \\
\hline
\end{tabular}




\begin{tabular}{||l|l|l|l|l|l|l||}
\hline 10.13 & 2.53 & 19.51 & -1.761 & -2.148 & -1.954 & 390.75 \\
9.28 & 2.32 & 19.15 & -1.721 & -2.100 & -1.910 & 382.00 \\
\hline 8.48 & 2.12 & 18.79 & -1.669 & -2.058 & -1.863 & 372.50 \\
\hline 7.66 & 1.91 & 18.45 & -1.624 & -2.018 & -1.822 & 364.37 \\
\hline 6.85 & 1.71 & 18.09 & -1.580 & -1.978 & -1.778 & 355.50 \\
\hline 6.07 & 1.52 & 17.73 & -1.536 & -1.933 & -1.734 & 346.75 \\
\hline 5.29 & 1.32 & 17.36 & -1.488 & -1.894 & -1.692 & 338.37 \\
\hline 4.56 & 1.14 & 17.01 & -1.445 & -1.853 & -1.649 & 329.75 \\
\hline 3.80 & 0.95 & 16.65 & -1.408 & -1.811 & -1.608 & 321.62 \\
\hline 3.13 & 0.78 & 16.30 & -1.359 & -1.768 & -1.563 & 312.63 \\
\hline 2.41 & 0.60 & 15.91 & -1.307 & -1.728 & -1.516 & 303.12 \\
\hline 1.76 & 0.44 & 15.56 & -1.263 & -1.688 & -1.475 & 295.00 \\
\hline 1.20 & 0.30 & 15.22 & -1.223 & -1.658 & -1.439 & 287.88 \\
\hline 0.74 & 0.18 & 14.87 & -1.172 & -1.627 & -1.398 & 279.63 \\
\hline 0.33 & 0.08 & 14.57 & -1.135 & -1.600 & -1.368 & 273.50 \\
\hline-0.05 & -0.01 & 14.39 & -1.123 & -1.580 & -1.353 & 270.50 \\
\hline-0.03 & -0.01 & 14.33 & -1.130 & -1.578 & -1.355 & 271.00 \\
\hline
\end{tabular}

Series 2 - Normal Mix, $5 \%$ Corrosion

\begin{tabular}{||c|c|c|c|c|c|c||}
\hline $\begin{array}{c}\text { Load } \\
(\mathrm{kN})\end{array}$ & $\begin{array}{c}\text { Moment } \\
(\mathrm{kN}-\mathrm{m})\end{array}$ & $\begin{array}{c}\text { M.P. Displ. E. Curv. LVDT } \\
(\mathrm{mm})\end{array}$ & $\begin{array}{c}\text { W. Curv. LVDT } \\
(\mathrm{mm})\end{array}$ & $\begin{array}{c}\text { Curv. LVDT Avg. } \\
(\mathrm{mm})\end{array}$ & $\begin{array}{c}\text { Curvature } \\
(\mathrm{l} / \mathrm{km})\end{array}$ \\
\hline \hline-0.03 & -0.01 & 0.00 & 0.001 & 0.001 & 0.001 & -0.15 \\
\hline 0.96 & 0.24 & 0.02 & 0.001 & 0.003 & 0.001 & -0.12 \\
\hline 1.93 & 0.48 & 0.04 & 0.000 & 0.000 & 0.001 & -0.10 \\
\hline 2.25 & 0.56 & 0.07 & 0.002 & 0.002 & -0.000 & 0.04 \\
\hline 3.36 & 0.84 & 0.10 & 0.002 & 0.001 & 0.001 & -0.21 \\
\hline 4.38 & 1.09 & 0.11 & 0.002 & 0.001 & 0.001 & -0.18 \\
\hline 5.43 & 1.36 & 0.13 & 0.001 & -0.001 & -0.002 & 0.33 \\
\hline 6.46 & 1.62 & 0.15 & 0.001 & -0.004 & -0.002 & 0.45 \\
\hline 7.48 & 1.87 & 0.18 & 0.001 & -0.001 & -0.000 & 0.05 \\
\hline 8.50 & 2.12 & 0.20 & 0.000 & -0.001 & -0.001 & 0.12 \\
\hline 9.49 & 2.37 & 0.22 & -0.000 & -0.001 & -0.001 & 0.19 \\
\hline 10.49 & 2.62 & 0.24 & -0.000 & -0.002 & -0.001 & 0.21 \\
\hline 11.48 & 2.87 & 0.26 & -0.001 & -0.002 & -0.002 & 0.33 \\
\hline 12.48 & 3.12 & 0.28 & -0.001 & -0.002 & -0.002 & 0.39 \\
\hline 13.53 & 3.38 & 0.31 & -0.001 & -0.002 & -0.002 & 0.45 \\
\hline 14.55 & 3.64 & 0.33 & -0.002 & -0.006 & -0.009 & 1.81 \\
\hline 15.54 & 3.89 & 0.34 & -0.003 & -0.003 & -0.003 & 0.61 \\
\hline 16.59 & 4.15 & 0.37 & -0.003 & -0.008 & -0.006 & 1.20 \\
\hline 17.68 & 4.42 & 0.42 & -0.003 & -0.004 & -0.004 & 0.73 \\
\hline 18.71 & 4.68 & 0.45 & -0.004 & -0.005 & -0.005 & 0.91 \\
\hline 19.73 & 4.93 & 0.48 & -0.004 & -0.006 & -0.007 & 1.37 \\
\hline 20.76 & 5.19 & 0.53 & -0.004 & -0.008 & -0.011 & 2.16 \\
\hline 19.37 & 4.84 & 0.67 & -0.005 & -0.004 & -0.007 & 1.37 \\
\hline 18.00 & 4.50 & 0.67 & -0.003 & -0.003 & -0.006 & 1.21 \\
\hline 16.83 & 4.21 & 0.68 & -0.003 & -0.003 & -0.007 & 1.30 \\
\hline 15.72 & 3.93 & 0.70 & -0.003 & -0.006 & -0.006 & 1.11 \\
\hline & & & & & & \\
\hline
\end{tabular}




\section{CORROSION EFFECTS ON BOND STRENGTH IN REINFORCED CONCRETE}

Appendix I

Structural Results

\begin{tabular}{|c|c|c|c|c|c|c|}
\hline 16.79 & 4.20 & 0.90 & -0.003 & -0.003 & -0.003 & 0.69 \\
\hline 17.84 & 4.46 & 0.97 & -0.003 & -0.003 & -0.003 & 0.65 \\
\hline 18.93 & 4.73 & 1.05 & -0.003 & -0.006 & -0.006 & 1.27 \\
\hline 19.99 & 5.00 & 1.13 & -0.005 & -0.004 & -0.004 & 0.74 \\
\hline 21.06 & 5.27 & 1.22 & -0.004 & -0.004 & -0.004 & 0.80 \\
\hline 22.12 & 5.53 & 1.30 & -0.005 & -0.008 & -0.007 & 1.39 \\
\hline 23.06 & 5.76 & 1.39 & -0.005 & -0.008 & -0.008 & 1.64 \\
\hline 21.91 & 5.48 & 1.36 & -0.007 & -0.010 & -0.008 & 1.55 \\
\hline 22.98 & 5.74 & 1.43 & -0.005 & -0.004 & -0.005 & 0.91 \\
\hline 24.13 & 6.03 & 1.51 & -0.005 & -0.008 & -0.009 & 1.71 \\
\hline 25.14 & 6.29 & 1.58 & -0.008 & -0.006 & -0.005 & 1.04 \\
\hline 26.15 & 6.54 & 1.67 & -0.007 & -0.009 & -0.009 & 1.89 \\
\hline 27.20 & 6.80 & 1.74 & -0.008 & -0.007 & -0.006 & 1.11 \\
\hline 28.24 & 7.06 & 1.82 & -0.008 & -0.007 & -0.006 & 1.11 \\
\hline 29.25 & 7.31 & 1.91 & -0.008 & -0.008 & -0.007 & 1.32 \\
\hline 30.32 & 7.58 & 1.99 & -0.007 & -0.008 & -0.007 & 1.36 \\
\hline 31.36 & 7.84 & 2.08 & -0.007 & -0.010 & -0.011 & 2.14 \\
\hline 32.37 & 8.09 & 2.17 & -0.010 & -0.009 & -0.008 & 1.51 \\
\hline 33.47 & 8.37 & 2.27 & -0.008 & -0.012 & -0.014 & 2.81 \\
\hline 34.48 & 8.62 & 2.38 & -0.009 & -0.015 & -0.012 & 2.45 \\
\hline 35.55 & 8.89 & 2.44 & -0.009 & -0.009 & -0.008 & 1.69 \\
\hline 36.56 & 9.14 & 2.55 & -0.010 & -0.014 & -0.014 & 2.70 \\
\hline 35.76 & 8.94 & 2.77 & -0.046 & -0.053 & -0.053 & 10.50 \\
\hline 33.28 & 8.32 & 2.77 & -0.049 & -0.056 & -0.056 & 11.10 \\
\hline 31.60 & 7.90 & 2.79 & -0.054 & -0.059 & -0.057 & 11.33 \\
\hline 30.26 & 7.57 & 2.82 & -0.055 & -0.057 & -0.060 & 12.09 \\
\hline 29.20 & 7.30 & 2.84 & -0.060 & -0.062 & -0.061 & 12.16 \\
\hline 28.69 & 7.17 & 3.04 & -0.086 & -0.093 & -0.090 & 18.05 \\
\hline 29.52 & 7.38 & 3.26 & -0.107 & -0.125 & -0.117 & 23.30 \\
\hline 30.42 & 7.61 & 3.47 & -0.133 & -0.161 & -0.148 & 29.50 \\
\hline 31.31 & 7.83 & 3.67 & -0.162 & -0.201 & -0.180 & 36.09 \\
\hline 32.27 & 8.07 & 3.88 & -0.195 & -0.233 & -0.216 & 43.24 \\
\hline 33.23 & 8.31 & 4.09 & -0.224 & -0.261 & -0.243 & 48.58 \\
\hline 34.24 & 8.56 & 4.29 & -0.256 & -0.294 & -0.274 & 54.81 \\
\hline 35.12 & 8.78 & 4.49 & -0.283 & -0.334 & -0.310 & 62.08 \\
\hline 36.03 & 9.01 & 4.70 & -0.325 & -0.363 & -0.345 & 68.90 \\
\hline 37.07 & 9.27 & 4.91 & -0.364 & -0.400 & -0.384 & 76.83 \\
\hline 37.95 & 9.49 & 5.11 & -0.401 & -0.434 & -0.421 & 84.13 \\
\hline 38.86 & 9.71 & 5.32 & -0.440 & -0.489 & -0.464 & 92.89 \\
\hline 39.71 & 9.93 & 5.53 & -0.475 & -0.521 & -0.497 & 99.40 \\
\hline 40.46 & 10.11 & 5.74 & -0.511 & -0.556 & -0.534 & 106.88 \\
\hline 41.31 & 10.33 & 5.95 & -0.563 & -0.593 & -0.579 & 115.87 \\
\hline 42.17 & 10.54 & 6.15 & -0.603 & -0.632 & -0.619 & 123.87 \\
\hline 42.89 & 10.72 & 6.36 & -0.638 & -0.668 & -0.654 & 130.88 \\
\hline 43.66 & 10.92 & 6.58 & -0.686 & -0.708 & -0.698 & 139.50 \\
\hline 42.14 & 10.54 & 6.71 & -0.722 & -0.738 & -0.730 & 146.00 \\
\hline
\end{tabular}




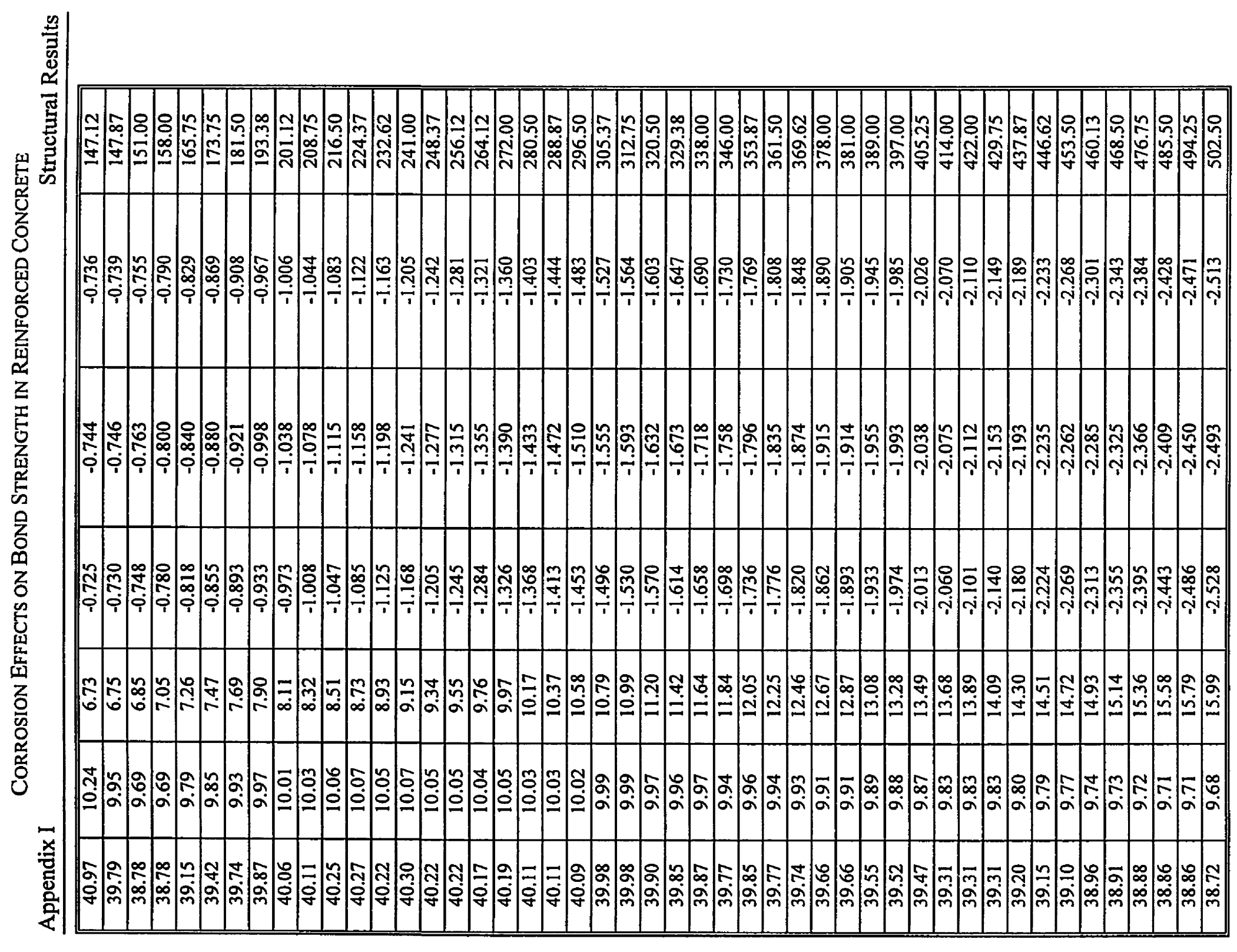


CORROSION EFFECTS ON BOND STRENGTH IN REINFORCED CONCRETE

Appendix I

Structural Results

\begin{tabular}{|c|c|c|c|c|c|c|}
\hline 38.64 & 9.66 & 16.21 & -2.569 & -2.528 & -2.550 & 510.00 \\
\hline 38.67 & 9.67 & 16.41 & -2.598 & -2.566 & -2.588 & 517.62 \\
\hline 38.64 & 9.66 & 16.61 & -2.634 & -2.606 & -2.623 & 524.62 \\
\hline 38.54 & 9.63 & 17.18 & -2.741 & -2.683 & -2.716 & 543.13 \\
\hline 38.46 & 9.61 & 17.38 & -2.779 & -2.725 & -2.755 & 551.00 \\
\hline 38.46 & 9.61 & 17.84 & -2.872 & -2.809 & -2.837 & 567.38 \\
\hline 38.54 & 9.63 & 18.05 & -2.908 & -2.848 & -2.881 & 576.25 \\
\hline 38.51 & 9.63 & 18.25 & -2.948 & -2.885 & -2.921 & 584.25 \\
\hline 38.46 & 9.61 & 18.46 & -2.990 & -2.925 & -2.963 & 592.50 \\
\hline 38.56 & 9.64 & 18.67 & -3.028 & -2.963 & -3.001 & 600.12 \\
\hline $\begin{array}{l}38.48 \\
\end{array}$ & 9.62 & 18.87 & -3.066 & -2.936 & -3.008 & 601.63 \\
\hline 38.59 & 9.65 & 19.07 & -3.103 & -2.970 & -3.015 & 603.00 \\
\hline 38.59 & 9.65 & 19.28 & $-3 . \overline{142}$ & -3.007 & -3.180 & 636.00 \\
\hline 37.47 & 9.37 & 19.31 & -3.153 & -3.013 & -3.180 & 636.00 \\
\hline 36.38 & 9.09 & 19.13 & -3.128 & -2.983 & -3.176 & 635.13 \\
\hline 35.33 & 8.83 & 18.98 & -3.103 & -2.958 & -3.142 & 628.38 \\
\hline 34.21 & 8.55 & 18.84 & -3.078 & -2.933 & -3.012 & 602.37 \\
\hline 33.17 & 8.29 & 18.68 & -3.053 & -2.905 & -2.983 & 596.50 \\
\hline 32.11 & 8.03 & 18.50 & -3.023 & -2.875 & -2.953 & 590.50 \\
\hline 31.06 & 7.77 & 18.35 & -3.005 & -2.853 & -2.933 & 586.50 \\
\hline 30.10 & 7.53 & 18.23 & -2.986 & -2.835 & -2.914 & 582.75 \\
\hline 28.69 & 7.17 & 18.20 & -2.983 & -2.830 & -2.911 & 582.12 \\
\hline 29.33 & 7.33 & 17.45 & -2.871 & -2.724 & -2.784 & 556.87 \\
\hline 26.61 & 6.65 & 16.85 & -2.808 & -2.684 & -2.749 & 549.75 \\
\hline 24.85 & 6.21 & 16.87 & -2.809 & -2.687 & -2.750 & 550.00 \\
\hline 23.57 & 5.89 & 16.87 & -2.808 & -2.694 & -2.753 & 550.50 \\
\hline 22.58 & 5.64 & 16.90 & -2.808 & -2.689 & -2.753 & 550.50 \\
\hline 22.10 & 5.52 & 16.62 & -2.766 & -2.649 & -2.706 & 541.25 \\
\hline 21.14 & 5.28 & 16.34 & -2.721 & -2.605 & -2.663 & 532.62 \\
\hline 20.08 & 5.02 & 16.08 & -2.679 & -2.569 & -2.624 & 524.88 \\
\hline 18.92 & 4.73 & 15.81 & -2.640 & -2.528 & -2.583 & 516.62 \\
\hline 17.79 & 4.45 & 15.55 & -2.599 & -2.488 & -2.543 & 508.50 \\
\hline 16.61 & 4.15 & 15.29 & -2.554 & -2.453 & -2.503 & 500.62 \\
\hline 15.48 & 3.87 & 15.02 & -2.513 & -2.421 & -2.465 & 493.00 \\
\hline 14.37 & 3.59 & 14.78 & -2.476 & -2.386 & -2.430 & 486.00 \\
\hline 13.16 & 3.29 & 14.51 & -2.429 & -2.345 & -2.388 & 477.50 \\
\hline 11.95 & 2.99 & 14.25 & -2.387 & -2.307 & -2.346 & 469.12 \\
\hline 10.78 & 2.69 & 13.97 & -2.340 & -2.266 & -2.303 & 460.50 \\
\hline 9.67 & 2.42 & 13.72 & -2.286 & -2.228 & -2.254 & 450.87 \\
\hline 8.62 & 2.15 & 13.46 & -2.239 & -2.188 & -2.213 & 442.50 \\
\hline 7.57 & 1.89 & 13.20 & -2.187 & -2.145 & -2.165 & 433.00 \\
\hline 6.50 & 1.63 & 12.91 & -2.133 & -2.119 & -2.124 & 424.88 \\
\hline 5.54 & 1.39 & 12.64 & -2.076 & -2.081 & -2.075 & 415.00 \\
\hline 4.60 & 1.15 & 12.36 & -2.013 & -2.035 & -2.023 & 404.50 \\
\hline 3.37 & 0.84 & 12.22 & -1.983 & -2.020 & -2.003 & 400.50 \\
\hline 2.35 & 0.59 & 12.14 & -1.965 & -2.011 & -1.991 & 398.13 \\
\hline 1.47 & 0.37 & 11.92 & -1.933 & -1.988 & -1.960 & 392.00 \\
\hline 0.64 & 0.16 & 11.72 & -1.899 & -1.959 & -1.932 & 386.37 \\
\hline
\end{tabular}




\section{CORROSION EFFECTS ON BOND STRENGTH IN REINFORCED CONCRETE}

Appendix I

Structural Results

Series 2 - Normal Mix, $8 \%$ Corrosion

\begin{tabular}{|c|c|c|c|c|c|c|}
\hline $\begin{array}{l}\text { Load } \\
(\mathrm{kN})\end{array}$ & $\begin{array}{c}\text { Moment } \\
(\mathrm{kN}-\mathrm{m})\end{array}$ & $\begin{array}{c}\text { M.P. Displ. } \\
(\mathrm{mm})\end{array}$ & $\begin{array}{c}\begin{array}{c}\text { E. Curv. LVDT } \\
(\mathrm{mm})\end{array} \\
\end{array}$ & $\begin{array}{l}\text { W. Curv. LVDT } \\
(\mathrm{mm})\end{array}$ & $\begin{array}{l}\text { Curv. LVDT Avg. } \\
(\mathrm{mm})\end{array}$ & $\begin{array}{c}\text { Curvature } \\
(1 / \mathrm{km})\end{array}$ \\
\hline-0.05 & -0.01 & 0.00 & -0.000 & -0.001 & -0.003 & 0.51 \\
\hline-0.07 & -0.02 & 0.00 & -0.001 & -0.001 & -0.005 & 1.05 \\
\hline-0.02 & -0.01 & -0.01 & -0.003 & 0.002 & 0.002 & -0.36 \\
\hline 1.32 & 0.33 & 0.06 & -0.001 & -0.004 & -0.003 & 0.55 \\
\hline 2.53 & 0.63 & 0.07 & 0.000 & -0.001 & -0.002 & 0.41 \\
\hline 2.32 & 0.58 & 0.04 & -0.003 & -0.005 & -0.003 & 0.69 \\
\hline 1.35 & 0.34 & 0.03 & 0.001 & -0.004 & -0.007 & 1.34 \\
\hline 2.41 & 0.60 & 0.09 & 0.012 & -0.030 & -0.008 & 1.61 \\
\hline 3.43 & 0.86 & 0.11 & 0.011 & -0.031 & -0.008 & 1.69 \\
\hline 4.43 & 1.11 & 0.13 & 0.011 & -0.032 & -0.009 & 1.75 \\
\hline 5.42 & 1.36 & 0.15 & 0.011 & -0.032 & -0.009 & 1.87 \\
\hline 6.43 & 1.61 & 0.18 & 0.010 & -0.036 & -0.014 & 2.79 \\
\hline 7.49 & 1.87 & 0.20 & 0.011 & -0.032 & -0.011 & 2.12 \\
\hline 8.54 & 2.14 & 0.24 & 0.011 & -0.032 & -0.010 & 2.09 \\
\hline 9.55 & 2.39 & 0.26 & 0.009 & -0.034 & -0.011 & 2.23 \\
\hline 10.61 & 2.65 & 0.29 & 0.012 & -0.037 & -0.015 & 3.08 \\
\hline 11.61 & 2.90 & 0.31 & 0.010 & -0.036 & -0.016 & 3.19 \\
\hline 12.66 & 3.16 & 0.34 & 0.009 & -0.036 & -0.013 & 2.52 \\
\hline 13.65 & 3.41 & 0.36 & 0.009 & -0.037 & -0.013 & 2.61 \\
\hline 14.73 & 3.68 & 0.37 & 0.010 & -0.040 & -0.021 & 4.22 \\
\hline 15.78 & 3.95 & 0.41 & 0.008 & -0.042 & -0.021 & 4.19 \\
\hline 16.78 & 4.20 & 0.43 & 0.007 & -0.039 & -0.015 & 2.94 \\
\hline $\begin{array}{ll}17.91 \\
\end{array}$ & 4.48 & 0.46 & 0.006 & -0.041 & -0.018 & 3.52 \\
\hline 18.96 & 4.74 & 0.48 & 0.004 & -0.038 & -0.016 & 3.12 \\
\hline 19.95 & 4.99 & 0.51 & 0.004 & -0.042 & -0.021 & 4.10 \\
\hline 21.01 & 5.25 & 0.53 & 0.006 & -0.040 & -0.021 & 4.16 \\
\hline 22.07 & 5.52 & 0.56 & 0.004 & -0.043 & -0.017 & 3.40 \\
\hline 23.14 & 5.78 & 0.58 & 0.005 & -0.046 & -0.023 & 4.58 \\
\hline 24.15 & 6.04 & 0.62 & 0.004 & -0.044 & -0.023 & 4.53 \\
\hline 25.14 & 6.29 & 0.64 & 0.002 & -0.044 & -0.020 & 3.91 \\
\hline 23.35 & 5.84 & 0.82 & -0.029 & -0.054 & -0.040 & 8.01 \\
\hline 20.36 & 5.09 & 0.84 & -0.031 & -0.055 & -0.043 & 8.55 \\
\hline 18.40 & 4.60 & 0.84 & -0.033 & -0.053 & -0.043 & 8.65 \\
\hline 17.03 & 4.26 & 0.86 & -0.035 & -0.056 & -0.045 & 8.96 \\
\hline 15.91 & 3.98 & 0.87 & -0.037 & -0.062 & -0.050 & 10.03 \\
\hline 14.75 & 3.69 & 0.87 & -0.044 & -0.058 & -0.048 & 9.61 \\
\hline 13.92 & 3.48 & 1.08 & -0.069 & -0.071 & -0.069 & 13.84 \\
\hline 14.74 & 3.68 & 1.28 & -0.094 & -0.087 & -0.089 & 17.80 \\
\hline 15.81 & 3.95 & 1.45 & -0.111 & -0.104 & -0.109 & 21.83 \\
\hline 16.80 & 4.20 & 1.60 & -0.125 & -0.112 & -0.119 & 23.74 \\
\hline 17.85 & 4.46 & 1.73 & -0.140 & -0.129 & -0.133 & 26.68 \\
\hline 18.92 & 4.73 & 1.87 & -0.148 & -0.140 & -0.146 & 29.18 \\
\hline 19.99 & 5.00 & 2.01 & -0.160 & -0.148 & -0.154 & 30.76 \\
\hline 21.02 & 5.25 & 2.16 & -0.170 & -0.160 & -0.165 & 33.01 \\
\hline 22.10 & 5.52 & 2.28 & -0.181 & -0.173 & -0.176 & 35.13 \\
\hline
\end{tabular}




\begin{tabular}{|c|c|c|c|c|c|c|}
\hline 23.14 & 5.78 & 2.42 & -0.179 & -0.185 & -0.184 & 36.84 \\
\hline 24.15 & 6.04 & 2.56 & -0.188 & -0.196 & -0.190 & 38.08 \\
\hline 25.22 & 6.31 & 2.71 & -0.195 & -0.212 & -0.205 & 40.98 \\
\hline 26.21 & 6.55 & 2.84 & -0.203 & -0.222 & -0.213 & 42.66 \\
\hline 27.22 & 6.81 & 2.96 & -0.212 & -0.234 & -0.222 & 44.46 \\
\hline 28.24 & 7.06 & 3.10 & -0.217 & -0.242 & -0.235 & 46.96 \\
\hline 29.25 & 7.31 & 3.24 & -0.215 & -0.259 & -0.238 & 47.67 \\
\hline 30.32 & 7.58 & 3.38 & -0.224 & -0.266 & -0.246 & 49.26 \\
\hline 31.36 & 7.84 & 3.54 & -0.228 & -0.280 & -0.258 & 51.64 \\
\hline 32.40 & 8.10 & 3.70 & -0.237 & -0.287 & -0.262 & 52.34 \\
\hline 33.44 & 8.36 & 3.87 & -0.249 & -0.302 & -0.280 & 55.90 \\
\hline 34.45 & 8.61 & 4.03 & -0.255 & -0.317 & -0.286 & 57.29 \\
\hline 35.52 & 8.88 & 4.22 & -0.267 & -0.335 & -0.301 & 60.24 \\
\hline 34.16 & 8.54 & 4.33 & -0.289 & -0.357 & -0.323 & 64.60 \\
\hline 32.96 & 8.24 & 4.34 & -0.287 & -0.352 & -0.323 & 64.60 \\
\hline 31.89 & 7.97 & 4.38 & -0.288 & -0.359 & -0.326 & 65.17 \\
\hline 32.99 & 8.25 & 4.58 & -0.305 & -0.381 & -0.344 & 68.76 \\
\hline 34.03 & 8.51 & 4.75 & -0.313 & -0.402 & -0.359 & 71.84 \\
\hline 34.85 & 8.71 & 4.95 & -0.328 & -0.425 & -0.381 & 76.20 \\
\hline 35.66 & 8.91 & 5.15 & -0.339 & -0.451 & -0.395 & 79.08 \\
\hline 36.51 & 9.13 & 5.37 & -0.355 & -0.463 & -0.411 & 82.25 \\
\hline 37.31 & 9.33 & 5.57 & -0.371 & -0.483 & -0.428 & 85.62 \\
\hline 38.00 & 9.50 & 5.76 & -0.384 & -0.509 & -0.450 & 89.92 \\
\hline 38.56 & 9.64 & 5.96 & -0.382 & -0.541 & -0.463 & 92.65 \\
\hline 39.12 & 9.78 & 6.17 & -0.395 & -0.585 & -0.491 & 98.20 \\
\hline 39.71 & 9.93 & 6.38 & -0.412 & -0.632 & -0.522 & 104.37 \\
\hline 40.09 & 10.02 & 6.58 & -0.423 & -0.674 & -0.551 & 110.12 \\
\hline 40.59 & 10.15 & 6.78 & -0.433 & -0.696 & -0.565 & 113.00 \\
\hline 40.97 & 10.24 & 6.98 & -0.445 & -0.717 & -0.580 & 116.00 \\
\hline 41.15 & 10.29 & 7.19 & -0.457 & -0.708 & -0.583 & 116.50 \\
\hline 41.31 & 10.33 & 7.39 & -0.470 & -0.721 & -0.595 & 119.00 \\
\hline 41.55 & 10.39 & 7.61 & -0.474 & -0.733 & -0.605 & 121.00 \\
\hline 41.63 & 10.41 & 7.81 & -0.483 & -0.748 & -0.615 & 123.00 \\
\hline 41.79 & 10.45 & 8.02 & -0.489 & -0.763 & -0.626 & 125.25 \\
\hline 41.93 & 10.48 & 8.23 & -0.498 & -0.778 & -0.639 & 127.75 \\
\hline 42.06 & 10.52 & 8.43 & -0.505 & -0.795 & -0.650 & 130.00 \\
\hline 42.01 & 10.50 & 8.64 & -0.515 & -0.797 & -0.655 & 131.00 \\
\hline 42.09 & 10.52 & 8.84 & -0.525 & -0.814 & -0.671 & 134.12 \\
\hline 41.98 & 10.50 & 9.04 & -0.535 & -0.830 & -0.683 & 136.50 \\
\hline 41.93 & 10.48 & 9.25 & -0.536 & -0.846 & -0.693 & 138.50 \\
\hline 41.90 & 10.48 & 9.46 & -0.545 & -0.853 & -0.698 & 139.62 \\
\hline 41.90 & 10.48 & 9.68 & -0.546 & -0.871 & -0.710 & 142.00 \\
\hline 41.87 & 10.47 & 9.88 & -0.557 & -0.885 & -0.721 & 144.12 \\
\hline 41.95 & 10.49 & 10.10 & -0.560 & -0.900 & -0.730 & 146.00 \\
\hline 41.90 & 10.48 & 10.32 & -0.569 & -0.914 & -0.741 & 148.25 \\
\hline 41.87 & 10.47 & 10.53 & -0.570 & -0.924 & -0.748 & 149.62 \\
\hline 41.85 & 10.46 & 10.74 & -0.578 & -0.935 & -0.758 & 151.62 \\
\hline 41.90 & 10.48 & 10.94 & -0.578 & -0.951 & -0.765 & 153.00 \\
\hline
\end{tabular}


CORROSION EFFECTS ON BOND STRENGTH IN REINFORCED CONCRETE

Appendix I

Structural Results

\begin{tabular}{|c|c|c|c|c|c|c|}
\hline 42.14 & 10.54 & 11.15 & -0.585 & -0.972 & -0.779 & 155.75 \\
\hline 42.35 & 10.59 & 11.35 & -0.604 & -1.005 & -0.804 & 160.87 \\
\hline 42.57 & 10.64 & 11.56 & -0.618 & -1.040 & -0.829 & 165.87 \\
\hline 42.59 & 10.65 & 11.77 & -0.640 & -1.075 & -0.859 & 171.75 \\
\hline 42.70 & 10.68 & 11.97 & -0.658 & -1.105 & -0.883 & 176.50 \\
\hline 42.83 & 10.71 & 12.18 & -0.675 & -1.139 & -0.908 & 181.62 \\
\hline 42.81 & 10.70 & 12.38 & -0.695 & -1.167 & -0.933 & 186.50 \\
\hline 42.86 & 10.72 & 12.58 & -0.718 & -1.198 & -0.958 & $1 \overline{91.62}$ \\
\hline 42.94 & 10.74 & 12.80 & -0.743 & -1.223 & -0.985 & 197.00 \\
\hline 42.99 & 10.75 & 13.00 & -0.763 & -1.254 & -1.010 & 202.00 \\
\hline 43.07 & 10.77 & 13.21 & -0.780 & -1.278 & -1.030 & 206.00 \\
\hline 43.10 & 10.78 & 13.42 & -0.797 & -1.305 & -1.053 & 210.62 \\
\hline 43.10 & 10.78 & 13.62 & -0.815 & -1.332 & -1.075 & 215.00 \\
\hline 43.10 & 10.78 & 13.82 & -0.833 & -1.358 & -1.097 & 219.37 \\
\hline 43.21 & 10.80 & 14.04 & -0.828 & -1.383 & -1.106 & 221.12 \\
\hline 43.21 & 10.80 & 14.24 & -0.845 & -1.408 & -1.128 & 225.50 \\
\hline 43.29 & 10.82 & 14.46 & -0.858 & -1.435 & -1.148 & 229.50 \\
\hline 43.31 & 10.83 & 14.67 & -0.876 & -1.438 & -1.158 & 231.50 \\
\hline 43.34 & 10.84 & 14.87 & -0.896 & -1.454 & -1.175 & 235.00 \\
\hline 43.42 & 10.86 & 15.09 & -0.908 & -1.475 & -1.192 & 238.37 \\
\hline 43.42 & 10.86 & 15.29 & -0.925 & -1.499 & -1.213 & 242.50 \\
\hline 43.50 & 10.88 & 15.50 & -0.943 & -1.520 & -1.233 & 246.50 \\
\hline 43.55 & 10.89 & 15.71 & -0.948 & -1.538 & -1.245 & 249.00 \\
\hline 43.69 & 10.92 & 15.91 & -0.967 & -1.564 & -1.266 & 253.12 \\
\hline 43.80 & 10.95 & 16.10 & -0.987 & -1.590 & -1.289 & 257.87 \\
\hline 43.74 & 10.94 & 16.31 & -1.003 & -1.613 & -1.309 & 261.75 \\
\hline 43.82 & 10.96 & 16.52 & -1.020 & -1.639 & -1.330 & 266.00 \\
\hline 43.93 & 10.98 & 16.73 & -1.043 & -1.645 & -1.345 & 269.00 \\
\hline 43.96 & 10.99 & 16.95 & -1.060 & -1.670 & -1.368 & 273.50 \\
\hline 44.09 & 11.02 & 17.16 & -1.078 & -1.694 & -1.387 & 277.37 \\
\hline 44.20 & 11.05 & 17.36 & -1.097 & -1.720 & -1.410 & 282.00 \\
\hline 44.22 & 11.06 & 17.58 & -1.115 & -1.746 & -1.432 & 286.37 \\
\hline 44.44 & 11.11 & 17.79 & -1.135 & -1.774 & -1.456 & 291.12 \\
\hline 44.52 & 11.13 & 18.00 & -1.155 & -1.804 & -1.480 & 296.00 \\
\hline 44.52 & 11.13 & 18.21 & -1.173 & -1.833 & -1.504 & 300.87 \\
\hline 44.68 & 11.17 & 18.41 & -1.196 & -1.859 & -1.530 & 306.00 \\
\hline 44.73 & 11.18 & 18.62 & -1.223 & -1.884 & -1.554 & 310.87 \\
\hline 44.81 & 11.20 & 18.83 & -1.231 & -1.884 & -1.559 & 311.75 \\
\hline 44.81 & 11.20 & 19.03 & -1.255 & -1.907 & -1.583 & 316.62 \\
\hline 44.94 & 11.24 & 19.24 & -1.275 & -1.938 & -1.608 & 321.50 \\
\hline 45.05 & 11.26 & 19.44 & -1.298 & -1.963 & -1.633 & 326.50 \\
\hline 45.02 & 11.26 & 19.64 & -1.315 & -1.988 & -1.653 & 330.62 \\
\hline 45.16 & 11.29 & 19.85 & -1.336 & -2.003 & -1.672 & 334.37 \\
\hline 45.18 & 11.30 & 20.06 & -1.355 & -2.029 & -1.694 & 338.87 \\
\hline 45.21 & 11.30 & 20.27 & -1.378 & -2.046 & -1.714 & 342.87 \\
\hline 45.37 & 11.34 & 20.47 & -1.402 & -2.073 & -1.739 & 347.87 \\
\hline 45.29 & 11.32 & 20.68 & -1.428 & -2.098 & -1.763 & 352.62 \\
\hline 45.37 & 11.34 & 20.88 & -1.450 & -2.115 & -1.785 & 357.00 \\
\hline
\end{tabular}




\begin{tabular}{|c|c|c|c|c|c|c|}
\hline Z9' $\varepsilon 8 \varepsilon$ & $8 \mathrm{I}^{\circ} \mathrm{I}^{-}$ & It $\varepsilon^{\prime} z^{-}$ & $066^{\circ} \mathrm{I}^{-}$ & SE'ZZ & $I L^{\prime} t$ & $\$ 8.81$ \\
\hline$S L^{\circ} \downarrow 8 \varepsilon$ & $726^{\circ} \mathrm{I}^{-}$ & S†E'Z" & $666^{\circ} I^{-}$ & $\angle S \cdot Z Z$ & $96 \%$ & $88.6 \mathrm{I}$ \\
\hline $21^{\circ} 88 \varepsilon$ & $I^{\circ} 6^{\circ} I^{-}$ & $09 \varepsilon^{\circ} z^{-}$ & $8 \mathrm{IS}^{\circ} \mathrm{I}^{-}$ & $8 L^{\circ} Z Z$ & $t \tau^{\circ} s$ & 56.02 \\
\hline $0 S^{\circ} 16 \varepsilon$ & $856^{\circ} \mathrm{I}^{-}$ & SLE'Z- & $8 E S^{\circ} \mathrm{I}^{-}$ & $00^{\circ} \varepsilon z$ & $0 S^{\circ} S$ & 20.22 \\
\hline$\angle \varepsilon^{\prime} \triangleright 6 \varepsilon$ & ZL6 ${ }^{\circ} \mathrm{I}^{-}$ & $68 \varepsilon z^{-}$ & ESS I- & $Z Z^{\circ} \varepsilon Z$ & $9 L^{\prime} \mathrm{S}$ & $\varepsilon 0^{\circ} \varepsilon z$ \\
\hline $2 I^{\circ} \angle 6 \varepsilon$ & $986^{\circ} \mathrm{I}^{-}$ & tot $z^{-}$ & $\angle 9 S^{\prime} \mathrm{I}^{-}$ & $\varepsilon \nabla^{\circ} \varepsilon \tau$ & $20^{\circ} 9$ & $\angle 0^{\circ}+2$ \\
\hline $0 s^{\circ} 00 t$ & $\varepsilon 00^{\circ} Z^{-}$ & ozt $\sigma^{\circ}$ & $\$ 85^{\circ} \mathrm{I}^{-}$ & $69^{\circ} \varepsilon Z$ & $\angle Z^{\prime} 9$ & $60^{\circ} \mathrm{sZ}$ \\
\hline $2 I^{\circ} \dagger 0 t$ & $120^{\circ} Z^{-}$ & $8 \varepsilon t^{\circ} \tau^{-}$ & $009^{\circ} \mathrm{I}^{-}$ & $98^{\circ} \varepsilon Z$ & $\angle S^{\circ} 9$ & $9 \tau^{\prime} 9 z$ \\
\hline $00^{\circ} \angle 0 B$ & ৎEO'Z- & $\nabla s_{t} \tau^{\circ} Z^{-}$ & $919^{\circ} \mathrm{I}^{-}$ & $90^{\circ} \pitchfork \tau$ & 58.9 & $16 \angle 2$ \\
\hline os'0lt & $\varepsilon S 0^{\circ} Z^{-}$ & $0<\theta^{\circ} Z^{-}$ & 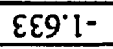 & $9 z^{\prime} \downarrow z$ & $0 \mathrm{I} L$ & $00^{\circ} 82$ \\
\hline $29^{\circ} \varepsilon \mathrm{Ib}$ & $890^{\circ} \tau^{-}$ & $580^{\circ} Z^{-}$ & $8+9^{\circ} \mathrm{l}^{-}$ & $9 b^{\circ}+2$ & $6 E^{\circ} L$ & $\angle S 6 Z$ \\
\hline $29^{\circ} 91 \mathrm{t}$ & $\varepsilon 80^{\circ} \tau^{-}$ & $66 t^{\circ} z^{-}$ & $899^{\circ} \mathrm{I}^{-}$ & $\angle 9^{\circ} t z$ & $6 S^{\circ} \mathrm{L}$ & $\nabla \varepsilon \cdot 0 \varepsilon$ \\
\hline SZ'LIt & $980^{\circ} \tau^{-}$ & $60 s^{\circ} z^{-}$ & $599^{\circ} \mathrm{I}^{-}$ & $89^{\circ} \curvearrowleft \tau$ & $\varepsilon 8^{\circ} \mathrm{L}$ & $\varepsilon \varepsilon^{\circ} 1 \varepsilon$ \\
\hline 0S.9It & $\varepsilon 80^{\circ} Z^{-}$ & $\varepsilon 6 t^{\circ} \tau^{-}$ & $599^{\circ} 1^{-}$ & $\angle 9^{\circ} \Delta z$ & $\varepsilon I^{\circ} 8$ & $\varepsilon \varsigma \tau \varepsilon$ \\
\hline ZI'9It & $180^{\circ} Z^{-}$ & $98 b^{\circ} z^{-}$ & 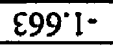 & $89^{\circ} \mathrm{tz}$ & 25.8 & $80^{\circ} \downarrow \varepsilon$ \\
\hline $0 s^{\circ} 6 \mathrm{It}$ & $860^{\circ} Z^{-}$ & $\nabla z S^{\prime} z^{-}$ & $\varepsilon 89^{\circ} 1^{-}$ & $\angle 6^{\circ} \circ z$ & $8 I^{\circ} 6$ & $\tau L^{\circ} 9 \varepsilon$ \\
\hline $29^{\circ} 62 t$ & $8 \mathrm{bl} \mathrm{I}^{\circ}$ & $8 S S^{\circ} Z^{-}$ & SEL'I- & $\nabla L S \mathcal{S Z}$ & $0 I^{\prime} 6$ & $0 t^{\circ} 9 \varepsilon$ \\
\hline $2 I^{\circ} 8 Z \downarrow$ & $|b|^{\circ} \tau^{-}$ & $90 s^{\circ} z^{-}$ & OELI' & $58^{\circ} \mathrm{SZ}$ & $\varepsilon S^{\prime} 6$ & $118 \varepsilon$ \\
\hline 00.827 & $0+I^{\prime} Z^{-}$ & $D t s^{\circ} z^{-}$ & $I^{\prime} \varepsilon L^{\circ} \mathrm{I}^{-}$ & $00^{\circ} 92$ & 186 & $\varepsilon \tau^{\circ} \sigma \varepsilon$ \\
\hline $00^{\circ} Z \varepsilon \downarrow$ & $091^{\prime} Z^{-}$ & $\angle 9 S^{\circ} Z^{-}$ & $\varepsilon S L^{\prime} I^{-}$ & $\angle 0.92$ & $\angle O O I$ & $0 \varepsilon^{\circ} 0 t$ \\
\hline$\angle 810 D$ & $60 \tau^{\circ} z^{-}$ & $819^{\circ} Z^{-}$ & $66 L^{\circ} \mathrm{I}^{-}$ & $60^{\circ} 92$ & SEOI & $2 t^{\circ} I t$ \\
\hline $00^{\circ} \mathrm{ZSB}$ & $09 Z^{\circ} z^{-}$ & $699^{\circ} z^{-}$ & $058^{\circ} \mathrm{I}^{-}$ & $+l^{\prime} 92$ & $79^{\circ} 0 \mathrm{I}$ & $t s^{\circ} z \phi$ \\
\hline Z9. $\varepsilon 9 b$ & $81 \varepsilon^{\circ} \tau^{-}$ & $62 L^{\circ} Z^{-}$ & $806^{\circ} \mathrm{I}^{-}$ & $\nabla z^{\prime} 9 z$ & 26.01 & $99^{\circ} \varepsilon \mathrm{D}$ \\
\hline $00^{\circ} 290$ & OIE'Z- & $60 L^{\circ} Z^{-}$ & S06. $\mathrm{I}^{-}$ & 50.92 & $8 I \cdot I I$ & $\varepsilon L^{\prime} \not b$ \\
\hline $2 l^{\circ} 09 \mathrm{~b}$ & I0 $\varepsilon^{\circ} z^{-}$ & $10 L^{\circ} Z^{-}$ & $\varepsilon 68^{\circ} \mathrm{I}^{-}$ & $68^{\circ} s 2$ & $\varepsilon Z^{\prime I I}$ & $26^{\circ}+5$ \\
\hline 0SSSD & $8 \angle Z^{\prime} Z^{-}$ & ZL9'Z $Z^{-}$ & $8 \angle 8^{\circ} \mathrm{I}^{-}$ & $t 9^{\prime} s Z$ & $\varepsilon Z^{\prime} I I$ & $26^{\circ}+0$ \\
\hline$s Z^{\prime} 1 s b$ & $9 \varsigma Z^{\circ} Z^{-}$ & $1+9^{\circ} z^{-}$ & S98. I- & $\varepsilon t^{\prime} s \tau$ & 92.11 & $20^{\circ} S \mathrm{p}$ \\
\hline $00^{\circ} \angle D D$ & SEZ'Z- & E19.7- & $\varepsilon S 8^{\circ} \mathrm{I}^{-}$ & $\varepsilon Z^{\prime} \leq Z$ & $\nabla Z^{\prime} I I$ & $\angle 6^{\circ} t 5$ \\
\hline sでたた & IIIZ/- & $28 \mathrm{~S}^{\circ} \mathrm{Z}^{-}$ & $9 \varepsilon 8^{\circ} \mathrm{I}^{-}$ & $200^{\circ} \Omega$ & 92 II & $20^{\circ} \mathrm{st}$ \\
\hline$\angle \varepsilon " 6 \varepsilon D$ & $\angle 61^{\circ} Z^{-}$ & $99 \varsigma^{\circ} z^{-}$ & EZ8. I- & $z 8^{\circ} \nabla z$ & $82^{\circ} \mathrm{II}$ & $E I^{\prime} S t$ \\
\hline $0 S^{\circ} \triangleright \varepsilon \phi$ & ELI'Z- & SES Z" & $908^{\circ} \mathrm{I}^{-}$ & $19^{\circ} \nabla 2$ & $8 z^{\prime} I 1$ & $0 I^{\prime} \$ t$ \\
\hline$\angle E E^{\prime} 0 E D$ & $Z S I^{\prime} Z^{-}$ & 0152 & $06 L^{\circ} 1^{-1}$ & $0 \nabla^{\circ} \pitchfork z$ & $8 Z^{\prime} 11$ & OI'St \\
\hline $00^{\circ} 82 \mathrm{t}$ & $0+\mathrm{II}^{\circ} \mathrm{Z}-$ & Eos $Z^{-}$ & $\varepsilon \angle L^{\circ} I^{-}$ & $0 z^{\circ} \nabla z$ & $0 \varepsilon^{\prime} I I$ & $81^{\circ} \mathrm{St}$ \\
\hline $0 S^{\circ} \varepsilon Z \downarrow$ & $811^{\circ} \mathrm{Z}^{-}$ & SLナ Z- & SSL'I- & $66^{\circ} \varepsilon Z$ & $0 \varepsilon^{\prime} I I$ & $8 I^{\circ} S t$ \\
\hline $05^{\circ} 81 \mathrm{t}$ & $\varepsilon 60^{\circ} Z^{-}$ & 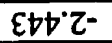 & $S \varepsilon L^{\circ} I^{-}$ & $6 L^{\circ} \varepsilon Z$ & ZEII & $9 \tau^{\circ} s t$ \\
\hline $00^{\circ} D I t$ & $0 \angle 0^{\circ} Z^{-}$ & $0 ح \nabla^{\circ} \nearrow^{-}$ & $91 L^{\circ} I^{-}$ & $\angle S^{\prime} \varepsilon Z$ & $I E^{\prime} I I$ & $t \tau^{\prime} S t$ \\
\hline LEIID & $\angle S 0^{\circ} Z^{-}$ & Elto $Z^{-}$ & S69. I- & $\angle \varepsilon^{\cdot} \varepsilon Z$ & ZE.II & $9 \tau^{\circ} s t$ \\
\hline $00^{\circ} 907$ & $0 \varepsilon 0^{\circ} Z^{-}$ & $\varepsilon 8 \varepsilon^{\prime} Z^{-}$ & $\varepsilon \angle 9^{\circ} \mathrm{I}^{-}$ & $9 l^{\circ} \varepsilon Z$ & $Z \varepsilon^{\prime} \mathrm{II}$ & $6 \tau^{\circ} S t$ \\
\hline$\angle E^{\circ} 10 D$ & $\angle 00^{\circ} Z^{-}$ & દSE'Z- & $t S 9^{\circ} I^{-}$ & 56.22 & $0 \varepsilon^{\prime} I I$ & $I \tau s t$ \\
\hline$s \tau \cdot 86 \varepsilon$ & $166^{\circ} \mathrm{I}^{-}$ & $8 Z \varepsilon^{\prime} Z^{-}$ & ES9. I- $^{-}$ & $S L^{\prime} Z Z$ & $0 \varepsilon^{\prime} I I$ & $I \tau^{\prime} S t$ \\
\hline $00^{\circ} \varepsilon 6 \varepsilon$ & S96. I- & $86 \tau^{\circ} Z^{-}$ & $\varepsilon \varepsilon 9^{\circ} 1^{-}$ & $t s^{\prime} Z 2$ & ZE'II & $6 \tau^{\circ} S t$ \\
\hline $0 S^{\circ} 16 \varepsilon$ & $856^{\circ} \mathrm{I}^{-}$ & EOE'Z- & $809^{\circ} \mathrm{I}^{-}$ & $\nabla \varepsilon z z$ & $\nabla E^{\prime} I I$ & $\angle \varepsilon^{*} S t$ \\
\hline$S L^{\circ} S 8 \varepsilon$ & $6261^{-1}$ & $\varepsilon\left\llcorner Z^{\circ} Z^{-}\right.$ & [85. I- & $\varepsilon I^{\prime} Z z$ & $9 \varepsilon \| I$ & $z t s t$ \\
\hline $00^{\circ} 08 \varepsilon$ & $006^{\circ} \mathrm{I}^{-}$ & $\varepsilon \oplus \tau^{\circ} Z^{-}$ & SSSI- & $\varepsilon 6^{\circ} \mathrm{IL}$ & $9 \varepsilon^{\circ}[\mathrm{I}$ & $2 t s t$ \\
\hline $00^{\circ} S \angle \mathcal{L}$ & SL8' I- & siz' ${ }^{-}$ & EES 1- & $Z L^{\prime} I Z$ & $\underline{S E^{\prime} I I}$ & $0 t s t$ \\
\hline $00^{\circ} Z L E$ & $098^{\circ} I^{-}$ & $961^{\circ} z^{-}$ & ors 1- & IS'IZ & tE.II & 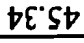 \\
\hline $2 I^{\circ} \angle 9 \varepsilon$ & 9E8' I- & $0 \mathrm{LI}^{\circ} \mathrm{Z}^{-}$ & $86 \mathrm{t}^{\circ} \mathrm{I}^{-}$ & $0 \varepsilon^{\prime} I Z$ & SELII & $00, s t$ \\
\hline $00^{\circ} Z 9 \varepsilon$ & $018^{\prime} \mathrm{I}^{-}$ & $z+I^{\circ} z^{-}$ & SLO $1^{-}$ & $0 I^{\prime} I Z$ & $\nabla \varepsilon^{\prime} ! I$ & $\angle E^{\prime} S D$ \\
\hline
\end{tabular}


$\varepsilon Z I$

\begin{tabular}{|c|c|c|c|c|c|c|}
\hline $0+2$ & $210^{\circ} 0^{-}$ & $\angle 00^{\circ} 0$ & $\varepsilon 10^{\circ} 0$ & $6 \varepsilon^{\circ} 0$ & $98^{\circ} \varepsilon$ & $\varepsilon t^{\prime} \varsigma \mathrm{I}$ \\
\hline$S Z^{\circ} \mathcal{E}$ & $910^{\circ} 0^{-}$ & $600^{\circ} 0^{-}$ & $\angle 10^{\circ} 0$ & $9 \varepsilon^{\circ} 0$ & $8 L^{\prime} \varepsilon$ & II'SI \\
\hline $80^{\circ} \mathrm{t}$ & $020^{\circ} 0^{-}$ & $220^{\circ} 0$ & $\varepsilon Z 0^{\circ} 0$ & SE'0 & $95^{\circ} \varepsilon$ & $2 \tau^{\circ}+1$ \\
\hline $80^{\circ} 2$ & $210^{\circ} 0^{-}$ & $\angle E O^{\circ} 0$ & $210^{\circ} 0$ & $\nabla \varepsilon^{\prime} 0$ & $87^{\circ} \varepsilon$ & $26^{\circ} \varepsilon I$ \\
\hline $08^{\circ} \mathrm{I}$ & $600^{\circ} 0^{-}$ & IEO 0 & $\$ 20^{\circ} 0$ & $\varepsilon \varepsilon^{\circ} 0$ & $\angle E^{\prime} \varepsilon$ & $6 t^{\circ} \varepsilon I$ \\
\hline$s 6 \%$ & $\mathrm{slO}^{\circ} 0^{-}$ & $\varepsilon 10^{\circ} 0$ & $100^{\circ} 0$ & IE'0 & $\nabla \tau^{*} \varepsilon$ & $\$ 6{ }^{\circ} \mathrm{I}$ \\
\hline strz & $210^{\circ} 0^{-}$ & $\angle 10^{\circ} 0^{-}$ & $610^{\circ} 0$ & $0 \varepsilon^{\circ} 0$ & $Z I^{\circ} \varepsilon$ & $\angle D^{\prime} Z I$ \\
\hline$Z L \cdot 1$ & $600^{\circ} 0^{-}$ & $910^{\circ} 0$ & $110^{\circ} 0$ & $82^{\circ} 0$ & SO० $\varepsilon$ & $I Z \cdot Z I$ \\
\hline$\varepsilon 0^{\circ} \mathrm{Z}$ & $010^{\circ} 0^{-}$ & 9200 & $9 \varepsilon 0^{\circ} 0^{-}$ & $92^{\circ} 0$ & 262 & $69^{\circ}$ I I \\
\hline SLO & $700^{\circ} 0^{-}$ & $120^{\circ} 0$ & $800^{\circ} 0$ & $S Z^{\circ} 0$ & $8 L Z$ & ZI'II \\
\hline $58 \%$ & $\$ 10^{\circ} 0^{-}$ & $200^{\circ} 0$ & $\angle 10^{\circ} 0$ & $\nabla \tau^{\circ} 0$ & $\varepsilon 9^{\circ} \mathrm{Z}$ & $75^{\circ} 01$ \\
\hline$\varepsilon Z^{\prime} Z$ & $110^{\circ} 0^{-}$ & $700^{\circ} 0$ & $\angle 00^{\circ} 0$ & $\varepsilon Z^{\circ} 0$ & $09 \%$ & $6 \varepsilon 01$ \\
\hline $81^{\circ} \mathrm{Z}$ & $110^{\circ} 0^{-}$ & $1 \varepsilon 0^{\circ} 0$ & $700^{\circ} 0^{-}$ & $\varepsilon \tau^{\circ} 0$ & $S S^{\prime} Z$ & $6 I^{\circ} 0 \mathrm{I}$ \\
\hline S6. I & $010^{\circ} 0^{-}$ & $\mathrm{SOO}^{\circ} 0^{-}$ & $\angle 10^{\circ} 0$ & $12^{\circ} 0$ & $0 \varepsilon Z$ & $61^{\circ} 6$ \\
\hline 090 & $\varepsilon 00^{\circ} 0^{-}$ & $\nabla 10^{\circ} 0$ & $\varepsilon 00^{\circ} 0$ & $81^{\circ} 0$ & $\varepsilon 0^{\circ} \mathrm{Z}$ & II'8 \\
\hline $\mathrm{SO}^{\circ} 0^{-}$ & $000^{\circ} 0$ & $800^{\circ} 0^{-}$ & $110^{\circ} 0$ & $91^{\circ} 0$ & $S L^{\prime} I$ & $10 . \mathrm{L}$ \\
\hline$\varepsilon 0^{\circ} \mathrm{Z}$ & $010^{\circ} 0^{-}$ & $810^{\circ} 0$ & $\angle 10^{\circ} 0$ & $21^{\circ} 0$ & $60^{\circ} 1$ & $\angle 6.5$ \\
\hline $\mathrm{SI} \mathrm{I}^{\circ}$ & $900^{\circ} 0^{-}$ & $510^{\circ} 0$ & $200^{\circ} 0$ & $0 I^{\circ} 0$ & $6 I^{\circ} 1$ & $\angle L L^{\circ} D$ \\
\hline $0 D^{2} Z$ & $210^{\circ} 0^{-}$ & $110^{\circ} 0$ & $110^{\circ} 0$ & $80^{\circ} 0$ & 960 & $\$ 8^{\prime} \mathcal{E}$ \\
\hline$L L \cdot I$ & $600^{\circ} 0^{-}$ & $820^{\circ} 0^{-}$ & $800^{\circ} 0$ & 70.0 & $\varepsilon L^{\prime} 0$ & $06{ }^{\circ} \mathrm{Z}$ \\
\hline $28^{\circ} \mathrm{Z}$ & $D 10^{\circ} 0^{-}$ & I90.0- & $500^{\circ} 0$ & 100 & $\angle \nabla 0$ & $88^{\circ} \mathrm{I}$ \\
\hline SSZ & $\varepsilon 10^{\circ} 0^{-}$ & $\$ 10^{\circ} 0^{-}$ & $010^{\circ} 0$ & $00^{\circ} 0$ & $82^{\circ} 0$ & III \\
\hline $\begin{array}{c}\text { (uX/l) } \\
\text { andes.lno }\end{array}$ & 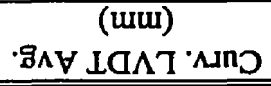 & 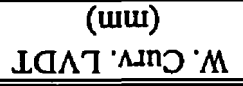 & 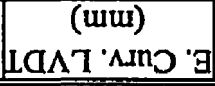 & $\begin{array}{c}\text { (uw) } \\
\mathrm{ds} ! \mathrm{d}^{\circ} \mathrm{d} \omega \\
\end{array}$ & $\begin{array}{c}\text { (u-NY) } \\
\text { quəuow }\end{array}$ & $\begin{array}{l}\text { (NX) } \\
\text { peo7 }\end{array}$ \\
\hline
\end{tabular}

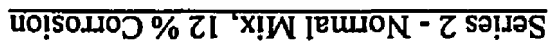

\begin{tabular}{|c|c|c|c|c|c|c|}
\hline $0 S^{\circ} 062$ & ESt' I- & ह98. [- & $0+0^{\circ} \mathrm{I}^{-}$ & $0 I^{\prime} 8 \mathrm{I}$ & $80^{\circ} 0^{-}$ & $b\left[^{\circ} 0^{-}\right.$ \\
\hline $0 S^{\circ} 162$ & $8 S^{\circ} \mathrm{I}^{-}$ & $\angle 98^{\circ} \mathrm{I}^{-}$ & St0 I- & SI'8I & $80^{\circ} 0^{-}$ & $\mathrm{ZI}^{\circ} \mathrm{O}^{-}$ \\
\hline $29^{\circ}+6 z$ & ELt゚ I- & EL8 I- & $\varepsilon \angle 0^{\prime} 1^{-}$ & SE $8 I$ & $91^{\circ} 0$ & $69^{\circ} 0$ \\
\hline$\angle \varepsilon^{\prime} 662$ & $\angle 6 t^{\circ} I^{-}$ & $088^{\circ} \mathrm{I}^{-}$ & EII'I- & $\angle S^{\prime} 81$ & $9 \varepsilon^{\circ} 0$ & St I \\
\hline SZ'EOE & 9IS'I- & $\varepsilon 68^{\circ} \mathrm{I}^{-}$ & $6 \varepsilon I^{\circ} \mathrm{I}^{-}$ & $6 L \cdot 8 I$ & $\angle S^{\prime} O$ & $O \varepsilon^{\circ} Z$ \\
\hline$\angle \varepsilon^{\prime} 60 \varepsilon$ & $\angle D S^{\circ} I^{-}$ & $826^{\circ} 1^{-}$ & E9I'I- & $10^{\circ} 6 \mathrm{I}$ & $18^{\circ} 0$ & $\nabla Z^{\prime} \varepsilon$ \\
\hline $00^{\circ}$ SIE & SLS'I- & $196^{\circ} \mathrm{I}^{-}$ & $06 \mathrm{I}^{\circ} \mathrm{I}^{-}$ & $b Z^{\prime} 6 I$ & 50.1 & $\angle I^{\prime} t$ \\
\hline$\angle E^{\prime} I Z E$ & $\angle 09^{\circ} \mathrm{I}^{-}$ & $966^{\circ} \mathrm{I}^{-}$ & tIZ'- & $9 b^{\circ} 6 I$ & $\angle Z I I$ & oI's \\
\hline Z9.92E & हE9' I- & $820^{\circ} Z^{\circ}$ & $8 \varepsilon Z^{\prime} I^{-}$ & 89.61 & $z S^{\prime} I$ & $80^{\circ} 9$ \\
\hline SLZEE & $799^{\circ} \mathrm{I}^{-}$ & $890^{\circ} \mathrm{Z}-$ & $6 S Z^{\prime} I^{-}$ & 16.61 & $6 L^{\circ} I$ & $\angle I L$ \\
\hline SZ'8EE & $169^{\circ} \mathrm{I}^{-}$ & EOI'Z- & $6 \mathrm{LZ}^{\prime} \mathrm{I}^{-}$ & $\varepsilon I^{\circ} 0 Z$ & $\mathrm{SO}^{\circ} \mathrm{Z}$ & $12^{\prime} 8$ \\
\hline$L \varepsilon^{\prime} \triangleright \triangleright \varepsilon$ & $Z Z L^{\circ} \mathrm{I}^{-}$ & 6El'Z- & EOE'I- & $9 \varepsilon^{\circ} 0 Z$ & $\tau \varepsilon^{\prime} \tau$ & $\angle 2 \cdot 6$ \\
\hline $29^{\circ} 6 t \varepsilon$ & $80 L^{\circ} \mathrm{I}^{-}$ & OLI' & SZE'I- & $6 S^{\circ} 02$ & $65^{\circ} \mathrm{Z}$ & SEOI \\
\hline $00^{\circ} \varsigma \varsigma \mathcal{E}$ & SLL'1- & $70 z^{\prime} z^{-}$ & S†E'I- & $6 L^{\circ} 0 Z$ & $88^{\circ} \mathrm{Z}$ & $25^{\circ} 11$ \\
\hline ZI.09E & $108^{\circ} \mathrm{I}^{-}$ & IEZ'Z- & ZLE'I- & $10^{\circ} \mathrm{IZ}$ & $9 I^{\circ} \varepsilon$ & $79^{\circ} \mathrm{ZI}$ \\
\hline 0S $99 \varepsilon$ & EE8 I- & 99Z'て- & 00t' I- & $\varepsilon Z^{\prime} I Z$ & $9 t^{\circ} \varepsilon$ & $78^{\circ} \varepsilon I$ \\
\hline $00^{\circ} Z \angle E$ & $098^{\circ} \mathrm{I}^{-}$ & $\angle 6 C^{\circ} Z^{-}$ & EZt I- & $95^{\circ} \mathrm{IL}$ & $\nabla L \mathcal{L}$ & $\angle 6^{\circ}+1$ \\
\hline OS'9LE & E88. I- & †I $\varepsilon^{\prime} Z^{-}$ & $80 t^{\circ} 1^{-}$ & $0 L^{\circ} I Z$ & $\varepsilon 0^{\prime} b$ & OI'9I \\
\hline OS.08E & E06 I- & $\angle \varepsilon \varepsilon Z^{-}$ & S9t' I- & $26^{\circ} I Z$ & IZ't & 58.91 \\
\hline $0 S^{\circ} \varepsilon 8 \varepsilon$ & $816^{\circ} 1^{-}$ & OSE Z- & 6Lt' I- & DI'ZZ & $L \nabla^{\circ} t$ & $98^{\circ} \mathrm{LI}$ \\
\hline
\end{tabular}




\begin{tabular}{|c|c|c|c|c|c|c|}
\hline 16.26 & $\overline{4.07}$ & 0.42 & 0.002 & 0.005 & -0.011 & 2.23 \\
\hline 15.66 & 3.92 & 0.63 & 0.008 & -0.019 & -0.017 & 3.47 \\
\hline 15.44 & 3.86 & 0.64 & -0.031 & 0.010 & -0.011 & 2.10 \\
\hline 14.71 & 3.68 & 0.64 & -0.004 & 0.011 & -0.022 & 4.45 \\
\hline 14.83 & 3.71 & 0.67 & 0.005 & -0.019 & -0.023 & 4.53 \\
\hline 14.54 & 3.64 & 0.76 & 0.009 & -0.002 & -0.022 & 4.37 \\
\hline 15.62 & 3.90 & 0.95 & 0.017 & -0.026 & -0.009 & 1.85 \\
\hline 16.15 & 4.04 & 1.02 & -0.001 & 0.020 & -0.018 & 3.52 \\
\hline 16.53 & 4.13 & 1.04 & 0.020 & -0.001 & -0.016 & 3.23 \\
\hline 17.66 & 4.42 & 1.20 & -0.005 & 0.012 & -0.014 & 2.87 \\
\hline 18.56 & 4.64 & 1.30 & 0.022 & 0.015 & -0.019 & 3.70 \\
\hline 18.63 & 4.66 & 1.30 & 0.018 & 0.009 & -0.019 & 3.73 \\
\hline 19.31 & 4.83 & 1.36 & 0.003 & -0.026 & -0.014 & 2.85 \\
\hline 19.56 & 4.89 & 1.40 & 0.014 & -0.006 & -0.014 & 2.70 \\
\hline 19.72 & 4.93 & 1.44 & 0.019 & -0.022 & -0.014 & 2.87 \\
\hline 19.92 & 4.98 & 1.46 & -0.008 & -0.030 & -0.020 & 3.98 \\
\hline 20.76 & 5.19 & 1.53 & 0.006 & 0.001 & -0.017 & 3.40 \\
\hline 21.34 & 5.33 & 1.61 & 0.005 & 0.016 & -0.007 & 1.43 \\
\hline 22.28 & 5.57 & 1.71 & 0.002 & -0.026 & -0.020 & 4.03 \\
\hline 22.23 & 5.56 & 1.90 & -0.004 & -0.037 & -0.037 & 7.42 \\
\hline 21.03 & 5.26 & 1.93 & -0.005 & -0.008 & -0.047 & 9.48 \\
\hline 19.79 & 4.95 & 1.96 & -0.063 & -0.070 & -0.075 & 14.97 \\
\hline 18.12 & 4.53 & 2.10 & -0.063 & -0.165 & -0.125 & 24.95 \\
\hline 16.61 & 4.15 & 2.11 & -0.064 & -0.148 & -0.124 & 24.78 \\
\hline 15.36 & 3.84 & 2.10 & -0.055 & -0.159 & -0.131 & 26.20 \\
\hline 14.22 & 3.56 & 2.14 & -0.067 & -0.171 & -0.134 & 26.70 \\
\hline 14.34 & 3.58 & 2.33 & -0.083 & -0.210 & -0.165 & 33.00 \\
\hline 15.11 & 3.78 & 2.50 & -0.064 & -0.269 & -0.185 & 36.90 \\
\hline 15.13 & 3.78 & 2.51 & -0.101 & -0.259 & -0.190 & 37.90 \\
\hline 15.23 & 3.81 & 2.60 & -0.088 & -0.259 & -0.199 & 39.73 \\
\hline 15.74 & 3.93 & 2.78 & -0.103 & -0.290 & -0.225 & 45.00 \\
\hline 16.33 & 4.08 & 2.92 & -0.139 & -0.358 & -0.243 & 48.65 \\
\hline 16.85 & 4.21 & 3.06 & -0.111 & -0.347 & -0.268 & 53.57 \\
\hline 17.26 & 4.32 & 3.27 & -0.161 & -0.389 & -0.303 & 60.58 \\
\hline 17.73 & 4.43 & 3.48 & -0.163 & -0.377 & -0.316 & 63.27 \\
\hline 18.33 & 4.58 & 3.71 & -0.205 & -0.445 & -0.342 & 68.45 \\
\hline 18.91 & 4.73 & 3.91 & -0.224 & -0.480 & -0.370 & 74.00 \\
\hline 19.31 & 4.83 & 4.11 & -0.240 & -0.528 & -0.401 & 80.12 \\
\hline 19.81 & 4.95 & 4.31 & -0.274 & -0.578 & -0.425 & 84.95 \\
\hline 19.99 & 5.00 & 4.52 & -0.251 & -0.588 & -0.452 & 90.45 \\
\hline 20.37 & 5.09 & 4.73 & -0.292 & -0.628 & -0.477 & 95.30 \\
\hline 20.26 & 5.07 & 4.97 & -0.358 & -0.657 & -0.515 & 102.97 \\
\hline 20.50 & 5.12 & 5.19 & -0.396 & -0.688 & -0.547 & 109.35 \\
\hline 20.04 & 5.01 & 5.40 & -0.356 & -0.743 & -0.582 & 116.35 \\
\hline 19.28 & 4.82 & 5.60 & -0.433 & $-0,800$ & -0.610 & 121.90 \\
\hline 18.20 & 4.55 & 5.75 & -0.441 & -0.814 & -0.640 & 128.03 \\
\hline 17.21 & 4.30 & 5.89 & -0.424 & -0.845 & -0.669 & 133.73 \\
\hline 16.30 & 4.07 & 5.97 & -0.433 & -0.870 & -0.683 & 136.60 \\
\hline
\end{tabular}




\section{CORROSION EFFECTS ON BOND STRENGTH IN REINFORCED CONCRETE}

\begin{tabular}{||l|l|l|l|l|l|l||}
\hline 15.35 & 3.84 & 6.05 & -0.503 & -0.894 & -0.691 & 138.25 \\
\hline 14.45 & 3.61 & 6.15 & -0.443 & -0.895 & -0.713 & 142.53 \\
\hline 13.70 & 3.43 & 6.36 & -0.499 & -0.946 & -0.741 & 148.25 \\
\hline 13.11 & 3.28 & 6.54 & -0.607 & -0.943 & -0.763 & 152.65 \\
\hline 12.56 & 3.14 & 6.75 & -0.605 & -0.993 & -0.791 & 158.20 \\
\hline 11.99 & 3.00 & 6.95 & -0.587 & -1.009 & -0.821 & 164.10 \\
\hline 11.81 & 2.95 & 7.14 & -0.601 & -1.045 & -0.848 & 169.68 \\
\hline 11.52 & 2.88 & 7.34 & -0.646 & -1.076 & -0.886 & 177.20 \\
\hline 10.88 & 2.72 & 7.54 & -0.632 & -1.131 & -0.927 & 185.32 \\
\hline 9.90 & 2.48 & 7.76 & -0.722 & -1.166 & -0.948 & 189.62 \\
\hline 9.73 & 2.43 & 7.94 & -0.709 & -1.219 & -0.980 & 196.05 \\
\hline 9.30 & 2.32 & 8.13 & -0.762 & -1.214 & -0.999 & 199.82 \\
\hline 8.84 & 2.21 & 8.37 & -0.753 & -1.241 & -1.036 & 207.25 \\
\hline 8.48 & 2.12 & 8.54 & -0.799 & -1.319 & -1.071 & 214.25 \\
\hline 8.01 & 2.00 & 8.75 & -0.880 & -1.311 & -1.095 & 219.00 \\
\hline 7.73 & 1.93 & 8.91 & -0.866 & -1.375 & -1.124 & 224.75 \\
\hline 7.26 & 1.82 & 9.11 & -0.828 & -1.404 & -1.154 & 230.75 \\
\hline 6.64 & 1.66 & 9.30 & -0.872 & -1.384 & -1.181 & 236.25 \\
\hline 6.51 & 1.63 & 9.50 & -0.933 & -1.398 & -1.204 & 240.75 \\
\hline 6.19 & 1.55 & 9.70 & -0.983 & -1.483 & -1.234 & 246.75 \\
\hline 5.86 & 1.47 & 9.93 & -0.961 & -1.441 & -1.263 & 252.50 \\
\hline 5.55 & 1.39 & 10.06 & -1.003 & -1.548 & -1.305 & 261.00 \\
\hline 5.21 & 1.30 & 10.25 & -1.050 & -1.574 & -1.333 & 266.50 \\
\hline 4.88 & 1.22 & 10.41 & -1.066 & -1.545 & -1.351 & 270.25 \\
\hline 4.64 & 1.16 & 10.56 & -1.096 & -1.595 & -1.368 & 273.50 \\
\hline 4.33 & 1.08 & 10.82 & -1.129 & -1.584 & -1.400 & 280.00 \\
\hline 4.22 & 1.06 & 10.98 & -1.144 & -1.640 & -1.423 & 284.50 \\
\hline 3.78 & 0.94 & 11.18 & -1.173 & -1.684 & -1.453 & 290.50 \\
\hline 3.59 & 0.90 & 11.36 & -1.173 & -1.710 & -1.473 & 294.50 \\
\hline 3.52 & 0.88 & 11.59 & -1.231 & -1.730 & -1.505 & 301.00 \\
\hline 3.41 & 0.85 & 11.73 & -1.296 & -1.754 & -1.540 & 308.00 \\
\hline 3.19 & 0.80 & 11.87 & -1.290 & -1.795 & -1.563 & 312.50 \\
\hline 3.06 & 0.77 & 12.04 & -1.308 & -1.775 & -1.590 & 318.00 \\
\hline 3.09 & 0.77 & 12.23 & -1.340 & -1.863 & -1.619 & 323.75 \\
\hline 2.83 & 0.71 & 12.47 & -1.356 & -1.884 & -1.656 & 331.25 \\
\hline 2.62 & 0.66 & 12.69 & -1.405 & -1.914 & -1.678 & 335.50 \\
\hline 2.38 & 0.60 & 12.88 & -1.379 & -2.001 & -1.710 & 342.00 \\
\hline 2.43 & 0.61 & 13.10 & -1.408 & -1.966 & -1.735 & 347.00 \\
\hline 2.36 & 0.59 & 13.25 & -1.484 & -1.994 & -1.764 & 352.75 \\
\hline 1.94 & 0.49 & 13.32 & -1.495 & -1.993 & -1.759 & 351.75 \\
\hline & & & & & & \\
\hline & & & & & \\
\hline & & & & & & \\
\hline
\end{tabular}




\begin{tabular}{|c|c|c|c|c|c|c|}
\hline $6 Z^{\prime} \angle \varepsilon$ & $981^{\circ} 0^{-}$ & $8 \nabla 2^{\circ} 0^{-}$ & $2 \mathrm{ZI}^{\circ} 0^{-}$ & $59^{\circ} \mathrm{Z}$ & $8 \varepsilon^{\circ} L$ & $25^{\circ} 62$ \\
\hline $80^{\circ} S \mathcal{E}$ & SLI $0^{-}$ & $\tau+\tau^{\circ} 0^{-}$ & $911^{\circ} 0^{-}$ & $9 S^{2} \mathrm{Z}$ & $2 I^{\prime} \mathrm{L}$ & $8 t^{\circ} 82$ \\
\hline$s L \downarrow \varepsilon$ & $0 \angle I^{\circ} 0^{-}$ & $9 \varepsilon Z^{\circ} 0^{-}$ & $011^{\circ} 0^{-}$ & $6 t^{2} Z$ & $t 8.9$ & $9 \varepsilon^{\circ} \angle Z$ \\
\hline$\varepsilon 0^{\circ} \varepsilon \varepsilon$ & $591^{\circ} 0^{-}$ & 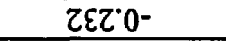 & SOI. $0^{-}$ & 162 & $6 S^{\prime} 9$ & $\nabla \varepsilon^{\circ} 9 Z$ \\
\hline $9 S^{\prime} Z \varepsilon$ & E91.0- & $\angle Z Z^{\circ} 0^{-}$ & $660^{\circ} 0^{-}$ & $\varepsilon \varepsilon \tau$ & $1 \varepsilon^{\prime} 9$ & $S Z^{\circ} s Z$ \\
\hline$\nabla[\cdot 1 \varepsilon$ & $9 \mathrm{SlO}^{\circ} \mathrm{O}^{-}$ & $612^{\circ} 0^{-}$ & $\varepsilon 60^{\circ} 0^{-}$ & $2 z^{\prime} Z$ & $90^{\circ} 9$ & $\varepsilon Z^{\prime} \triangleright Z$ \\
\hline $66^{\circ} 62$ & OSI $0^{-}$ & EIZ ${ }^{\circ} 0^{-}$ & $980^{\circ} 0^{-}$ & $9 I^{\prime} \mathrm{Z}$ & $08^{\circ} \mathrm{S}$ & $Z Z^{\circ} \varepsilon Z$ \\
\hline 89.82 & $\varepsilon \neq l^{\circ} 0^{-}$ & $\mathrm{LOZ}^{\circ} \mathrm{O}^{-}$ & $6 \angle 0^{\circ} 0^{-}$ & $90^{\prime} z$ & $t S^{\prime} S$ & SI'ZZ \\
\hline$\nabla L^{\prime} L Z$ & $6 \varepsilon \mathrm{I}^{\circ} \mathrm{O}^{-}$ & $202^{\circ} 0^{-}$ & $\varepsilon \angle 0^{\circ} 0^{-}$ & 66.1 & SZ'S & 00.12 \\
\hline $12^{\prime} 92$ & IEl'0- & $561^{\circ} 0^{-}$ & $\angle 90^{\circ} 0^{-}$ & $68^{\prime} 1$ & $\angle 6^{\circ} \circ$ & $98^{\circ} 6 \mathrm{I}$ \\
\hline $0 I^{\prime} S Z$ & $9 \mathrm{ClO}^{\circ}$ & $68 \mathrm{I}^{\circ} \mathrm{O}^{-}$ & $190^{\circ} 0^{-}$ & $28^{\circ} \mathrm{I}$ & $69^{\circ} b$ & $\angle L \cdot 8 I$ \\
\hline $16^{\circ} \varepsilon Z$ & $0 Z I^{\circ} 0^{-}$ & $281^{\circ} 0^{-}$ & $\angle S 0^{\circ} 0^{-}$ & $\varepsilon L^{\prime} I$ & $2 t^{\circ} t$ & $0 L \cdot L I$ \\
\hline $9 S^{\prime} z z$ & Ell.0- & $\forall \angle I^{\circ} 0^{-}$ & $\mathrm{t} S 0^{\circ} 0^{-}$ & S9.1 & $91^{\circ} \mathrm{b}$ & 29.91 \\
\hline SI'IL & $901^{\circ} 0^{-}$ & E9 [०0- & $8+0^{\circ} 0^{-}$ &  & $88^{\circ} \varepsilon$ & $2 S^{\circ} \mathrm{SI}$ \\
\hline 19.02 & Eol'0- & SSI'0- & $0 S 0^{\circ} 0^{-}$ & $s+1$ & $6 S^{\circ} \varepsilon$ & $L \varepsilon^{\prime} D I$ \\
\hline$t Z^{\prime} 61$ & $960^{\circ} 0^{-}$ & St $I^{\circ} 0^{-}$ & $670^{\circ} 0^{-}$ & $\angle E^{\prime} l$ & $Z \varepsilon \mathcal{\varepsilon}$ & $\angle Z^{\circ} \varepsilon I$ \\
\hline $69^{\circ} \mathrm{LI}$ & $880^{\circ} 0^{-}$ &  & $\varepsilon \rightarrow 0^{\circ} 0^{-}$ & $9 Z^{\prime} \mathrm{I}$ & $\varepsilon 0^{\circ} \varepsilon$ & $2 I^{\circ} \mathrm{ZI}$ \\
\hline $6 L^{\circ} S 1$ & $6 \angle 0^{\circ} 0^{-}$ & IZI"0- & $9 \varepsilon 0^{\circ} 0^{-}$ & $\varepsilon I^{\prime} I$ & $9 L^{\prime} Z$ & EO II \\
\hline$\angle Z^{\prime} \supset 1$ & $\mathrm{I} \angle 0^{\circ} 0^{-}$ & I I I ${ }^{\circ} 0^{-}$ & $0 \varepsilon 0^{\circ} 0^{-}$ & 50.1 & $6 t^{\prime} Z$ & \begin{tabular}{|l|}
96.6 \\
\end{tabular} \\
\hline $9 Z^{\prime} \mathrm{Zl}$ & $190^{\circ} 0^{-}$ & $\varepsilon 60^{\circ} 0^{-}$ & $920^{\circ} 0^{-}$ & $\varepsilon 6^{\circ} 0$ & $6 I^{\prime} Z$ & $S L^{\prime} 8$ \\
\hline$I t^{\prime} L$ & $\angle E 0^{\circ} 0^{-}$ & $850^{\circ} 0^{-}$ & $910^{\circ} 0^{-}$ & $\$ 9^{\circ} 0$ & 26.1 & $89^{\circ} \mathrm{L}$ \\
\hline $85^{\circ} 9$ & $\varepsilon \varepsilon 0^{\circ} 0^{-}$ & $\mathrm{ISO}^{\circ} \mathrm{O}^{-}$ & SIO'0- & 19.0 & IZZ & 78.8 \\
\hline $06 . \mathrm{S}$ & $0 E 0^{\circ} 0^{-}$ & $5+0^{\circ} 0^{-}$ & $\$ 10^{\circ} 0^{-}$ & $85^{\circ} 0$ & $8 b^{\prime} 2$ & 16.6 \\
\hline 05.5 & $820^{\circ} 0^{-}$ & $2+0^{\circ} 0^{-}$ & $\mathrm{SLO}^{\circ} 0^{-}$ & $95^{\circ} 0$ & $9 L Z$ & $t 0^{\circ} \mathrm{LI}$ \\
\hline $9 \varepsilon^{\prime} S$ & $\angle 20^{\circ} 0^{-}$ & $8 \varepsilon 0^{\circ} 0^{-}$ & $+10^{\circ} 0^{-}$ & $S S^{\circ} 0$ & $80^{\circ} \varepsilon$ & ZЕ'ZI \\
\hline$t \tau^{\prime} \dagger$ & $120^{\circ} 0^{-}$ & {$\left[\varepsilon 0^{\circ} 0^{-}\right.$} & $\varepsilon 10^{\circ} 0^{-}$ & $\varepsilon S^{\circ} 0$ & $8 \varepsilon^{\prime} \varepsilon$ & $I \varsigma^{\circ} \varepsilon I$ \\
\hline$s \varepsilon^{*} \varepsilon$ & $\angle 10^{\circ} 0^{-}$ & $020^{\circ} 0^{-}$ & $110^{\circ} 0^{-}$ & $60^{\circ} 0$ & $I L^{\prime} \varepsilon$ & $\varepsilon 8^{\circ} \triangleright I$ \\
\hline 90.1 & $500^{\circ} 0^{-}$ & $\varepsilon 00^{\circ} 0^{-}$ & $E 00^{\circ} 0^{-}$ & $\angle \varepsilon^{\prime} 0$ & $66^{\circ} \varepsilon$ & $86^{\circ} \mathrm{SI}$ \\
\hline$\$ 9^{\circ} 0$ & $\varepsilon 00^{\circ} 0^{-}$ & $200^{\circ} 0^{-}$ & $500^{\circ} 0^{-}$ & $\varsigma \varepsilon^{\circ} 0$ & $0 L^{\circ} \varepsilon$ & $18^{\circ} b I$ \\
\hline$S t^{\circ} 0$ & $200^{\circ} 0^{-}$ & $000^{\circ} 0^{-}$ & $700^{\circ} 0^{-}$ & $\varepsilon \varepsilon^{\circ} 0$ & $9 t^{\prime} \varepsilon$ & $98^{\circ} \varepsilon \mathrm{I}$ \\
\hline $1 t^{\circ} 0$ & $200^{\circ} 0^{-}$ & $000^{\circ} 0^{-}$ & $100^{\circ} 0^{-}$ & โદ:0 & $8 I^{\circ} \varepsilon$ & $\varepsilon L^{\prime} Z \mathbf{I}$ \\
\hline$I \varepsilon^{\prime} 0$ & $200^{\circ} 0^{-}$ & $000^{\circ} 0$ & $200^{\circ} 0^{-}$ & $S Z^{\circ} 0$ & 062 & 19.11 \\
\hline $82^{\prime} 0$ & $100^{\circ} 0^{-}$ & $100^{\circ} 0$ & $500^{\circ} 0^{-}$ & $\varsigma Z^{\circ} 0$ & $s 9^{\circ} \mathrm{Z}$ & $65^{\circ} 0 \mathrm{I}$ \\
\hline $0 t^{\prime} 0$ & $200^{\circ} 0^{-}$ & $100^{\circ} 0$ & $500^{\circ} 0^{-}$ & $12^{\circ} 0$ & $8 \varepsilon^{2} \tau$ & $25 \cdot 6$ \\
\hline $70 \% 0$ & $000^{\circ} 0^{-}$ & $200^{\circ} 0$ & $\varepsilon 00^{\circ} 0^{-}$ & $81^{\circ} 0$ & III & st 8 \\
\hline 000 & $000^{\circ} 0$ & $200^{\circ} 0$ & $\varepsilon 00^{\circ} 0^{-}$ & $9 \mathrm{l}^{\circ} 0$ & 98.1 & $\varepsilon t^{\circ} L$ \\
\hline tII0- & $100^{\circ} 0$ & $\varepsilon 00^{\circ} 0$ & $\varepsilon 00^{\circ} 0^{-}$ & $\varepsilon I^{\circ} 0$ & 09.1 & $8 \varepsilon^{\circ} 9$ \\
\hline $91^{\circ} 0^{-}$ & $100^{\circ} 0$ & $\varepsilon 00^{\circ} 0$ & $100^{\circ} 0^{-}$ & $2 I^{\circ} 0$ & $t \varepsilon^{\cdot} I$ & $\angle E^{\prime} S$ \\
\hline $62^{\circ} 0^{-}$ & $100^{\circ} 0$ & $500^{\circ} 0$ & $800^{\circ} 0^{-}$ & $80^{\circ} 0$ & $80^{\circ} \mathrm{I}$ & $I \varepsilon^{\prime} t$ \\
\hline$D \varepsilon^{\circ} 0^{-}$ & $200^{\circ} 0$ & $\varepsilon 00^{\circ} 0$ & $100^{\circ} 0^{-}$ & $90^{\circ} 0$ & $18^{\prime} 0$ & $\varepsilon Z^{\prime} \varepsilon$ \\
\hline $00^{\circ} 0^{-}$ & 200.0 & $100^{\circ} 0$ & $100^{\circ} 0^{-}$ & \pm 0.0 & $\varepsilon S^{\circ} 0$ & $\varepsilon I^{\prime} Z$ \\
\hline $80^{\circ} 0^{-}$ & $200^{\circ} 0$ & $500^{\circ} 0$ & $100^{\circ} 0$ & 20.0 & $92^{\circ} 0$ & $50^{\circ} \mathrm{I}$ \\
\hline $9 L^{\circ} 0^{-}$ & $t 00^{\circ} 0$ & $500^{\circ} 0$ & $100^{\circ} 0$ & $10^{\circ} 0$ & $10^{\circ} 0^{-}$ & $50^{\circ} 0^{-}$ \\
\hline $0 \varepsilon^{\circ} 0^{-}$ & $200^{\circ} 0$ & $900^{\circ} 0$ & $100^{\circ} 0$ & 00.0 & $\mathrm{SO}^{\circ} \mathrm{O}^{-}$ & $z z^{\circ} 0^{-}$ \\
\hline (ur/l) & (uw) & (uru) & (uw) & (wW) & $(\mathrm{W}-\mathrm{NY})$ & (NY) \\
\hline aมnex.un & ' & La $\Lambda T^{\circ}$ An & $\mathrm{L} Q \Lambda \mathrm{T}^{\circ} \wedge \mathrm{An} \mathrm{D}^{\prime} \mathrm{g}$ & ${ }^{\top} \mathrm{ds} ! \mathrm{d}^{\circ} \mathrm{d}^{\prime} \mathrm{W}$ & дนәшоผ & peof \\
\hline
\end{tabular}

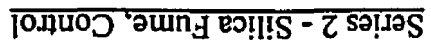




\section{CORROSION EFFECTS ON BOND STRENGTH IN REINFORCED CONCRETE}

Appendix I

Structural Results

\begin{tabular}{|c|c|c|c|c|c|c|}
\hline 30.56 & 7.64 & 2.73 & -0.129 & -0.254 & -0.192 & 38.30 \\
\hline 31.55 & 7.89 & 2.85 & -0.136 & -0.260 & -0.198 & 39.61 \\
\hline 32.51 & 8.13 & 2.90 & -0.143 & -0.266 & -0.205 & 40.90 \\
\hline 33.55 & 8.39 & 2.97 & -0.149 & -0.271 & -0.209 & 41.85 \\
\hline 34.61 & 8.65 & 3.05 & -0.153 & -0.277 & -0.215 & 43.01 \\
\hline 35.74 & 8.93 & 3.14 & -0.161 & -0.285 & -0.223 & 44.55 \\
\hline 36.78 & 9.19 & 3.25 & -0.167 & -0.291 & -0.229 & 45.83 \\
\hline 37.76 & 9.44 & 3.32 & -0.173 & -0.298 & -0.235 & 47.06 \\
\hline 38.80 & 9.70 & 3.41 & -0.180 & -0.307 & -0.244 & 48.76 \\
\hline 39.85 & 9.96 & 3.49 & -0.185 & -0.316 & -0.250 & 49.96 \\
\hline 40.97 & 10.24 & 3.57 & -0.187 & -0.323 & -0.255 & 51.09 \\
\hline 41.95 & 10.49 & 3.66 & -0.196 & -0.334 & -0.265 & 52.90 \\
\hline 42.99 & 10.75 & 3.73 & -0.202 & -0.340 & -0.271 & 54.26 \\
\hline 44.12 & 11.03 & 3.85 & -0.212 & -0.351 & -0.282 & 56.39 \\
\hline 45.16 & 11.29 & 3.97 & -0.222 & -0.361 & -0.285 & 56.91 \\
\hline 46.20 & 11.55 & 4.09 & -0.233 & -0.372 & -0.303 & 60.58 \\
\hline 51.03 & 12.76 & 4.65 & -0.294 & -0.406 & -0.351 & 70.19 \\
\hline 52.15 & 13.04 & 4.78 & -0.310 & -0.418 & -0.365 & 73.01 \\
\hline 53.14 & 13.28 & 4.89 & -0.324 & -0.429 & -0.377 & 75.40 \\
\hline 54.15 & 13.54 & 5.05 & -0.352 & -0.443 & -0.397 & 79.35 \\
\hline 55.14 & 13.78 & 5.21 & -0.383 & -0.455 & -0.419 & 83.84 \\
\hline 56.28 & 14.07 & 5.37 & -0.408 & -0.466 & -0.437 & 87.48 \\
\hline 57.35 & 14.34 & 5.54 & -0.431 & -0.487 & -0.458 & 91.51 \\
\hline 58.39 & 14.60 & 5.73 & -0.460 & -0.505 & -0.484 & 96.79 \\
\hline 59.49 & 14.87 & 5.93 & -0.489 & -0.530 & -0.511 & 102.12 \\
\hline 60.56 & 15.14 & 6.21 & -0.540 & -0.565 & -0.554 & 110.75 \\
\hline 61.49 & 15.37 & 6.65 & -0.627 & -0.614 & -0.622 & 124.37 \\
\hline 62.45 & 15.61 & 7.06 & -0.716 & -0.680 & -0.700 & 140.00 \\
\hline 63.12 & 15.78 & 7.49 & -0.797 & -0.739 & -0.768 & 153.50 \\
\hline 63.52 & 15.88 & 7.88 & -0.885 & -0.798 & -0.843 & 168.50 \\
\hline 63.94 & 15.99 & 8.29 & -0.968 & -0.870 & -0.920 & 184.00 \\
\hline 64.21 & 16.05 & 8.69 & -1.046 & -0.930 & -0.990 & 198.00 \\
\hline 64.45 & 16.11 & 9.11 & -1.138 & -0.999 & -1.070 & 214.00 \\
\hline 64.75 & 16.19 & 9.53 & -1.223 & -1.065 & -1.145 & 229.00 \\
\hline 65.07 & 16.27 & 9.95 & -1.313 & -1.121 & -1.219 & 243.88 \\
\hline 65.25 & 16.31 & 10.37 & -1.399 & -1.190 & -1.297 & 259.37 \\
\hline 65.41 & 16.35 & 10.79 & -1.491 & -1.249 & -1.371 & 274.25 \\
\hline 65.79 & 16.45 & 11.21 & -1.578 & -1.318 & -1.449 & 289.75 \\
\hline 66.13 & 16.53 & 11.61 & -1.671 & -1.395 & -1.535 & 307.00 \\
\hline 66.00 & 16.50 & 12.01 & -1.751 & -1.463 & -1.608 & 321.62 \\
\hline 66.37 & 16.59 & 12.43 & -1.850 & -1.538 & -1.696 & 339.12 \\
\hline 66.51 & 16.63 & 12.85 & -1.945 & -1.601 & -1.776 & 355.25 \\
\hline 66.85 & 16.71 & 13.25 & -2.037 & -1.671 & -1.856 & 371.13 \\
\hline 66.96 & 16.74 & 13.65 & -2.118 & -1.733 & -1.928 & 385.63 \\
\hline 67.31 & 16.83 & 14.06 & -2.210 & -1.803 & -2.009 & 401.75 \\
\hline 67.63 & 16.91 & 14.46 & -2.293 & -1.870 & -2.085 & 417.00 \\
\hline 67.87 & 16.97 & 14.88 & -2.380 & -1.945 & -2.165 & 433.00 \\
\hline
\end{tabular}




\begin{tabular}{|c|c|c|c|c|c|c|}
\hline $0 S^{\circ} 80 \varepsilon$ & EtS'1- & $s 82^{\prime} I^{-}$ & $96 \mathrm{~L}^{\circ} \mathrm{I}^{-}$ & $6 \varepsilon^{\circ} 0 \mathrm{I}$ & $50^{\circ} 0^{-}$ & $1 Z^{\prime} 0^{-}$ \\
\hline$S L^{\circ} 60 \varepsilon$ & $60 S^{\circ} I^{-}$ & $062^{\prime} \mathrm{I}^{-}$ & $208^{\circ} \mathrm{I}^{-}$ & stol & 010 & $55^{\circ} 0$ \\
\hline $00^{\circ} 01 \varepsilon$ & OSS'I- & $262^{\prime} I^{-}$ & S08. I- & $\angle t^{\circ} 0 I$ & $2 t^{\circ} 0$ & $69 . \mathrm{I}$ \\
\hline $21^{\circ} 01 \varepsilon$ & ISS I- & $\varepsilon 6 Z^{\prime} \mathrm{l}^{-}$ & $508^{\prime} \mathrm{I}^{-}$ & $6 t^{\circ} 0 \mathrm{I}$ & $\varepsilon L^{\prime} 0$ & $\varepsilon \sigma^{\circ} z$ \\
\hline OS'OIE & ESS'I- & $\varepsilon 6 Z^{\prime} I^{-}$ & $808^{\circ} \mathrm{I}^{-}$ & $60^{\circ} 0 \mathrm{I}$ & IZ' I & $58^{\circ} t$ \\
\hline$\angle \varepsilon I I \varepsilon$ & LSS I- & $862^{\prime} \mathrm{I}^{-}$ & $218^{\circ} 1^{-}$ & $\varepsilon S^{\circ} 0 \mathrm{I}$ & $\angle 6 \sigma^{\circ}$ & $88^{\circ} \mathrm{L}$ \\
\hline $88^{\circ} 91 \mathcal{E}$ & $68 \mathrm{~S}^{\circ} \mathrm{I}^{-}$ & SIE'I- & $\mathrm{I}^{198^{\circ} \mathrm{I}^{-}}$ & $58^{\circ} 0 \mathrm{I}$ & $60^{\circ} \varepsilon$ & $8 \varepsilon^{\prime} Z I$ \\
\hline$\angle 8^{\circ} 62 E$ & $6+9.1-$ & $\varepsilon 9 \varepsilon^{\prime} \mathrm{I}^{-}$ & $2760^{\circ}$ & $\varepsilon b I I$ & $00^{\circ}$ & $6 S^{\circ} \angle I$ \\
\hline$s \tau^{\prime} \tau \triangleright \varepsilon$ & $\mathrm{II} L^{\circ} \mathrm{I}^{-}$ & sltil- & $\angle 10^{\circ} T^{-}$ & 8611 & $99^{\circ} \mathrm{S}$ & $99^{\circ} \mathrm{ZZ}$ \\
\hline $0 S^{\circ} D S \varepsilon$ & $E L L^{\circ} I^{-}$ & 09ti- & $680^{\circ} \mathrm{Z}^{-}$ & $29^{\circ} \mathrm{ZI}$ & $50^{\circ} \mathrm{L}$ & $9 I^{\prime} 82$ \\
\hline $0 S^{\circ} \angle 9 \varepsilon$ & $8 \varepsilon 8^{\circ} \mathrm{I}^{-}$ & $\varepsilon Z S^{\circ} \mathrm{I}^{-}$ & $\left.191^{\prime}\right)^{-}$ & $\nabla \varepsilon^{\prime \prime} \varepsilon I$ & $\varsigma Z^{\prime} 8$ & $66^{\circ} Z \varepsilon$ \\
\hline $00^{\circ} \triangleright 6 \varepsilon$ & $0 \angle 6^{\circ} 1^{-}$ & $0 \angle 9^{\circ} 1^{-1}$ & $\varepsilon L Z^{\prime} Z^{-}$ & $10^{\circ}+1$ & 80.6 & $2 \varepsilon^{\prime} 9 \varepsilon$ \\
\hline 29.800 & $\varepsilon \mapsto 0^{\circ} z^{-}$ & $\varepsilon \varepsilon L^{\prime} I^{-1}$ & $I L \varepsilon^{\prime} \tau^{-}$ & $9 b^{\circ}+b$ & $\varepsilon 8^{\prime} 6$ & $t \varepsilon^{\prime} 6 \varepsilon$ \\
\hline$S L L E D$ & $68 \mathrm{I}^{\circ} \mathrm{Z}^{-}$ & $8581^{-}$ & SIS'Z- & SO'SI & $\angle I 01$ & $\angle 9^{\circ} 0 t$ \\
\hline$S Z^{\circ} L \varepsilon t$ & $98 \mathrm{I}^{\circ} \mathrm{Z}^{-}$ & $558^{\circ} \mathrm{I}^{-}$ & SIS'- & $S 0^{\circ} \mathrm{SI}$ & $D t 01$ & $\angle L^{\prime} I t$ \\
\hline $8 \varepsilon^{\circ} L \varepsilon t$ & $\angle 8 I^{\circ} Z^{-}$ & $558^{\circ} \mathrm{I}^{-}$ & EIS'Z- & $90^{\circ} \mathrm{SI}$ & $\angle L O O I$ & $\angle 0^{\circ} \varepsilon p$ \\
\hline OS. $9 \varepsilon \phi$ & $\varepsilon 8 I^{\circ} Z^{-}$ & $6+8^{\circ} \mathrm{I}^{-}$ & $905^{2} 2-$ & $S 0^{\circ} \mathrm{SI}$ & $8 I^{\circ} 11$ & $\varepsilon L^{\circ} \circ D$ \\
\hline$S L^{\circ} 0 t D$ & t0ح' & E68. I- & $\varepsilon S S^{\circ} \tau^{-}$ & $\angle I S S$ & $88^{\circ} I I$ & $E S^{\circ} \angle t$ \\
\hline $00^{\circ} 08 \mathrm{t}$ & $00 \nabla^{\circ} z^{-}$ & $\$ 80^{\circ} Z^{-}$ & SOL'Z- & $88^{\circ} \mathrm{SI}$ & 96.11 & $S 8^{\circ} \angle t$ \\
\hline $0 S^{\circ} 6 \mathrm{Lt}$ & $86 \varepsilon^{\circ} Z^{-}$ & $\$ 80^{\circ} Z^{-}$ & tOL'Z- & $68^{\circ} \mathrm{SI}$ & $69^{\circ} \mathrm{II}$ & $9 L^{\circ} 9 t$ \\
\hline $0 S^{\circ} 6 \mathrm{Lt}$ & $86 E^{\prime} Z^{-}$ & $580^{\circ} Z^{-}$ & tOL'Z- & $68^{\circ} \mathrm{SI}$ & $8 Z^{\circ} \mathrm{II}$ & $0 I^{\circ} \mathrm{St}$ \\
\hline$s L^{\circ} 6 L t$ & $66 E^{\circ} Z^{-}$ & $880^{\circ} \mathrm{Z}-$ & $\varepsilon 0 L^{\prime} Z^{-}$ & $06^{\circ} \mathrm{SI}$ & $0 Z^{\circ} Z I$ & $6 L .80$ \\
\hline $0 S^{\prime} \varepsilon 8 D$ & 8【だで & SIIt- & $\forall I L^{\prime} Z^{-}$ & $10^{\circ} 91$ & $\angle \nabla Z I$ & $88^{\circ} 6 t$ \\
\hline $05^{\circ} 58 t$ & $8 Z \nabla^{\circ} Z^{-}$ & $\varepsilon \varepsilon I^{\prime} Z^{-}$ & $81 L^{\circ} Z^{-}$ & 60.91 & $Z L Z Z I$ & $68^{\circ} 0 \mathrm{~S}$ \\
\hline$\angle E^{\circ} 88 \mathrm{t}$ & $\tau+t^{\circ} \tau-$ & ESI'Z- & $s Z L^{\prime} Z^{-}$ & $8 I^{\circ} 91$ & $10^{\circ} \varepsilon \mathrm{I}$ & $60 . \mathrm{ZS}$ \\
\hline $0 S^{\circ} 06 t$ & $\varepsilon S t^{\circ} \tau^{-}$ & $89 I^{\prime} Z-$ & {$\left[E L^{\circ} Z^{-}\right.$} & $9 \tau^{\circ} 91$ & $\angle Z^{\circ} \varepsilon I$ & $80^{\circ} \varepsilon S$ \\
\hline$\varepsilon I^{\circ} \varepsilon 6 \hbar$ & $99 b^{\circ} z^{-}$ & S8I'Z- & $0 \nabla L^{\prime} Z^{-}$ & SE91 & $S S^{\circ} E I$ & $0 Z^{\prime} \triangleright S$ \\
\hline$S L^{\prime} S 6 t$ & $6 L \nabla^{\circ} Z^{-}$ & $20 Z^{\prime 2}-$ & $\varepsilon S L^{\prime \prime} Z^{-}$ & $t t^{\circ} 9 \mathrm{I}$ & $\not 8^{\circ} \varepsilon 1$ & SE'SS \\
\hline $0 S^{\circ} 86 t$ & $\varepsilon 6 t^{\circ} z^{-}$ & LIZ'Z- & $\varepsilon 9 L^{\prime} Z^{-}$ & IS"9l & $60^{\circ}+1$ & $\angle E " 9 S$ \\
\hline$O S^{\circ} 10 S$ & $80 \mathrm{~s}^{\circ} \mathrm{Z}^{-}$ & $\mathcal{S E Z}^{\prime} Z^{-}$ & $S L L^{\prime} Z^{-}$ & [9.9] & $8 \varepsilon \mapsto I$ & $t S^{\circ} \angle S$ \\
\hline $29^{\circ}+0 \mathrm{~s}$ & $\varepsilon Z S^{\circ} \tau^{-}$ & $2 S 2^{2} z^{-}$ & $06 L^{\prime} Z^{-}$ & $69^{\circ} 91$ & $69^{\circ}+I$ & $\angle L \cdot 8 S$ \\
\hline $88^{\circ} \mathrm{LOS}$ & $6 E S^{\circ} Z^{-}$ & $89 Z^{\prime} Z^{-}$ & $\varepsilon 08^{\prime} z^{-}$ & 18.91 & $\angle 6 \circ I$ & $98.6 \mathrm{~S}$ \\
\hline 00.115 & SSS'Z- & $58 \mathrm{C}^{\circ} \mathrm{Z}^{-}$ & $028^{\circ} \mathrm{Z}^{-}$ & 68.91 & $\nabla Z^{\prime} S I$ & 96.09 \\
\hline $05^{\circ} E I S$ & $89 \mathrm{~S}^{\circ} \mathrm{Z}^{-}$ & $86 Z^{\prime} Z^{-}$ & $\varepsilon \varepsilon 8^{\circ} Z^{-}$ & $\angle 6.91$ & $\nabla S^{\circ} S I$ & $9 I^{\prime} 29$ \\
\hline 00.915 & $085^{2} z^{-}$ & $01 \varepsilon Z^{-}$ & $t 68^{\circ} Z^{-}$ & $\mathrm{SO}^{\circ} \mathrm{LI}$ & $\varepsilon 8^{\circ} \mathrm{SI}$ & દE' $\varepsilon 9$ \\
\hline$\angle 8.81 \mathrm{~S}$ & $66 S^{\circ} z^{-}$ & $\angle Z \varepsilon^{\prime} Z^{-}$ & $858^{\circ} \mathrm{Z}-$ & $D I L I$ & $9 I^{\circ} 91$ & $\not 9^{\circ} \circ 9$ \\
\hline $00^{\circ} 125$ & S09. $z^{-}$ & $6 \varepsilon \varepsilon^{\prime} Z^{-}$ & $0 \angle 8^{\circ} Z^{-}$ & $I Z \angle I$ & $7 t^{\circ} 91$ & $9 L \cdot 59$ \\
\hline$\varepsilon 9^{\circ} \varepsilon Z S$ & $819^{\circ} Z^{-}$ & tSE'Z- & $188^{\circ} \mathrm{Z}^{-}$ & $\tau \varepsilon^{\prime} L I$ & $\angle L ' 9 \mathrm{I}$ & $\angle 0^{\circ} \angle 9$ \\
\hline OS'9ZS & $\varepsilon \varepsilon 9^{\circ} Z^{-}$ & $99 \varepsilon^{\prime} Z^{-}$ & $968^{\circ} Z^{-}$ & $I t^{\circ} L I$ & $S 0 \circ \mathrm{LI}$ & 1289 \\
\hline OS'SZS & $829^{\circ} 2$ & $89 \varepsilon \tau^{-}$ & $\varepsilon 88^{\circ} \mathrm{Z}^{-}$ & $\angle \varepsilon^{\prime} \angle I$ & $9 \varepsilon^{\prime} \angle I$ & $\not t 69$ \\
\hline$\angle 8^{\circ} 60 \mathrm{~S}$ & $6+S^{\circ} Z^{-}$ & t62 Z & $86 L^{\circ} Z^{-}$ & $76.9 \mathrm{I}$ & $0 \varepsilon^{\prime} \angle I$ & oz'69 \\
\hline$s Z^{\circ} S 6 t$ & $9 L t^{\circ} Z^{-}$ & $92 Z^{\circ} Z^{-}$ & $0 Z L^{\prime} Z^{-}$ & $\varepsilon S^{\circ} 9 \mathrm{I}$ & $12 \angle 1$ & 9889 \\
\hline$S L^{\circ} 6 L D$ & $66 \varepsilon^{2} z^{-}$ & 6SI'Z- & $\varepsilon \varepsilon 9^{\circ} Z^{-}$ & $\varepsilon I^{\circ} 9 \mathrm{l}$ & $9 I^{\circ} \mathrm{LI}$ & 79.89 \\
\hline $0 S 590$ & $8 Z \varepsilon^{\prime} Z^{-}$ & $760^{\circ} z^{-}$ & SSS'Z- & $I L^{\circ} S I$ & II'LI & $\varepsilon+89$ \\
\hline $21^{\circ} 6 t t$ & $9 b \tau^{\circ} z^{-}$ & $020^{\circ} z^{-}$ & S9t'Z- & $6 Z^{\circ} \mathrm{SI}$ & $90^{\circ} \mathrm{LI}$ & $t Z^{\prime} 89$ \\
\hline
\end{tabular}




\section{CORROSION EFFECTS ON BOND STRENGTH IN REINFORCED CONCRETE}

Series 2 - Silica Fume, 2 \% Corrosion

\begin{tabular}{|c|c|c|c|c|c|c|}
\hline $\begin{array}{l}\text { Load } \\
(\mathrm{kN})\end{array}$ & $\begin{array}{l}\text { Moment } \\
(\mathrm{kN}-\mathrm{m})\end{array}$ & $\begin{array}{l}\text { M.P. Displ. } \\
\text { (mm) }\end{array}$ & $\begin{array}{c}\begin{array}{c}\text { E. Curv. LVDT } \\
(\mathrm{mm})\end{array} \\
\end{array}$ & $\begin{array}{l}\text { W. Curv. LVDT } \\
(\mathrm{mm})\end{array}$ & $\begin{array}{l}\text { Curv. LVDT Avg. } \\
(\mathrm{mm})\end{array}$ & $\begin{array}{c}\text { Curvature } \\
(1 / \mathrm{km})\end{array}$ \\
\hline-0.09 & -0.02 & 0.00 & 0.001 & 0.004 & 0.003 & -0.61 \\
\hline 0.96 & 0.24 & 0.03 & -0.000 & -0.005 & -0.006 & 1.19 \\
\hline 1.94 & 0.49 & 0.07 & -0.001 & -0.005 & -0.006 & 1.12 \\
\hline 0.76 & 0.19 & 0.19 & 0.041 & 0.017 & 0.029 & -5.75 \\
\hline 1.84 & 0.46 & 0.26 & 0.040 & 0.015 & 0.026 & -5.26 \\
\hline 2.90 & 0.73 & 0.31 & 0.043 & 0.018 & 0.028 & -5.60 \\
\hline 3.89 & 0.97 & 0.34 & 0.041 & 0.015 & 0.027 & -5.35 \\
\hline 4.86 & 1.21 & 0.35 & $\overline{0.042}$ & 0.019 & 0.030 & -6.08 \\
\hline 5.89 & 1.47 & 0.37 & 0.040 & 0.015 & 0.026 & -5.20 \\
\hline 6.94 & 1.74 & 0.41 & 0.041 & 0.017 & 0.029 & -5.86 \\
\hline 7.94 & 1.98 & 0.43 & 0.041 & 0.013 & 0.025 & -4.98 \\
\hline 8.95 & 2.24 & 0.46 & 0.040 & 0.016 & 0.028 & -5.55 \\
\hline 9.94 & 2.48 & 0.48 & 0.037 & 0.011 & 0.024 & -4.83 \\
\hline 10.97 & 2.74 & 0.51 & 0.040 & 0.014 & 0.027 & -5.46 \\
\hline 12.01 & 3.00 & 0.53 & 0.037 & 0.011 & 0.023 & -4.66 \\
\hline 13.04 & 3.26 & 0.56 & 0.038 & 0.013 & 0.027 & -5.30 \\
\hline 14.03 & 3.51 & 0.57 & 0.038 & 0.012 & 0.026 & -5.21 \\
\hline 15.09 & 3.77 & 0.59 & 0.036 & 0.010 & 0.023 & -4.69 \\
\hline 16.12 & 4.03 & 0.64 & 0.038 & 0.013 & 0.025 & -5.06 \\
\hline 17.15 & 4.29 & 0.64 & 0.037 & 0.012 & 0.022 & -4.44 \\
\hline 18.21 & 4.55 & 0.68 & 0.036 & 0.007 & 0.021 & -4.11 \\
\hline 19.25 & 4.81 & 0.70 & 0.036 & 0.010 & 0.024 & -4.80 \\
\hline 20.33 & 5.08 & 0.73 & 0.035 & 0.003 & 0.020 & -3.90 \\
\hline 19.16 & 4.79 & 0.81 & 0.026 & -0.001 & 0.011 & -2.20 \\
\hline 17.90 & 4.48 & 0.84 & 0.022 & 0.001 & 0.009 & -1.77 \\
\hline 16.64 & 4.16 & 0.85 & 0.017 & 0.001 & 0.009 & -1.76 \\
\hline 15.37 & 3.84 & 0.86 & 0.014 & 0.000 & -0.000 & 0.06 \\
\hline 14.30 & 3.58 & 0.88 & 0.011 & -0.003 & 0.004 & -0.71 \\
\hline 13.14 & 3.28 & 0.91 & 0.008 & -0.006 & 0.001 & -0.12 \\
\hline 11.91 & 2.98 & 0.92 & 0.005 & -0.008 & -0.001 & 0.29 \\
\hline 10.85 & 2.71 & 0.97 & 0.002 & -0.011 & -0.003 & 0.54 \\
\hline 11.00 & 2.75 & 1.22 & -0.025 & -0.025 & -0.025 & 5.05 \\
\hline 12.04 & 3.01 & 1.40 & -0.042 & -0.027 & -0.033 & 6.65 \\
\hline 13.12 & 3.28 & 1.55 & -0.059 & -0.028 & -0.044 & 8.75 \\
\hline 14.13 & 3.53 & 1.70 & -0.079 & -0.031 & -0.057 & 11.34 \\
\hline 15.18 & 3.80 & 1.82 & -0.099 & -0.032 & -0.065 & 13.01 \\
\hline 16.20 & 4.05 & 1.96 & -0.105 & -0.031 & -0.067 & 13.49 \\
\hline 17.25 & 4.31 & 2.05 & -0.119 & -0.036 & -0.078 & 15.64 \\
\hline 18.31 & 4.58 & 2.18 & -0.138 & -0.036 & -0.086 & 17.16 \\
\hline 19.37 & 4.84 & 2.29 & -0.153 & -0.026 & -0.089 & 17.76 \\
\hline 20.36 & 5.09 & 2.41 & -0.175 & -0.019 & -0.097 & 19.46 \\
\hline 21.39 & 5.35 & 2.52 & -0.194 & -0.017 & -0.112 & 22.41 \\
\hline 22.42 & 5.60 & 2.63 & -0.212 & -0.011 & -0.113 & 22.56 \\
\hline 23.43 & 5.86 & 2.75 & -0.227 & -0.007 & -0.117 & 23.34 \\
\hline
\end{tabular}




\section{CORROSION EFFECTS ON BOND STRENGTH IN REINFORCED CONCRETE}

Appendix I

Structural Results

\begin{tabular}{|c|c|c|c|c|c|c|}
\hline 24.37 & 6.09 & 2.84 & -0.245 & -0.004 & -0.124 & 24.79 \\
\hline 25.41 & 6.35 & 2.95 & -0.263 & 0.000 & -0.131 & 26.15 \\
\hline 26.47 & 6.62 & 3.06 & -0.282 & 0.005 & -0.138 & 27.68 \\
\hline 27.49 & 6.87 & 3.18 & -0.304 & 0.003 & -0.150 & 29.99 \\
\hline 28.58 & 7.15 & 3.30 & -0.325 & 0.011 & -0.159 & 31.76 \\
\hline 29.62 & 7.41 & 3.43 & -0.369 & 0.036 & -0.166 & 33.25 \\
\hline 30.64 & 7.66 & 3.54 & -0.404 & 0.048 & -0.178 & 35.60 \\
\hline 31.65 & 7.91 & 3.66 & -0.442 & 0.082 & -0.180 & 36.09 \\
\hline 32.77 & 8.19 & 3.78 & -0.472 & 0.092 & -0.190 & 38.02 \\
\hline 33.79 & 8.45 & 3.92 & -0.509 & 0.108 & -0.202 & 40.31 \\
\hline 34.77 & 8.69 & 4.05 & -0.552 & 0.127 & -0.213 & 42.58 \\
\hline 35.82 & 8.95 & 4.19 & -0.585 & 0.143 & -0.222 & 44.40 \\
\hline 36.78 & 9.19 & 4.31 & -0.623 & 0.159 & -0.233 & 46.60 \\
\hline 37.87 & 9.47 & 4.45 & -0.675 & 0.181 & -0.248 & 49.58 \\
\hline 38.88 & 9.72 & 4.58 & -0.766 & 0.193 & -0.287 & 57.44 \\
\hline 39.90 & 9.97 & 4.72 & -0.816 & 0.211 & -0.303 & 60.56 \\
\hline 40.99 & 10.25 & 4.86 & -0.862 & 0.227 & -0.318 & 63.65 \\
\hline 42.09 & 10.52 & 5.01 & -0.913 & 0.241 & -0.338 & 67.54 \\
\hline 43.10 & 10.78 & 5.16 & -0.973 & 0.263 & -0.356 & 71.13 \\
\hline 44.12 & 11.03 & 5.30 & -1.025 & 0.275 & -0.376 & 75.25 \\
\hline 45.10 & 11.28 & 5.43 & -1.073 & 0.285 & -0.395 & 78.91 \\
\hline 46.06 & 11.52 & 5.57 & -1.131 & 0.294 & -0.420 & 83.93 \\
\hline 47.13 & 11.78 & 5.70 & -1.193 & 0.305 & -0.444 & 88.80 \\
\hline 48.15 & 12.04 & 5.86 & -1.249 & 0.315 & -0.468 & 93.62 \\
\hline 49.19 & 12.30 & 6.00 & -1.363 & 0.323 & -0.520 & 104.00 \\
\hline 50.23 & 12.56 & 6.14 & -1.406 & 0.214 & -0.594 & 118.87 \\
\hline 51.21 & 12.80 & 6.29 & -1.464 & 0.222 & -0.623 & 124.50 \\
\hline 52.28 & 13.07 & 6.46 & -1.565 & 0.223 & -0.673 & 134.50 \\
\hline 53.24 & 13.31 & 6.64 & -1.623 & 0.233 & -0.695 & 139.00 \\
\hline 54.28 & 13.57 & 6.82 & -1.708 & 0.240 & -0.733 & 146.50 \\
\hline 55.32 & 13.83 & 7.02 & -1.773 & 0.199 & -0.788 & 157.50 \\
\hline 56.31 & 14.08 & 7.26 & -1.860 & 0.206 & -0.827 & 165.38 \\
\hline 57.38 & 14.34 & 7.50 & -1.937 & 0.211 & -0.865 & 173.00 \\
\hline 58.29 & 14.57 & 7.76 & -2.018 & 0.213 & -0.903 & 180.50 \\
\hline 59.11 & 14.78 & 8.01 & -2.098 & 0.214 & -0.942 & 188.37 \\
\hline 59.73 & 14.93 & 8.26 & -2.178 & 0.215 & -0.980 & 196.00 \\
\hline 60.26 & 15.07 & 8.51 & -2.248 & 0.214 & -1.018 & 203.50 \\
\hline 60.69 & 15.17 & 8.76 & -2.438 & 0.211 & -1.114 & 222.87 \\
\hline 61.12 & 15.28 & 9.00 & -2.508 & 0.124 & -1.192 & $238.3 \overline{7}$ \\
\hline 61.44 & 15.36 & 9.26 & -2.583 & 0.117 & -1.233 & 246.50 \\
\hline 61.65 & 15.41 & 9.51 & -2.658 & 0.106 & -1.278 & 255.50 \\
\hline 61.76 & 15.44 & 9.77 & -2.729 & 0.082 & -1.325 & 265.00 \\
\hline 62.05 & 15.51 & 10.02 & -2.863 & 0.067 & -1.399 & 279.75 \\
\hline 62.08 & 15.52 & 10.27 & -2.931 & 0.053 & -1.440 & 288.00 \\
\hline 62.24 & 15.56 & 10.53 & -3.008 & 0.027 & -1.493 & 298.50 \\
\hline 62.26 & 15.57 & 10.77 & -3.128 & 0.018 & -1.556 & 311.25 \\
\hline 61.25 & 15.31 & 10.91 & -3.185 & 0.018 & -1.584 & 316.88 \\
\hline
\end{tabular}




\begin{tabular}{|c|c|c|c|c|c|c|}
\hline$\overline{60.26}$ & 15.07 & 10.89 & -3.186 & 0.024 & -1.583 & 316.50 \\
\hline 59.19 & 14.80 & 10.85 & -3.185 & 0.031 & -1.578 & 315.62 \\
\hline 58.07 & 14.52 & 10.77 & -3.180 & 0.038 & -1.573 & 314.50 \\
\hline 56.95 & 14.24 & 10.71 & -3.175 & 0.045 & -1.566 & 313.25 \\
\hline 55.91 & 13.98 & 10.65 & -3.171 & 0.051 & -1.560 & 312.00 \\
\hline 54.90 & 13.72 & 10.58 & -3.164 & 0.055 & -1.556 & 311.13 \\
\hline 53.75 & 13.44 & 10.52 & -3.158 & 0.061 & -1.550 & 310.00 \\
\hline 52.66 & 13.16 & 10.46 & -3.153 & 0.067 & -1.545 & 309.00 \\
\hline 51.59 & 12.90 & 10.38 & -3.145 & 0.073 & -1.538 & 307.62 \\
\hline 50.41 & 12.60 & 10.27 & -3.135 & 0.083 & -1.528 & 305.50 \\
\hline 49.19 & 12.30 & 10.19 & -3.126 & 0.091 & -1.518 & 303.62 \\
\hline 48.07 & 12.02 & 10.13 & -3.118 & 0.096 & -1.513 & 302.63 \\
\hline 46.92 & 11.73 & 10.05 & -3.110 & 0.103 & -1.503 & 300.63 \\
\hline 45.80 & 11.45 & 9.99 & -3.103 & 0.110 & -1.498 & 299.50 \\
\hline 44.60 & 11.15 & 9.92 & -3.094 & 0.117 & -1.489 & 297.87 \\
\hline 43.55 & 10.89 & 9.86 & -3.086 & 0.123 & -1.483 & 296.50 \\
\hline 42.43 & 10.61 & 9.79 & -3.079 & 0.130 & -1.475 & 295.00 \\
\hline 41.39 & 10.35 & 9.72 & -3.072 & 0.138 & -1.466 & 293.12 \\
\hline 39.90 & 9.97 & 9.72 & -3.073 & 0.139 & -1.468 & 293.50 \\
\hline 40.99 & 10.25 & 9.72 & -3.072 & 0.139 & -1.465 & 293.00 \\
\hline 39.87 & 9.97 & 9.51 & -3.040 & 0.165 & -1.438 & 287.50 \\
\hline 38.80 & 9.70 & 9.50 & -3.038 & 0.167 & -1.438 & 287.63 \\
\hline 37.66 & 9.41 & 9.22 & -2.988 & 0.204 & -1.393 & 278.50 \\
\hline 36.08 & 9.02 & 9.05 & -2.952 & 0.221 & -1.365 & 273.00 \\
\hline 34.83 & 8.71 & 8.92 & -2.920 & 0.235 & -1.340 & 268.00 \\
\hline 33.39 & 8.35 & 8.73 & -2.875 & 0.248 & -1.313 & 262.50 \\
\hline 31.92 & 7.98 & 8.57 & -2.849 & 0.255 & -1.295 & 259.00 \\
\hline 30.40 & 7.60 & 8.40 & -2.808 & 0.260 & -1.273 & 254.62 \\
\hline 28.77 & 7.19 & 8.23 & -2.764 & 0.263 & -1.249 & 249.87 \\
\hline 27.17 & 6.79 & 8.05 & -2.725 & 0.265 & -1.230 & 246.00 \\
\hline 25.35 & 6.34 & $\begin{array}{l}7.88 \\
\end{array}$ & -2.689 & 0.266 & -1.210 & 242.00 \\
\hline 23.49 & 5.87 & 7.71 & -2.656 & 0.266 & -1.194 & 238.87 \\
\hline 21.62 & 5.40 & 7.55 & -2.620 & 0.264 & -1.177 & 235.37 \\
\hline 19.72 & 4.93 & 7.37 & -2.583 & 0.261 & -1.159 & 231.75 \\
\hline 17.95 & 4.49 & 7.21 & -2.543 & 0.257 & -1.141 & 228.12 \\
\hline 16.32 & 4.08 & 7.04 & -2.505 & 0.253 & -1.125 & 225.00 \\
\hline 14.75 & 3.69 & 6.89 & -2.465 & 0.247 & -1.108 & 221.50 \\
\hline 13.32 & 3.33 & 6.74 & -2.429 & 0.242 & -1.093 & 218.62 \\
\hline 11.89 & 2.97 & 6.58 & -2.388 & 0.235 & -1.075 & 215.00 \\
\hline 10.57 & 2.64 & 6.44 & -2.348 & 0.229 & -1.058 & 211.62 \\
\hline 9.33 & 2.33 & 6.29 & -2.308 & 0.221 & -1.043 & 208.50 \\
\hline 7.90 & 1.97 & 6.12 & -2.258 & 0.212 & $-1.02 \mathrm{I}$ & 204.12 \\
\hline 6.50 & 1.63 & 5.92 & -2.204 & 0.201 & -1.000 & 200.00 \\
\hline 5.18 & 1.29 & 5.72 & -2.018 & 0.190 & -0.913 & 182.50 \\
\hline 3.95 & 0.99 & 5.53 & -1.959 & 0.178 & -0.889 & 177.75 \\
\hline 2.77 & 0.69 & 5.34 & -1.903 & 0.165 & -0.867 & 173.37 \\
\hline 1.50 & 0.37 & 5.11 & -1.832 & 0.195 & -0.816 & 163.25 \\
\hline
\end{tabular}




\begin{tabular}{||c|c|c|c|c|c|c||}
\hline 0.33 & 0.08 & 5.02 & -1.795 & 0.197 & -0.800 & 160.00 \\
\hline-2.24 & -0.56 & 4.95 & -1.776 & 0.191 & -0.793 & 158.50 \\
\hline-1.14 & -0.28 & 4.94 & -1.775 & 0.191 & -0.793 & 158.50 \\
\hline-0.40 & -0.10 & 4.93 & -1.773 & 0.190 & -0.791 & 158.13 \\
\hline
\end{tabular}

Series 2 - Silica Fume, $5 \%$ Corrosion

\begin{tabular}{|c|c|c|c|c|c|c|}
\hline $\begin{array}{l}\text { Load } \\
(\mathrm{kN})\end{array}$ & $\begin{array}{l}\text { Moment } \\
(\mathrm{kN}-\mathrm{m})\end{array}$ & $\begin{array}{l}\text { M.P. Displ. } \\
(\mathrm{mm})\end{array}$ & $\begin{array}{l}\text { E. Curv. LVDT } \\
(\mathrm{mm})\end{array}$ & $\begin{array}{c}\text { W. Curv. LVDT } \\
(\mathrm{mm})\end{array}$ & $\begin{array}{l}\text { Curv. LVDT Avg. } \\
(\mathrm{mm})\end{array}$ & $\begin{array}{c}\text { Curvature } \\
(1 / \mathrm{km})\end{array}$ \\
\hline 0.76 & 0.19 & 0.00 & **** & *** & **** & 0.00 \\
\hline 0.09 & 0.02 & -0.02 & $* * *$ & *** & **** & -0.18 \\
\hline 1.21 & 0.30 & 0.02 & **** & **** & **** & 0.11 \\
\hline 2.29 & 0.57 & 0.03 & *** & $* * *$ & $* * *$ & 0.18 \\
\hline 3.38 & 0.85 & 0.05 & **** & *** & $* * *$ & 0.40 \\
\hline 4.42 & 1.11 & 0.07 & *** & *** & $* * *$ & 0.55 \\
\hline 5.50 & 1.38 & 0.12 & **** & *** & $* * *$ & 0.84 \\
\hline 6.55 & 1.64 & 0.14 & $* * *$ & $* * *$ & $* * *$ & 1.02 \\
\hline 7.58 & 1.89 & 0.18 & **** & *** & $* * *$ & 1.27 \\
\hline 8.64 & 2.16 & 0.20 & **** & $* * *$ & $* * *$ & 1.42 \\
\hline 9.72 & 2.43 & 0.22 & $* * *$ & $* * *$ & *** & 1.60 \\
\hline 10.79 & 2.70 & 0.25 & $* * *$ & $* * *$ & $* * *$ & 1.82 \\
\hline 11.87 & 2.97 & 0.28 & $* * *$ & $* * *$ & **** & 2.00 \\
\hline 12.99 & 3.25 & 0.31 & $* * *$ & $* * *$ & *** & 2.25 \\
\hline 14.09 & 3.52 & 0.34 & **** & $* * *$ & *** & 2.44 \\
\hline 15.12 & 3.78 & 0.37 & *** & *** & **** & 2.65 \\
\hline 16.24 & 4.06 & 0.38 & $* * *$ & $* * *$ & $* * *$ & 2.76 \\
\hline 17.31 & 4.33 & 0.41 & $* * *$ & $* * *$ & *** & 2.94 \\
\hline 18.37 & 4.59 & 0.44 & *** & $* * *$ & $* * *$ & 3.16 \\
\hline 19.40 & 4.85 & 0.48 & *** & *** & *** & 3.45 \\
\hline 18.11 & 4.53 & 0.60 & *** & $* * *$ & **** & 4.36 \\
\hline 16.41 & 4.10 & 0.66 & **** & **** & *** & 4.76 \\
\hline 14.73 & 3.68 & 0.70 & **** & **** & $* * *$ & 5.05 \\
\hline 13.12 & 3.28 & 0.78 & $* * *$ & $* * *$ & $* * *$ & 5.63 \\
\hline 11.61 & 2.90 & 0.81 & *** & **** & *** & 5.89 \\
\hline 10.50 & 2.63 & 0.83 & $* * *$ & **** & *** & 6.03 \\
\hline 9.38 & 2.34 & 0.89 & $* * *$ & $* * *$ & *** & 6.51 \\
\hline 9.28 & 2.32 & 1.10 & $* * *$ & **** & $* * *$ & 8.00 \\
\hline 10.20 & 2.55 & 1.30 & *** & **** & $* * *$ & 9.45 \\
\hline 11.13 & 2.78 & 1.51 & *** & **** & $* * *$ & 10.98 \\
\hline 12.18 & 3.05 & 1.70 & *** & *** & $* * *$ & 12.32 \\
\hline 13.23 & 3.31 & 1.88 & *** & *** & $* * *$ & 13.63 \\
\hline 14.30 & 3.58 & 2.04 & *** & *** & *** & 14.83 \\
\hline 15.42 & 3.85 & 2.23 & *** & **** & **** & 16.25 \\
\hline 16.47 & 4.12 & 2.44 & $* * *$ & **** & $* * *$ & 17.70 \\
\hline 17.56 & 4.39 & 2.62 & *** & $* * *$ & *** & 19.01 \\
\hline 18.62 & 4.66 & 2.82 & **** & *** & *** & 20.47 \\
\hline
\end{tabular}




\begin{tabular}{|c|c|c|c|c|c|c|}
\hline 19.67 & 4.92 & 3.02 & $* * *$ & **** & $* * *$ & 21.96 \\
\hline 20.64 & 5.16 & 3.22 & **** & **** & *** & 23.41 \\
\hline 21.67 & 5.42 & 3.44 & $* * *$ & $* * *$ & $* * *$ & 24.97 \\
\hline 22.66 & 5.66 & 3.68 & **** & $* * *$ & $* * *$ & 26.72 \\
\hline 23.46 & 5.86 & 3.88 & $* * *$ & **** & $* * *$ & 28.21 \\
\hline 24.10 & 6.02 & 4.09 & *** & $* * *$ & $* * *$ & 29.73 \\
\hline 24.85 & 6.21 & 4.29 & $* * *$ & *** & $* * *$ & 31.19 \\
\hline 25.57 & 6.39 & 4.50 & $* * *$ & *** & $* * *$ & 32.68 \\
\hline 26.05 & 6.51 & 4.70 & $* * *$ & $* * *$ & **** & 34.13 \\
\hline 26.21 & 6.55 & 4.90 & **** & $* * *$ & $* * *$ & 35.59 \\
\hline 25.97 & 6.49 & 5.10 & *** & $* * *$ & *** & 37.08 \\
\hline 26.21 & 6.55 & 5.32 & $* * *$ & *** & **** & 38.64 \\
\hline 26.45 & 6.61 & 5.54 & $* * *$ & $* * *$ & $* * *$ & 40.24 \\
\hline 26.53 & 6.63 & 5.74 & $* * *$ & **** & **** & 41.69 \\
\hline 26.66 & 6.67 & 5.96 & **** & **** & $* * *$ & 43.29 \\
\hline 26.69 & 6.67 & 6.16 & **** & $* * *$ & $* * *$ & 44.75 \\
\hline 26.69 & 6.67 & 6.36 & $* * *$ & **** & $* * *$ & 46.24 \\
\hline 26.69 & 6.67 & 6.56 & **** & $* * *$ & **** & 47.65 \\
\hline 26.66 & 6.67 & 6.78 & *** & $* * *$ & $* * *$ & 49.25 \\
\hline 26.53 & 6.63 & 6.98 & $* * *$ & **** & $* * *$ & 50.71 \\
\hline 26.45 & 6.61 & 7.19 & **** & $* * *$ & *** & 52.23 \\
\hline 26.42 & 6.61 & 7.40 & **** & **** & **** & 53.76 \\
\hline 26.31 & 6.58 & 7.62 & **** & $* * *$ & **** & 55.36 \\
\hline 26.29 & 6.57 & 7.82 & $* * *$ & $* * *$ & $* * *$ & 56.82 \\
\hline 26.15 & 6.54 & 8.03 & **** & $* * *$ & $* * *$ & 58.38 \\
\hline 26.15 & 6.54 & 8.24 & **** & **** & **** & 59.87 \\
\hline 26.07 & 6.52 & 8.45 & $* * *$ & **** & $* * *$ & 61.43 \\
\hline 25.99 & 6.50 & 8.66 & $* * *$ & $* * *$ & $* * *$ & 62.92 \\
\hline 25.91 & 6.48 & 8.86 & $* * *$ & **** & **** & 64.41 \\
\hline 25.83 & 6.46 & 9.08 & **** & $* * *$ & $* * *$ & 65.98 \\
\hline 25.78 & 6.45 & 9.28 & **** & *** & $* * *$ & 67.43 \\
\hline 25.75 & 6.44 & 9.48 & $* * *$ & $* * *$ & $* * *$ & 68.88 \\
\hline 25.62 & 6.41 & 9.68 & $* * *$ & *** & **** & 70.34 \\
\hline 25.62 & 6.41 & 9.90 & $* * *$ & **** & $* * *$ & 71.94 \\
\hline 25.57 & 6.39 & 10.11 & $* * *$ & **** & $* * *$ & 73.50 \\
\hline 25.54 & 6.39 & 10.32 & **** & **** & $* * *$ & 75.03 \\
\hline 25.49 & 6.37 & 10.52 & $* * *$ & $* * *$ & **** & 76.44 \\
\hline 25.43 & 6.36 & 10.72 & **** & $* * *$ & $* * *$ & 77.90 \\
\hline 25.35 & 6.34 & 10.93 & $* * *$ & **** & $* * *$ & 79.42 \\
\hline 25.43 & 6.36 & 11.14 & **** & **** & *** & 80.99 \\
\hline 25.35 & 6.34 & 11.36 & **** & $* * *$ & $* * *$ & 82.55 \\
\hline 25.35 & 6.34 & 11.56 & $* * *$ & **** & $* * *$ & 84.00 \\
\hline 25.25 & 6.31 & 11.76 & **** & $* * *$ & **** & 85.46 \\
\hline 25.19 & 6.30 & 11.97 & $* * *$ & $* * *$ & $* * *$ & 86.99 \\
\hline 25.11 & 6.28 & 12.18 & *** & **** & $* * *$ & 88.51 \\
\hline 25.17 & 6.29 & 12.38 & $* * *$ & $* * *$ & $* * *$ & 89.97 \\
\hline 25.14 & 6.29 & 12.58 & $* * *$ & **** & $* * *$ & 91.42 \\
\hline
\end{tabular}


Corrosion EFFECTS ON BOND STRENGTH IN REINFORCED CONCRETE

Appendix I

Structural Results

\begin{tabular}{|c|c|c|c|c|c|c|}
\hline 25.09 & 6.27 & 12.78 & $\overline{* * *}$ & **** & $\overline{* * *}$ & 92.87 \\
\hline 25.11 & 6.28 & 12.99 & $* * *$ & **** & **** & 94.40 \\
\hline 25.06 & 6.27 & 13.20 & *** & *** & *** & 95.93 \\
\hline 25.06 & 6.27 & 13.42 & $* * *$ & $* * *$ & **** & 97.53 \\
\hline 25.11 & 6.28 & 13.62 & $* * *$ & **** & *** & 99.02 \\
\hline 25.22 & 6.31 & 13.82 & $* * *$ & **** & $* * *$ & 100.47 \\
\hline 25.17 & 6.29 & 14.04 & $* * *$ & $* * *$ & *** & 102.03 \\
\hline 25.25 & 6.31 & 14.24 & *** & $* * *$ & $* * *$ & 103.49 \\
\hline 25.22 & 6.31 & 14.46 & **** & $* * *$ & **** & 105.09 \\
\hline 25.30 & 6.33 & 14.68 & **** & $* * *$ & *** & 106.69 \\
\hline 25.27 & 6.32 & 14.89 & $* * *$ & $* * *$ & $* * *$ & 108.25 \\
\hline 25.19 & 6.30 & 15.10 & $* * *$ & $* * *$ & $* * *$ & 109.78 \\
\hline 25.22 & 6.31 & 15.32 & *** & **** & *** & 111.34 \\
\hline 25.19 & 6.30 & 15.54 & **** & **** & $* * *$ & 112.94 \\
\hline 25.25 & 6.31 & 15.75 & $* * *$ & $* * *$ & *** & 114.47 \\
\hline 25.25 & 6.31 & 16.02 & *** & $* * *$ & **** & 116.43 \\
\hline 25.33 & 6.33 & 16.23 & *** & $* * *$ & **** & 117.96 \\
\hline 25.35 & 6.34 & 16.44 & **** & $* * *$ & *** & 119.49 \\
\hline 25.33 & 6.33 & 16.65 & *** & **** & **** & 121.06 \\
\hline 25.35 & 6.34 & 16.86 & *** & **** & **** & 122.60 \\
\hline 25.33 & 6.33 & 17.08 & *** & **** & **** & 124.20 \\
\hline 25.35 & 6.34 & 17.29 & **** & **** & *** & 125.73 \\
\hline 25.43 & 6.36 & 17.51 & *** & *** & **** & 127.30 \\
\hline 25.41 & 6.35 & 17.72 & $* * *$ & **** & *** & 128.84 \\
\hline 25.43 & 6.36 & 17.93 & *** & **** & *** & 130.34 \\
\hline 25.49 & 6.37 & 18.14 & **** & **** & $* * *$ & 131.86 \\
\hline 25.43 & 6.36 & 18.35 & *** & $* * *$ & $* * *$ & 133.43 \\
\hline 25.51 & 6.38 & 18.56 & *** & $* * *$ & *** & 134.95 \\
\hline 25.59 & 6.40 & 18.79 & *** & **** & **** & 136.57 \\
\hline 25.54 & 6.39 & 19.00 & *** & $* * *$ & $* * *$ & 138.12 \\
\hline 25.57 & 6.39 & 19.21 & $* * *$ & **** & $* * *$ & 139.63 \\
\hline 25.62 & 6.41 & 19.42 & **** & **** & $* * *$ & 141.21 \\
\hline 25.62 & 6.41 & 19.64 & $* * *$ & $* * *$ & **** & 142.75 \\
\hline 25.59 & 6.40 & 19.85 & $* * *$ & **** & $* * *$ & 144.29 \\
\hline 25.65 & 6.41 & 20.06 & **** & $* * *$ & $* * *$ & 145.84 \\
\hline 25.67 & 6.42 & 20.27 & **** & **** & $* * *$ & 147.38 \\
\hline 25.65 & 6.41 & 20.51 & $* * *$ & $* * *$ & $* * *$ & 149.10 \\
\hline 25.70 & 6.43 & 20.73 & **** & *** & $* * *$ & 150.69 \\
\hline 25.70 & 6.43 & 20.95 & **** & $* * *$ & $* * *$ & 152.33 \\
\hline 25.78 & 6.45 & 21.17 & **** & **** & **** & 153.93 \\
\hline 25.67 & 6.42 & 21.41 & **** & $* * *$ & $* * *$ & 155.65 \\
\hline 25.54 & 6.39 & 21.64 & $* * *$ & $* * *$ & $* * *$ & 157.31 \\
\hline 25.38 & 6.35 & 21.85 & $* * *$ & **** & *** & 158.86 \\
\hline 25.09 & 6.27 & 22.07 & $* * *$ & *** & **** & 160.45 \\
\hline 25.03 & 6.26 & 22.29 & **** & **** & **** & 162.04 \\
\hline 24.50 & 6.12 & 22.49 & $7 * *$ & **** & **** & 163.51 \\
\hline 23.59 & 5.90 & 22.71 & $* * *$ & $* * *$ & **** & 165.11 \\
\hline
\end{tabular}




\section{CORROSION EFFECTS ON BOND STRENGTH IN REINFORCED CONCRETE}

Appendix I

Structural Results

\begin{tabular}{|c|c|c|c|c|c|c|}
\hline 22.79 & 5.70 & 22.93 & $* * *$ & **** & **** & 166.70 \\
\hline 22.68 & 5.67 & 23.14 & $* * *$ & **** & **** & 168.26 \\
\hline 23.01 & 5.75 & 23.36 & $* * *$ & *** & **** & 169.80 \\
\hline 23.41 & 5.85 & 23.56 & $* \dot{* *}$ & *** & *** & 171.26 \\
\hline 23.78 & 5.94 & 23.78 & $* * *$ & *** & *** & 172.89 \\
\hline 23.91 & 5.98 & 23.99 & $* * *$ & *** & **** & 174.43 \\
\hline 23.99 & 6.00 & 24.22 & **** & **** & **** & 176.04 \\
\hline 23.97 & 5.99 & 24.44 & $* * *$ & **** & $* * *$ & 177.64 \\
\hline 23.99 & 6.00 & 24.66 & $* * *$ & *** & **** & 179.24 \\
\hline 24.05 & 6.01 & 24.87 & **** & *** & $* * *$ & 180.80 \\
\hline 24.10 & 6.02 & 25.10 & $* * *$ & **** & *** & 182.44 \\
\hline 24.07 & 6.02 & 25.32 & *** & **** & $* * *$ & 184.08 \\
\hline 24.10 & 6.02 & 25.54 & **** & *** & *** & 185.64 \\
\hline 24.13 & 6.03 & 25.75 & *** & *** & $* * *$ & 187.20 \\
\hline 24.18 & 6.04 & 25.97 & $* * *$ & *** & *** & 188.77 \\
\hline 24.15 & 6.04 & 26.20 & $* * *$ & **** & $* * *$ & 190.44 \\
\hline 24.18 & 6.04 & 26.40 & **** & **** & **** & 191.93 \\
\hline 24.18 & 6.04 & 26.62 & $* * *$ & **** & *** & 193.49 \\
\hline 24.18 & 6.04 & 26.82 & *** & **** & $* * *$ & 194.98 \\
\hline 24.23 & 6.06 & 27.12 & $* * *$ & **** & *** & 197.13 \\
\hline 24.18 & 6.04 & 27.32 & **** & **** & **** & 198.58 \\
\hline 24.15 & 6.04 & 27.53 & $* * *$ & **** & $* * *$ & 200.11 \\
\hline 24.13 & 6.03 & 27.74 & *** & **** & **** & 201.63 \\
\hline 24.15 & 6.04 & 27.94 & $* * *$ & **** & $* * *$ & 203.09 \\
\hline 24.21 & 6.05 & 28.14 & $* * *$ & **** & **** & 204.58 \\
\hline 24.13 & 6.03 & 28.38 & **** & **** & **** & 206.29 \\
\hline 24.15 & 6.04 & 28.60 & **** & *** & **** & 207.92 \\
\hline 24.18 & 6.04 & 28.82 & **** & *** & **** & 209.49 \\
\hline 24.15 & 6.04 & 29.04 & $* * *$ & ${ }^{* * *}$ & $* * *$ & 211.12 \\
\hline 24.26 & 6.06 & 29.26 & $* * *$ & **** & *** & 212.68 \\
\hline 24.31 & 6.08 & 29.48 & $* * *$ & **** & $* * *$ & 214.28 \\
\hline 24.42 & 6.10 & 29.70 & **** & **** & **** & 215.92 \\
\hline 24.42 & 6.10 & 29.94 & **** & **** & **** & 217.63 \\
\hline 24.45 & 6.11 & 30.28 & **** & **** & $* * *$ & 220.10 \\
\hline 24.42 & 6.10 & 30.52 & **** & **** & $* * *$ & 221.84 \\
\hline 24.50 & 6.12 & 30.74 & *** & **** & $* * *$ & 223.44 \\
\hline 24.45 & 6.11 & 30.98 & **** & **** & **** & 225.22 \\
\hline 24.47 & 6.12 & 31.22 & $* * *$ & **** & $* * *$ & 226.93 \\
\hline 24.50 & 6.12 & 31.46 & $* * *$ & **** & $* * *$ & 228.68 \\
\hline 24.61 & 6.15 & 31.70 & **** & **** & ***** & 230.42 \\
\hline 24.61 & 6.15 & 31.95 & **** & **** & *** & 232.28 \\
\hline 24.69 & 6.17 & 32.18 & **** & **** & $* * *$ & 233.95 \\
\hline 24.63 & 6.16 & 32.45 & **** & **** & **** & 235.91 \\
\hline 24.69 & 6.17 & 32.70 & **** & **** & **** & 237.69 \\
\hline 24.74 & 6.18 & 32.94 & **** & $* * *$ & $* * *$ & 239.44 \\
\hline 24.71 & 6.18 & 33.16 & *** & **** & $* * *$ & 241.04 \\
\hline 24.82 & 6.20 & 33.40 & **** & **** & $* * *$ & 242.78 \\
\hline
\end{tabular}




\begin{tabular}{|c|c|c|c|c|c|c|}
\hline$S 0^{\circ} \angle 62$ & $* * *$ & $* * *$ & $* * *$ & $98^{\circ} 0 \mathrm{t}$ & $08^{\circ} \varepsilon$ & {$\left[Z^{\prime} s\right]$} \\
\hline$\angle t^{\prime} 862$ & $* * *$ & $* * *$ & $* * *$ & $90^{\circ} \mathrm{It}$ & $66^{\circ} \varepsilon$ & S6. SI \\
\hline 96.662 & $* * *$ & $* * *$ & $* * *$ & $9 \tau^{\circ} 10$ & $6 I^{\circ} b$ & SL'9I \\
\hline ZSIOE & $* * *$ & $* * *$ & $* * *$ & $80^{\circ} 10$ & $2 \nabla^{\circ} t$ & $99^{\circ} \mathrm{LI}$ \\
\hline ZI'EOE & $* * *$ & $* * *$ & $* * *$ & $0 L I t$ & $89^{\circ} \mathrm{t}$ & IL'8I \\
\hline $8 S^{\circ}+0 \varepsilon$ & $* * *$ & $* * *$ & $\star * * *$ & $06^{\circ} \mathrm{It}$ & $56^{\circ} \mathrm{t}$ & 18.61 \\
\hline$\varepsilon 0^{\circ} 90 \varepsilon$ & $* * *$ & $* * *$ & $* * *$ & $01^{\circ} 26$ & $\varepsilon \tau^{\circ} S$ & 26.02 \\
\hline$\triangleright \varepsilon \angle O E$ & $* * *$ & $* * *$ & $* * *$ & $87^{\circ} 20$ & $2 S^{\circ} S$ & $01^{\circ} \mathrm{ZZ}$ \\
\hline $59.80 \varepsilon$ & $* * *$ & $* * *$ & $* * * *$ & 9ヤで & $18^{\circ} \mathrm{S}$ & SZ'EZ \\
\hline$Z L 80 \varepsilon$ & $* * *$ & **** & $* * *$ & $\angle \nabla^{\circ} Z t$ & $1 I^{\circ} 9$ & $s t^{\circ} t z$ \\
\hline Z6 LOE & $* * *$ & $* * *$ & $* * *$ & $9 \varepsilon^{\circ} Z \triangleright$ & $\angle E^{\circ} 9$ & $9 t^{\circ} \varsigma Z$ \\
\hline 乙E.90ह & $* * *$ & $* * *$ & $* * *$ & $D I^{\circ} z \phi$ & $8 \varepsilon^{\circ} 9$ & IS $S Z$ \\
\hline $8 S^{\prime}+0 \varepsilon$ & $* * *$ & $* * *$ & $* * *$ & $06^{\circ}$ It & $6 \varepsilon^{\circ} 9$ & $t S^{\circ} s 2$ \\
\hline$\angle 8^{\circ} Z 0 E$ & $* * *$ & $* * *$ & $* * *$ & $99^{\circ} 17$ & $\angle E^{\prime} 9$ & $60^{\circ} \subseteq 2$ \\
\hline $60^{\circ} 10 \varepsilon$ & $* * *$ & $* * *$ & $* * *$ & $2 t^{\circ} 10$ & $\angle \varepsilon^{\prime} 9$ & $9 t^{\circ} s z$ \\
\hline$s t^{\prime} 662$ & $* * *$ & $* * *$ & $* * *$ & $6 I^{\circ} \mathrm{It}$ & $L \varepsilon^{*} 9$ & $6 t^{\prime} S 2$ \\
\hline$\nabla L \angle 6 Z$ & $* * *$ & $* * *$ & **** & $96^{\circ} 00$ & $\angle E^{*} 9$ & $6 t^{\circ} 52$ \\
\hline $1 I^{\prime} 962$ & $* * *$ & $* * *$ & $* * *$ & $\varepsilon L^{\prime} O b$ & $\angle E^{\circ} 9$ & $9 b^{\circ} S 2$ \\
\hline$\angle \forall \forall 62$ & $* * *$ & $* * *$ & $* * *$ & ISOD & $9 \varepsilon^{\prime} 9$ & $\varepsilon b^{\circ} S Z$ \\
\hline $9 \angle 262$ & **** & $* * *$ & $* * *$ & $\angle Z O O D$ & $9 \varepsilon^{\prime} 9$ & $\varepsilon \nabla^{\circ} S Z$ \\
\hline 16.062 & $* * *$ & $* * *$ & $* * *$ & $20^{\circ} 0 \mathrm{t}$ & SE'9 & It $S Z$ \\
\hline$\varepsilon I^{\prime} 68 Z$ & **** & $* * *$ & ***** & LLGE & $\varsigma \varepsilon^{\circ} 9$ & $8 E^{\prime} S Z$ \\
\hline $67^{\circ} \angle 8 Z$ & $* * *$ & $* * *$ & $* * *$ & $S S^{\prime} 6 \varepsilon$ & SE.9 & $8 \mathcal{E}^{\circ} \mathrm{SZ}$ \\
\hline$\angle 9582$ & $* * *$ & $* * *$ & $* * *$ & $0 \mathcal{E}^{\circ} 6 \mathcal{E}$ & SE'9 & $8 \varepsilon^{\circ} S Z$ \\
\hline$\angle 6^{\circ} \varepsilon 82$ & $* * *$ & $* * *$ & $* * *$ & $90^{\circ} 6 \varepsilon$ & $\varepsilon \varepsilon^{\circ} 9$ & $\varepsilon \varepsilon^{\prime} \subseteq Z$ \\
\hline 62282 & $* * *$ & $* * *$ & $* * *$ & $\varepsilon 8^{\circ} 8 \varepsilon$ & $\varepsilon \varepsilon^{*} 9$ & $0 \varepsilon^{\circ} S Z$ \\
\hline $796 \mathrm{LZ}$ & $* * *$ & $* * *$ & $* * *$ & $\angle t^{\prime} 8 E$ & $\varepsilon \varepsilon^{*} 9$ & $\varepsilon \varepsilon^{\circ} \varsigma Z$ \\
\hline$\angle 6 L L 2$ & $* * *$ & $* * *$ & $* * *$ & $t \tau^{\prime} 8 E$ & $2 \varepsilon^{\circ} 9$ & $L Z Z^{*} S Z$ \\
\hline $2 \tau^{\circ} 9 L 2$ & $* * *$ & $* * *$ & $* * *$ & $00^{\circ} 8 \varepsilon$ & $1 \varepsilon^{\circ} 9$ & $S Z Z^{\prime} \mathbf{Z}$ \\
\hline$\nabla \nabla^{\circ} \forall \angle Z$ & $* * *$ & $* * *$ & $* * *$ & $S L L E$ & $62^{\prime} 9$ & $\angle I^{\circ} S Z$ \\
\hline $6 S^{\circ} \tau L 2$ & $* * *$ & $* * *$ & $* * *$ & $O S^{\circ} \angle \varepsilon$ & $62^{\prime} 9$ & $\angle I^{\circ} S Z$ \\
\hline $78^{\circ} 0<2$ & $* * *$ & $* * *$ & $* * *$ & $9 \tau^{\circ} \angle \varepsilon$ & $82^{\prime} 9$ & 11.52 \\
\hline $90^{\circ} 692$ & $* * *$ & **** & $* * *$ & $10^{\circ} \angle \varepsilon$ & $82 \% 9$ & $111^{\circ} s 2$ \\
\hline $12: \angle 92$ & $* * *$ & **** & ***** & $9 L^{\circ} 9 \varepsilon$ & $\angle Z^{\circ} 9$ & $60^{\circ} \varsigma 2$ \\
\hline $6 \varepsilon^{\circ} \varsigma 92$ & **** & $* * *$ & $* * *$ & IS.9E & $92^{\circ} 9$ & $\varepsilon 0^{\circ} \varsigma 2$ \\
\hline $9 L^{\circ} \varepsilon 9 Z$ & $* * *$ & $* * *$ & $* * *$ & $82^{\circ} 9 \varepsilon$ & 92.9 & $\varepsilon 0^{\circ} \mathrm{SZ}$ \\
\hline 10.292 & $* * *$ & $* * *$ & $* * *$ & $70^{\circ} 9 \varepsilon$ & $92^{\circ} 9$ & $E 0^{\circ} \mathrm{SZ}$ \\
\hline$\angle 2.092$ & ***** & $* * *$ & $* * *$ & $08^{\circ} \mathrm{SE}$ & $9 z^{\circ} 9$ & $\mathrm{EO} \mathrm{SZ}$ \\
\hline $2 S^{\prime} 8 S Z$ & $* * *$ & $* * *$ & $* * *$ & $9 S^{\prime} S E$ & $\angle Z^{\prime} 9$ & $60^{\circ} \mathrm{SZ}$ \\
\hline$\nabla L 9 S 2$ & $* * *$ & $* * *$ & $* * *$ & $Z \varepsilon^{\prime} \subseteq E$ & $92^{\prime} 9$ & $\varepsilon 0^{\circ} \varsigma Z$ \\
\hline$b I^{\prime} S S Z$ & $* * *$ & $* * *$ & $* * *$ & OI'SE & $92^{\prime} 9$ & $\varepsilon 0^{\circ} \mathrm{SZ}$ \\
\hline$\varepsilon \nabla^{\circ} \varepsilon S \tau$ & $* * *$ & $* * *$ & $* * *$ & $98^{\circ} \nabla \varepsilon$ & $9 Z^{\prime} 9$ & $\varepsilon 0^{\circ} \subseteq Z$ \\
\hline ZLIISZ & $* * *$ & ***** & $* * *$ & $\varepsilon 9^{\circ} \nabla \varepsilon$ & $9 \tau^{\prime} 9$ & $\varepsilon 0^{\circ} \subseteq Z$ \\
\hline 86.602 & $* * *$ & $* * *$ & $* * *$ & $6 \varepsilon^{\circ} \nabla \varepsilon$ & $\varepsilon Z^{*} 9$ & $\varepsilon 6^{\circ} \nabla \tau$ \\
\hline St 8 t & $* * *$ & $* * *$ & $* * *$ & $81^{\circ} \nabla \varepsilon$ & $22^{\circ} 9$ & $\angle 8^{\circ} \circ C$ \\
\hline $8 L^{\circ} 9 t Z$ & $* * *$ & ***** & $* * *$ & S6. $\varepsilon E$ & $22^{\circ} 9$ & $06^{\circ}+2$ \\
\hline $1 I^{\circ} \mathrm{s} \nabla \mathrm{Z}$ & $* * *$ & $* * *$ & ***** & $Z L^{\prime} \varepsilon E$ & $02 \% 9$ & $28^{\circ}+2$ \\
\hline
\end{tabular}




\section{CORROSION EFFECTS ON BOND STRENGTH IN REINFORCED CONCRETE}

\begin{tabular}{||c|c|c|c|c|c|c||}
\hline \hline 14.66 & 3.66 & 40.68 & $* * *$ & $* * *$ & $* * *$ & 295.71 \\
\hline 14.32 & 3.58 & 40.10 & $* * *$ & $* * *$ & $* * *$ & 291.49 \\
\hline 13.21 & 3.30 & 39.68 & $* * *$ & $* * *$ & $* * *$ & 288.44 \\
\hline 12.13 & 3.03 & 39.69 & $* * *$ & $* * *$ & $* * *$ & 288.51 \\
\hline 11.57 & 2.89 & 39.06 & $* * *$ & $* * *$ & $* * *$ & 283.93 \\
\hline 9.76 & 2.44 & 37.06 & $* * *$ & $* * *$ & $* * *$ & 269.39 \\
\hline 7.16 & 1.79 & 35.19 & $* * *$ & $* * *$ & $* * *$ & 255.79 \\
\hline 4.65 & 1.16 & 33.82 & $* * *$ & $* * *$ & $* * *$ & 245.84 \\
\hline 2.86 & 0.71 & 33.78 & $* * *$ & $* * *$ & $* * *$ & 245.54 \\
\hline 1.59 & 0.40 & 33.72 & $* * *$ & $* * *$ & $* * *$ & 245.11 \\
\hline 0.44 & 0.11 & 33.70 & $* * *$ & $* * *$ & $* * *$ & 244.96 \\
\hline 0.11 & 0.03 & 33.56 & $* * *$ & $* * *$ & $* * *$ & 243.94 \\
\hline
\end{tabular}

*** Curvature based on Midpoint Deflection as problem with data acquisition.

Series 2 - Silica Fume, $8 \%$ Corrosion

\begin{tabular}{||c|c|c|c|c|c|c||}
\hline $\begin{array}{c}\text { Load } \\
(\mathrm{kN})\end{array}$ & $\begin{array}{c}\text { Moment } \\
(\mathrm{kN}-\mathrm{m})\end{array}$ & $\begin{array}{c}\text { M.P. Displ. } \\
(\mathrm{mm})\end{array}$ & $\begin{array}{c}\text { E. Curv. LVDT } \\
(\mathrm{mm})\end{array}$ & $\begin{array}{c}\text { W. Curv. LVDT } \\
(\mathrm{mm})\end{array}$ & $\begin{array}{c}\text { Curv. LVDT Avg. } \\
(\mathrm{mm})\end{array}$ & $\begin{array}{c}\text { Curvature } \\
(1 / \mathrm{km})\end{array}$ \\
\hline \hline-0.31 & -0.08 & 0.00 & 0.005 & -0.011 & -0.010 & 1.98 \\
\hline 1.62 & 0.40 & -0.00 & 0.010 & -0.009 & -0.013 & 2.58 \\
\hline 0.18 & 0.04 & 0.00 & 0.010 & -0.003 & -0.009 & 1.72 \\
\hline 1.29 & 0.32 & 0.02 & 0.004 & -0.058 & -0.009 & 1.87 \\
\hline 2.44 & 0.61 & 0.06 & 0.010 & -0.007 & -0.013 & 2.55 \\
\hline 3.51 & 0.88 & 0.08 & 0.006 & -0.105 & -0.065 & 12.98 \\
\hline 4.57 & 1.14 & 0.11 & 0.022 & -0.109 & -0.063 & 12.53 \\
\hline 5.58 & 1.39 & 0.13 & 0.007 & -0.108 & -0.063 & 12.58 \\
\hline 6.65 & 1.66 & 0.16 & -0.013 & -0.118 & -0.068 & 13.52 \\
\hline 7.67 & 1.92 & 0.20 & 0.009 & -0.156 & -0.064 & 12.73 \\
\hline 8.72 & 2.18 & 0.21 & 0.002 & -0.109 & -0.064 & 12.80 \\
\hline 9.78 & 2.44 & 0.23 & 0.005 & -0.113 & -0.065 & 12.90 \\
\hline 10.80 & 2.70 & 0.26 & 0.007 & -0.171 & -0.068 & 13.65 \\
\hline 11.85 & 2.96 & 0.28 & -0.003 & -0.093 & -0.069 & 13.80 \\
\hline 12.96 & 3.24 & 0.32 & -0.001 & -0.111 & -0.066 & 13.20 \\
\hline 14.07 & 3.52 & 0.34 & -0.005 & -0.092 & -0.070 & 13.95 \\
\hline 15.09 & 3.77 & 0.38 & -0.003 & -0.177 & -0.075 & 14.90 \\
\hline 16.20 & 4.05 & 0.39 & -0.002 & -0.071 & -0.067 & 13.45 \\
\hline 17.26 & 4.31 & 0.43 & -0.009 & -0.035 & -0.072 & 14.37 \\
\hline 18.39 & 4.60 & 0.46 & -0.011 & -0.193 & -0.074 & 14.80 \\
\hline 19.46 & 4.87 & 0.48 & -0.013 & -0.108 & -0.070 & 13.92 \\
\hline 20.55 & 5.14 & 0.52 & 0.003 & -0.111 & -0.071 & 14.17 \\
\hline 19.10 & 4.78 & 0.64 & -0.004 & -0.114 & -0.075 & 14.90 \\
\hline 17.19 & 4.30 & 0.68 & -0.006 & -0.131 & -0.080 & 16.05 \\
\hline 15.84 & 3.96 & 0.70 & -0.008 & -0.142 & -0.085 & 16.90 \\
\hline 14.60 & 3.65 & 0.72 & 0.005 & -0.186 & -0.092 & 18.48 \\
\hline & & & & & & \\
\hline
\end{tabular}




\begin{tabular}{|c|c|c|c|c|c|c|}
\hline 13.45 & 3.36 & 0.77 & 0.006 & -0.142 & -0.079 & 15.80 \\
\hline 12.33 & 3.08 & 0.88 & 0.011 & -0.149 & -0.084 & 16.87 \\
\hline 12.01 & 3.00 & 1.08 & -0.009 & -0.170 & -0.085 & 16.93 \\
\hline 12.80 & 3.20 & 1.28 & 0.005 & -0.175 & -0.089 & 17.73 \\
\hline 13.83 & 3.46 & 1.45 & -0.003 & -0.321 & -0.098 & 19.57 \\
\hline 14.91 & 3.73 & 1.62 & 0.014 & -0.192 & -0.093 & 18.62 \\
\hline 15.96 & 3.99 & 1.78 & 0.029 & -0.221 & -0.095 & 19.08 \\
\hline 17.09 & 4.27 & 1.92 & 0.031 & -0.157 & -0.104 & 20.70 \\
\hline 18.12 & 4.53 & 2.07 & 0.038 & -0.211 & -0.097 & 19.47 \\
\hline 19.17 & 4.79 & 2.22 & 0.055 & -0.235 & -0.100 & 20.00 \\
\hline 20.24 & 5.06 & 2.37 & 0.059 & -0.227 & -0.097 & 19.43 \\
\hline 21.31 & 5.33 & 2.53 & 0.059 & -0.231 & -0.096 & 19.23 \\
\hline 22.42 & 5.60 & 2.68 & 0.102 & -0.240 & -0.098 & 19.62 \\
\hline 23.41 & 5.85 & 2.83 & 0.112 & -0.240 & -0.098 & 19.52 \\
\hline 24.50 & 6.12 & 2.98 & 0.071 & -0.320 & -0.095 & 18.90 \\
\hline 25.59 & 6.40 & 3.15 & 0.115 & -0.214 & -0.095 & 18.93 \\
\hline 26.61 & 6.65 & 3.32 & 0.112 & -0.225 & -0.092 & 18.35 \\
\hline 27.62 & 6.91 & 3.47 & 0.150 & -0.250 & -0.095 & 19.08 \\
\hline 28.64 & 7.16 & 3.64 & 0.110 & -0.369 & -0.097 & 19.43 \\
\hline 29.65 & 7.41 & 3.81 & 0.140 & -0.276 & -0.101 & 20.10 \\
\hline 30.69 & 7.67 & 3.99 & 0.102 & -0.274 & -0.101 & 20.12 \\
\hline 31.73 & 7.93 & 4.18 & 0.112 & -0.292 & -0.103 & 20.68 \\
\hline 32.69 & 8.17 & 4.37 & 0.046 & -0.298 & -0.116 & 23.12 \\
\hline 33.57 & 8.39 & 4.56 & 0.060 & -0.284 & -0.123 & 24.62 \\
\hline 34.59 & 8.65 & 4.78 & 0.075 & -0.302 & -0.141 & 28.20 \\
\hline 35.41 & 8.85 & 4.98 & 0.056 & -0.357 & -0.127 & 25.42 \\
\hline 36.24 & 9.06 & 5.18 & 0.080 & -0.342 & -0.140 & 28.07 \\
\hline 36.99 & 9.25 & 5.38 & 0.064 & -0.413 & -0.170 & 33.93 \\
\hline \begin{tabular}{|l|l|}
37.50 \\
\end{tabular} & 9.37 & 5.58 & 0.051 & -0.420 & -0.196 & 39.27 \\
\hline \begin{tabular}{|l|}
37.84 \\
\end{tabular} & 9.46 & 5.77 & 0.037 & -0.397 & -0.178 & 35.53 \\
\hline 38.30 & 9.57 & 5,97 & 0.022 & -0.393 & -0.201 & 40.15 \\
\hline 38.72 & 9.68 & 6.17 & 0.009 & -0.456 & -0.217 & 43.42 \\
\hline 39.28 & 9.82 & 6.37 & -0.015 & -0.427 & -0.236 & 47.15 \\
\hline 39.66 & 9.91 & 6.58 & 0.009 & -0.448 & -0.232 & 46.40 \\
\hline 39.82 & 9.95 & 6.79 & -0.020 & -0.503 & -0.255 & 50.95 \\
\hline 39.82 & 9.95 & 6.98 & -0.038 & -0.439 & -0.265 & 52.95 \\
\hline 39.95 & 9.99 & 7.19 & -0.045 & -0.444 & -0.283 & 56.60 \\
\hline 40.35 & 10.09 & 7.39 & -0.079 & -0.516 & -0.327 & 65.30 \\
\hline 40.43 & 10.11 & 7.60 & -0.095 & -0.526 & -0.323 & 64.62 \\
\hline 40.38 & 10.09 & 7.80 & -0.126 & -0.573 & -0.348 & 69.50 \\
\hline 40.03 & 10.01 & 8.00 & -0.152 & -0.565 & -0.369 & 73.73 \\
\hline 39.10 & 9.77 & 8.21 & -0.176 & -0.585 & -0.393 & 78.50 \\
\hline 37.98 & 9.49 & 8.41 & -0.206 & -0.605 & -0.436 & 87.27 \\
\hline 37.04 & 9.26 & 8.63 & -0.210 & -0.580 & -0.431 & 86.15 \\
\hline 36.56 & 9.14 & 8.87 & -0.277 & -0.685 & -0.492 & 98.40 \\
\hline 36.03 & 9.01 & 9.12 & -0.357 & -0.741 & -0.539 & 107.80 \\
\hline 34.67 & 8.67 & 9.30 & -0.406 & -0.662 & -0.574 & 114.72 \\
\hline
\end{tabular}




\begin{tabular}{|c|c|c|c|c|c|c|}
\hline $00^{\circ} 0 L \varepsilon$ & $058 \mathrm{I}^{-}$ & $890^{\circ} Z^{-}$ & $509 \mathrm{I}^{-}$ & $79.8 I$ & 009 & $66^{\circ} \varepsilon Z$ \\
\hline $00^{\circ} \varsigma 9 \varepsilon$ & sZ8'1- & st0 $0^{\circ}$ & SLS I- & $t t^{\circ} 8 \mathrm{I}$ & $86^{\circ} \mathrm{S}$ & $D 6^{\circ} \varepsilon \tau$ \\
\hline$\varsigma \tau^{\circ} \varepsilon 9 \varepsilon$ & $918^{\circ} 1^{-}$ & $0 \mathrm{zo} \mathrm{Z}^{\circ}$ & $805^{\prime} \mathrm{I}^{-}$ & $t 2.8 I$ & $86^{\circ} \mathrm{S}$ & $t 6^{\circ} \varepsilon Z$ \\
\hline$S L^{\prime} 9 S \varepsilon$ & $68 \mathrm{~L}^{\circ} \mathrm{I}^{-}$ & s10 Z- & tIS I- & $\$ 0.81$ & $90^{\prime} 9$ & $9 \tau^{\circ} b \tau$ \\
\hline $0 S^{\circ} 6 \nabla \varepsilon$ & $80 \mathrm{~L}^{\circ} \mathrm{I}^{-}$ & $996^{\circ} \mathrm{I}^{-}$ & olt I- & $28^{\circ} \mathrm{LI}$ & 50.9 & sint \\
\hline$S L^{\prime} 9 \triangleright \delta \varepsilon$ & $t \varepsilon L^{\circ} I^{-}$ & $806^{\circ} \mathrm{I}^{-}$ & sot. I- & $\varepsilon 9^{\circ} \mathrm{LI}$ & $10^{\circ} 9$ & $50^{\circ} \circ z$ \\
\hline SLLLEE & $689^{\circ} \mathrm{I}^{-}$ & $006^{\circ} \mathrm{I}^{-}$ & I0t I- & $2 b^{\circ} L I$ & $\varepsilon 0^{\circ} 9$ & $\varepsilon I^{\circ} b z$ \\
\hline SZ' $\varepsilon \varepsilon \varepsilon$ & $999^{\circ} 1-$ & $8 \angle 8^{\circ} \mathrm{I}^{-}$ & $\varepsilon \not \varepsilon^{\prime} I^{-}$ & $1 Z^{\prime} \angle I$ & 60.9 & $s I^{\circ} b z$ \\
\hline sZ.6ZE & $9+9^{\circ} \mathrm{I}^{-}$ & $668^{\circ} \mathrm{I}^{-}$ & $\nabla \angle E^{\circ} I^{-}$ & $00^{\circ} \mathrm{LI}$ & 50.9 & $1 z^{\circ} b z$ \\
\hline $00^{\circ} \varepsilon Z \varepsilon$ & S19.1- & $618^{\circ} I^{-}$ & $9 \angle Z^{\prime} I^{-}$ & $8 L^{\prime} 9 \mathrm{I}$ & $80^{\circ} 9$ & $1 \varepsilon^{\circ} b \tau$ \\
\hline $5 Z^{\circ} \angle I \varepsilon$ & $98 \mathrm{~S}^{\prime} \mathrm{I}^{-}$ & EZ8. I- & OEE I- & $65^{\circ} 9 \mathrm{I}$ & $01 ' 9$ & $z \nabla^{\circ} \dagger z$ \\
\hline$s \tau^{\circ} s \mid \varepsilon$ & $9 \mathrm{SS}^{\prime} \mathrm{I}^{-}$ & $508^{\circ} \mathrm{I}^{-}$ & IOE [- & $8 \varepsilon^{\circ} 9 \mathrm{I}$ & SI'9 & $19^{\circ} \nabla z$ \\
\hline$S L \cdot 80 \varepsilon$ & $t \rightarrow S^{\prime} I^{-}$ & $98 \mathrm{~L}^{\circ} \mathrm{I}^{-}$ & $89 \mathrm{Z}^{\circ} \mathrm{I}^{-}$ & $6 I^{\circ} 91$ & $81^{\prime} 9$ & $t L^{\prime} t z$ \\
\hline$S L L^{\circ} \varepsilon O E$ & $6 \mathrm{IS}^{\prime} \mathrm{I}^{-}$ & $\pm 6 L^{\circ} I^{-}$ & $9 \mathrm{ST}^{\circ} \mathrm{I}^{-}$ & $66^{\circ} \mathrm{SI}$ & 229 & $06^{\circ} \nabla z$ \\
\hline 00862 & $06 t^{\prime} I^{-}$ & $62 L^{\circ} I^{-}$ & $\varepsilon 0 Z^{\circ} I^{-}$ & $08^{\prime} S \mathrm{I}$ & $\angle Z^{\prime} 9$ & $90^{\circ} \textrm{ }$ \\
\hline$s Z^{\prime} 962$ & $180^{\circ} 1^{-}$ & OILI- & $I^{\prime E I^{\prime}} \mathrm{I}^{-}$ & $6 S^{\prime} \mathrm{SI}$ & $0 \varepsilon^{\prime} 9$ & $6 I^{\circ} S Z$ \\
\hline $00^{\circ} \varepsilon 6 Z$ & s9b. I- & $S 89^{\circ} \mathrm{I}^{-}$ & $96 \mathrm{I}^{\circ} \mathrm{l}^{-}$ & $0 t^{\prime} \leqq I$ & $\angle Z^{\prime} 9$ & $60^{\circ} \varsigma \mathrm{Z}$ \\
\hline $05^{\circ} \angle 8 Z$ & $8 \varepsilon D^{\circ} 1^{-}$ & $899^{\circ} \mathrm{I}^{-}$ & $581^{\circ} 1^{\circ}$ & $0 Z^{\prime} \subseteq I$ & $0 \varepsilon^{\prime \prime} 9$ & $6 \mathrm{I}^{\circ} \mathrm{SZ}$ \\
\hline$S Z 6 L Z$ & $96 \varepsilon^{\circ} \mathrm{I}^{-}$ & SE9 I- $^{-}$ & $8 \mathrm{II}^{\circ} \mathrm{I}^{-}$ & $00^{\circ} \mathrm{SI}$ & $\varepsilon \varepsilon^{\prime} 9$ & $0 \varepsilon S Z$ \\
\hline$S Z \cdot 9 L Z$ & {$\left[8 E^{\circ} \mathrm{I}^{-}\right.$} & $519^{\circ} 1^{-}$ & OII I- & $08^{\circ} \forall l$ & $8 \varepsilon^{\circ} 9$ & IS'SZ \\
\hline $00^{\circ} 0 \angle Z$ & OSE I- & $68 \mathrm{~S}^{\circ} \mathrm{I}^{-}$ & EI0 $\mathrm{I}^{-}$ & $09^{\circ} \mathrm{bI}$ & $1 t^{\circ} 9$ & $29^{\circ} \varsigma \mathrm{Z}$ \\
\hline SL'29Z & DIE' I- & SSS' I- & $\Delta+0^{\circ} \mathrm{I}^{-}$ & 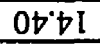 & $t 709$ & $S L^{\prime} S Z$ \\
\hline $0 S^{\circ} 9 S 2$ & E8Z' I- & $66 S^{\circ} \mathrm{I}^{-}$ & $\angle D 0^{\circ} I^{-}$ & $0 \tau^{\circ} \forall I$ & $\angle t^{\circ} 9$ & $98^{\circ} \mathrm{SZ}$ \\
\hline $0 S^{\circ} E S Z$ & $89 \mathrm{C} \mathrm{I}^{\circ-}$ & E6t' I- & $8+60^{\circ} 0^{-}$ & $00 \div 1$ & [S.9 & 20.92 \\
\hline$S L^{\prime} S \not Z$ & $622^{\prime} \mathrm{I}^{-}$ & $\varepsilon \angle t^{\prime} \mathrm{I}^{-}$ & $\angle S 6^{\circ} 0^{-}$ & $6 L^{\circ} \varepsilon I$ & $\angle S^{*} 9$ & $9 z^{\prime} 92$ \\
\hline$s \tau^{\circ} 0 \Delta Z$ & $10 \mathrm{Z}^{\prime} \mathrm{I}^{-}$ & Obt I- & $\nabla \varepsilon 6^{\circ} 0^{-}$ & $6 S^{\circ} \varepsilon I$ & $65^{\circ} 9$ & $\angle \varepsilon^{\prime} 9 Z$ \\
\hline$s Z^{\prime}+\varepsilon Z$ & $\mathrm{ILI}^{\prime} \mathrm{I}^{-}$ & $80 t^{\circ} \mathrm{I}^{-}$ & $\varepsilon 26^{\circ} 0^{-}$ & $8 \varepsilon^{\circ} \varepsilon l$ & $69^{\circ} 9$ & $s s^{\circ} 92$ \\
\hline $00^{\circ} 8 z 2$ & $00 \mathrm{I}^{\prime} \mathrm{I}^{-}$ & S9E'I- & $988^{\circ} 0^{-}$ & $8 I^{\circ} \varepsilon I$ & 69.9 & $\angle L^{\circ} 9 Z$ \\
\hline $0 S^{\circ} \varepsilon Z Z$ & $8 \mathrm{II}^{\prime} \mathrm{I}^{-}$ & SEE I- & $1 \angle 8^{\circ} 0^{-}$ & $76^{\circ} \mathrm{ZI}$ & $\varepsilon L^{\prime} 9$ & $\varepsilon 6^{\circ} 9 \mathrm{Z}$ \\
\hline$S L 81 Z$ & $560^{\circ} I^{-}$ & $0<Z^{\prime} I^{-}$ & $9+8^{\circ} 0^{-}$ & $\nabla L Z I$ & $9 L^{\prime} 9$ & $E O^{\circ} \angle Z$ \\
\hline $00 \mathrm{ZIZ}$ & $090^{\circ} \mathrm{I}^{-}$ & $88 \mathrm{Z}^{\circ} \mathrm{I}^{-}$ & $0288^{\circ} 0^{-}$ & $t S \mathrm{Zl}$ & $\varepsilon 8^{\circ} 9$ & $0 \varepsilon \angle Z$ \\
\hline$S L{ }^{\circ} 90 Z$ & $\rightarrow E 0^{\circ} I^{-}$ & $I+z^{\circ} I^{-}$ & $68 \mathrm{~L}^{\circ} \mathrm{O}^{-}$ & $\nabla \varepsilon Z I$ & $58^{\circ} 9$ & $I+\angle Z$ \\
\hline $00^{\circ} 102$ & SOO' I- & ${ }^{\circ} 02^{\prime} \mathrm{I}^{-}$ & OLL'O- & $\varepsilon l^{\circ} \mathrm{Zl}$ & 16.9 & $29^{\circ} \mathrm{L2}$ \\
\hline $29^{\circ} 961$ & $\varepsilon 86^{\circ} 0^{-}$ & $891^{\circ} \mathrm{I}^{-}$ & $\$ 9 L^{\circ} 0^{-}$ & 0611 & $\varepsilon 6.9$ & $\varepsilon L \angle Z$ \\
\hline $0 \varepsilon^{\prime} 681$ & $\angle \nabla 6^{\circ} 0^{-}$ & It $I^{\circ} I^{-}$ & $Z E L^{\circ} 0^{-}$ & $0 L^{\prime} I I$ & $86^{\circ} 9$ & $26 . \angle 2$ \\
\hline $09^{\circ} \mathrm{Z8I}$ & $\varepsilon 16^{\circ} 0^{-}$ & $660^{\circ} \mathrm{I}^{-}$ & $269^{\circ} 0^{-}$ & $80^{\circ} \mathrm{II}$ & $\mathrm{SO}^{\circ} \mathrm{L}$ & 12.82 \\
\hline$S 9^{\circ} \varsigma L \mathrm{~L}$ & $8 \angle 8^{\circ} 0^{-}$ & $60 \mathrm{I}^{\circ} \mathrm{I}^{-}$ & $\angle S 9^{\circ} 0^{-}$ & $9 Z^{\circ} \mathrm{II}$ & $S I^{\circ} \mathrm{L}$ & 85.82 \\
\hline $8 \angle 69 \mathrm{I}$ & $608^{\circ} 0^{-}$ & $020^{\circ} \mathrm{I}^{-}$ & $259^{\circ} 0^{-}$ & $90 \mathrm{II}$ & $12 \mathrm{~L}$ & 28.82 \\
\hline$\varepsilon 0^{\circ}+91$ & $028^{\circ} 0^{-}$ & $196^{\circ} 0^{-}$ & $929^{\circ} 0^{-}$ & $78^{\circ} 0 \mathrm{I}$ & $0 \varepsilon^{\circ} L$ & $0 z^{\circ} 62$ \\
\hline $08^{\circ} 9 \mathrm{SI}$ & $\$ 8 L^{\circ} 0^{-}$ & $\pm 26^{\circ} 0^{-}$ & $\varepsilon 6 S^{\circ} 0^{-}$ & $\varepsilon 9^{\circ} 0 \mathrm{I}$ & $6 \varepsilon^{\prime} L$ & $t 5^{\circ} 62$ \\
\hline SI'ISI & 9SL'0- & $608^{\circ} 0^{-}$ & $6 S^{\circ} 0^{-}$ & $t \nabla \circ 01$ & $S b^{\circ} L$ & $8 L^{\circ} 62$ \\
\hline$\angle E^{\circ} S \neq I$ & $\angle Z L^{\prime} 0^{-}$ & $\angle 28^{\circ} 0^{-}$ & $\angle S^{\circ} O^{-}$ & $\nabla Z^{\circ} 0 \mathrm{I}$ & $\angle S^{\circ} L$ & $9 Z^{\circ} 0 \varepsilon$ \\
\hline $00^{\circ} 8 \varepsilon I$ & $069^{\circ} 0^{-}$ & $1 \varepsilon 8^{\circ} 0^{-}$ & EZS.0- & $\varepsilon 0^{\circ} 0 \mathrm{I}$ & $89^{\circ} \mathrm{L}$ & $Z L^{\circ} O E$ \\
\hline $06^{\circ} 0 \varepsilon I$ & S59.0- & $58 L^{\circ} 0^{-}$ & $06 t^{\circ} 0^{-}$ & $\varepsilon 8.6$ & $\varepsilon 8^{\circ} \mathrm{L}$ & IE'IE \\
\hline$\angle \varepsilon^{\prime} \varepsilon Z I$ & $\angle 19^{\circ} 0^{\circ}$ & $\angle \varepsilon L^{\circ} 0^{-}$ & $290^{\circ} 0^{-}$ & $\varepsilon 9^{\circ} 6$ & $16^{\circ} \mathrm{L}$ & S9.1E \\
\hline Zह'0ZI & $209^{\circ} 0^{-}$ & $8+L^{\circ} 0^{-}$ & $9 \varepsilon t^{\circ} 0^{-}$ & $\varepsilon t^{\prime} 6$ & E['8 & $\varepsilon \varsigma^{\prime} \tau \varepsilon$ \\
\hline$\angle 60^{\circ} 81 \mathrm{I}$ & $565^{\circ} 0^{-}$ & $169^{\circ} 0^{-}$ & $81 t^{\circ} 0^{-}$ & $\nabla \varepsilon^{\prime} 6$ & $\varepsilon \rightarrow \cdot 8$ & $\varepsilon L^{\prime} \varepsilon \varepsilon$ \\
\hline
\end{tabular}




\begin{tabular}{|c|c|c|c|c|c|c|}
\hline 23.62 & 5.90 & 18.84 & -1.590 & -2.081 & -1.854 & 370.75 \\
\hline 23.75 & 5.94 & 19.06 & -1.620 & -2.100 & -1.875 & 375.00 \\
\hline 23.89 & 5.97 & 19.25 & -1.666 & -2.099 & -1.909 & 381.75 \\
\hline 23.65 & 5.91 & 19.45 & -1.685 & -2.110 & -1.931 & 386.25 \\
\hline 23.81 & 5.95 & 19.65 & -1.716 & -2.163 & -1.960 & 392.00 \\
\hline 23.73 & 5.93 & 19.85 & -1.721 & -2.180 & -1.968 & 393.50 \\
\hline 23.62 & 5.90 & 20.04 & -1.753 & -2.195 & -1.988 & 397.50 \\
\hline 23.62 & 5.90 & 20.25 & -1.768 & -2.164 & -1.996 & 399.25 \\
\hline 23.33 & 5.83 & 20.48 & -1.794 & -2.259 & -2.025 & 405.00 \\
\hline 23.22 & 5.80 & 20.67 & -1.823 & -2.201 & -2.056 & 411.25 \\
\hline 23.25 & 5.81 & 20.86 & -1.855 & -2.258 & -2.076 & 415.25 \\
\hline 22.98 & 5.74 & 21.05 & -1.845 & -2.274 & -2.078 & 415.50 \\
\hline 23.27 & 5.82 & 21.25 & -1.880 & -2.314 & -2.113 & 422.50 \\
\hline 22.98 & 5.74 & 21.46 & -1.910 & -2.306 & -2.110 & 422.00 \\
\hline 22.76 & 5.69 & 21.67 & -1.938 & -2.328 & -2.134 & 426.75 \\
\hline 22.66 & 5.66 & 21.87 & -1.949 & -2.284 & -2.120 & 424.00 \\
\hline 22.44 & 5.61 & 22.06 & -1.978 & -2.308 & -2.159 & 431.75 \\
\hline 22.26 & 5.56 & 22.27 & -1.991 & -2.298 & -2.156 & 431.25 \\
\hline 22.26 & 5.56 & 22.46 & -2.010 & -2.306 & -2.161 & 432.25 \\
\hline 21.56 & 5.39 & 22.68 & -2.033 & -2.275 & -2.188 & 437.50 \\
\hline 21.16 & 5.29 & 22.87 & -2.058 & -2.298 & -2.213 & 442.50 \\
\hline 20.87 & 5.22 & 23.07 & -2.083 & -2.293 & -2.206 & 441.25 \\
\hline 20.34 & 5.08 & 23.25 & -2.084 & -2.308 & -2.205 & 441.00 \\
\hline 20.32 & 5.08 & 23.46 & -2.110 & -2.309 & -2.221 & 444.25 \\
\hline 20.32 & 5.08 & 23.66 & -2.130 & -2.296 & -2.244 & 448.75 \\
\hline 20.17 & 5.04 & 23.86 & -2.120 & -2.319 & -2.229 & 445.75 \\
\hline 20.38 & 5.10 & 24.05 & -2.138 & -2.311 & -2.250 & 450.00 \\
\hline 20.02 & 5.00 & 24.25 & -2.140 & -2.348 & -2.250 & 450.00 \\
\hline 20.27 & 5.07 & 24.45 & -2.156 & -2.334 & -2.281 & 456.25 \\
\hline 19.93 & 4.98 & 24.65 & -2.178 & -2.333 & -2.274 & 454.75 \\
\hline 20.20 & 5.05 & 24.84 & -2.169 & -2.340 & -2.273 & 454.50 \\
\hline 20.15 & 5.04 & 25.05 & -2.196 & -2.349 & -2.294 & 458.75 \\
\hline 20.13 & 5.03 & 25.26 & -2.208 & -2.378 & -2.305 & 461.00 \\
\hline 20.00 & 5.00 & 25.45 & -2.231 & -2.384 & -2.319 & 463.75 \\
\hline 20.07 & 5.02 & 25.66 & -2.245 & -2.388 & -2.339 & 467.75 \\
\hline 19.99 & 5.00 & 25.86 & -2.280 & -2.409 & -2.356 & 471.25 \\
\hline 19.78 & 4.94 & 26.05 & -2.290 & -2.420 & -2.374 & 474.75 \\
\hline 20.05 & 5.01 & 26.25 & -2.246 & -2.434 & -2.354 & 470.75 \\
\hline 20.11 & 5.03 & 26.43 & -2.266 & -2.439 & -2.389 & 477.75 \\
\hline 19.63 & 4.91 & 26.63 & -2.296 & -2.455 & -2.389 & 477.75 \\
\hline 19.79 & 4.95 & 26.83 & -2.305 & -2.471 & -2.405 & 481.00 \\
\hline 19.92 & 4.98 & 27.04 & -2.318 & -2.486 & -2.415 & 483.00 \\
\hline 19.46 & 4.86 & 27.25 & -2.335 & -2.501 & -2.438 & 487.50 \\
\hline 19.55 & 4.89 & 27.45 & -2.366 & -2.506 & -2.446 & 489.25 \\
\hline 19.53 & 4.88 & 27.65 & -2.338 & -2.530 & -2.453 & 490.50 \\
\hline 19.42 & 4.86 & 27.85 & -2.359 & -2.546 & -2.473 & 494.50 \\
\hline 19.42 & 4.86 & 28.03 & -2.385 & -2.560 & -2.495 & 499.00 \\
\hline
\end{tabular}




\begin{tabular}{|c|c|c|c|c|c|c|}
\hline 19.27 & 4.82 & 28.23 & -2.378 & -2.581 & -2.500 & 500.00 \\
\hline 19.25 & 4.81 & 28.42 & -2.413 & -2.593 & -2.520 & 504.00 \\
\hline 19.38 & 4.85 & 28.63 & -2.424 & -2.615 & -2.534 & 506.75 \\
\hline 19.32 & 4.83 & 28.83 & -2.428 & -2.594 & -2.525 & 505.00 \\
\hline 19.24 & 4.81 & 29.03 & -2.444 & -2.611 & -2.554 & 510.75 \\
\hline 19.12 & 4.78 & 29.25 & -2.466 & -2.628 & -2.568 & 513.50 \\
\hline 19.17 & 4.79 & 29.46 & -2.489 & -2.639 & -2.589 & 517.75 \\
\hline 19.03 & 4.76 & 29.65 & -2.506 & -2.658 & -2.599 & 519.75 \\
\hline 19.01 & 4.75 & 29.85 & -2.451 & -2.678 & -2.585 & 517.00 \\
\hline 18.86 & 4.72 & 30.06 & -2.476 & -2.685 & -2.593 & 518.50 \\
\hline 19.00 & 4.75 & 30.26 & -2.509 & -2.705 & -2.628 & 525.50 \\
\hline 18.99 & 4.75 & 30.46 & -2.523 & -2.724 & -2.646 & 529.25 \\
\hline 18.79 & 4.70 & 30.66 & -2.544 & -2.746 & -2.683 & 536.50 \\
\hline 18.74 & 4.69 & 30.87 & -2.569 & -2.781 & -2.684 & 536.75 \\
\hline 18.79 & 4.70 & 31.06 & -2.600 & -2.801 & -2.705 & 541.00 \\
\hline 18.70 & 4.67 & 31.27 & -2.615 & -2.816 & -2.739 & 547.75 \\
\hline 18.52 & 4.63 & 31.48 & -2.623 & -2.844 & -2.744 & 548.75 \\
\hline 18.63 & 4.66 & 31.70 & -2.646 & -2.878 & -2.780 & 556.00 \\
\hline 18.39 & 4.60 & 31.91 & -2.680 & -2.926 & -2.814 & 562.75 \\
\hline 18.52 & 4.63 & 32.11 & -2.678 & -2.956 & -2.836 & 567.25 \\
\hline 18.43 & 4.61 & 32.29 & -2.703 & -2.915 & -2.829 & 565.75 \\
\hline 18.34 & 4.58 & 32.48 & -2.736 & -2.923 & -2.843 & 568.50 \\
\hline 18.26 & 4.56 & 32.69 & -2.759 & -2.961 & -2.880 & 576.00 \\
\hline 18.60 & 4.65 & 32.90 & -2.785 & -2.986 & -2.905 & 581.00 \\
\hline 18.44 & 4.61 & 33.09 & -2.810 & -3.013 & -2.933 & 586.50 \\
\hline 18.04 & 4.51 & 33.29 & -2.846 & -3.048 & -2.960 & 592.00 \\
\hline 17.98 & 4.49 & 33.50 & -2.803 & -3.071 & -2.943 & 588.50 \\
\hline 18.12 & 4.53 & 33.70 & -2.825 & -3.094 & -2.985 & 597.00 \\
\hline 18.27 & 4.57 & 33.91 & -2.860 & -3.139 & -3.009 & 601.75 \\
\hline 18.28 & 4.57 & 34.11 & -2.883 & -3.159 & -3.053 & 610.50 \\
\hline 18.32 & 4.58 & 34.33 & -2.914 & -3.169 & -3.078 & 615.50 \\
\hline 18.33 & 4.58 & 34.53 & -2.930 & -3.231 & -3.096 & 619.25 \\
\hline 18.29 & 4.57 & 34.74 & -2.933 & -3.264 & -3.123 & 624.50 \\
\hline 18.41 & 4.60 & 34.94 & -2.979 & -3.294 & -3.166 & 633.25 \\
\hline 18.36 & 4.59 & 35.15 & -3.006 & -3.306 & -3.194 & 638.75 \\
\hline 18.33 & 4.58 & 35.34 & -3.035 & -3.348 & -3.206 & 641.25 \\
\hline 18.38 & 4.60 & 35.55 & -3.059 & -3.368 & -3.240 & 648.00 \\
\hline 18.50 & 4.63 & 35.76 & -3.065 & -3.405 & -3.253 & 650.50 \\
\hline 18.44 & 4.61 & 35.97 & -3.091 & -3.434 & -3.278 & 655.50 \\
\hline 18.59 & 4.65 & 36.18 & -3.144 & -3.468 & -3.326 & 665.25 \\
\hline 18.53 & 4.63 & 36.39 & -3.160 & -3.504 & -3.364 & 672.75 \\
\hline 18.65 & 4.66 & 36.60 & -3.220 & -3.519 & -3.361 & 672.25 \\
\hline 18.48 & 4.62 & 36.83 & -3.220 & -3.556 & -3.405 & 681.00 \\
\hline 18.68 & 4.67 & 37.05 & -3.269 & -3.594 & -3.450 & 690.00 \\
\hline 18.55 & 4.64 & 37.26 & -3.261 & -3.640 & -3.473 & 694.50 \\
\hline 18.61 & 4.65 & 37.47 & -3.296 & -3.661 & -3.506 & 701.25 \\
\hline 18.68 & 4.67 & 37.68 & -3.334 & -3.701 & -3.533 & 706.50 \\
\hline
\end{tabular}




\section{CORROSION EFFECTS ON BOND STRENGTH IN REINFORCED CONCRETE}

Appendix I

Structural Results

\begin{tabular}{|c|c|c|c|c|c|c|}
\hline 18.63 & 4.66 & 37.88 & -3.351 & -3.728 & -3.549 & 709.75 \\
\hline 18.73 & 4.68 & 38.08 & -3.393 & -3.739 & -3.598 & 719.50 \\
\hline 18.69 & 4.67 & 38.28 & -3.359 & -3.766 & -3.585 & 717.00 \\
\hline 18.78 & 4.69 & 38.45 & -3.408 & -3.795 & -3.625 & 725.00 \\
\hline 18.78 & 4.69 & 38.65 & -3.401 & -3.831 & -3.656 & 731.25 \\
\hline 18.84 & 4.71 & 38.86 & -3.430 & -3.839 & -3.658 & 731.50 \\
\hline 18.91 & 4.73 & 39.07 & -3.464 & -3.881 & -3.694 & 738.75 \\
\hline 18.82 & 4.71 & 39.28 & -3.505 & -3.910 & -3.710 & 742.00 \\
\hline 18.80 & 4.70 & 39.48 & -3.525 & -3.925 & -3.748 & 749.50 \\
\hline 18.84 & 4.71 & 39.69 & -3.539 & -3.955 & -3.768 & 753.50 \\
\hline 18.92 & 4.73 & 39.90 & -3.569 & -3.994 & -3.796 & 759.25 \\
\hline 18.72 & 4.68 & 40.08 & -3.604 & -4.024 & -3.843 & 768.50 \\
\hline 18.88 & 4.72 & 40.28 & -3.600 & -4.026 & -3.863 & 772.50 \\
\hline 18.86 & 4.72 & 40.51 & -3.620 & -4.083 & -3.878 & 775.50 \\
\hline 18.80 & 4.70 & 40.72 & -3.644 & -4.114 & -3.905 & 781.00 \\
\hline 18.89 & 4.72 & 40.92 & -3.690 & -4.110 & -3.895 & 779.00 \\
\hline 18.87 & 4.72 & 41.14 & -3.698 & -4.131 & -3.924 & 784.75 \\
\hline 18.94 & 4.74 & 41.34 & -3.720 & -4.168 & -3.975 & 795.00 \\
\hline 18.93 & 4.73 & 41.55 & -3.746 & -4.206 & -3.989 & 797.75 \\
\hline 19.05 & 4.76 & 41.76 & -3.774 & -4.241 & -4.015 & 803.00 \\
\hline 19.00 & 4.75 & 41.96 & -3.783 & -4.251 & -4.019 & 803.75 \\
\hline 19.08 & 4.77 & 42.17 & -3.820 & -4.281 & -4.039 & 807.75 \\
\hline 18.96 & 4.74 & 42.37 & -3.831 & -4.300 & -4.104 & 820.75 \\
\hline 19.01 & 4.75 & 42.56 & -3.858 & -4.340 & -4.114 & 822.75 \\
\hline 19.14 & 4.79 & 42.76 & -3.871 & -4.356 & -4.140 & 828.00 \\
\hline 19.20 & 4.80 & 43.00 & -3.893 & -4.381 & -4.150 & 830.00 \\
\hline 19.19 & 4.80 & 43.20 & -3.928 & -4.421 & -4.193 & 838.50 \\
\hline 18.83 & 4.71 & 43.40 & -3.931 & -4.439 & -4.204 & 840.75 \\
\hline 17.85 & 4.46 & 43.56 & -3.929 & -4.479 & -4.239 & 847.75 \\
\hline 16.72 & 4.18 & 43.71 & -3.958 & -4.516 & -4.229 & 845.75 \\
\hline 15.47 & 3.87 & 43.81 & -3.965 & -4.568 & -4.288 & 857.50 \\
\hline 14.42 & 3.61 & 43.91 & -3.974 & -4.588 & -4.291 & 858.25 \\
\hline 13.95 & 3.49 & 44.11 & -3.990 & -4.624 & -4.306 & 861.25 \\
\hline 13.84 & 3.46 & 44.32 & -4.015 & -4.654 & -4.356 & 871.25 \\
\hline 13.94 & 3.49 & 44.53 & -4.036 & -4.674 & -4.379 & 875.75 \\
\hline 13.89 & 3.47 & 44.74 & -4.004 & -4.694 & -4.364 & 872.75 \\
\hline 13.92 & 3.48 & 44.99 & -4.014 & -4.738 & -4.385 & 877.00 \\
\hline 14.21 & 3.55 & 45.20 & -4.043 & -4.755 & -4.431 & 886.25 \\
\hline 14.37 & 3.59 & 45.41 & -4.056 & -4.778 & -4.423 & 884.50 \\
\hline 14.35 & 3.59 & 45.62 & -4.076 & -4.790 & -4.435 & 887.00 \\
\hline 13.18 & 3.29 & 45.54 & -4.060 & -4.796 & -4.443 & 888.50 \\
\hline 11.81 & 2.95 & 45.36 & -4.055 & -4.781 & -4.421 & 884.25 \\
\hline 10.75 & 2.69 & 45.17 & -4.038 & -4.778 & $-4.42 \mathrm{I}$ & 884.25 \\
\hline 9.93 & 2.48 & 45.03 & -4.028 & -4.765 & -4.420 & 884.00 \\
\hline 9.11 & 2.28 & 44.16 & -3.954 & -4.681 & -4.341 & 868.25 \\
\hline 7.84 & 1.96 & 43.59 & -3.944 & -4.651 & -4.301 & 860.25 \\
\hline 6.78 & 1.69 & 43.60 & -3.954 & -4.641 & -4.316 & 863.25 \\
\hline
\end{tabular}




\begin{tabular}{||l|l|l|l|l|l|l||}
\hline 5.67 & 1.42 & 42.95 & -3.890 & -4.585 & -4.255 & 851.00 \\
\hline 4.81 & 1.20 & 41.11 & -3.729 & -4.513 & -4.143 & 828.50 \\
\hline 3.63 & 0.91 & 39.57 & -3.608 & -4.416 & -4.044 & 808.75 \\
\hline 2.58 & 0.65 & 38.22 & -3.514 & -4.348 & -3.923 & 784.50 \\
\hline 1.81 & 0.45 & 36.84 & -3.485 & -4.286 & -3.866 & 773.25 \\
\hline 1.14 & 0.29 & 36.38 & -3.465 & -4.265 & -3.868 & 773.50 \\
\hline 0.15 & 0.04 & 36.28 & -3.443 & -4.266 & -3.886 & 777.25 \\
\hline
\end{tabular}

Series 2 - Silica Fume, $10 \%$ Corrosion

\begin{tabular}{|c|c|c|c|c|c|c|}
\hline $\begin{array}{l}\text { Load } \\
(\mathrm{kN})\end{array}$ & $\begin{array}{c}\text { Moment } \\
(\mathrm{kN}-\mathrm{m})\end{array}$ & $\begin{array}{c}\text { M.P. Displ. } \\
\text { (mm) }\end{array}$ & $\begin{array}{c}\text { E. Curv. LVDT } \\
(\mathrm{mm})\end{array}$ & $\begin{array}{l}\text { W. Curv. LVDT } \\
\text { (mm) }\end{array}$ & $\begin{array}{l}\text { Curv. LVDT Avg. } \\
(\mathrm{mm})\end{array}$ & $\begin{array}{c}\text { Curvature } \\
(1 / \mathrm{km})\end{array}$ \\
\hline 0.00 & $\overline{0.00}$ & 0.00 & ***** & ***** & **** & 0.00 \\
\hline 3.13 & 0.78 & 0.01 & $* * * *$ & $* * * *$ & $* * * *$ & 0.05 \\
\hline 9.50 & 2.38 & 0.14 & $* * * *$ & $* * * *$ & $* * * *$ & 1.02 \\
\hline 16.13 & 4.03 & 0.29 & ***** & $* * * *$ & $* * * *$ & 2.10 \\
\hline 19.30 & 4.82 & 0.34 & $* * * *$ & $* * * *$ & $* * * *$ & 2.50 \\
\hline 20.81 & 5.20 & 0.40 & $* * * *$ & $* * * *$ & $* * * *$ & 2.93 \\
\hline 20.09 & 5.02 & 0.50 & $* * * *$ & $* * * *$ & $* * * *$ & 3.61 \\
\hline 18.48 & 4.62 & 0.59 & $* * * *$ & ***** & $* * * *$ & 4.27 \\
\hline 16.57 & 4.14 & 0.63 & $* * * *$ & $* * * *$ & $* * * *$ & 4.59 \\
\hline 14.42 & 3.60 & 0.66 & $* * * *$ & $* * * *$ & $* * * *$ & 4.78 \\
\hline 12.17 & 3.04 & 0.69 & ***** & $* * * *$ & $* * * *$ & 5.03 \\
\hline 9.72 & 2.43 & 0.73 & $* * * *$ & $* * * *$ & $* * * *$ & 5.34 \\
\hline 8.49 & 2.12 & 0.75 & $* * * *$ & $* * * *$ & $* * * *$ & 5.43 \\
\hline 7.43 & 1.86 & 0.88 & $* * * *$ & $* * * *$ & $* * * *$ & 6.40 \\
\hline 6.56 & 1.64 & 1.17 & ***** & $* * * *$ & **** & 8.51 \\
\hline 5.79 & 1.45 & 1.43 & $* * * *$ & $* * * *$ & $* * * *$ & 10.40 \\
\hline 5.35 & 1.34 & 1.56 & $* * * *$ & $* * * *$ & $* * * *$ & 11.37 \\
\hline 6.21 & 1.55 & 2.09 & $* * * *$ & $* * * *$ & $* * * *$ & 15.19 \\
\hline 7.05 & 1.76 & 2.78 & $\overline{* * * *}$ & $* * * *$ & $* * * *$ & 20.21 \\
\hline 7.37 & 1.84 & 3.16 & $* * * *$ & $* * * *$ & $* * * *$ & 22.98 \\
\hline 8.51 & 2.13 & 3.85 & $* * * *$ & $* * * *$ & **** & 28.01 \\
\hline 9.21 & 2.30 & 4.16 & $* * * *$ & $* * * *$ & $* * * *$ & 30.21 \\
\hline 10.12 & 2.53 & 4.50 & $* * * *$ & $* * * * *$ & $* * * *$ & 32.70 \\
\hline 9.96 & 2.49 & 4.92 & $* * * *$ & $\overline{* * * * *}$ & $* * * *$ & 35.75 \\
\hline 8.65 & 2.16 & 5.60 & $* * * *$ & $* * * *$ & $* * * *$ & 40.68 \\
\hline 7.01 & 1.75 & 6.22 & ***** & $* * * *$ & $* * * *$ & 45.20 \\
\hline 6.31 & 1.58 & 6.53 & ***** & $* * * *$ & $* * * *$ & 47.49 \\
\hline 4.61 & 1.15 & 7.32 & ***** & $* * * *$ & $* * * *$ & 53.23 \\
\hline 3.85 & 0.96 & 8.00 & ***** & $* * * *$ & $* * * *$ & 58.17 \\
\hline 3.40 & 0.85 & 8.41 & **** & $* * * *$ & $* * * *$ & 61.15 \\
\hline 3.82 & 0.96 & 9.05 & $* * * *$ & $* * * *$ & $* * * *$ & 65.82 \\
\hline 2.94 & 0.74 & 9.61 & ***** & $* * * *$ & $* * * *$ & 69.90 \\
\hline 3.23 & 0.81 & 10.43 & $* * * *$ & ***** & **** & 75.83 \\
\hline 3.25 & $0.8 \mathrm{I}$ & 10.84 & ***** & $* * * *$ & $* * * *$ & 78.77 \\
\hline
\end{tabular}


CORROSION EFFECTS ON BOND STRENGTH IN REINFORCED CONCRETE

\begin{tabular}{|l|l|l|l|l|l|l||}
\hline 2.99 & 0.75 & 10.92 & $* * * *$ & $* * * *$ & $* * * *$ & 79.40 \\
\hline 2.97 & 0.74 & 11.16 & $* * * *$ & $* * * *$ & $* * *$ & 81.13 \\
\hline 2.63 & 0.66 & 11.29 & $* * * *$ & $* * * *$ & $* * *$ & 82.10 \\
\hline 2.25 & 0.56 & 11.86 & $* * * *$ & $* * * *$ & $* * *$ & 86.24 \\
\hline 1.74 & 0.43 & 13.35 & $* * * *$ & $* * * *$ & $* * * *$ & 97.06 \\
\hline 1.41 & 0.35 & 14.47 & $* * * *$ & $* * * *$ & $* * * *$ & 105.23 \\
\hline 1.65 & 0.41 & 15.35 & $* * * *$ & $* * * *$ & $* * * *$ & 111.63 \\
\hline 1.65 & 0.41 & 16.10 & $* * * *$ & $* * * *$ & $* * * *$ & 117.04 \\
\hline 1.85 & 0.46 & 16.96 & $* * * *$ & $* * * *$ & $* * * *$ & 123.32 \\
\hline 1.89 & 0.47 & 17.68 & $* * * *$ & $* * * *$ & $* * * *$ & 128.56 \\
\hline 1.90 & 0.48 & 18.77 & $* * * *$ & $* * * *$ & $* * * *$ & 136.45 \\
\hline 1.89 & 0.47 & 19.55 & $* * * *$ & $* * * *$ & $* * * *$ & 142.09 \\
\hline 1.87 & 0.47 & 19.95 & $* * * *$ & $* * * *$ & $* * * *$ & 145.03 \\
\hline
\end{tabular}

**** Curvature based upon Midpoint deflection as problem with data acquistion 
CORROSION EFFECTS ON BOND STRENGTH IN REINFORCED CONCRETE

Appendix I

Structural Results

Series $3-14.5 \%$ Corrosion

\begin{tabular}{|c|c|c|c|c|c|c|}
\hline $\begin{array}{l}\text { Load } \\
(\mathrm{kN})\end{array}$ & $\begin{array}{l}\text { Moment } \\
(\mathrm{kN}-\mathrm{m})\end{array}$ & $\begin{array}{l}\text { M.P. Displ. } \\
\text { (mm) }\end{array}$ & $\begin{array}{l}\text { E. Curv. LVDT } \\
(\mathrm{mm})\end{array}$ & $\begin{array}{l}\text { W. Curv. LVDT } \\
(\mathrm{mm})\end{array}$ & $\begin{array}{l}\text { Curv. LVDT Avg. } \\
(\mathrm{mm})\end{array}$ & $\begin{array}{c}\text { Curvature } \\
(1 / \mathrm{km})\end{array}$ \\
\hline 0.84 & 0.21 & 0.00 & 0.004 & 0.003 & -0.007 & -0.68 \\
\hline 1.88 & 0.47 & 0.01 & -0.004 & 0.007 & -0.006 & -1.43 \\
\hline 2.80 & 0.70 & 0.04 & 0.007 & -0.002 & -0.006 & $0 . \overline{48}$ \\
\hline 3.87 & 0.97 & 0.04 & 0.002 & -0.006 & -0.006 & 1.15 \\
\hline 4.93 & 1.23 & 0.09 & 0.003 & 0.001 & -0.008 & -0.20 \\
\hline 5.93 & 1.48 & 0.12 & 0.006 & -0.001 & -0.007 & 0.12 \\
\hline 6.99 & 1.75 & 0.14 & 0.006 & 0.002 & -0.007 & -0.48 \\
\hline 8.06 & 2.02 & 0.18 & 0.005 & 0.000 & -0.007 & -0.05 \\
\hline 7.97 & 1.99 & 0.18 & 0.003 & -0.004 & -0.007 & 0.88 \\
\hline 8.96 & 2.24 & 0.20 & 0.006 & 0.000 & -0.007 & 0.00 \\
\hline 9.79 & 2.45 & 0.21 & 0.005 & -0.004 & -0.006 & 0.80 \\
\hline 9.97 & 2.49 & 0.24 & -0.003 & -0.002 & -0.006 & 0.35 \\
\hline 10.53 & 2.63 & 0.22 & 0.004 & 0.002 & -0.006 & -0.35 \\
\hline 11.64 & 2.91 & 0.26 & 0.006 & -0.000 & -0.007 & 0.08 \\
\hline 12.97 & 3.24 & 0.29 & -0.000 & -0.002 & -0.007 & 0.48 \\
\hline 14.17 & 3.54 & 0.30 & 0.008 & -0.007 & -0.007 & 1.35 \\
\hline 15.43 & 3.86 & 0.31 & 0.003 & -0.008 & -0.007 & 1.65 \\
\hline 16.52 & 4.13 & 0.30 & 0.008 & -0.001 & -0.007 & 0.28 \\
\hline 17.76 & 4.44 & 0.30 & 0.004 & -0.000 & -0.006 & 0.03 \\
\hline 18.87 & 4.72 & 0.30 & 0.004 & -0.006 & -0.006 & 1.10 \\
\hline 20.14 & 5.03 & 0.31 & 0.006 & -0.007 & -0.006 & 1.35 \\
\hline 19.04 & 4.76 & 0.33 & 0.009 & -0.003 & -0.007 & 0.60 \\
\hline 20.17 & 5.04 & 0.35 & 0.007 & -0.007 & -0.007 & 1.45 \\
\hline 21.48 & 5.37 & 0.39 & 0.005 & -0.014 & -0.008 & 2.75 \\
\hline 20.31 & 5.08 & 0.37 & 0.012 & -0.009 & -0.007 & 1.75 \\
\hline 21.54 & 5.38 & $\overline{0.40}$ & 0.012 & -0.012 & -0.008 & 2.45 \\
\hline 22.82 & 5.70 & $\overline{0.42}$ & 0.008 & -0.008 & -0.008 & 1.50 \\
\hline 23.97 & 5.99 & 0.41 & 0.012 & -0.005 & -0.008 & 1.05 \\
\hline 25.14 & 6.29 & 0.42 & 0.007 & -0.007 & -0.009 & 1.35 \\
\hline 26.23 & 6.56 & 0.41 & 0.004 & -0.006 & -0.007 & 1.15 \\
\hline 26.85 & 6.71 & 0.41 & 0.011 & -0.005 & -0.008 & 0.98 \\
\hline 25.54 & 6.39 & 0.41 & 0.009 & -0.006 & -0.007 & 1.15 \\
\hline 26.42 & 6.61 & 0.41 & 0.008 & -0.009 & -0.008 & 1.83 \\
\hline 24.10 & 6.02 & 0.41 & 0.009 & -0.006 & -0.008 & 1.20 \\
\hline 25.19 & 6.30 & 0.42 & 0.010 & -0.007 & -0.008 & 1.37 \\
\hline 27.01 & 6.75 & 0.42 & 0.012 & -0.014 & -0.008 & 2.80 \\
\hline 25.65 & 6.41 & 0.42 & 0.007 & -0.005 & -0.006 & 1.07 \\
\hline 26.69 & 6.67 & 0.44 & 0.003 & -0.003 & -0.008 & 0.65 \\
\hline 25.49 & 6.37 & 0.43 & 0.005 & -0.014 & -0.008 & 2.70 \\
\hline 27.20 & 6.80 & 0.43 & 0.009 & -0.007 & -0.009 & 1.30 \\
\hline 26.15 & 6.54 & 0.43 & 0.007 & -0.010 & -0.008 & 1.98 \\
\hline 27.49 & 6.87 & 0.46 & 0.007 & -0.007 & -0.010 & 1.40 \\
\hline 25.99 & 6.50 & 0.45 & 0.012 & -0.013 & -0.008 & 2.55 \\
\hline 24.95 & 6.24 & 0.44 & 0.007 & -0.012 & -0.008 & 2.37 \\
\hline
\end{tabular}


CORROSION EFFECTS ON BOND STRENGTH IN REINFORCED CONCRETE

Appendix I

Structural Results

\begin{tabular}{|c|c|c|c|c|c|c|}
\hline 26.21 & 6.55 & 0.46 & 0.006 & -0.016 & -0.008 & 3.28 \\
\hline 25.14 & 6.29 & 0.46 & 0.009 & -0.007 & -0.009 & 1.37 \\
\hline 24.15 & 6.04 & 0.45 & 0.009 & -0.007 & -0.009 & 1.48 \\
\hline 25.19 & 6.30 & 0.47 & 0.009 & -0.007 & -0.009 & 1.40 \\
\hline 24.07 & 6.02 & 0.46 & 0.009 & -0.007 & -0.009 & 1.35 \\
\hline 25.17 & 6.29 & 0.48 & 0.011 & -0.007 & -0.009 & 1.35 \\
\hline 26.26 & 6.57 & 0.49 & 0.010 & -0.014 & -0.009 & 2.78 \\
\hline 25.14 & 6.29 & 0.48 & 0.009 & -0.007 & -0.010 & 1.43 \\
\hline 24.05 & 6.01 & 0.48 & 0.003 & -0.014 & -0.009 & 2.88 \\
\hline 25.14 & 6.29 & 0.51 & 0.008 & -0.008 & -0.010 & 1.57 \\
\hline 26.34 & 6.59 & 0.53 & 0.010 & -0.012 & -0.010 & 2.37 \\
\hline 27.65 & 6.91 & 0.55 & 0.004 & -0.011 & -0.011 & 2.18 \\
\hline 28.85 & 7.21 & 0.57 & 0.007 & -0.010 & -0.012 & 1.93 \\
\hline 29.92 & 7.48 & 0.54 & 0.004 & -0.013 & -0.010 & 2.50 \\
\hline 31.04 & 7.76 & 0.58 & 0.005 & -0.007 & -0.011 & 1.32 \\
\hline 29.94 & 7.49 & 0.57 & 0.008 & -0.010 & -0.011 & 1.93 \\
\hline 31.01 & 7.75 & 0.62 & 0.002 & -0.018 & -0.011 & 3.52 \\
\hline 32.16 & 8.04 & 0.67 & 0.004 & -0.010 & -0.011 & 2.08 \\
\hline 33.20 & 8.30 & 0.72 & 0.002 & -0.003 & -0.011 & 0.58 \\
\hline 34.32 & 8.58 & 0.75 & 0.003 & -0.011 & -0.013 & 2.13 \\
\hline 34.75 & 8.69 & 0.98 & 0.001 & -0.036 & -0.025 & 7.25 \\
\hline 36.03 & 9.01 & 1.05 & -0.012 & -0.039 & -0.031 & 7.80 \\
\hline 37.18 & 9.29 & 1.10 & -0.005 & -0.038 & -0.031 & 7.58 \\
\hline 38.32 & 9.58 & 1.17 & 0.000 & -0.046 & -0.032 & 9.18 \\
\hline 39.36 & 9.84 & 1.21 & 0.003 & -0.045 & -0.032 & 9.05 \\
\hline 40.62 & 10.15 & 1.25 & 0.009 & -0.062 & -0.033 & 12.30 \\
\hline 39.55 & 9.89 & 1.27 & 0.007 & -0.054 & -0.034 & 10.72 \\
\hline 40.62 & 10.15 & 1.44 & 0.012 & -0.065 & -0.038 & 12.98 \\
\hline 41.90 & 10.48 & 1.52 & 0.008 & -0.073 & -0.040 & 14.65 \\
\hline 42.97 & 10.74 & 1.50 & 0.016 & -0.075 & -0.039 & 15.05 \\
\hline 41.95 & 10.49 & 1.52 & 0.011 & -0.072 & -0.041 & 14.37 \\
\hline 43.13 & 10.78 & 1.53 & 0.009 & -0.080 & -0.040 & 16.08 \\
\hline 44.36 & 11.09 & 1.56 & 0.007 & -0.077 & -0.041 & 15.40 \\
\hline 45.50 & 11.38 & 1.56 & 0.014 & -0.075 & -0.040 & 15.03 \\
\hline 46.49 & 11.62 & 1.56 & 0.012 & -0.074 & -0.043 & 14.82 \\
\hline 45.21 & 11.30 & 1.58 & 0.011 & -0.076 & -0.042 & 15.10 \\
\hline 46.70 & 11.68 & 1.63 & 0.012 & -0.081 & -0.042 & 16.13 \\
\hline 47.99 & 12.00 & 1.65 & 0.014 & -0.077 & -0.043 & 15.40 \\
\hline 46.78 & 11.70 & 1.65 & 0.013 & -0.078 & -0.043 & 15.62 \\
\hline 45.66 & 11.42 & 1.65 & 0.013 & -0.081 & -0.045 & 16.18 \\
\hline 44.52 & 11.13 & 1.83 & 0.014 & -0.100 & -0.052 & 19.98 \\
\hline 44.54 & 11.14 & 2.05 & 0.006 & -0.127 & -0.063 & 25.30 \\
\hline 45.72 & 11.43 & 2.18 & 0.006 & -0.127 & -0.069 & 25.45 \\
\hline 46.92 & 11.73 & 2.31 & 0.006 & -0.143 & -0.075 & 28.53 \\
\hline 48.01 & 12.00 & 2.44 & 0.010 & -0.150 & -0.079 & 29.93 \\
\hline 49.16 & 12.29 & 2.57 & 0.005 & -0.156 & -0.085 & 31.15 \\
\hline 50.25 & 12.56 & 2.66 & 0.004 & -0.163 & -0.088 & 32.52 \\
\hline
\end{tabular}




\begin{tabular}{|c|c|c|c|c|c|c|}
\hline 51.27 & 12.82 & 2.86 & -0.006 & -0.205 & -0.112 & 40.93 \\
\hline 52.44 & 13.11 & 2.97 & 0.001 & -0.212 & -0.116 & 42.45 \\
\hline 53.14 & 13.28 & 3.20 & -0.002 & -0.230 & -0.123 & 46.05 \\
\hline 54.23 & 13.56 & 3.32 & -0.006 & -0.231 & -0.126 & 46.12 \\
\hline 54.87 & 13.72 & 3.54 & -0.006 & -0.255 & -0.134 & 50.98 \\
\hline 55.91 & 13.98 & 3.72 & -0.009 & -0.260 & -0.138 & 52.08 \\
\hline 56.82 & 14.20 & 3.91 & -0.008 & -0.270 & -0.144 & 54.00 \\
\hline 57.78 & 14.44 & 4.10 & -0.006 & -0.277 & -0.151 & 55.30 \\
\hline 58.13 & 14.53 & 4.32 & -0.001 & -0.299 & -0.158 & 59.80 \\
\hline 56.79 & 14.20 & 4.16 & -0.006 & -0.287 & -0.150 & 57.45 \\
\hline 54.34 & 13.58 & 4.03 & 0.001 & -0.272 & -0.146 & 54.40 \\
\hline 52.01 & 13.00 & 3.96 & 0.003 & -0.268 & -0.142 & 53.67 \\
\hline 50.63 & 12.66 & 3.96 & 0.001 & -0.274 & -0.143 & 54.80 \\
\hline 49.40 & 12.35 & 3.92 & -0.001 & -0.272 & -0.141 & 54.43 \\
\hline 50.47 & 12.62 & 4.00 & -0.003 & -0.271 & -0.147 & 54.15 \\
\hline 51.67 & 12.92 & 4.07 & -0.003 & -0.275 & -0.150 & 55.03 \\
\hline 52.71 & 13.18 & 4.09 & -0.004 & -0.283 & -0.149 & 56.57 \\
\hline 53.86 & 13.46 & 4.18 & -0.004 & -0.283 & -0.155 & 56.60 \\
\hline 54.98 & 13.74 & 4.22 & -0.007 & -0.291 & -0.155 & 58.27 \\
\hline 56.10 & 14.02 & 4.28 & -0.005 & -0.293 & -0.157 & 58.55 \\
\hline 57.14 & 14.28 & 4.37 & -0.006 & -0.291 & -0.159 & 58.10 \\
\hline 58.23 & 14.56 & 4.53 & -0.009 & -0.299 & -0.165 & 59.82 \\
\hline 59.33 & 14.83 & $4 . \overline{69}$ & -0.010 & -0.309 & -0.170 & 61.82 \\
\hline 60.42 & 15.11 & 4.86 & -0.012 & -0.312 & -0.172 & 62.48 \\
\hline 61.54 & 15.39 & 4.99 & -0.008 & -0.324 & -0.175 & 64.85 \\
\hline 62.69 & 15.67 & 5.15 & -0.012 & -0.331 & -0.181 & 66.13 \\
\hline 64.00 & 16.00 & 5.19 & -0.011 & -0.334 & -0.183 & 66.83 \\
\hline 65.41 & 16.35 & 5.35 & -0.008 & -0.389 & -0.218 & 77.83 \\
\hline 62.80 & 15.70 & 5.41 & -0.017 & -0.543 & -0.295 & 108.68 \\
\hline 59.62 & 14.91 & 5.48 & -0.022 & -0.651 & -0.349 & 130.25 \\
\hline 57.54 & 14.38 & 5.48 & -0.018 & -0.692 & -0.368 & 138.43 \\
\hline 55.94 & 13.98 & 5.50 & -0.024 & -0.720 & -0.382 & 143.98 \\
\hline 54.60 & 13.65 & 5.52 & -0.025 & -0.744 & -0.397 & 148.72 \\
\hline 53.35 & 13.34 & 5.66 & -0.042 & -0.809 & -0.434 & 161.78 \\
\hline 51.88 & 12.97 & 5.69 & -0.031 & -0.821 & -0.437 & 164.28 \\
\hline 50.65 & 12.66 & 5.72 & -0.017 & -0.838 & -0.439 & 167.58 \\
\hline 49.53 & 12.38 & 5.79 & -0.032 & -0.859 & -0.458 & 171.83 \\
\hline 47.90 & 11.98 & 5.81 & -0.038 & -0.869 & -0.466 & 173.87 \\
\hline 46.81 & 11.70 & 5.90 & -0.054 & -0.897 & -0.485 & 179.45 \\
\hline 45.66 & 11.42 & 5.98 & -0.085 & -0.948 & -0.522 & 189.68 \\
\hline 44.68 & 11.17 & 6.07 & -0.086 & -0.987 & $-0 . \overline{5} \overline{38}$ & 197.35 \\
\hline 43.63 & 10.91 & 6.16 & -0.076 & -1.000 & -0.549 & 199.97 \\
\hline 42.54 & 10.64 & 6.27 & -0.089 & -1.040 & -0.567 & 208.00 \\
\hline 41.10 & 10.27 & 6.34 & -0.086 & -1.051 & -0.580 & 210.25 \\
\hline 41.53 & 10.38 & 6.59 & -0.108 & -1.116 & -0.624 & 223.25 \\
\hline 40.41 & 10.10 & 6.77 & -0.136 & -1.165 & -0.665 & 233.00 \\
\hline 39.26 & 9.81 & 6.94 & -0.179 & -1.210 & -0.695 & 242.00 \\
\hline
\end{tabular}




\section{CORROSION EFFECTS ON BOND STRENGTH IN REINFORCED CONCRETE}

\begin{tabular}{|c|c|c|c|c|c|c|}
\hline 38.00 & 9.50 & 7.02 & -0.164 & -1.238 & -0.709 & 247.50 \\
\hline 37.34 & 9.33 & 7.26 & -0.193 & -1.281 & -0.749 & 256.25 \\
\hline 36.48 & 9.12 & 7.46 & -0.201 & -1.340 & -0.783 & 268.00 \\
\hline 37.20 & 9.30 & 7.68 & -0.206 & -1.398 & -0.818 & 279.50 \\
\hline 36.78 & 9.19 & 7.92 & -0.231 & -1.455 & -0.857 & 291.00 \\
\hline 35.66 & 8.91 & 8.11 & -0.248 & -1.505 & -0.890 & 301.00 \\
\hline 35.23 & 8.81 & 8.32 & -0.271 & -1.545 & -0.926 & 309.00 \\
\hline 34.00 & 8.50 & 8.35 & -0.274 & -1.565 & -0.933 & 313.00 \\
\hline 33.47 & 8.37 & 8.56 & -0.310 & -1.609 & -0.973 & 321.75 \\
\hline 33.31 & 8.33 & 8.78 & -0.322 & -1.675 & -1.015 & 335.00 \\
\hline 32.93 & 8.23 & 9.02 & -0.360 & -1.743 & -1.059 & 348.50 \\
\hline 32.80 & 8.20 & 9.26 & -0.377 & -1.814 & -1.108 & 362.75 \\
\hline 33.25 & 8.31 & 9.50 & -0.395 & -1.839 & -1.126 & 367.75 \\
\hline 33.39 & 8.35 & 9.72 & -0.394 & -1.913 & -1.171 & 382.50 \\
\hline 32.83 & 8.21 & 9.96 & -0.428 & -1.973 & -1.214 & 394.50 \\
\hline 32.08 & 8.02 & 10.19 & -0.453 & -1.975 & -1.225 & 395.00 \\
\hline 31.55 & 7.89 & 10.43 & -0.464 & -2.046 & -1.265 & 409.25 \\
\hline 31.44 & 7.86 & 10.66 & -0.474 & -2.098 & -1.305 & 419.50 \\
\hline 31.47 & 7.87 & 10.90 & -0.498 & -2.165 & -1.344 & 433.00 \\
\hline 31.52 & 7.88 & 11.13 & -0.518 & -2.226 & -1.385 & 445.25 \\
\hline 31.47 & 7.87 & 11.36 & -0.554 & -2.295 & -1.439 & $45 \overline{9} .00$ \\
\hline 31.36 & 7.84 & 11.55 & -0.550 & -2.226 & -1.400 & 445.25 \\
\hline 31.33 & 7.83 & 11.75 & -0.565 & -2.280 & -1.435 & 456.00 \\
\hline 31.49 & 7.87 & 11.97 & -0.630 & -2.325 & -1.490 & 465.00 \\
\hline 31.65 & 7.91 & 12.18 & -0.644 & -2.378 & -1.529 & 475.50 \\
\hline 32.03 & 8.01 & 12.39 & -0.656 & -2.448 & -1.576 & 489.50 \\
\hline 32.53 & 8.13 & 12.59 & -0.669 & -2.508 & -1.603 & 501.50 \\
\hline 32.61 & 8.15 & 12.80 & -0.683 & -2.531 & -1.620 & 506.25 \\
\hline 32.75 & 8.19 & 13.01 & -0.696 & -2.590 & -1.655 & 518.00 \\
\hline 33.25 & 8.31 & 13.22 & -0.709 & -2.635 & -1.688 & 527.00 \\
\hline 33.89 & 8.47 & 13.44 & -0.724 & -2.708 & -1.730 & 541.50 \\
\hline 34.77 & 8.69 & 13.64 & -0.739 & -2.770 & -1.768 & 554.00 \\
\hline 34.40 & 8.60 & 13.85 & -0.751 & -2.805 & -1.799 & 561.00 \\
\hline 34.88 & 8.72 & 14.05 & -0.760 & -2.859 & -1.825 & 571.75 \\
\hline 35.17 & 8.79 & 14.25 & -0.772 & -2.900 & -1.850 & 580.00 \\
\hline 35.31 & 8.83 & 14.47 & -0.784 & -2.955 & -1.885 & 591.00 \\
\hline 35.60 & 8.90 & 14.67 & -0.796 & -2.966 & -1.895 & 593.25 \\
\hline 35.82 & 8.95 & 14.91 & -0.806 & -3.045 & -1.936 & 609.00 \\
\hline 35.66 & 8.91 & 15.11 & -0.823 & -3.100 & -1.970 & 620.00 \\
\hline 35.44 & 8.86 & 15.35 & -0.842 & -3.151 & -2.010 & 630.25 \\
\hline 35.33 & 8.83 & 15.55 & -0.856 & -3.208 & -2.048 & 641.50 \\
\hline 35.17 & 8.79 & 15.77 & -0.869 & -3.236 & -2.076 & 647.25 \\
\hline 34.64 & 8.66 & 15.98 & -0.889 & -3.285 & -2.100 & 657.00 \\
\hline 34.67 & 8.67 & 16.19 & -0.904 & -3.324 & -2.130 & 664.75 \\
\hline 34.35 & 8.59 & 16.41 & -0.932 & -3.360 & -2.161 & 672.00 \\
\hline $33 . \overline{71}$ & 8.43 & 16.63 & -0.945 & -3.398 & -2.193 & 679.50 \\
\hline 33.57 & 8.39 & 16.85 & -0.972 & -3.445 & -2.225 & 689.00 \\
\hline
\end{tabular}




\section{CORROSION EFFECTS ON BOND STRENGTH IN REINFORCED CONCRETE}

\begin{tabular}{|c|c|c|c|c|c|c|}
\hline 33.47 & 8.37 & 17.06 & -0.992 & -3.496 & -2.256 & 699.25 \\
\hline 33.57 & 8.39 & 17.26 & -1.004 & -3.528 & -2.286 & 705.50 \\
\hline 33.89 & 8.47 & 17.47 & -1.029 & -3.580 & -2.315 & 716.00 \\
\hline 34.37 & 8.59 & 17.68 & -1.040 & -3.610 & -2.340 & 722.00 \\
\hline 34.91 & 8.73 & 17.90 & -1.053 & -3.654 & -2.371 & 730.75 \\
\hline 34.43 & 8.61 & 18.11 & -1.070 & -3.695 & -2.400 & 739.00 \\
\hline 34.16 & 8.54 & 18.33 & -1.078 & -3.744 & -2.428 & 748.75 \\
\hline 34.21 & 8.55 & 18.54 & -1.094 & -3.788 & -2.455 & 757.50 \\
\hline 34.27 & 8.57 & 18.76 & -1.105 & -3.819 & -2.479 & 763.75 \\
\hline 34.45 & 8.61 & 18.98 & -1.120 & -3.864 & -2.505 & 772.75 \\
\hline 34.64 & 8.66 & 19.19 & -1.129 & -3.903 & -2.530 & 780.50 \\
\hline 34.72 & 8.68 & 19.41 & -1.134 & -3.953 & -2.560 & 790.50 \\
\hline 34.69 & 8.67 & 19.62 & -1.155 & -3.996 & -2.590 & 799.25 \\
\hline 34.80 & 8.70 & 19.83 & -1.161 & -4.039 & -2.616 & 807.75 \\
\hline 34.45 & 8.61 & 20.05 & -1.164 & -4.079 & -2.641 & 815.75 \\
\hline 33.87 & 8.47 & 20.26 & -1.170 & -4.118 & -2.664 & 823.50 \\
\hline 33.63 & 8.41 & 20.47 & -1.179 & -4.173 & -2.685 & 834.50 \\
\hline 33.52 & 8.38 & 20.69 & -1.180 & -4.198 & -2.705 & 839.50 \\
\hline 33.41 & 8.35 & 20.90 & -1.183 & -4.249 & -2.730 & 849.75 \\
\hline 33.23 & 8.31 & 21.12 & -1.190 & -4.275 & -2.758 & 855.00 \\
\hline 33.07 & 8.27 & 21.33 & -1.204 & -4.330 & -2.780 & 866.00 \\
\hline 32.96 & 8.24 & 21.54 & -1.206 & -4.371 & -2.805 & 874.25 \\
\hline 33.07 & 8.27 & 21.76 & -1.210 & -4.410 & -2.826 & 882.00 \\
\hline 33.15 & 8.29 & 21.97 & -1.219 & -4.454 & -2.850 & 890.75 \\
\hline 33.17 & 8.29 & 22.19 & -1.215 & -4.490 & -2.875 & 898.00 \\
\hline 33.23 & 8.31 & 22.41 & -1.223 & -4.538 & -2.909 & 907.50 \\
\hline 33.47 & 8.37 & 22.62 & -1.230 & -4.574 & -2.918 & 914.75 \\
\hline 33.52 & 8.38 & 22.83 & -1.238 & -4.605 & -2.936 & 921.00 \\
\hline 33.52 & 8.38 & 23.04 & -1.234 & -4.640 & -2.955 & 928.00 \\
\hline 33.52 & 8.38 & 23.25 & -1.238 & -4.680 & -2.974 & 936.00 \\
\hline 33.31 & 8.33 & 23.46 & -1.230 & -4.716 & -2.990 & 943.25 \\
\hline 32.24 & 8.06 & 23.62 & -1.219 & -4.391 & -2.829 & 878.25 \\
\hline 30.88 & 7.72 & 22.33 & -1.116 & -4.260 & -2.694 & 852.00 \\
\hline 21.16 & 5.29 & 21.43 & -1.079 & -4.318 & -2.714 & 863.50 \\
\hline 16.46 & 4.12 & 21.44 & -1.076 & -4.244 & -2.676 & 848.75 \\
\hline 14.37 & 3.59 & 21.46 & -1.085 & -4.301 & -2.720 & 860.25 \\
\hline 13.26 & 3.31 & 21.48 & -1.084 & -4.190 & -2.653 & 838.00 \\
\hline 12.78 & 3.20 & 20.95 & -1.034 & -4.135 & -2.580 & 827.00 \\
\hline 8.83 & 2.21 & 19.59 & -0.866 & -4.049 & -2.471 & 809.75 \\
\hline 4.60 & 1.15 & 19.20 & -0.822 & -4.039 & -2.448 & 807.75 \\
\hline 2.45 & 0.61 & 19.18 & -0.813 & -4.041 & -2.445 & 808.25 \\
\hline 1.25 & 0.31 & 19.16 & -0.816 & -4.038 & -2.441 & 807.50 \\
\hline 0.53 & 0.13 & 19.09 & -0.800 & -4.008 & -2.420 & 801.50 \\
\hline
\end{tabular}

** Curvature based soley on West Curvature-meter as results no good from east

meter as a crack passed through anchorage point. 
TEST TARGET (QA-3)
